UNIVERSIDADE DE SÃO PAULO

ESCOLA DE ENGENHARIA DE SÃO CARLOS

DEPARTAMENTO DE ENGENHARIA DE ESTRUTURAS

YAGHO DE SOUZA SIMÕES

ANÁLISE NUMÉRICA DE PILARES DE AÇO ISOLADOS E INSERIDOS EM PAREDES EM SITUAÇÃO DE INCÊNDIO

SÃO CARLOS 

YAGHO DE SOUZA SIMÕES

\title{
ANÁLISE NUMÉRICA DE PILARES DE AÇO ISOLADOS E INSERIDOS EM PAREDES EM SITUAÇÃO DE INCÊNDIO
}

\author{
VERSÃO CORRIGIDA
}

A versão original encontra-se na Escola de Engenharia de São Carlos

Dissertação apresentada ao Departamento de Engenharia de Estruturas da Escola de Engenharia de São Carlos, Universidade de São Paulo, como parte integrante dos requisitos necessários para obtenção do título de Mestre em Engenharia de Estruturas.

Orientador: Prof. Dr. Jorge Munaiar Neto 
AUTORIZO A REPRODUÇÃO E DIVULGAÇÃO TOTAL OU PARCIAL DESTE TRABALHO, POR QUALQUER MEIO CONVENCIONAL OU ELETRÔNICO, PARA FINS DE ESTUDOS E PESQUISA, DESDE QUE CITADA A FONTE.

Ficha catalográfica elaborada pela Biblioteca Prof. Dr. Sérgio Rodrigues Fontes da EESC/USP com os dados inseridos pelo(a) autor(a).

\begin{tabular}{|l|}
\hline S593a \\
Simões, Yagho de Souza \\
Análise numérica de pilares de aço isolados e inseridos em paredes em \\
situação de incêndio / Yagho de Souza Simões; orientador Jorge Munaiar \\
Neto. São Carlos, 2018. \\
Dissertação (Mestrado) - Programa de Pós-Graduação em Engenharia \\
Civil (Engenharia de Estruturas) e Área de Concentração em Estruturas -- \\
Escola de Engenharia de São Carlos da Universidade de São Paulo, 2018. \\
1. Pilares. 2. Aço. 3. Paredes. 4. Fogo. 5. Gradiente Térmico. 6. Método \\
Simplificado. I. Título.
\end{tabular}




\section{FOLHA DE JULGAMENTO}

Candidato: Engenheiro YAGHO DE SOUZA SIMÕES.

Título da dissertação: "Análise numérica de pilares de aço isolados e inseridos em paredes sujeitos à ação do fogo".

Data da defesa: 10/04/2018.

Comissão Julgadora:

Prof. Associado Jorge Munaiar Nelo (Orientador) (Escola de Engenharia de São Carlos/EESC)

Prof. Dr. Valdir Pignatta e Silva

(Escola Politécnica/EP-USP)

Prof. Dr. Macksuel Soares de Azevedo

(Universidade Federal do Espírito Santo/UFES)
Resultado:
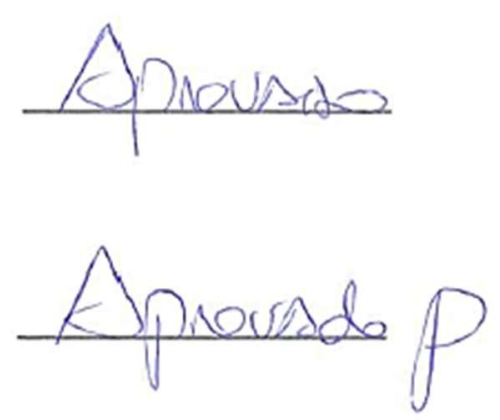

APROVADO

Coordenador do Programa de Pós-Graduação em Engenharia Civil (Engenharia de Estruturas):

Prof. Titular Humberto Breves Coda

Presidente da Comissão de Pós-Graduação:

Prof. Associado Luís Fernando Cosia Alberto 

À minha família. 



\section{AGRADECIMENTOS}

Primeiramente, a Deus, por se fazer presente ao longo da minha vida, seja nos momentos bons ou ruins, e por me ajudar a alcançar meus objetivos.

À minha Mãe, Taniêde, meu exemplo de vida, por me apoiar em todas as minhas escolhas. A quem eu devo gratidão.

Ao meu Pai, Luiz Orlando, que sempre me ensinou a ter valores e princípios.

Às minhas irmãs, Lorena e Bruna, minhas fontes inspiradoras, por sempre acreditarem que eu sou capaz!

Aos meus sobrinhos, João Inácio e Pedro Henrique. Agradeço por vocês serem tão especiais em minha vida e por terem a capacidade de transformar qualquer dia ruim em um momento único de felicidade.

Ao meu melhor amigo, Osvaldo, por se fazer presente mesmo na distância, por acreditar em mim quando eu mesmo já perdi a fé e por sempre me lembrar que para ser feliz é preciso Sonhar, Sentir, Sorrir, Viver e Amar.

Ao meu orientador, Jorge Munaiar Neto, pela paciência, pela atenção e, principalmente, pelos ensinamentos passados ao longo desses dois anos.

Ao Fábio, pela ajuda constante no desenvolvimento dessa dissertação e por sempre estar disposto a me ajudar. Sem dúvidas, essa conquista não é só minha, é nossa.

À Rafaella, uma das pessoas mais incríveis que conheci em São Carlos e que me ensinou o verdadeiro significado da palavra amizade. Minha amiga, irmã e que muitas vezes tem se tornado uma mãe pela preocupação constante. O meu muito obrigado, Rafa, por tudo! A Bahia e o Maranhão nunca foram tão unidos!

Ao Giovane, meu grande amigo, pelos conselhos, pelos ensinamentos (as longas maratonas de estudo do primeiro semestre serão sempre lembradas por mim), pela preocupação e pelo carinho, constantes ao longo desses anos.

Aos meus outros amigos do Departamento de Estruturas, agradeço pelo companheirismo e parceria: Maria, Aline, Lisiane, Fernanda, Carol, Tito, Emerson, Fabiana e em especial ao Alex e à Francielle, dois queridos amigos que pude ter uma maior convivência.

Aos meus amigos da UEFS e colegas de profissão: Isadora, Luana, Ramon, Verônica, Maurício, Caroline, Shirley e Matheus. Vocês foram os maiores incentivadores para eu adentrar ao mundo da Pós-Graduação. 
Aos amigos do ensino médio que até hoje estão presentes em minha vida: Maurício, Daiane, Aline, Mayane, Gabrielli, Laila, Bia, Uanderson, Ana, Paulo Milena, Thaynara, Patrícia, Ailla e Ayla. Agradeço a confiança que vocês têm em mim!

Aos amigos que conquistei ao longo dessa vida: João Paulo, Jonathan, Caíque, Rodrigo, Helder, Josafá, Eduardo e Diego. Obrigado pelo apoio, pelos conselhos e pelo fato de juntos termos construído uma irmandade!

Aos grandes mestres que tive a honra de conhecer na UEFS: Eduardo Cohim, Cíntia e José Mário.

Aos meus amigos de mestrado, ingressantes de 2017, Murilo, Gabriela, Daniele, Ana, Mariana Rossi, Rafael e Mariana Posterlli, por dividirem momentos inesquecíveis comigo e por me fazer acreditar que na vida, como diz um certo autor, amizade é muito mais que uma mão estendida ou um belo sorriso a sua frente, é o alimento que sacia a alma e é ofertado por alguém que crê em nós. Para isso, basta fazer as escolhas certas. E eu tenho certeza de que eu fiz as melhores escolhas.

Ao Departamento de Estruturas da Escola de Engenharia de São Carlos (EESC - USP) pela oportunidade em realizar o Mestrado.

À Coordenação de Aperfeiçoamento de Pessoal de Nível Superior pelo fomento à essa pesquisa.

E a todos aqueles que direta ou indiretamente torceram por mim.

Obrigado. 
“Talvez não tenha conseguido fazer o melhor, mas lutei para que o melhor fosse feito. Não sou o que deveria ser, mas graças a Deus, não sou o que era antes”.

(Martin Luther King) 



\section{RESUMO}

SIMÕES, Y.S. Análise numérica de pilares de aço isolados e inseridos em paredes em situação de incêndio. 2018. 198p. Dissertação (Mestrado em Engenharia de Estruturas) Escola de Engenharia de São Carlos, Universidade de São Paulo, São Carlos, 2018.

Em um incêndio, pilares de aço inseridos em paredes apresentam uma resposta termoestrutural diferente daqueles isolados, de modo que a compartimentação oferece um aumento de sua resistência ao fogo. Poucos estudos foram desenvolvidos até o presente momento para avaliar o desempenho de pilares em contato com paredes, sendo que aqueles já realizados apresentaram respostas que ainda deixam dúvidas sobre esses elementos. Diante disso, este trabalho propõe analisar, em contexto numérico, o comportamento de pilares de aço isolados e inseridos em paredes sujeitos à ação térmica, a partir do uso do código computacional ABAQUS versão 6.14. A modelagem termoestrutural, considerando a parede somente como elemento de compartimentação, promoveu resultados pouco consistentes, o que leva a concluir que a alvenaria influencia na resposta estrutural de pilares em situação de incêndio. Por essa razão, ao inserir molas que controlam o deslocamento axial das paredes na modelagem numérica, os resultados alcançados passaram a ser mais representativos. Análises complementares a respeito da influência do fator de carga e do nível de rigidez axial e rotacional na resistência ao fogo dos pilares também foram realizadas. Para todos os modelos, constatou-se a influência negativa do fator de carga quando aumentado. Quanto à restrição axial, foi verificado que sua presença possui maior influência na resistência ao fogo em comparação com sua intensidade, uma vez que a elevação desse parâmetro não afetou o tempo crítico dos pilares, para a maior parte dos casos analisados. Em relação à rigidez rotacional, ela se mostrou favorável para a resistência ao fogo. Além do mais, a pesquisa contou com uma avaliação do método simplificado da ABNT NBR 14323:2013 para cálculo da evolução da temperatura em perfis de aço. Concluiu-se que ele apresenta melhores resultados para os pilares com aquecimento uniforme na seção transversal. Por essa razão, foi proposta uma nova metodologia de cálculo de temperatura para pilares em contato com paredes, validada por meio de testes numéricos.

Palavras-chave: Pilares. Aço. Paredes. Fogo. Gradiente Térmico. Método Simplificado. 



\begin{abstract}
SIMÕES, Y.S. Numerical Analysis of isolated and embedded on walls steel columns under fire situation. 2018. 198p. Dissertation (M. Sc in Structural Engineering) - School of Engineering of São Carlos, University of São Paulo, São Carlos, 2018.

In a fire situation, steel columns embedded on walls demonstrate a different thermo- structural response from those isolated, so that the subdivision offers an increase of its fire resistance. Few studies have been developed in order to evaluate the performance of columns in contact with walls, and those already performed showed results that still leave doubts about these elements. Therefore, this work proposes to analyze, in a numerical context, the behavior of isolated and embedded on walls steel columns in fire using the software ABAQUS 6.14 as a modeling tool. The thermo-structural modeling, considering the wall only as a compartmentation element, has presented poor results, which leads to the conclusion that the masonry has influence on the structural response of columns subjected to fire situation. For this reason, when inserting springs in order to control the axial displacement of the walls in numerical modeling, the obtained results were satisfactory. Further analyzes in respect of the load factor influence and the level of axial and rotational stiffness on the fire resistance of columns were also performed. For all the models, it was verified a negative influence of the load factor when increased. However, when it comes to the axial restriction, it was verified that its presence had more influence in the fire resistance of the structural element despite of its intensity, once the increase of this parameter did not affect the critical time of the columns, for most cases analyzed. In respect to rotational stiffness, it was proven favorable to the fire resistance. In addition, this research employed the simplified method presented in the ABNT NBR 14323: 2013 to calculate the temperature evolution in steel profiles. It was concluded that it presents good results only for the columns with uniform heating in the cross section. For this reason, a new methodology to calculate the temperature of columns in contact with wall was proposed, validated by numerical tests.
\end{abstract}

Keywords: Columns. Steel. Walls. Fire. Thermal Gradient. Simplified Method. 



\section{LISTA DE FIGURAS}

Figura 2.1- Evolução das forças axiais em pilares com restrição térmica

Figura 2.2 - Modelo dos ensaios experimentais proposto em Ali, Sirnms e O'Connor (1997), Ali et al. (1998) e Ali e O'Connor (2001)

Figura 2.3 - Modelo numérico proposto por Ali et al. (1998).

Figura 2.4 - Representação do modelo dos ensaios descritos em Rodrigues, Neves e Valente (2000)

Figura 2.5 - Modelo de ensaio de Correia (2011)

Figura 2.6 - Aspectos da modelagem numérica de Correia, Rodrigues e Gomes (2013): a) Representação do modelo numérico completo; b) Detalhe construtivo da ligação das vigas superiores do sistema de restrição; c) Ligação entre a viga superior e o pilar do sistema de restrição

Figura 2.7 - Evolução da força axial em função do tempo para diferentes intensidades de restrições térmicas

Figura 2.8 - Representação modelos numéricos termoestruturais de Valente e Neves (1999)48

Figura 2.9 - Princípio básico do método de Franssen (2000).

Figura 2.10 - Modelo estrutural proposto por Velarde (2008)

Figura 2.11 - Deformada de um pilar inserido em parede com restrição térmica

Figura 2.12 - Comportamento de pilares inseridos em paredes com aquecimento em uma face

Figura 2.13 - Modelo de ensaio utilizado em Dwaikat et al. (2011).....

Figura 2.14 - Cenários de isolamento térmico para os pilares estudados em Dwaikat et al. (2011)

Figura 2.15 - Diagrama "N-M" para pilares sujeitos a gradientes térmicos ao longo das mesas

Figura 2.16 - Modelos numéricos propostos por Zhang et al. (2015): a) térmico; b) termoestrutural

Figura 2.17 - Arranjo das vigas superiores da estrutura de restrição utilizada nos ensaios: a) Correia e Rodrigues (2012); b) Rocha (2016)

Figura 2.18 - Representação do sistema de ensaio utilizado em Rocha (2016)

Figura 2.19 - Posições dos termopares utilizadas para os pilares no programa experimental: a) isolados; b) com alma ortogonal à superfície da parede; c) com alma paralela à superfície da parede; d) representação das seções para medição das temperaturas 
Figura 2.20 - Modelo numérico proposto por Rocha (2016) 67

Figura 2.21 - Diferentes associações entre o perfil de aço e a alvenaria 69

Figura 2.22 - Diferentes orientações dos perfis frente à ação térmica................................... 70

Figura 2.23 - Seção transversal de um pilar de aço inserido em parede ................................ 73

Figura 2.24 - Zonas de temperatura para os perfis de aço definidas em Correia, Rodrigues e

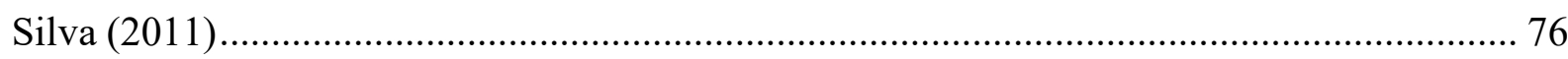

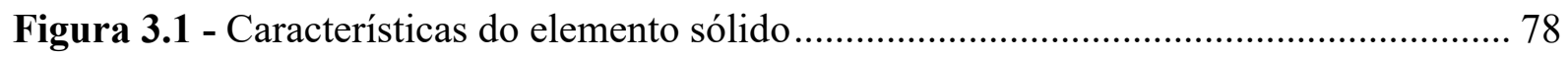

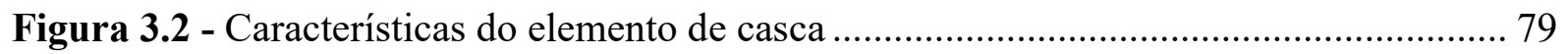

Figura 3.3 - Tipos de superfície para o elemento finito do tipo casca convencional.............. 80

Figura 3.4 - Representação dos modelos térmicos para os pilares: a) H100-ORT-T7; b) H100-

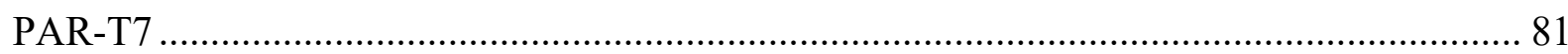

Figura 3.5 - Comparação entre as curvas experimentais e a curva de incêndio-padrão ISO 834:1999 para os pilares estudados 82

Figura 3.6 - Comparação entre os resultados dos modelos térmicos constituídos por elementos de casca e sólido para o pilar H220-ISO 85

Figura 3.7 - Comparação entre os resultados dos modelos térmicos constituídos por elementos de casca e sólido para o pilar H220-ORT-T15 86

Figura 3.8 - Comparação entre os resultados dos modelos térmicos constituídos por elementos de casca e sólido para o pilar H220-PAR-T15 86

Figura 3.9 - Validação dos modelos numéricos térmicos para os pilares isolados: a) H100-ISO;

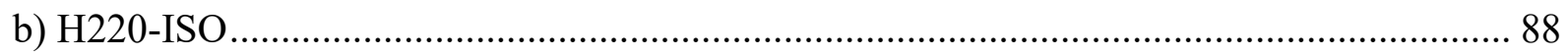

Figura 3.10 - Validação dos modelos numéricos térmicos para o pilar H100-ORT-T7 ......... 88

Figura 3.11 - Validação dos modelos numéricos térmicos para o pilar H100-PAR-T7 .......... 89

Figura 3.12 - Validação dos modelos numéricos térmicos para o pilar H220-ORT-T15 ....... 89

Figura 3.13 - Validação dos modelos numéricos térmicos para o pilar H220-PAR-T15 ....... 90

Figura 4.1 - Representação do modelo numérico baseado na estratégia numérica I para o pilar isolado H220-ISO

Figura 4.2 - Representação do modelo numérico baseado na estratégia numérica I para o pilar H100-ORT-T7

Figura 4.3 - Representação do modelo numérico baseado na estratégia numérica II para o pilar H220-PAR-T15.

Figura 4.4 - Validação dos modelos numéricos dos pilares isolados: a) H100-ISO; b) H220ISO 
Figura 4.5 - Comparação entre os resultados numéricos e experimentais para os pilares inseridos em paredes formados pelo perfil de aço HEA 100

Figura 4.6 - Comparação entre os resultados numéricos e experimentais para os pilares inseridos em paredes formados pelo perfil de aço HEA 220 .

Figura 4.7 - Curva referente à temperatura média em função do tempo para os pilares formados pelos perfis $\mathrm{H} 100$ e H220, isolados ou inseridos em paredes 101

Figura 4.8 - Curva referente ao gradiente térmico em função do tempo para os pilares....... 102

Figura 4.9 - Representação das paredes no ensaio experimental 103

Figura 4.10 - Representação numérica dos pilares inseridos em paredes 103

Figura 4.11 - Comparação entre os resultados numéricos e experimental para diferentes travamentos da lateral das paredes 104

Figura 4.12 - Representação gráfica do modelo elastoplástico perfeito. 107

Figura 4.13 - Validação da modelagem numérica para os pilares de aço formados pelo perfil de aço HEA 100 108

Figura 4.14 - Validação da modelagem numérica para os pilares de aço formados pelo perfil de aço HEA 220

Figura 4.15 - Análise do deslocamento axial para os pilares isolados 111

Figura 4.16 - Análise do deslocamento axial para os pilares inseridos em paredes: a) formados pelo perfil HEA 100; b) formados pelo perfil HEA 220

Figura 4.17 - Posicionamento dos transdutores de deslocamento no ensaio experimental... 113

Figura 4.18 - Resultado numérico para o pilar isolado formado pelo perfil HEA 160 114

Figura 4.19 - Resultados numéricos para os pilares inseridos em paredes formados pelo perfil HEA 200 .

Figura 4.20 - Resultado numérico para o pilar de aço isolado 116

Figura 4.21 - Resultados numéricos para os pilares de aço inseridos em paredes descritos em Rocha (2016) 116

Figura 4.22 - Resultados numéricos para os pilares de aço descritos em Simões (2016) ..... 117

Figura 5.1 - Influência da variação do fator de carga no desenvolvimento das forças axiais relativas para os pilares de aço isolados

Figura 5.2 - Influência do nível de rigidez axial no desenvolvimento das forças axiais relativas para os pilares de aço isolados

Figura 5.3 - Influência do nível de rigidez rotacional no desenvolvimento das forças axiais relativas para os pilares de aço isolados 
Figura 5.4 - Influência da variação do fator de carga no desenvolvimento das forças axiais relativas para os pilares de aço H100-ORT-T7 e H100-PAR-T7

Figura 5.5 - Influência do nível de rigidez axial no desenvolvimento das forças axiais relativas para os pilares de aço H100-ORT-T7 e H100-PAR-T7

Figura 5.6 - Influência do nível de rigidez rotacional no desenvolvimento das forças axiais relativas para os pilares de aço H100-ORT-T7 e H100-PAR-T7

Figura 5.7 - Influência da variação do fator de carga no desenvolvimento das forças axiais relativas para os pilares de aço H220-ORT-T15 e H220-PAR-T15

Figura 5.8 - Influência do nível de rigidez axial no desenvolvimento das forças axiais relativas para os pilares de aço H220-ORT-T15 e H200-PAR-T15.

Figura 5.9 - Influência do nível de rigidez rotacional no desenvolvimento das forças axiais relativas para os pilares de aço H220-ORT-T15 e H220-PAR-T15 138

Figura 6.1 - Representação do perímetro exposto ao fogo para os pilares inseridos em paredes 142

Figura 6.2 - Representação da área bruta $\left(A_{g}\right)$ adotada para os pilares inseridos em paredes 143

Figura 6.3 - Comparação dos resultados dos modelos numéricos com o Método Simplificado da ABNT NBR 14323:2013 para pilares isolados H220-ISO e H100-ISO. 145

Figura 6.4 - Comparação dos resultados do modelo numéricos com o Método Simplificado da ABNT NBR 14323:2013 para pilares inseridos em paredes 146

Figura 6.5 - Evolução da temperatura de pilares de aço em função da variação do fator de massividade por meio do método simplificado da ABNT NBR 14323:2013. 147

Figura 6.6 - Representação da seção transversal do pilar em duas áreas iguais 148

Figura 6.7 - Comparação entre as temperaturas obtidas numericamente e pelo método simplificado proposto para os pilares inseridos em paredes (Parte 1) 150

Figura 6.8 - Comparação entre as temperaturas obtidas numericamente e pelo método simplificado proposto para os pilares inseridos em paredes (Parte 2) 151

Figura 6.9 - Comparação entre as temperaturas obtidas numericamente e pelo método simplificado proposto para os pilares inseridos em paredes (Parte 3 ) 152 


\section{LISTA DE TABELAS}

Tabela 2.1 - Características geométricas dos perfis de aço HEA 100 e HEA 220 .................63

Tabela 3.1 - Características dos pilares utilizados na modelagem numérica ......................... 77

Tabela 3.2 - Parâmetros testados para calibração do modelo numérico térmico...................... 84

Tabela 3.3 - Parâmetros adotados para calibração do modelo numérico térmico ....................87

Tabela 4.1 - Nomenclatura dos elementos finitos utilizados na modelagem numérica ..........91

Tabela 5.1 - Força normal resistente e rigidez axial dos pilares estudados ......................... 122

Tabela 6.1 - Perímetro exposto, área bruta e fator de massividade para os perfis de aço ..... 144

Tabela 6.2 - Identificação dos pilares empregados para validação do método simplificado proposto no presente trabalho. 



\section{SUMÁRIO}

1 INTRODUÇÃ

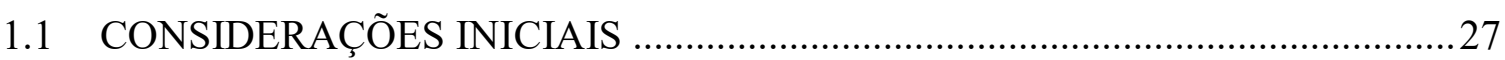

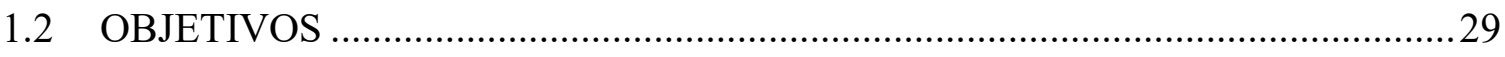

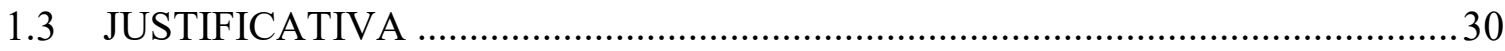

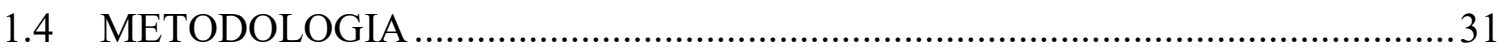

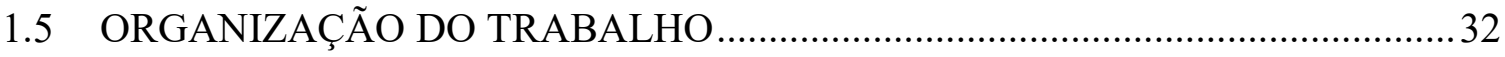

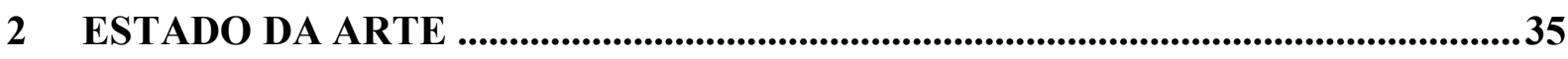

2.1 ASPECTOS GERAIS SOBRE AS RESTRIÇÕES TÉRMICAS ............................35

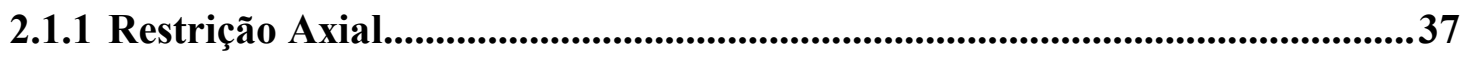

2.1.2 Restrição Rotacional ........................................................................................38

2.1.3 Comentários adicionais sobre a temática.................................................38

2.2 PESQUISAS CIENTÍFICAS SOBRE PILARES DE AÇO ISOLADOS ...............39

2.2.1 Estudos experimentais ................................................................................39

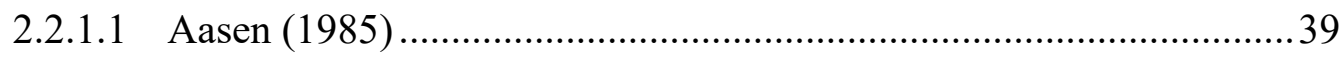

2.2.1.2 Ali, Sirnms e O'Connor (1997), Ali et al. (1998) e Ali e O'Connor

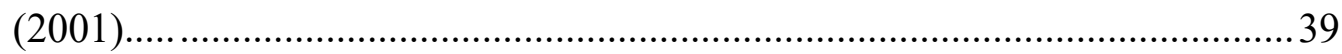

2.2.1.3 Rodrigues, Neves e Valente (2000) ........................................... 41

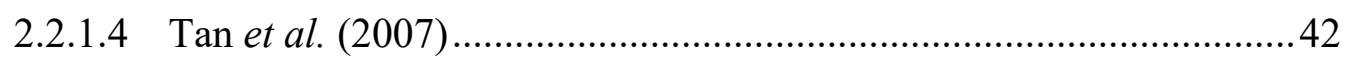

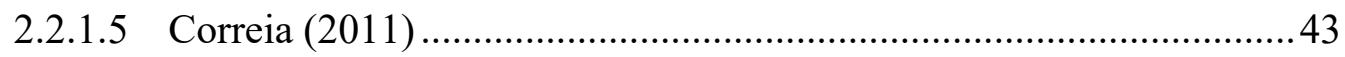

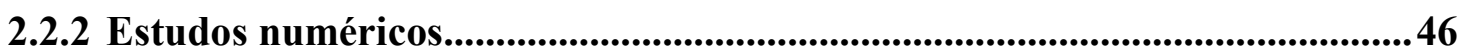

2.2.2.1 Poh e Bennetts (1995) ................................................................ 46

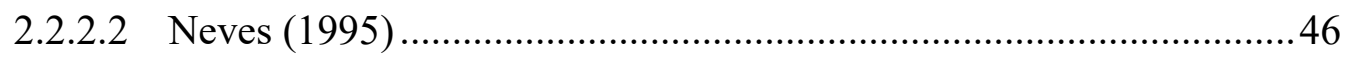

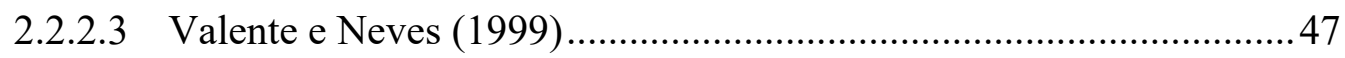

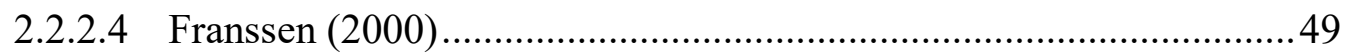

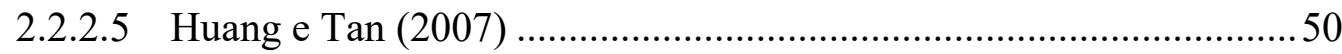

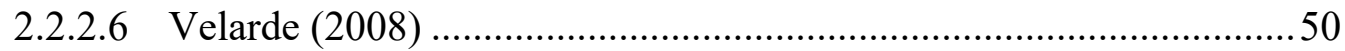

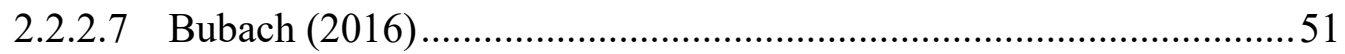

2.3 PILARES DE AÇO SOB AÇÃO TÉRMICA NÃO UNIFORME ...........................52

2.3.1 O fenômeno Thermal Bowing ...................................................................52 
2.3.2 Pesquisas científicas sobre pilares de aço com aquecimento não uniforme na seção transversal: sem interação das paredes............................................................... 55

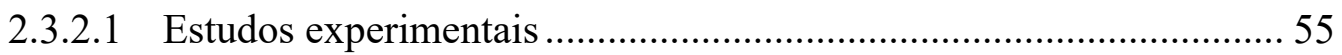

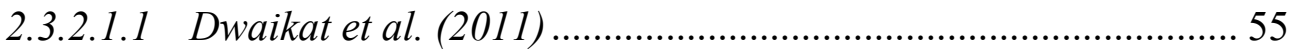

2.3.2.2 Estudos numéricos................................................................... 57

2.3.2.2.1 Garlock e Quiel (2006, 2007)............................................... 57

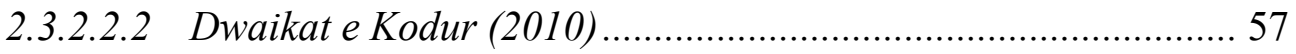

2.3.2.2.3 Agarwal, Choe e Varma (2014)................................................ 59

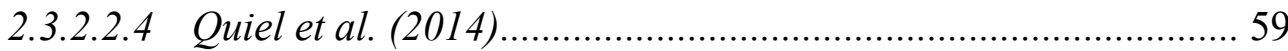

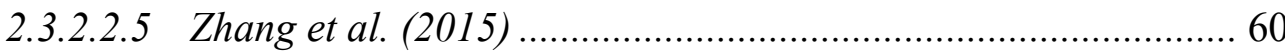

2.3.3 Pesquisas científicas sobre pilares de aço inseridos em paredes ................... 61

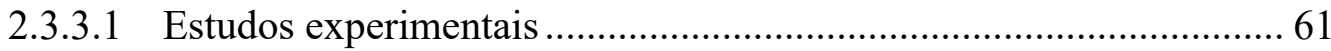

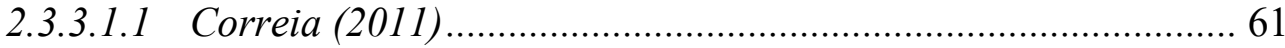

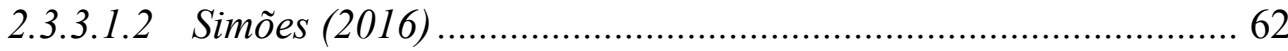

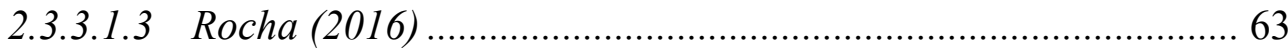

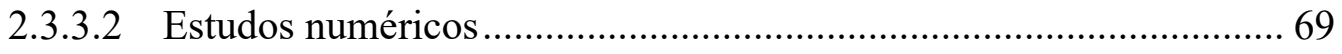

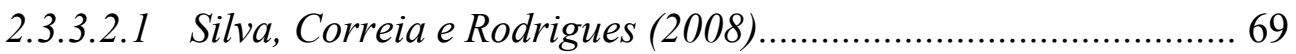

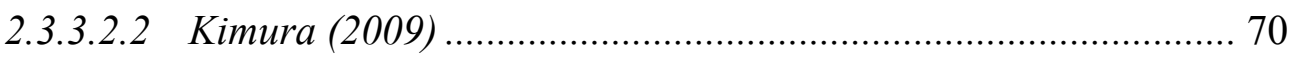

2.3.3.2.3 Dorr (2010) …................................................................ 71

2.4 MÉTODO SIMPLIFICADO PARA CÁLCULO DE TEMPERATURAS EM PERFIS DE AÇO PROPOSTO PELA ABNT NBR 14323:2013 …............................... 71

2.4.1 Sobre o método simplificado ............................................................................. 72

2.4.1.1 Elementos estruturais pertencentes a elementos de

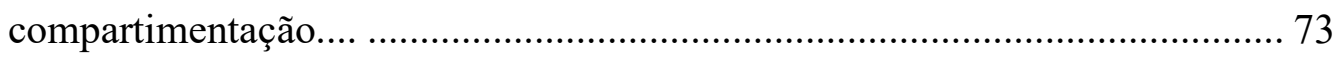

2.4.2 Pesquisas científicas sobre a metodologia de cálculo de temperatura em perfis de aço proposta pelos códigos normativos ....................................................................... 74

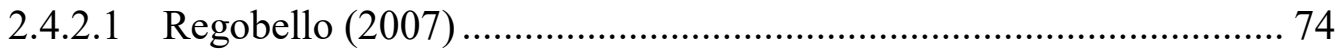

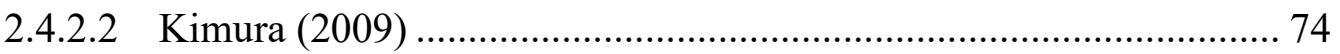

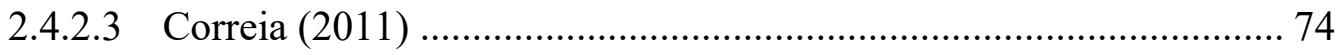


3 ANÁLISE NUMÉRICA TÉRMICA: MODELOS PROPOSTOS E VALIDAÇÃO 77

3.1 DEFINIÇÃO DO CAMPO DE ESTUDO …………………………………….......

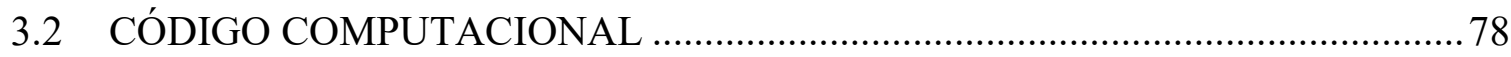

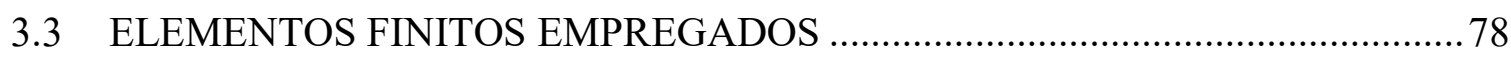

3.4 ASPECTOS GERAIS DA MODELAGEM NUMÉRICA ………………………...... 81

3.5 CONDIÇÕES DE CONTORNO E PROPRIEDADE DOS MATERIAIS ...............83

3.6 ANÁLISE DA EFICIÊNCIA DO ELEMENTO FINITO DE CASCA EM

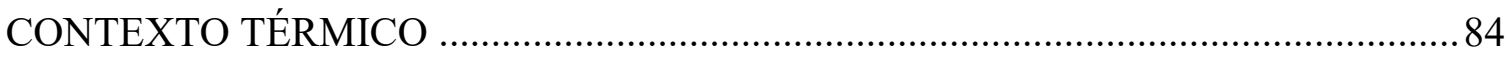

3.7 VALIDAÇÃO DOS MODELOS TÉRMICOS PROPOSTOS.................................... 87

4 ANÁLISE NUMÉRICA TERMOESTRUTURAL: ESTRATÉGIAS DE MODELAGEM, MODELOS PROPOSTOS E VALIDAÇÃO...........................................91

4.1 ELEMENTOS FINITOS UTILIZADOS............................................................91

4.2 ASPECTOS GERAIS SOBRE A MODELAGEM TERMOESTRUTURAL ........91

4.2.1 Estratégia numérica I..........................................................................................93

4.2.2 Estratégia numérica II ...................................................................................95

4.3 VALIDAÇÃO DA MODELAGEM TERMOESTRUTURAL ………………….....95

4.3.1 Utilização da estratégia numérica I ..................................................................96

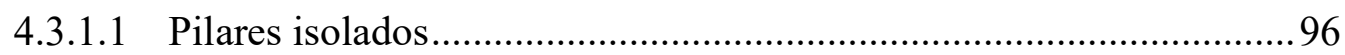

4.3.1.2 Pilares inseridos em paredes ................................................................97

4.3.1.2.1 Formados pelo perfil de aço HEA 100 .........................................97

4.3.1.2.2 Formados pelo perfil de aço HEA 220 ………………………....98

4.3.1.3 Considerações referentes aos resultados numéricos proporcionados pela estratégia numérica I

4.3.2 Influência das paredes no comportamento termoestrutural de pilares .....100

4.3.3 Utilização da estratégia numérica II.............................................................106

4.3.3.1 Considerações referentes aos resultados numéricos proporcionados pela estratégia numérica II .............................................................................. 110

4.3.4 Análise do deslocamento axial...........................................................................110

4.3.5 Comparação entre os resultados numéricos obtidos e aqueles apresentados

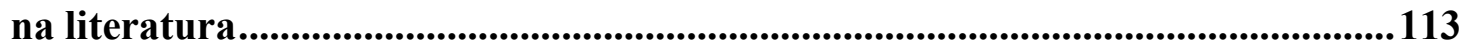

4.4 RESUMO DOS RESULTADOS NUMÉRICOS TERMOESTRUTURAIS .........118

5 ANÁLISE PARAMÉTRICA..............................................................................121

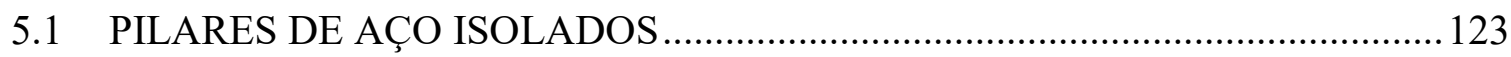


5.1.1 Análises paramétricas com relação à influência do fator de carga............. 123

5.1.2 Análises paramétricas com relação à influência à restrição térmica......... 125

5.1.2.1 Quanto à rigidez axial........................................................... 125

5.1.2.2 Quanto à rigidez rotacional .......................................................... 127

5.2 PILARES INSERIDOS EM PAREDES ......................................................... 128

5.2.1 Análises com relação aos pilares formados pelo perfil HEA 100 ............... 128

5.2.1.1 Análises paramétricas com relação à influência do fator de carga.. 128

5.2.1.2 Análises paramétricas com relação à influência da restrição

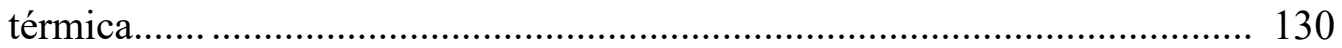

5.2.1.2.1 Restrição axial ................................................................... 130

5.2.1.2.2 Rigidez rotacional ........................................................... 132

5.2.2 Análises com relação aos pilares formados pelo perfil HEA 220 ............... 133

5.2.2.1 Influência do fator de carga ........................................................ 133

5.2.2.2 Influência da restrição térmica ...................................................... 136

5.2.2.2.1 Rigidez Axial .................................................................... 136

5.2.2.2.2 Rigidez Rotacional........................................................ 138

6 PROPOSTA DE MÉTODO SIMPLIFICADO PARA DETERMINAÇÃO DA EVOLUÇÃO DE TEMPERATURA EM PERFIS DE AÇO ........................................ 141

6.1 AVALIAÇÃO DO MÉTODO SIMPLIFICADO DA ABNT NBR 14323:2013 . 142

6.1.1 Emprego da metodologia de cálculo ............................................................. 142

6.1.2 Considerações relativas à modelagem numérica ......................................... 144

6.1.3 Análise dos resultados do estudo comparativo .............................................. 144

6.2 PROPOSTA DE METODOLOGIA PARA DETERMINAÇÃO DA TEMPERATURA EM SEÇÕES TRANSVERSAIS DE PILARES INSERIDOS EM

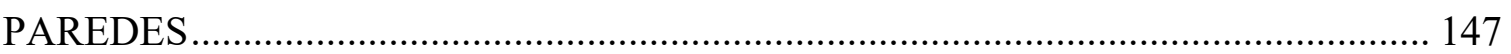

6.2.1 Hipóteses básicas de cálculo................................................................................... 147

6.2.2 Validação do método proposto ...................................................................... 148

6.3 SINOPSE DOS RESULTADOS APRESENTADOS ....................................... 153

7 BREVES CONSIDERAÇÕES E CONCLUSÕES .................................................... 155

7.1 COM RELAÇÃO ÀS ANÁLISES EM CONTEXTO TÉRMICO ....................... 156

7.2 COM RELAÇÃO ÀS ANÁLISES EM CONTEXTO TERMOESTRUTURAL. 156

7.3 COM RELAÇÃO ÀS ANÁLISES PARAMÉTRICAS ....................................... 158 
7.4 PROPOSTA DE MÉTODO SIMPLIFICADO PARA CÁLCULO DA TEMPERATURA EM PILARES INSERIDOS EM PAREDES.....................................159

7.5 SUGESTÕES PARA TRABALHOS FUTUROS ……………………................. 160

REFERÊNCIA BIBLIOGRÁFICA ......................................................................161

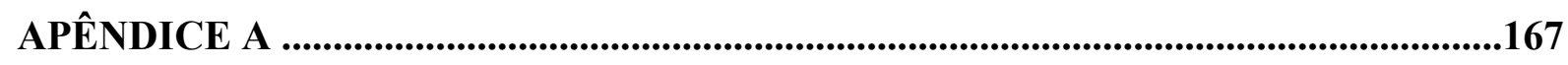

APÊNDICE B ......................................................................................................................171

APÊNDICE C .................................................................................................179

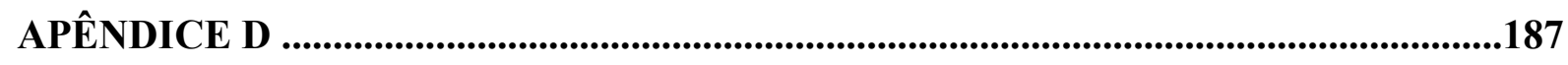

ANEXO A ….......................................................................................................................191

ANEXO B ..............................................................................................................................193 



\section{CAPÍTULO 1}

\section{INTRODUÇÃO}

\subsection{CONSIDERAÇÕES INICIAIS}

Nos últimos anos, foram desenvolvidas pesquisas com notáveis progressos a respeito do comportamento de estruturas de aço em situação de incêndio. Apesar disso, quando o estudo é voltado para o efeito da compartimentação na resposta termomecânica dos elementos estruturais sob ação do fogo, percebe-se que a compreensão ainda não está completa.

Segundo a Associação Brasileira de Normas Técnicas (ABNT) através da Norma Brasileira (NBR) 14432:2001, a compartimentação é considerada uma medida de proteção passiva que tem como função diminuir ou evitar a propagação interna ou externa de chamas, calor e gases em um edifício incendiado. As paredes, por exemplo, funcionam como um elemento de compartimentação e oferecem aumento da resistência ao fogo de pilares quando estão em contato com esse elemento estrutural.

Nas estruturas correntes compostas por elementos metálicos, grande parte dos pilares de aço se encontra inserida em paredes, de modo que, em situação de incêndio, apresentam comportamento estrutural diferente daqueles isolados.

A alvenaria protege parte do perfil de aço da exposição direta ao fogo, diminuindo a temperatura média dos pilares. Em contrapartida, uma vez que a ação térmica não age em todas as faces do pilar, em resposta à presença desses elementos de vedação, ocorre um aquecimento diferencial na seção transversal do elemento estrutural dando origem a um gradiente térmico. Essa não homogeneidade, do ponto de vista de temperatura, proporciona o aparecimento de esforços adicionais no pilar, caracterizando o fenômeno denominado Thermal Bowing. Assim, a resistência ao fogo do elemento passa a resultar da interação de uma série de fatores e não somente da degradação das propriedades mecânicas do aço com o aumento da temperatura.

O Thermal Bowing pode ser caracterizado como o surgimento inicial de uma curvatura do pilar para o lado exposto ao fogo, seguido de mudança em sua curvatura para o lado oposto. Esse comportamento ocorre devido aos efeitos da dilatação térmica em regime de aquecimento não uniforme e a perda de rigidez do material com o aumento da temperatura associados às 
restrições rotacionais presentes nas extremidades. O fenômeno é apresentado de forma detalhada em Garlock e Quiel (2007) e em Correia, Rodrigues e Real (2014).

As normas vigentes que abordam o dimensionamento de estruturas metálicas em situação de incêndio, em especial a norma brasileira ABNT NBR 14323:2013, assim como o Eurocode 3 Parte 1-2 (2005), tratam apenas dos pilares com distribuição uniforme da temperatura na seção transversal. O dimensionamento do elemento frente a essa ação excepcional consiste na determinação da temperatura média do perfil de aço com base em uma grandeza denominada "fator de massividade", a qual é obtida pela razão entre o perímetro exposto ao fogo e a área bruta da seção transversal.

No que concerne aos elementos estruturais pertencentes a paredes, as normas vigentes apenas fazem menção a essa configuração como um caso especial que necessita de uma análise térmica adequada, sem apresentar um método simplificado para sua abordagem. De acordo com Silva, Correia e Rodrigues (2008) e Correia et al. (2009) esse método representa com satisfatória precisão a evolução de temperatura do pilar de aço isolado, porém, para o caso em que há gradiente térmico na seção transversal, os resultados teóricos podem levar a valores bastante conservadores.

Além disso, os pilares, sejam isolados ou inseridos em paredes, fazem parte de uma estrutura global, de modo que interagem com as vigas ou lajes que podem estar apoiados sobre eles. Portanto, durante um incêndio, naturalmente esse elemento tende a se deformar, mas o restante da estrutura impõe restrições a essa deformação térmica, o que promove o aparecimento de esforços adicionais aos pilares que podem afetar a estabilidade dos mesmos, alterando a sua resistência ao fogo.

Basicamente, são dois os tipos de restrição térmica: a restrição axial, que impõe certo impedimento à deformação longitudinal do pilar, acarretando no aumento de suas forças axiais, e aquela responsável por impedir parcialmente o giro nas extremidades do mesmo, nomeada de restrição rotacional, que promove o aparecimento de momentos fletores. Correia (2011) e Bubach (2016) afirmam que ambas restrições possuem efeitos contrários na resistência ao fogo de pilares, de modo que a restrição axial age de forma a diminuir essa mesma resistência, enquanto a rotacional tende a aumentá-la.

O Eurocode 1 Parte 1-2 (2002), em relação ao projeto estrutural sob ação do fogo, indica que devem ser levadas em consideração nos cálculos não apenas ações diretas, mas também ações indiretas relacionadas ao incêndio, como, por exemplo, as restrições térmicas. Apesar disso, o Eurocode 3 Parte 1-2 (2005) e a respectiva versão brasileira ABNT NBR 14323:2013 fornecem um método simplificado de dimensionamento de estruturas de aço sob ação do fogo 
que não faz menção ao efeito da restrição proveniente da estrutura circundante. Esse método considera basicamente a redução das propriedades mecânicas do aço com a elevação da temperatura na realização dos cálculos.

Diante do exposto, esta pesquisa visa avaliar os efeitos da ação térmica uniforme e não uniforme sobre o comportamento estrutural de pilares de aço isolados e inseridos em paredes, respectivamente, com restrições térmicas nas extremidades. Para isso, são propostos modelos numéricos térmicos e termoestruturais desenvolvidos com o auxílio do código computacional ABAQUS versão 6.14, validados a partir dos ensaios experimentais descritos em Rocha (2016). Outras análises com o modelo validado também foram desenvolvidas, com o intuito de analisar parâmetros como o nível de restrição térmica e o fator de carga na resistência ao fogo dos pilares metálicos.

A partir dos modelos construídos, foi comparada a elevação da temperatura média dos perfis de aço proveniente da análise numérica com aquela obtida pelo método simplificado da ABNT NBR 14323:2013. Sugestões para o cálculo da evolução da temperatura para pilares inseridos em paredes também são apresentados no decorrer do trabalho, permitindo o aprofundamento do conhecimento na área de engenharia estrutural em incêndio.

\subsection{OBJETIVOS}

No contexto geral, o presente estudo busca desenvolver modelos numéricos térmicos e termoestruturais de pilares de aço isolados e inseridos em paredes com restrição térmica nas extremidades a fim de compreender o comportamento dos mesmos em situação de incêndio. De modo específico, o trabalho possui os seguintes objetivos:

- Realizar um conjunto de análises numéricas a partir do código computacional ABAQUS versão 6.14, capaz de representar comportamentos térmico e termoestrutural de pilares de aço isolados e em contato com paredes;

- Avaliar a influência da parede no comportamento termoestrutural de pilares sujeitos a gradientes térmicos na seção transversal;

- Analisar a influência da intensidade da restrição térmica e do nível de carga aplicado na resistência ao fogo de pilares metálicos;

- Comparar os resultados da modelagem numérica térmica com aqueles fornecidos pelos métodos simplificados oriundos das normas atuais; 
- Propor um método simplificado para cálculo da evolução da temperatura em pilares de aço inseridos em paredes;

- Comparar os resultados alcançados aos da literatura disponível.

\subsection{JUSTIFICATIVA}

No dimensionamento de pilares de aço em situação de incêndio, a norma brasileira ABNT NBR 14323:2013 e a europeia Eurocode 3 Parte 1-2 (2005) trazem métodos simplificados que admitem como hipótese: o elemento estrutural isolado com aquecimento uniforme e sem interação com alvenaria ou com a estrutura circundante. Diante disso, os códigos normativos atuais não representam os casos reais por não considerar a restrição térmica nas extremidades dos pilares e por não contemplar a maior parte dos casos presentes em estruturas correntes, que são os pilares embutidos em paredes.

O comportamento termoestrutural desses elementos estruturais inseridos em alvenaria difere daqueles quando estão isolados devido ao aparecimento de um gradiente térmico na seção transversal que induz o aumento de esforços atuantes. Além disso, quando se analisa um pilar com e sem restrição térmica em situação de incêndio, os resultados são bastante diferentes de modo que essa restrição pode impactar na estabilidade do elemento. Portanto, uma abordagem levando em consideração esses dois aspectos com intuito de compreender o comportamento dos pilares sob ação do fogo pode trazer grandes contribuições para as normas existentes e para o meio científico, justificando o desenvolvimento dessa pesquisa.

Estudos nacionais a respeito de estruturas em situação de incêndio, especificamente para pilares, são recentes e, portanto, ainda há questões que precisam ser respondidas. Quando se trata desses elementos estruturais associados a paredes, a carência de pesquisas é ainda maior, inclusive em contexto estrangeiro.

No âmbito da análise numérica, as pesquisas encontradas na literatura não conseguiram desenvolver um modelo numérico que representasse de forma satisfatória pilares de aço inseridos em paredes, não possibilitando compreender de forma adequada o seu comportamento em elevadas temperaturas. Todas elas consideraram a alvenaria apenas como elemento de compartimentação, o que difere do presente trabalho que passa a estudar a influência da alvenaria no comportamento termoestrutural dos pilares.

Assim, esta pesquisa vem com o intuito de suprir lacunas sobre o desempenho de pilares de aço, isolados e inseridos em alvenaria, com restrições axiais e rotacionais nas extremidades, contribuindo, portanto, para a área de engenharia de incêndio. 


\section{$1.4 \quad$ METODOLOGIA}

O presente estudo é caracterizado como explicativo e exploratório relativo ao comportamento estrutural, em situação de incêndio, de pilares de aço isolados e inseridos em paredes com restrições axial e rotacional nas extremidades. O desenvolvimento deste trabalho se inicia com uma pesquisa bibliográfica referente ao estado da arte na qual o tema central está inserido, seguido de uma abordagem numérica a respeito de pilares de aço a fim de representar os ensaios experimentais descritos em Rocha (2016).

Para realização da modelagem numérica foi utilizado o código computacional ABAQUS versão 6.14, que utiliza o Método dos Elementos Finitos para resolução dos problemas de engenharia. A modelagem aqui proposta consistiu em três etapas executadas em sequência. A primeira, chamada de análise térmica, é responsável por determinar o campo de temperaturas obtido no ensaio experimental em todo o tempo de aquecimento. A segunda fundamenta-se na inserção das imperfeições geométricas iniciais como um deslocamento no meio do vão do pilar. E na última etapa, denominada análise termoestrutural, o elemento imperfeito é carregado e recebe gradualmente o campo térmico previamente determinado visando então representar o comportamento do pilar em situação de incêndio.

Após a definição de cada modelo, os resultados numéricos obtidos passam por um processo de validação que consiste em compara-los com resultados experimentais, em particular, com aqueles apresentados em Rocha (2016). Na análise térmica, foi verificado se as temperaturas obtidas numericamente apresentavam boa concordância com aquelas medidas nos ensaios experimentais. Já na análise termoestrutural, os modelos foram validados basicamente pela evolução das forças de restrição desenvolvidas no experimento. Comentários a respeito sobre o deslocamento axial também são realizados nessa etapa.

A partir da validação dos modelos numéricos, outras abordagens foram desenvolvidas por meio de um conjunto de análises paramétricas. Buscou-se identificar a influência do fator de carga e da intensidade das restrições térmicas na resistência ao fogo dos elementos estruturais.

Por fim, o estudo contou com a avaliação da eficiência do método simplificado fornecido pela ABNT NBR 14323:2013 para cálculo da evolução de temperatura na seção transversal dos pilares de aço isolados e inseridos em paredes. A partir dessa análise teórica, foi proposto um novo método de cálculo para esse fim. 


\subsection{ORGANIZAÇÃO DO TRABALHO}

No Capítulo 1, realiza-se uma apresentação da temática abordada, seguida dos objetivos e justificativa para escolha do tema, finalizando com os aspectos gerais da metodologia empregada para a realização deste trabalho.

O Capítulo 2 trata do estado da arte. Inicialmente, apresenta-se a teoria sobre as restrições térmicas e seus impactos no comportamento termoestrutural dos pilares. Em seguida, são abordadas as principais pesquisas científicas produzidas sobre pilares de aço isolados e inseridos em paredes em situação de incêndio, com destaque ao estudo descrito em Rocha (2016), em razão de seus experimentos serem utilizados para validação dos modelos aqui propostos. O capítulo é finalizado com a descrição do método simplificado fornecido pela ABNT NBR 14323:2013 para o cálculo da temperatura em perfís de aço sob ação do fogo.

O Capítulo 3 apresenta a validação dos modelos numéricos térmicos. Além disso, são discutidos de forma detalhada os elementos finitos empregados, a estratégica numérica utilizada juntamente com as condições de contorno e as propriedades dos materiais consideradas para o desenvolvimento dessa análise.

O Capítulo 4 traz os resultados da modelagem termoestrutural realizada. Nele consta a validação dos modelos numéricos e as principais conclusões a respeito do desempenho dos pilares de aço em situação de incêndio. Nesse capítulo, é dado destaque à influência da parede no comportamento desses elementos estruturais sob elevadas temperaturas. As estratégias numéricas utilizadas para o desenvolvimento dos modelos numéricos também são comentadas ao longo do texto.

No Capítulo 5 é desenvolvido um conjunto de análises paramétricas, por meio da variação da intensidade da restrição térmica e do fator de carga, a fim de investigar a influência desses parâmetros no comportamento termomecânico dos pilares de aço.

No Capítulo 6 são comparados os resultados dos modelos numéricos térmicos aqui propostos com aqueles fornecidos pelo método simplificado da norma brasileira ABNT NBR 14323:2013 no que diz respeito a determinação da temperatura na seção transversal do pilar de aço. O capítulo é finalizado com a proposição de um novo método de cálculo de temperatura para os pilares em contato com paredes.

Por fim, o Capítulo 7 traz uma visão geral sobre os resultados obtidos e as principais conclusões alcançadas nas análises numéricas e paramétricas desenvolvidas. Devido à complexidade da temática, são dadas algumas sugestões para trabalhos futuros de modo a 
Capítulo 1 - Introdução

apontar ao meio científico algumas questões que ainda precisam ser respondidas sobre o conteúdo dessa dissertação. 


\section{CAPÍTULO 2}

\section{ESTADO DA ARTE}

O Capítulo 2 é composto de quatro seções responsáveis por retratar o conhecimento atual do meio científico a respeito da temática deste trabalho. Primeiramente (seção 2.1), realiza-se uma abordagem sobre o efeito das restrições térmicas no comportamento termoestrutural de pilares de aço. Em seguida, são descritas as principais pesquisas científicas relevantes ao estudo desses elementos estruturais com aquecimento uniforme (seção 2.2) e nãouniforme (seção 2.3) na seção transversal. Por fim (seção 2.4), o capítulo apresenta o método simplificado da ABNT NBR 14323:2013, semelhante ao proposto pelo Eurocode 3 Parte 1-2 (2005), sobre o cálculo da evolução da temperatura em perfis de aço, em conjunto com os trabalhos mais importantes que avaliaram a eficiência dessa metodologia.

\subsection{ASPECTOS GERAIS SOBRE AS RESTRIÇÕES TÉRMICAS}

De acordo com Neves (1995), o comportamento real de elementos estruturais em situação de incêndio deve ser analisado como um componente de uma estrutura completa, de modo que cada peça estrutural interaja com a estrutura a sua volta. No caso dos pilares, os mesmos possuem interação com as vigas ou lajes, que podem estar apoiados sobre eles, ou ainda com pilares contínuos. Essa estrutura envolta dos pilares, na literatura, é denominada envolvente ou circundante.

Durante a ocorrência de um incêndio, naturalmente, o pilar tende a se deformar, porém o restante da estrutura impõe restrições axiais e rotacionais a essa deformação. As restrições axiais atuam contra o alongamento do pilar, enquanto que as restrições rotacionais limitam as rotações das extremidades do elemento (SHEPHERD; BURGESS, 2011). O surgimento dessas restrições gera esforços adicionais à estrutura, que impactam diretamente na resistência ao fogo dos elementos estruturais.

De acordo com Neves (1995), ao resistir à expansão térmica do pilar, a estrutura envolvente provoca uma força reativa nesse elemento estrutural aumentando sua força de compressão. Esse aumento tende a ser cada vez menor com o tempo, uma vez que a elevação da temperatura causa redução da resistência e do módulo de elasticidade dos materiais 
constituintes. Quando esse material atinge o escoamento, essas forças começam a decrescer. Diante do exposto, o autor definiu o conceito de resistência ao fogo como sendo o instante em que a força axial que atua no pilar volta ao seu valor inicial (Figura 2.1). Esse conceito será utilizado nessa pesquisa para definição do tempo e da temperatura críticos.

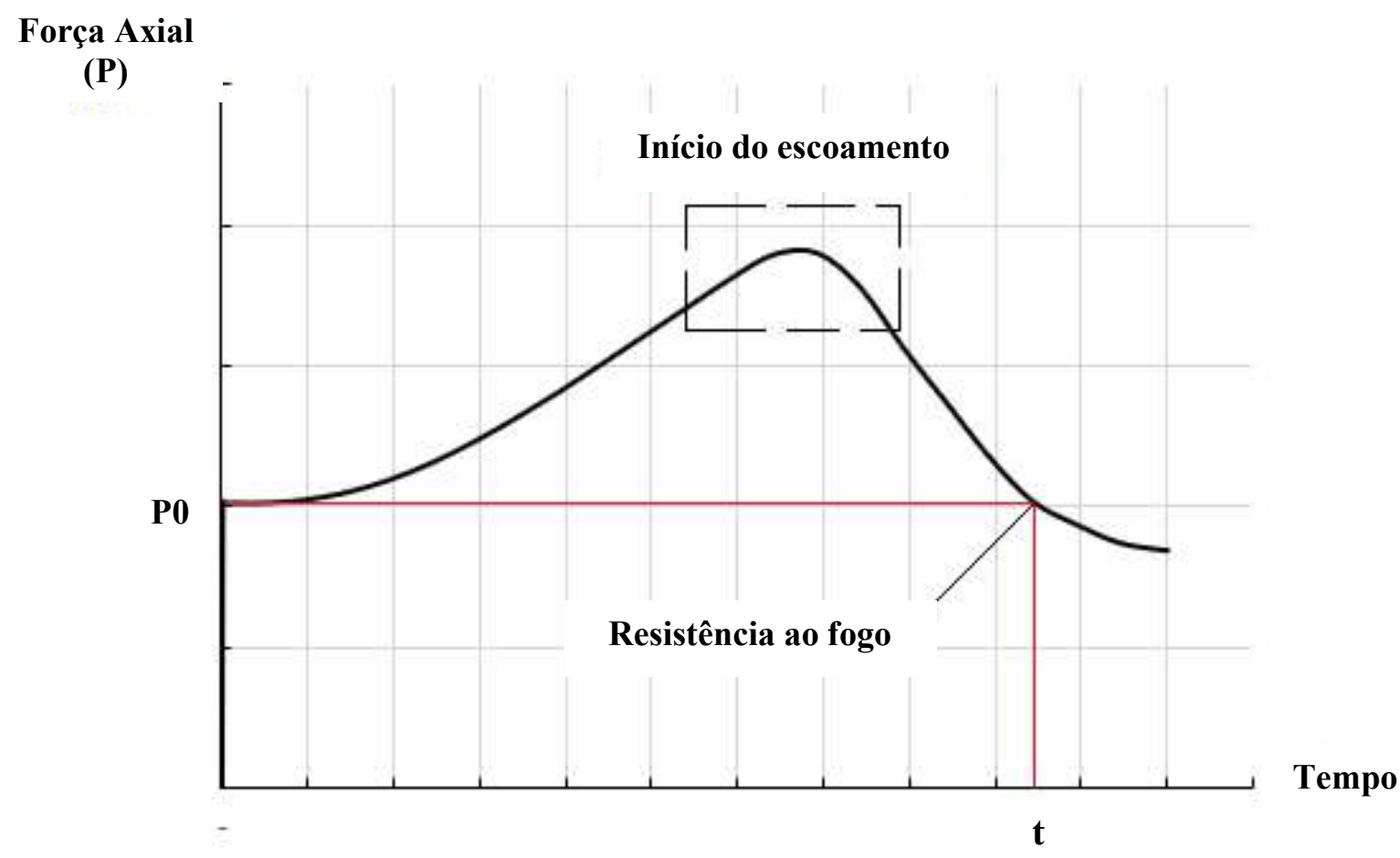

Figura 2.1- Evolução das forças axiais em pilares com restrição térmica

Fonte: Autor da Pesquisa (2018).

Outro tipo de limitação que ocorre nos pilares aquecidos é a restrição rotacional, a qual também é fornecida pelas vigas e lajes apoiadas sobre eles ou ainda por pilares contínuos. De acordo com Wang (2002), ela pode afetar o comportamento desses elementos de duas maneiras: alterando seu comprimento de flambagem ou provocando o aparecimento de momentos fletores em suas extremidades.

De modo a estudar o comprimento de flambagem de pilares em estruturas de multipavimentos, Webber et al. (2015) comprovaram que o aumento da rigidez dos pilares superiores e inferiores, em relação a um determinado pilar central, reduz a rotação de suas extremidades, diminuindo o comprimento de flambagem do mesmo.

A partir disso, é possível concluir de modo correlativo que, durante o incêndio, quando um pilar central perde rigidez devido à degradação de suas propriedades mecânicas a estrutura de restrição se encontra relativamente fria e, portanto, com maior rigidez. Consequentemente, 
com essa diferença em relação à rigidez, ocorrerá a diminuição do comprimento de flambagem do pilar comprometido (BUBACH, 2016). No tocante ao aparecimento de momentos fletores devido à restrição rotacional, frisa-se que esse ponto será discutido na seção 2.3 ao tratar de pilares com aquecimento não uniforme.

Grande parte dos estudos a respeito de pilares de aço sob elevadas temperaturas considera-os sem qualquer restrição, o que difere de situações reais. Com o desenvolvimento das pesquisas, as restrições já estão sendo inseridas, tanto em análises experimentais quanto em análises numéricas, porém, em muitos trabalhos, os dois tipos de restrições são tratados separadamente. Apesar disso, pesquisas mais recentes, como as descritas em Correia (2011), Bubach (2016), Rocha (2016) e Simões (2016), já consideram a ação conjunta dessas restrições térmicas, comprovando que elas impactam de forma contrária na resistência ao fogo dos pilares, com a restrição axial atuando de forma a reduzir tal resistência, enquanto a restrição rotacional age de maneira a aumenta-la.

O meio científico tem avaliado essas restrições por seu respectivo parâmetro adimensional. A seguir são descritas as equações apresentadas em Correia e Rodrigues (2011).

\subsubsection{Restrição Axial}

A restrição axial relativa é fornecida por um valor adimensional $\left(\propto_{A}\right)$ definido como a razão entre a rigidez axial da estrutura envolvente $\left(K_{A, S}\right)$ e a rigidez axial elástica do pilar $\left(K_{A, C}\right)$, expressa pela Equação 2.1.

$$
\propto_{A}=\frac{K_{A, S}}{K_{A, C}}
$$

O parâmetro $K_{A, C}$ é calculado por meio da Equação 2.2.

$$
K_{A, C}=\frac{E A}{L_{c}}
$$

Na qual, $E$ é o módulo de elasticidade do material, $A$ corresponde a área da seção transversal e $L_{c}$ é o comprimento do pilar. 


\subsubsection{Restrição Rotacional}

A restrição rotacional relativa $\left(\beta_{R}\right)$ é caracterizada como a razão entre a rigidez rotacional da estrutura envolvente $\left(K_{R, S}\right)$ e a rigidez rotacional elástica do pilar $\left(K_{R, C}\right)$ expressa pela Equação 2.3:

$$
\beta_{R}=\frac{K_{R, S}}{K_{R, C}}
$$

A rigidez rotacional do pilar, $K_{R, C}$, é calculada por meio da Equação 2.4:

$$
K_{R}=\frac{4 E}{L_{c}}
$$

Onde, $I$ é o momento de inércia da seção transversal do pilar.

\subsubsection{Comentários adicionais sobre a temática}

Alguns estudos têm discutido sobre a influência das paredes na restrição à deformação térmica dos pilares. Em Neves (1995) se menciona que esses elementos de compartimentação, mesmo quando não possuem função de apoio, irão contribuir para a rigidez do sistema global de tal forma que não é fácil sua avaliação.

Em Rocha (2016), a partir de resultados experimentais, verificou-se que os parâmetros adimensionais representados pelas Equações 2.1 e 2.3 exercem influência na resposta termoestrutural dos pilares. Quanto maior a intensidade dos parâmetros adimensionais, que são proporcionais à rigidez da estrutura circundante, maiores esforços serão desenvolvidos no pilar e, consequentemente, menores deslocamentos axiais e menores rotações.

Ainda de acordo com o autor, pilares em contato com paredes de diferentes espessuras, dado um mesmo perfil de aço, apresentaram desempenhos distintos sob a ação do fogo. Quando inseridos em paredes mais espessas, os elementos estruturais apresentaram maiores deslocamentos axiais, uma vez que a alvenaria contribui para aumentar a rigidez axial dos pilares o que acaba reduzindo o parâmetro $\propto_{A}$. Dessa maneira, a força de restrição se encontra diminuída, proporcionando um maior alongamento do pilar. Além disso, em Rocha (2016) é destacado que pilares mais esbeltos possuem rigidezes axial e rotacional relativas maiores 
quando comparados aos robustos, o que aumenta as forças de restrição e reduz os deslocamentos axiais gerados.

Tendo em vista o exposto, percebe-se que, além da estrutura circundante, outros elementos também impõem restrição térmica aos pilares. Essa abordagem é nova e pouco explorada no meio científico, razão pela qual o presente estudo busca contribuir para essa temática trazendo respostas para questões ainda não respondidas.

\subsection{PESQUISAS CIENTÍFICAS SOBRE PILARES DE AÇO ISOLADOS}

A presente seção descreve os principais estudos sobre pilares de aço com aquecimento uniforme em suas quatro faces, sendo dividida em estudos numéricos e experimentais. As pesquisas que apresentam ambas as análises serão direcionadas para o item correspondente aos estudos experimentais.

\subsubsection{Estudos experimentais}

\subsubsection{Aasen (1985)}

O estudo apresentado em Aasen (1985) consiste em uma análise experimental de pilares de aço em situação de incêndio, considerando restrições térmicas nas extremidades. $\mathrm{O}$ trabalho avaliou a influência das restrições axial e rotacional no comportamento desses elementos, de forma a identificar como tais parâmetros afetavam sua resistência ao fogo. Para isso, alguns pilares foram ensaiados com restrições e outros sem restrições. Como resultado, o autor destacou que elementos estruturais somente restritos rotacionalmente apresentaram distintos valores para a temperatura crítica, indicando que esse tipo de restrição pode ser benéfico a depender da esbeltez do pilar.

\subsubsection{Ali, Sirnms e O'Connor (1997), Ali et al. (1998) e Ali e O'Connor (2001)}

Em Ali e O'Connor (2001), por meio de estudo experimental, foi investigado o impacto das restrições rotacionais na resistência ao fogo de pilares metálicos em situação de incêndio. Os protótipos foram testados para cinco diferentes níveis de carregamentos, dois valores adimensionais de restrição rotacional, no caso, 0,18 e 0,93, e apenas um valor para a restrição axial adimensional, a citar 0,29 . Os resultados obtidos foram comparados com aqueles 
apresentados em Ali, Sirnms e O'Connor (1997) e em Ali et al. (1998) em que foram consideradas somente restrições axiais em seus experimentos. O sistema de ensaio utilizado nos estudos mencionados está representado na Figura 2.2.

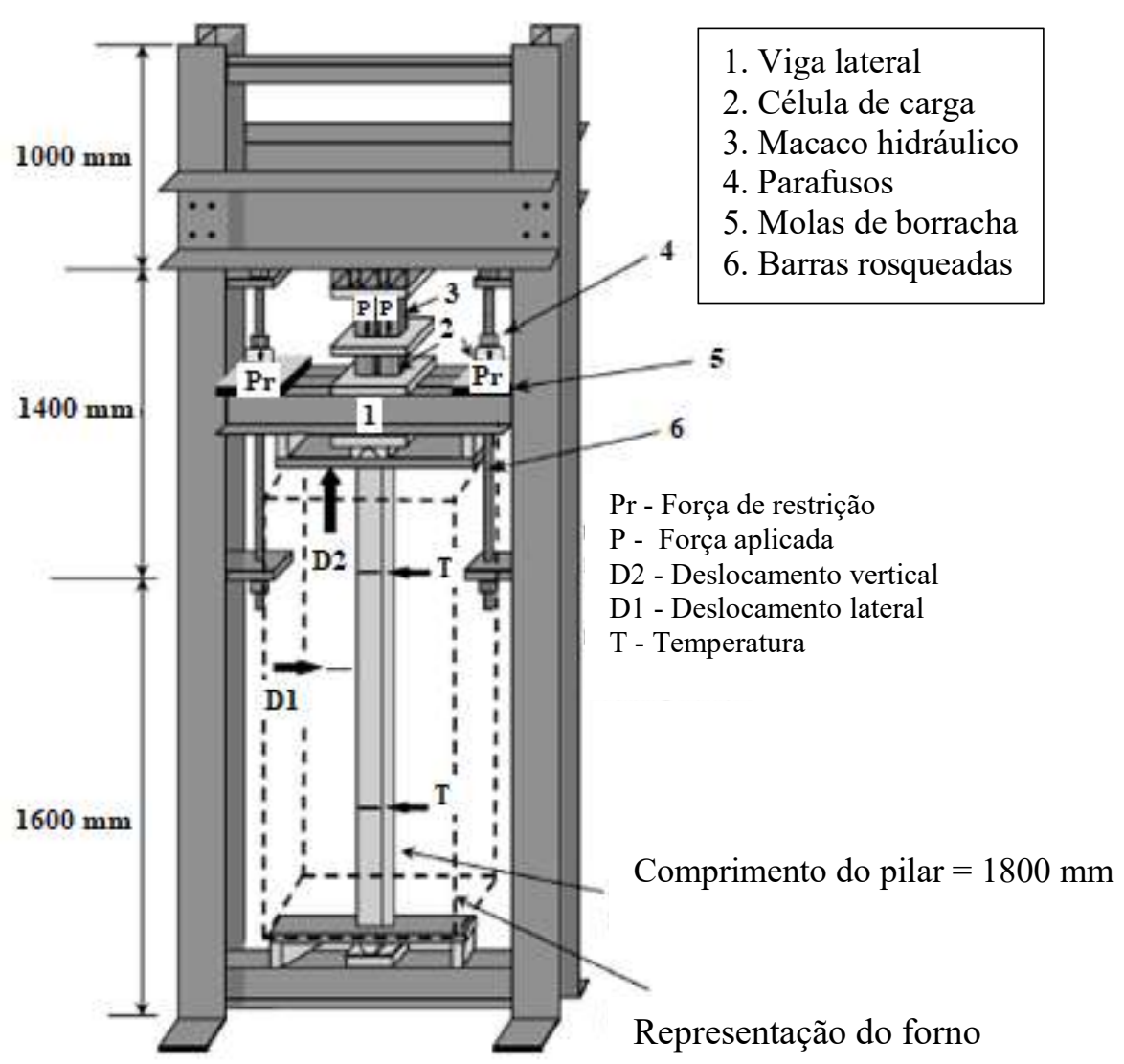

Figura 2.2 - Modelo dos ensaios experimentais proposto em Ali, Sirnms e O'Connor (1997), Ali et al. (1998) e Ali e O'Connor (2001)

Fonte: Ali e O'Connor (2001).

Os autores concluíram que o aumento da rigidez rotacional $(0,18$ para 0,93$)$ pouco afetou a intensidade das forças de restrição geradas, porém a temperatura crítica cresceu para um mesmo nível de carregamento. Além disso, no que concerne ao fator de carga, o seu aumento provocou uma queda brusca na temperatura crítica e na força máxima axial atingida.

Ademais, em Ali e O'Connor (2001) foi também realizado um estudo para determinação do comprimento efetivo de flambagem de pilares de aço submetidos a elevadas temperaturas. Após a realização dos ensaios, mediu-se a distância entre os pontos de inflexão presentes no pilar aquecidos. Quanto maior a restrição rotacional, menor foi o comprimento efetivo do pilar, de modo que para o valor igual a 0,93 de restrição rotacional adimensional, a grandeza medida 
resultou igual a $0,56 \mathrm{~L}$, enquanto que para o valor igual a 0,18 , o comprimento efetivo foi de $0,61 \mathrm{~L}$.

Em Ali et al. (1998), além de realizados os experimentos já mencionados, uma análise numérica também foi desenvolvida para os pilares de aço, por meio do código computacional VULCAN. O modelo proposto está representado na Figura 2.3 e ele foi capaz de representar adequadamente os experimentos executados.

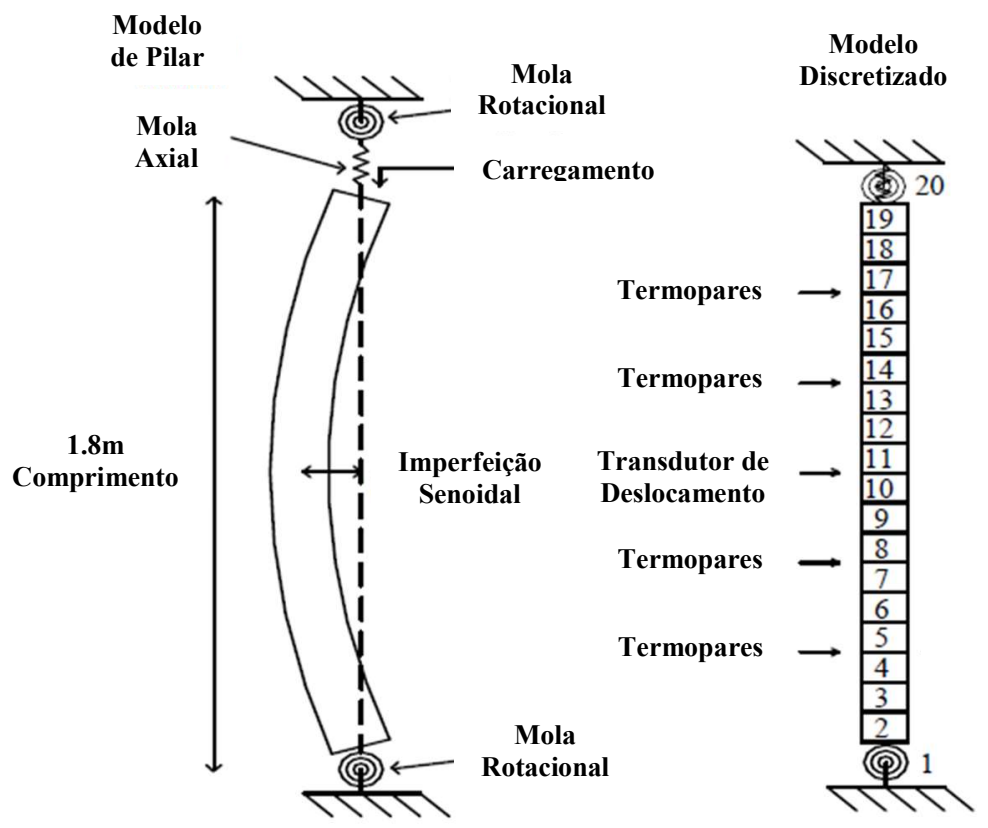

Figura 2.3 - Modelo numérico proposto por Ali et al. (1998)

Fonte: Ali et al. (1998).

Em relação ao modelo criado, os pilares foram discretizados em dezoito elementos finitos como pode ser visualizado na Figura 2.3. Além disso, os autores inseriram um elemento de mola rotacional em cada extremidade do pilar para representar a limitação ao giro no topo e na base presente nos ensaios. Em relação a restrição axial, outro elemento de mola foi colocado no topo do elemento estrutural, cuja rigidez foi variada até atingir os valores empregados nos experimentos.

\subsubsection{Rodrigues, Neves e Valente (2000)}

Nessa referência, foram realizados estudos de caráter experimental e numérico a respeito dos efeitos da restrição axial no comportamento de barras comprimidas sujeitas à ação térmica. Foram realizados 168 ensaios experimentais com a representação de pilares em escala 
reduzida, variando o grau da restrição térmica, esbeltez das barras e excentricidade do carregamento. O modelo dos ensaios pode ser visualizado pela Figura 2.4. Percebe-se a grande limitação dos experimentos, principalmente pelo tamanho do forno utilizado. Os resultados indicaram que é necessário considerar a restrição térmica no comportamento de pilares em situação de incêndio, uma vez que ela altera a resposta estrutural dos mesmos.

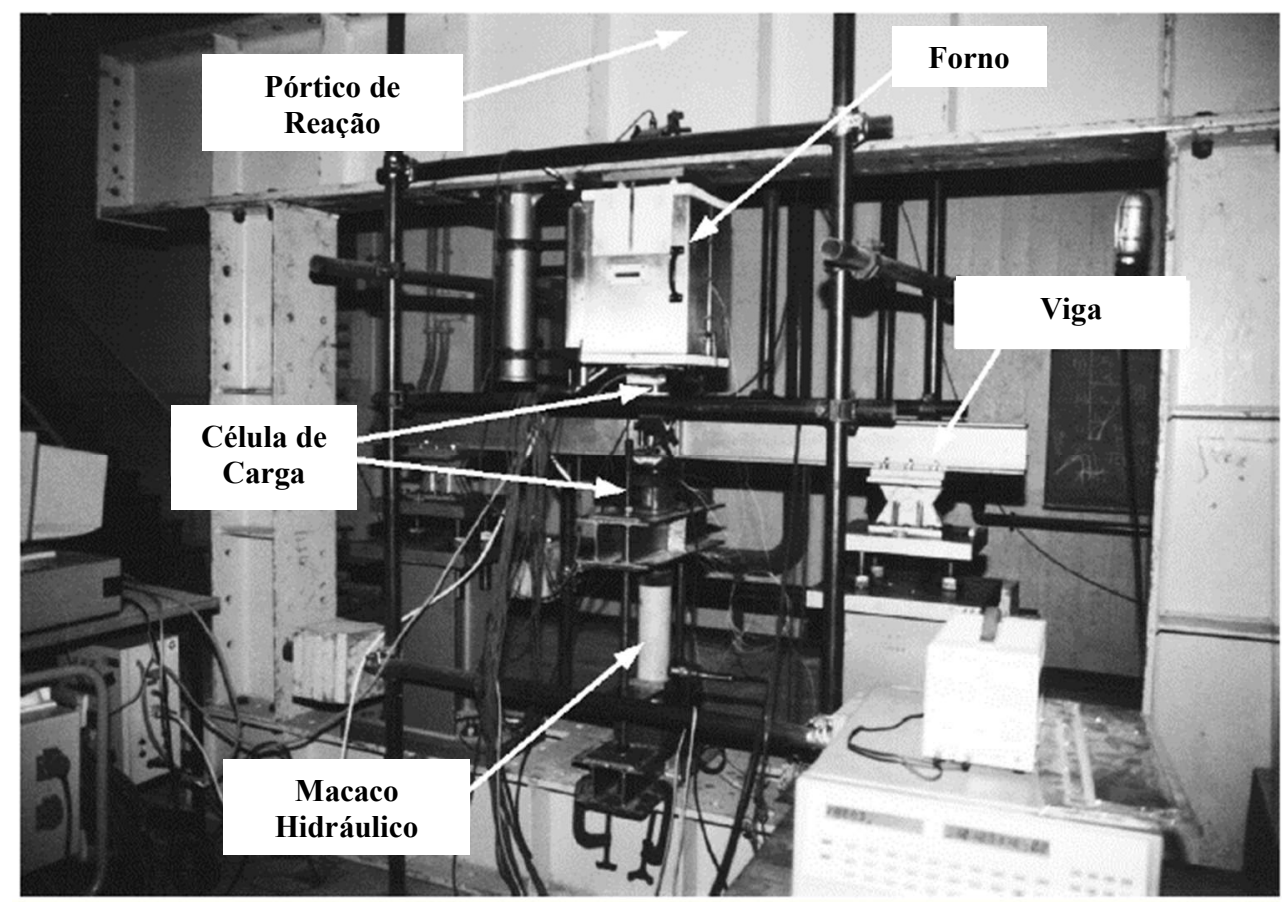

Figura 2.4 - Representação do modelo dos ensaios descritos em Rodrigues, Neves e Valente (2000)

Fonte: Rodrigues, Neves e Valente (2000).

Em relação à análise numérica, foi utilizado o programa computacional FINEFIRE para o desenvolvimento dos modelos propostos. Em linhas gerais, os resultados numéricos foram aceitáveis caso seja levado em consideração as peculiaridades presentes nos ensaios experimentais que não são facilmente representados em modelagens numéricas.

\subsubsection{Tan et al. (2007)}

Os autores buscaram avaliar como se comportavam os pilares metálicos, no que diz respeito à sua resistência ao fogo, sob o efeito de diferentes valores de restrições axial e rotacional. Foram ensaiados pilares rotulados com valores distintos de esbeltez, considerando a excentricidade do carregamento e um fator de carga fixo. 
Sobre o comportamento das forças de restrição, observou-se um aumento dessa grandeza no início do aquecimento (predomínio da expansão térmica do pilar) e decréscimo da mesma em elevadas temperaturas, devido à redução das propriedades mecânicas dos materiais (efeito mecânico predominante). $\mathrm{O}$ aumento da rigidez axial foi responsável por diminuir a resistência ao fogo dos pilares, uma vez que essa mesma rigidez acelera o processo de instabilidade dos pilares. Além disso, percebeu-se que a temperatura crítica de pilares esbeltos é menor em comparação com os pilares curtos.

\subsubsection{Correia (2011)}

O estudo apresentado em Correia (2011) consiste em uma tese de doutorado desenvolvida em Coimbra, Portugal, e engloba diversos conteúdos, sendo seu enfoque principal: o comportamento de pilares de aço e mistos de aço e concreto, isolados e inseridos em paredes, sob a ação do fogo. Devido à extensão da temática abordada, essa pesquisa deu origem a diversos artigos científicos.

Por essa razão, a descrição do estudo desenvolvido nessa tese será realizada a partir dos artigos que ela deu origem, de modo a adequar o conteúdo dos mesmos à organização desse capítulo que está dividido de acordo com o modo de aquecimento (uniforme ou não uniforme) da seção transversal do pilar.

Correia e Rodrigues (2012) e Correia, Rodrigues e Gomes (2013) são os principais trabalhos que tratam de pilares de aço isolados. A pesquisa de 2012 descreve o estudo experimental executado no Laboratório de Ensaio de Estruturas e Materiais da Universidade de Coimbra, sobre pilares metálicos com restrições térmicas nas extremidades. Foram ensaiados 14 pilares com a variação dos seguintes parâmetros: seção transversal do perfil metálico, fator de carga, intensidade das rigidezes axial e rotacional da estrutura envolvente, e diferentes níveis de esbeltez.

No que diz respeito aos procedimentos de ensaio, uma nova estrutura foi confeccionada e possibilitou levar em consideração o efeito da estrutura circundante no comportamento de pilares em situação de incêndio. Para isso, foi criado um sistema de restrição com rigidez variável, composta por vigas superiores que descarregavam em pilares, conforme ilustra a Figura 2.5 . 


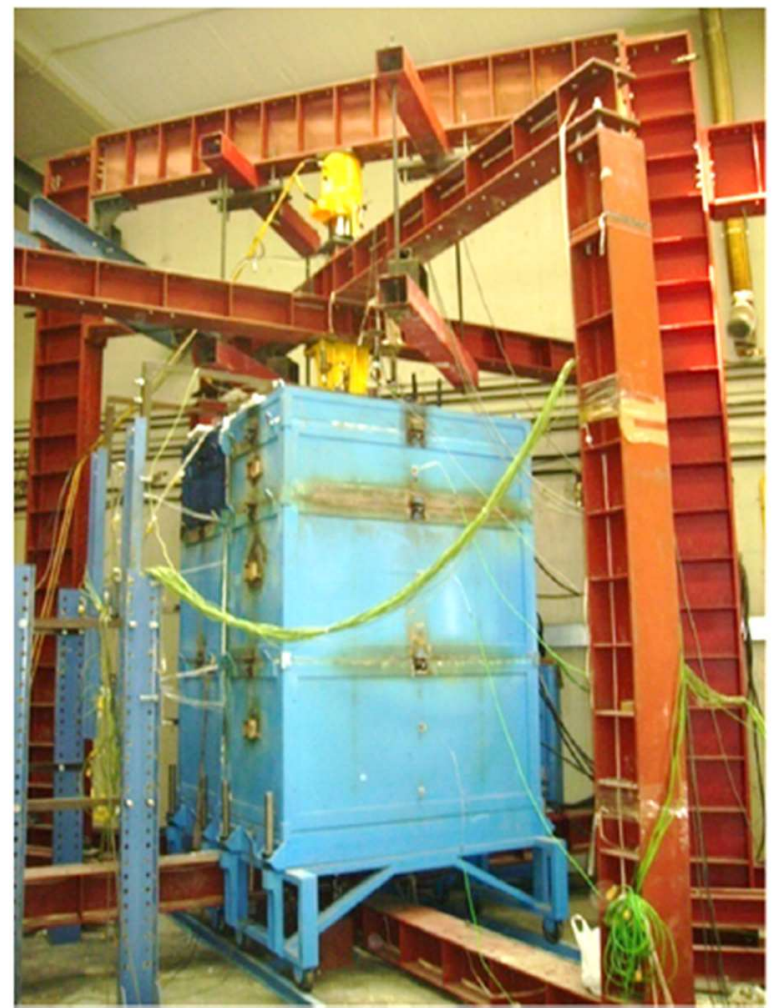

Figura 2.5 - Modelo de ensaio de Correia (2011)

Fonte: Correia (2011).

Nos experimentos foi possível obter três diferentes valores de rigidez axial e rotacional para o sistema de restrição, viabilizado pelo fato de os pilares dessa estrutura tridimensional possuírem mobilidade (enquanto posicionamento) e ocuparem diferentes posições nos ensaios. A intensidade da rigidez axial, em cada posição, foi determinada por meio de um experimento em que as vigas de restrição recebiam incrementos de força no meio do vão, cujo deslocamento referente a esse carregamento era medido por meio de transdutores.

A partir dos resultados experimentais, plotou-se o gráfico "Força versus Deslocamento" para obtenção da rigidez axial da estrutura envolvente. No caso da restrição rotacional, sua rigidez foi aferida a partir da reprodução numérica do sistema de restrição sem a presença dos pilares. Para isso, aplicou-se um momento fletor na estrutura para que pudesse ser medida as rotações correspondentes.

Além dos resultados já esperados em relação ao comportamento das forças de restrição e da influência do fator de carga na resistência ao fogo do elemento estrutural, como já descrito em estudos já citados, a pesquisa constatou que a rigidez da estrutura circundante não influenciava na temperatura crítica dos pilares, uma vez que o aumento desse valor elevava 
tanto as restrições axiais quanto as rotacionais e, por impactarem de forma distinta a resistência ao fogo desses elementos, os efeitos de ambas as restrições acabavam se compensando.

Posteriormente, em Correia, Rodrigues e Gomes (2013) foram utilizados os dados dos ensaios descritos em Correia e Rodrigues (2012) para o desenvolvimento de estudos de caráter numérico e teórico sobre os pilares metálicos com restrições térmicas. O objetivo do trabalho foi desenvolver um método de cálculo simplificado para obtenção da temperatura e do tempo críticos desses elementos estruturais sujeitos à ação do fogo.

Para isso, inicialmente foram propostos modelos numéricos realizados pelo código computacional ABAQUS e validados pelos ensaios experimentais. Como pode ser vista na Figura 2.6, o sistema de restrição dos ensaios experimentais foi modelado de forma completa para representação do pilar em situação de incêndio.

a)

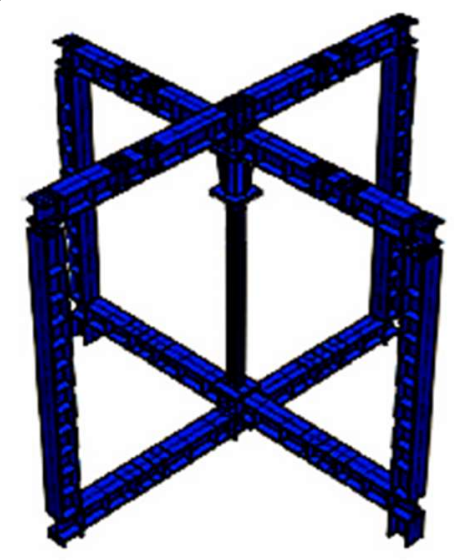

b)

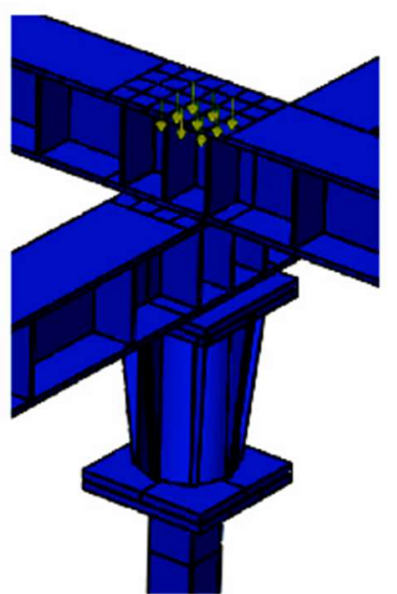

c)

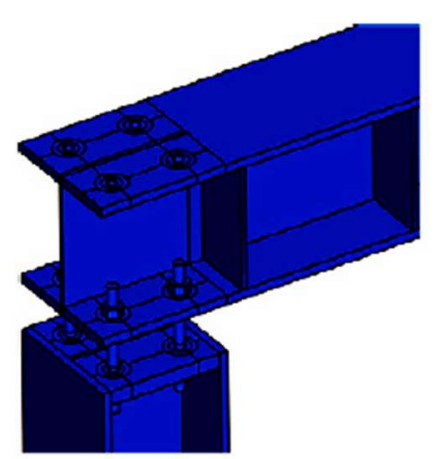

Figura 2.6 - Aspectos da modelagem numérica de Correia, Rodrigues e Gomes (2013): a) Representação do modelo numérico completo; b) Detalhe construtivo da ligação das vigas superiores do sistema de restrição; c) Ligação entre a viga superior e o pilar do sistema de restrição

Fonte: Correia, Rodrigues e Gomes (2013).

Em seguida, uma análise paramétrica foi desenvolvida a partir da variação do índice de esbeltez, nível de carga e rigidez da estrutura circundante para investigar a influência desses parâmetros na resistência ao fogo dos elementos estruturais.

Com a gama de resultados alcançados, plotaram-se os gráficos "Temperatura crítica versus Esbeltez" e "Tempo crítico versus Esbeltez" que apresentavam curvas com diferentes valores de rigidez da estrutura envolvente e do nível de carga aplicado. A partir disso, foram realizadas regressões lineares e quadráticas e, assim, obtidas as equações que descreviam os fenômenos em questão. 
Além disso, os autores aplicaram a metodologia apresentada no Eurocode 3 Parte 1-2 (2005) para obtenção da temperatura e tempo críticos dos pilares a fim de comparar com os resultados obtidos na pesquisa. Para efeitos de comparação, o modelo numérico foi considerado somente com restrição rotacional total nas extremidades, uma vez que a norma europeia não leva em consideração os efeitos de restrição axial térmica.

Os resultados numéricos e aqueles provenientes das equações propostas foram próximos, tanto para o tempo quanto para a temperatura crítica. Em relação ao Eurocode 3 Parte 1-2 (2005), essa mesma norma apresentou resultados maiores ao se comparar com as outras duas metodologias no que diz respeito à temperatura, mostrando-se não conservadores. Em relação ao tempo crítico, os resultados provenientes do método normatizado para os pilares mais esbeltos foram mais uma vez não conservadores, enquanto que para os menos esbeltos, a favor da segurança.

\subsubsection{Estudos numéricos}

\subsubsection{Poh e Bennetts (1995)}

Os autores desenvolveram um estudo numérico para avaliar o comportamento de pilares sob elevadas temperaturas, analisando os seguintes parâmetros em suas análises: campo térmico na seção transversal e ao longo do elemento estrutural, restrições térmicas, associação de força axial e momentos fletores biaxiais, não linearidade geométrica e do material, tensão residual, carregamento e descarregamento e esbeltez do pilar.

A representação das restrições axiais e rotacionais na modelagem numérica se deu a partir da inserção de molas nas extremidades, cuja intensidade da rigidez variou de zero a infinito. Os resultados apontaram que a proposta numérica para o comportamento estrutural à temperatura ambiente foi melhor representado em comparação ao desempenho dos pilares em elevadas temperaturas. Apesar disso, os modelos termoestruturais conseguiram reproduzir a elevação da força de restrição do elemento quando aquecido.

\subsubsection{Neves (1995)}

Em Neves (1995) se desenvolveu uma análise numérica por meio do código computacional $Z W A N$, com o intuito de estudar a influência da restrição à deformação axial, índice de esbeltez e excentricidade da força aplicada na resistência ao fogo dos pilares de aço 
isolados. Os resultados apontaram que, para elevados valores de rigidez axial, a temperatura crítica não apresentou mudanças significativas. Porém, à medida que a intensidade da restrição térmica diminuía, a temperatura crítica se tornava gradualmente maior até se aproximar da resposta de um pilar quando está livre para se deformar, como representado na Figura 2.7, que traz os resultados numéricos para um dado pilar estudado. Sobre a excentricidade da força aplicada, quando foram considerados altos valores para esse parâmetro, as alterações na resistência ao fogo foram insignificantes para qualquer intensidade da restrição térmica. Além disso, em geral, houve redução da temperatura crítica com o aumento da esbeltez dos pilares.

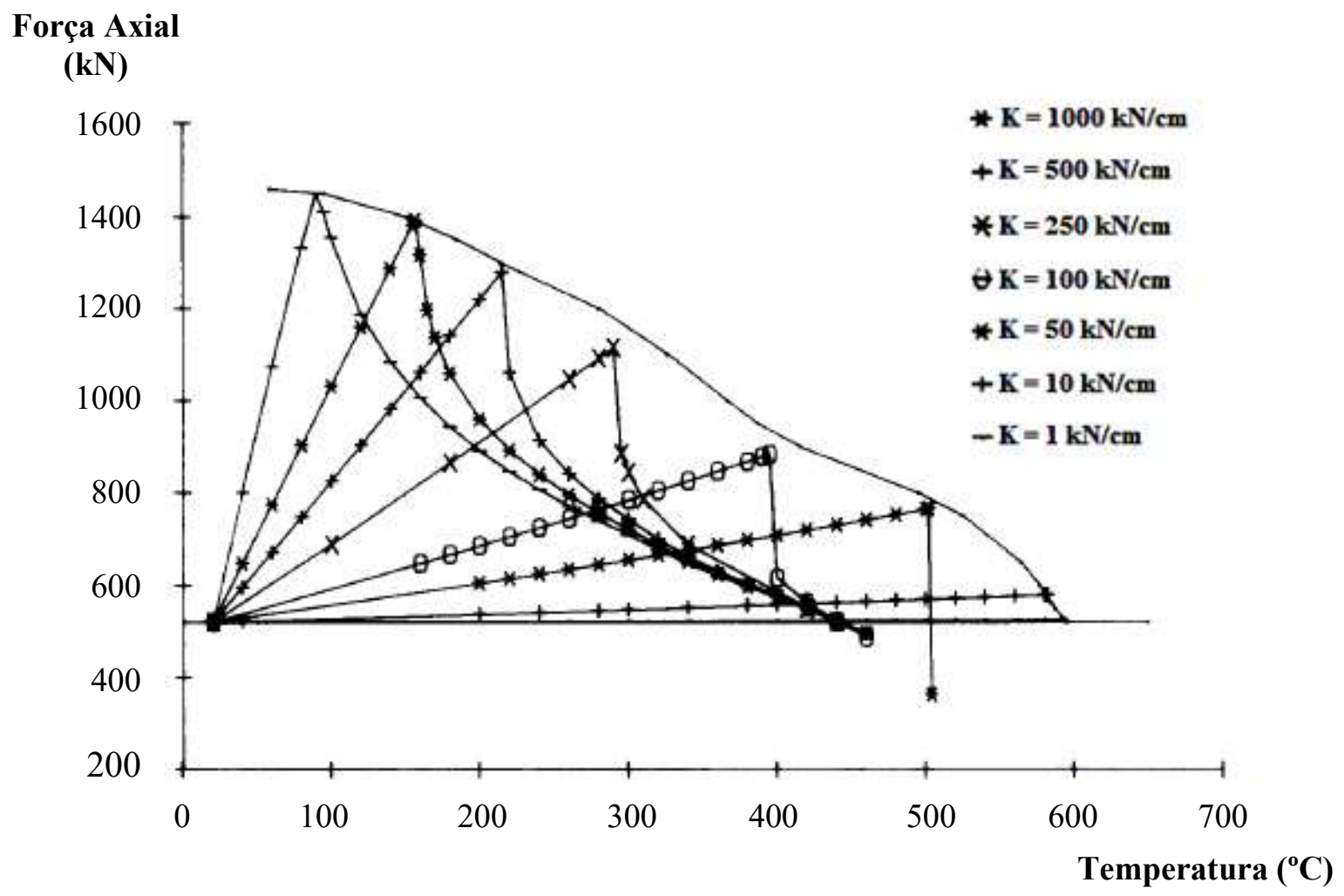

Figura 2.7 - Evolução da força axial em função do tempo para diferentes intensidades de restrições térmicas

Fonte: Neves (1995).

\subsubsection{Valente e Neves (1999)}

O estudo numérico analisou a influência da excentricidade do carregamento, esbeltez do elemento estrutural e o grau das restrições axiais e rotacionais no comportamento termoestrutural de pilares de aço. A modelagem numérica, realizada pelo código computacional 
FINEFIRE, levou em consideração a não linearidade geométrica dos pilares através de uma formulação lagrangiana aproximada e atualizada.

Com o intuito de avaliar a influência das restrições axial e rotacional separadamente, foram criados dois modelos indicados na Figura 2.8. A Figura 2.8a representa um pilar restrito apenas axialmente através de uma mola na extremidade e a Figura $2.8 \mathrm{~b}$ reproduz um pilar com restrições axial e rotacional simultaneamente.

a)

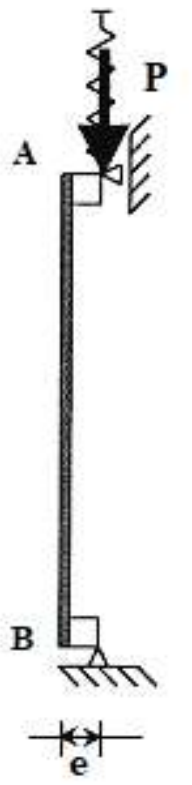

b)

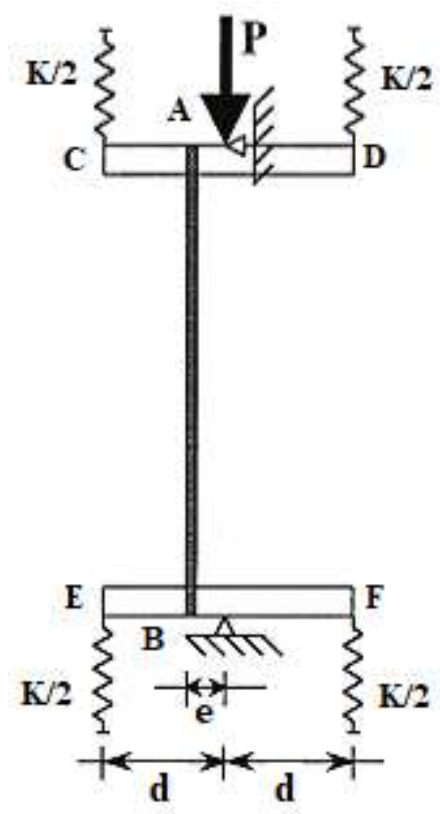

Figura 2.8 - Representação modelos numéricos termoestruturais de Valente e Neves (1999) Fonte: Valente e Neves (1999).

Os autores concluíram que a restrição axial possui efeito negativo na resistência ao fogo dos pilares, enquanto que a restrição rotacional gera um impacto positivo nessa propriedade, coincidindo com os resultados dos estudos outrora citados.

Ao comparar os resultados numéricos com aqueles alcançados utilizando os métodos fornecidos pelo Eurocode 3 Parte 1-2 (1995), na definição da temperatura crítica, Valente e Neves (1999) perceberam que aquela proveniente da referida norma era aceitável somente para pilares com níveis de restrições rotacionais elevados ou com baixa esbeltez. Os autores justificaram tal conclusão pelo fato de a normatização europeia não considerar as restrições axiais térmicas que existem nos pilares, nem mesmo os esforços que surgem por causa delas durante o incêndio.

Vale ressaltar que a norma europeia atual, Eurocode 3 Parte 1-2 (2005), ainda não contempla os efeitos da restrição axial em seu método simplificado de cálculo, o que permite 
afirmar que, possivelmente, as conclusões obtidas nesse trabalho ainda são consideradas válidas.

\subsubsection{Franssen (2000)}

O estudo numérico realizado em 2000 propôs uma nova metodologia para determinação da temperatura crítica de pilares de aço com restrição térmica nas extremidades, a partir do uso da técnica Arc-Length (comprimento de arco). Em suas modelagens, o autor percebeu que, mesmo variando o nível de rigidez axial, a temperatura crítica dos pilares pouco se diferenciava entre si, de forma que essa grandeza era mais dependente do fator de carga axial aplicado.

Diante disso, Franssen (2000) desenvolveu um método que consiste em modelar os pilares de aço totalmente restringidos e sem carregamento inicial, para obter o comportamento das forças de restrição geradas em função da elevação da temperatura. Assim, para identificar a temperatura crítica do elemento estrutural, basta conhecer a força axial aplicada no pilar à temperatura ambiente e, a partir da análise gráfica, determinar qual a temperatura de colapso do elemento. A Figura 2.9 traz a representação do princípio da metodologia exposta.

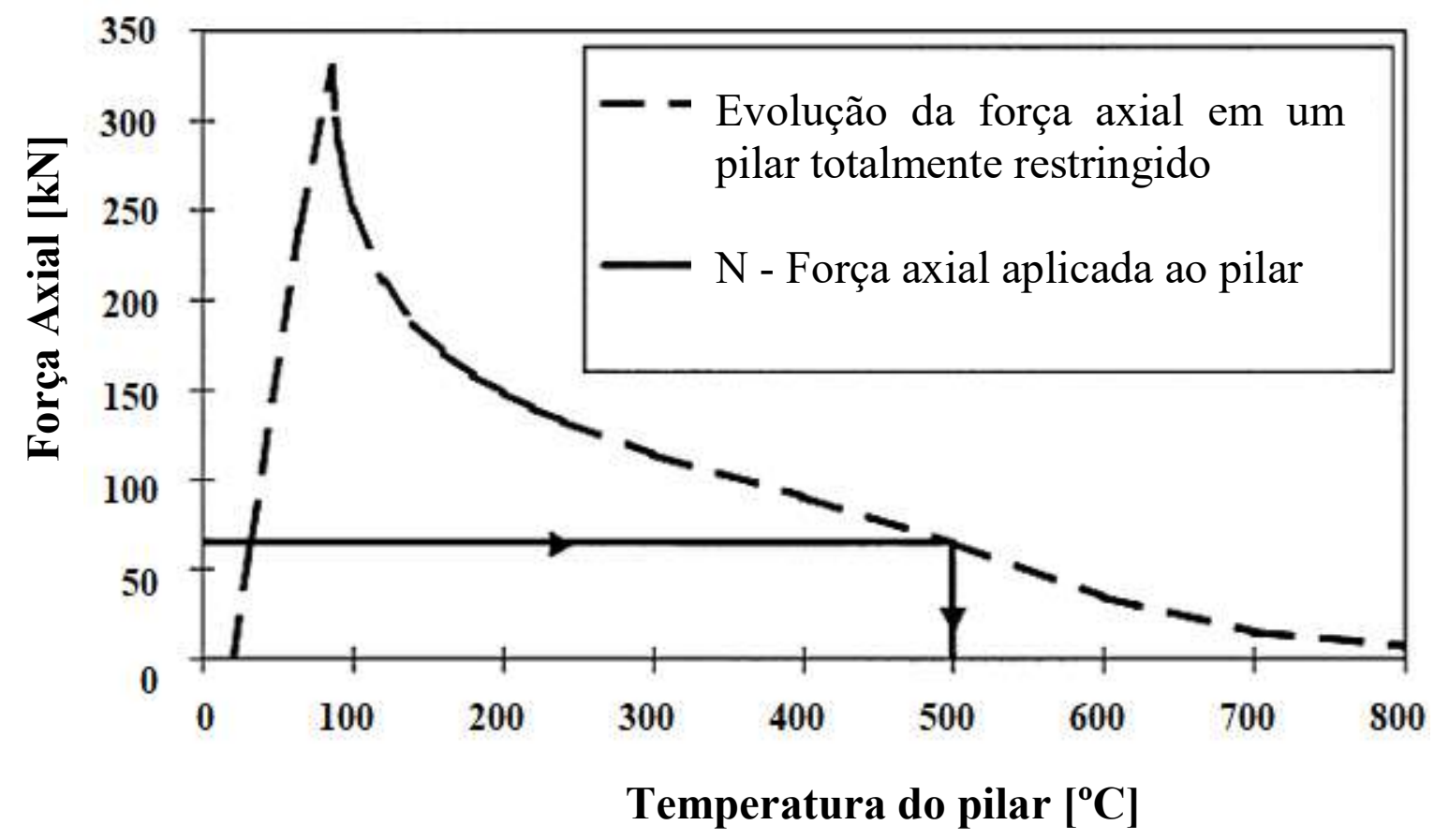

Figura 2.9 - Princípio básico do método de Franssen (2000)

Fonte: Franssen (2000). 
O autor ainda afirmou que mesmo a estrutura circundante sendo a responsável por promover a restrição térmica dos pilares, aumentando assim sua força axial, essa mesma estrutura pode contribuir para minimizar os efeitos negativos da restrição axial, de forma que os esforços que o pilar não mais suporta possam ser redistribuídos para essa estrutura envolvente durante a ação do fogo. Este fenômeno ainda precisa ser estudado com mais detalhes pelo meio científico.

\subsubsection{Huang e Tan (2007)}

De modo a reproduzir os ensaios apresentados em Tan et al. (2007), ver item 2.2.1.4, Huang e Tan (2007) desenvolveram uma análise numérica utilizando o código computacional FEMFAN2D, considerando as restrições axiais e rotacionais nas extremidades dos pilares e a não linearidade geométrica e do material. Boas previsões foram alcançadas por meio do modelo numérico proposto no que diz respeito ao desenvolvimento das forças internas nos pilares, deformação axial e deflexão lateral obtidos nos ensaios experimentais de referência. A partir disso, o trabalho buscou avaliar a influência da excentricidade da força aplicada, do tipo de modelo constitutivo do aço e do nível de esbeltez na resistência ao fogo dos pilares. Os autores concluíram que esses parâmetros afetam significativamente a intensidade da temperatura crítica alcançada pelo elemento estrutural.

\subsubsection{Velarde (2008)}

O autor realizou um estudo de pilares com ação do fogo em suas quatro faces, considerando a restrição térmica axial nas extremidades. A metodologia empregada consistiu na realização de quinhentas modelagens numéricas através do código computacional VULCAN, contemplando o aquecimento via curva da International Organization for Standardization (ISO) 834:1999, não linearidade geométrica e do material, imperfeições geométricas e variação do perfil de aço. O modelo numérico proposto está indicado na Figura 2.10.

Nele pode ser visto a inserção de uma mola axial na extremidade do pilar para representar a restrição à sua deformação longitudinal. Os resultados obtidos coincidiram com aqueles fornecidos pelas pesquisas citadas anteriormente no que concerne ao comportamento da força de restrição ao longo do tempo de exposição ao fogo e ao efeito da restrição axial na temperatura crítica. 


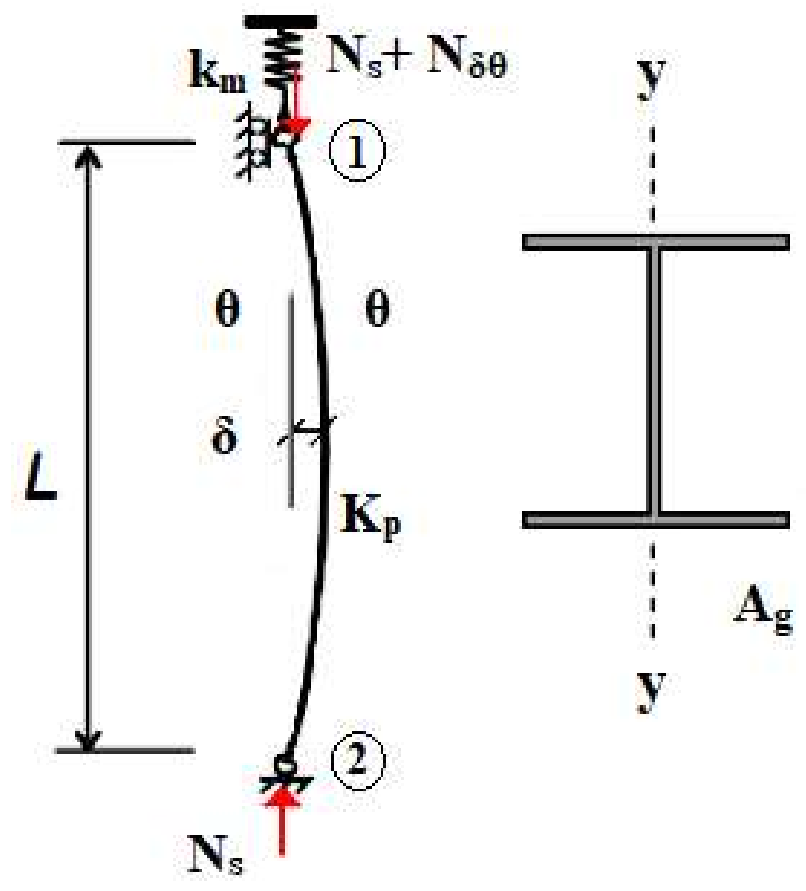

Figura 2.10 - Modelo estrutural proposto por Velarde (2008)

Fonte: Velarde (2008).

\subsubsection{Bubach (2016)}

A autora, a partir do código computacional ANSYS, realizou análises numéricas de pilares metálicos com seção I submetidos à ação do fogo em suas quatro faces com restrições térmicas nas extremidades. Para validação do modelo, os resultados numéricos foram comparados àqueles experimentais obtidos em Correia (2011).

As modelagens térmicas e termoestruturais foram realizadas utilizando o elemento finito do tipo casca (SHELL) o que possibilitou empregar molas axiais e rotacionais no modelo termomecânico para representar a estrutura de restrição presente nos ensaios experimentais de referência, uma vez que esse tipo de elemento finito apresenta seis graus de liberdade, três de deslocamento e três de rotação. Os resultados numéricos foram satisfatórios para os três parâmetros analisados: temperatura, deslocamento axial e força de restrição.

Após a validação dos modelos, foi realizada uma análise paramétrica utilizando dois perfis de aço, dois comprimentos para o pilar e três valores de restrições rotacional e axial, de forma a estudar a influência da esbeltez do pilar, do nível de carregamento aplicado e da rigidez da estrutura circundante na resistência ao fogo dos elementos estruturais. Os resultados obtidos, 
quanto ao impacto dessas grandezas na resistência ao fogo dos pilares, foram os mesmos daqueles encontrados nos estudos já mencionados.

A partir disso, realizou-se uma comparação dos resultados numéricos com aqueles oriundos da ABNT NBR 14323:2013, em relação ao cálculo das temperaturas e tempos críticos. Considerando apenas a rigidez rotacional na análise numérica, a norma apresentou valores conservadores, porém, contemplando ambas rigidezes, seus resultados foram maiores que o alcançado de forma numérica, sendo, portanto, contra segurança. Isso permite concluir que o atual código normativo não considera o efeito da restrição axial em seu método de cálculo.

\subsection{PILARES DE AÇO SOB AÇÃO TÉRMICA NÃO UNIFORME}

Até então, foram discutidos os principais estudos que buscaram compreender o comportamento de pilares metálicos sob ação do fogo em suas quatro faces. Apesar disso, na grande maioria das situações reais, os pilares estão inseridos em alvenarias, de modo que, na ocorrência de um incêndio, a ação térmica não atuará em todos os seus lados, promovendo um gradiente térmico na seção transversal. Esse aquecimento diferencial é responsável por impulsionar o aparecimento de momentos fletores nas extremidades de pilares restritos rotacionalmente. Esse fenômeno é chamado de Thermal Bowing e será discutido no item 2.3.1.

O meio científico conta com poucos estudos sobre pilares inseridos em paredes, principalmente em contexto experimental, devido ao elevado custo para a realização de ensaios com essa temática. Entretanto, algumas pesquisas tentam simular o aquecimento diferencial dos pilares embutidos em alvenarias a partir do uso de mantas de proteção térmica em algumas faces do elemento estrutural. Os principais trabalhos a respeito desse assunto serão abordados no item 2.3.2. Já no item 2.3.3, serão descritos os estudos que abordaram pilares em contato com paredes.

De modo similar à construção e apresentação do item 2.2, os itens 2.3 .2 e 2.3 .3 serão divididos em estudos numéricos e experimentais, ressaltando que pesquisas que apresentaram ambas as análises serão direcionadas para o subitem correspondente aos estudos experimentais.

\subsubsection{O fenômeno Thermal Bowing}

Pilares carregados axialmente com restrição térmica nas extremidades e sujeitos a um aquecimento diferencial em sua seção transversal podem sofrer o fenômeno Thermal Bowing. 
De maneira geral, ele é caracterizado pela mudança do centroide efetivo ${ }^{1}$ da seção transversal para o lado não exposto ao fogo, que passa a não coincidir com o seu centroide geométrico ${ }^{2}$, devido à perda das propriedades mecânicas dos materiais com o aumento da temperatura. Se os pilares estiverem carregados, há a formação de um momento de flexão em resposta à excentricidade entre a força aplicada e o centroide efetivo. Tal momento pode ser capaz de reverter a curvatura do pilar que inicialmente está voltada para a região do aquecimento (GARLOCK; QUIEL, 2007).

A Figura 2.11a mostra a deformada de um pilar de aço no início do aquecimento. Como pode ser visualizado, sua curvatura está voltada em direção à ação térmica. Com a redução da rigidez e da resistência do aço pela elevação da temperatura, gradualmente essa curvatura muda de direção e passa a migrar para o lado mais frio, como descrito anteriormente e indicado na Figura 2.11b.

a)

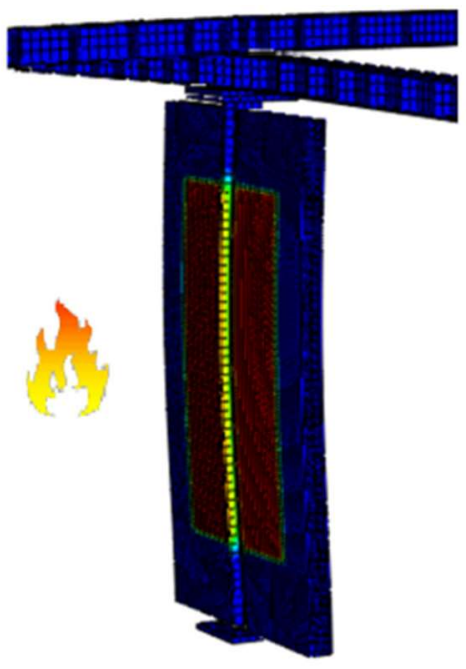

b)

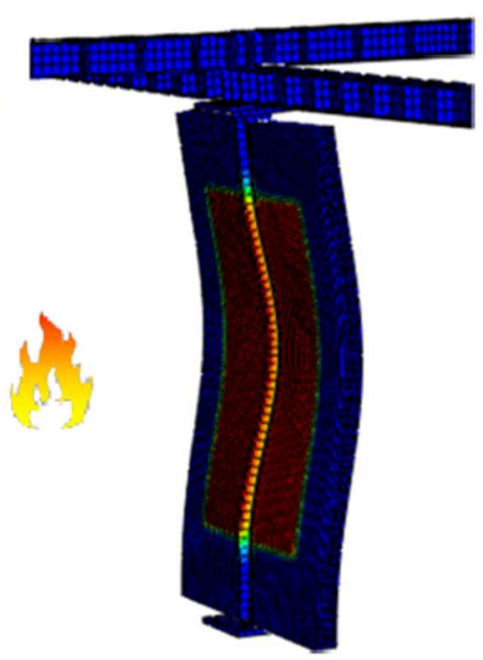

Figura 2.11 - Deformada de um pilar inserido em parede com restrição térmica Fonte: Correia, Rodrigues e Real (2014).

$\mathrm{Na}$ Figura 2.12, são representadas duas situações distintas. A Figura 2.12a mostra um pilar metálico com gradiente térmico ao longo da alma, enquanto a Figura $2.12 \mathrm{~b}$ reproduz o elemento com o aquecimento diferencial em torno da mesa. Seguindo as convenções de sinais definidas em Correia, Rodrigues e Real (2014), admite-se momento fletor positivo como aquele

\footnotetext{
${ }^{1}$ Centro de rigidez da seção transversal. Local no qual a força axial deve ser aplicada para não promover flexão na peça.

${ }^{2}$ Centro de geometria da seção transversal. No caso de perfis com duplo eixo de simetria, ele se localiza no meio da seção transversal. Sua posição não muda com o aquecimento.
} 
que produz tração na face menos aquecida do elemento estrutural e força axial positiva corresponde aquela que gera alongamento do pilar. A seguir, é detalhado o fenômeno do Thermal Bowing.

No início de um incêndio surge um momento fletor no pilar em resposta às deformações térmicas induzidas pelo gradiente de temperatura, proporcionado pelas restrições rotacionais nas extremidades do elemento estrutural. Como na região aquecida ocorrerá uma grande expansão térmica, as extremidades restringidas criam um momento fletor contrário a essa ação, chamado de $M t$, na tentativa de combater esse esforço, como pode ser vista na Figura 2.12. Diante disso, o lado exposto ao fogo se torna comprimido, enquanto que o lado menos aquecido é tracionado.

a)

CG - Centroide Geométrico

CR - Centro de rigidez (Centroide Efetivo)
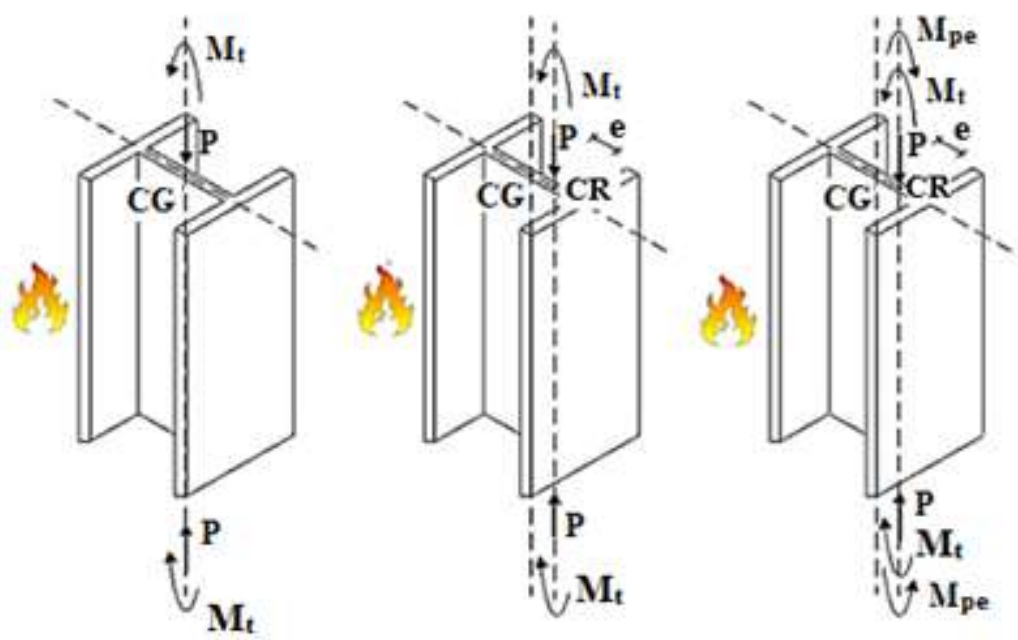

b)
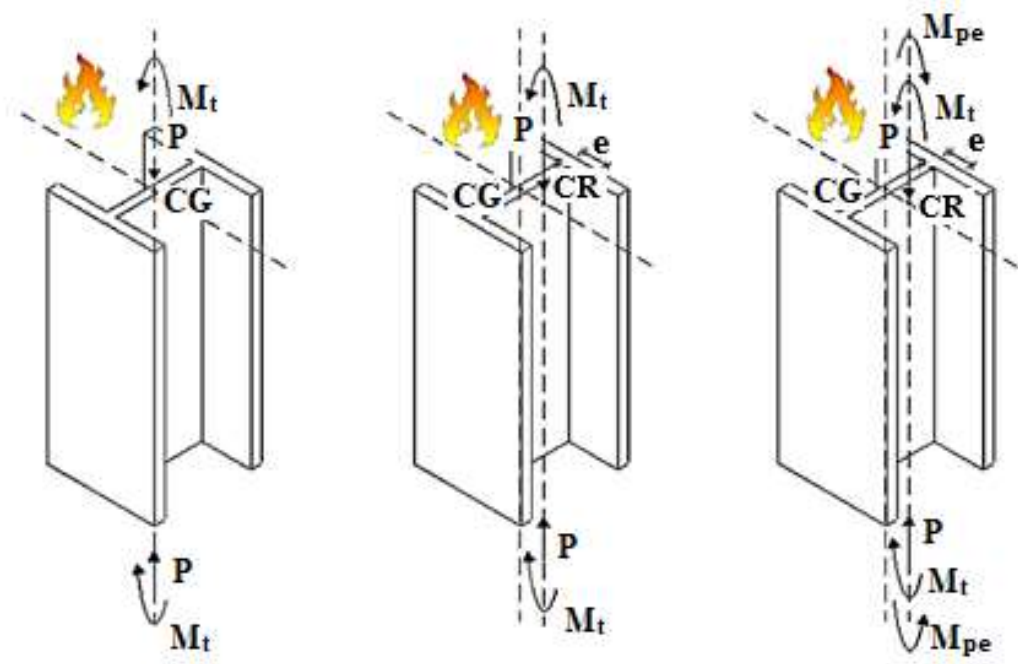

Figura 2.12 - Comportamento de pilares inseridos em paredes com aquecimento em uma face Fonte: Correia, Rodrigues e Real (2014). 
Até o instante em que o aumento da temperatura não altera as propriedades dos materiais, a posição do centroide efetivo da peça se mantém fixo. A partir da redução do módulo de elasticidade do material, essa grandeza passa a não mais coincidir com o centro geométrico, migrando para o lado mais frio. O aparecimento da excentricidade, entre a força aplicada e o centro de rigidez, faz surgir um novo momento fletor com o sentido contrário àquele gerado pelo aquecimento diferencial do pilar, representado por Mpe. É de se esperar que em algum momento do processo de aquecimento, a direção da curvatura do pilar se inverta e o sinal do momento resultante se altere quando $M p e$ for maior que $M t$.

De maneira geral, com a atuação do momento térmico $(M t)$, a região exposta ao fogo se torna ainda mais comprimida e, por essa razão, alcança o limite de escoamento e o regime plástico mais rapidamente. Nesse momento, as forças axiais deixam de crescer nos pilares restringidos e as tensões atuantes são redistribuídas. Situação diferente ocorre nos pilares sem restrições rotacionais, pois nesse caso não ocorre a geração de momentos fletores nas extremidades, o que diminui as tensões na região mais aquecida. Diante disso, para que haja escoamento dessa região, será necessário um aumento da força axial de compressão ou da agressividade do incêndio para reduzir ainda mais as propriedades mecânicas dos materiais constituintes. Dessa forma, conclui-se que a restrição rotacional altera o comportamento de um pilar em situação de incêndio (ROCHA, 2016).

\subsubsection{Pesquisas científicas sobre pilares de aço com aquecimento não uniforme na seção transversal: sem interação das paredes}

\subsubsection{Estudos experimentais}

\subsection{Dwaikat et al. (2011)}

Os autores realizaram estudos de caráter numérico e experimental sobre pilares de aço com restrição térmica submetidos a um aquecimento não uniforme na seção transversal. Nos experimentos, as faces do pilar foram isoladas termicamente de diferentes formas para gerar diversos cenários de gradientes térmicos. Além disso, os protótipos foram ensaiados com variados níveis de carga combinados com a aplicação do gradiente térmico em diferentes direções do pilar. O modelo dos ensaios experimentais e o modo em que os pilares receberam a manta de isolamento térmico podem ser visualizados nas Figuras 2.13 e 2.14, respectivamente. 


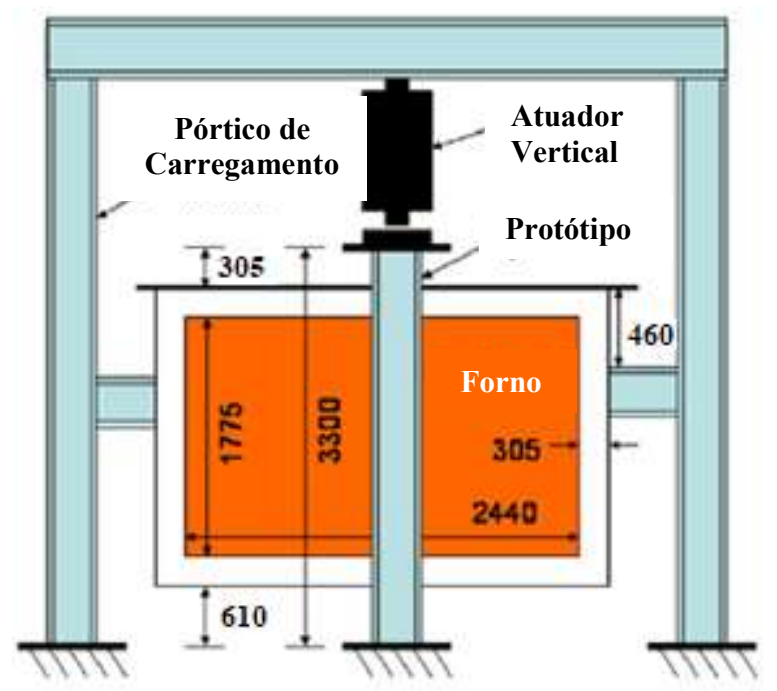

Figura 2.13 - Modelo de ensaio utilizado em Dwaikat et al. (2011)

Fonte: Dwaikat et al. (2011).

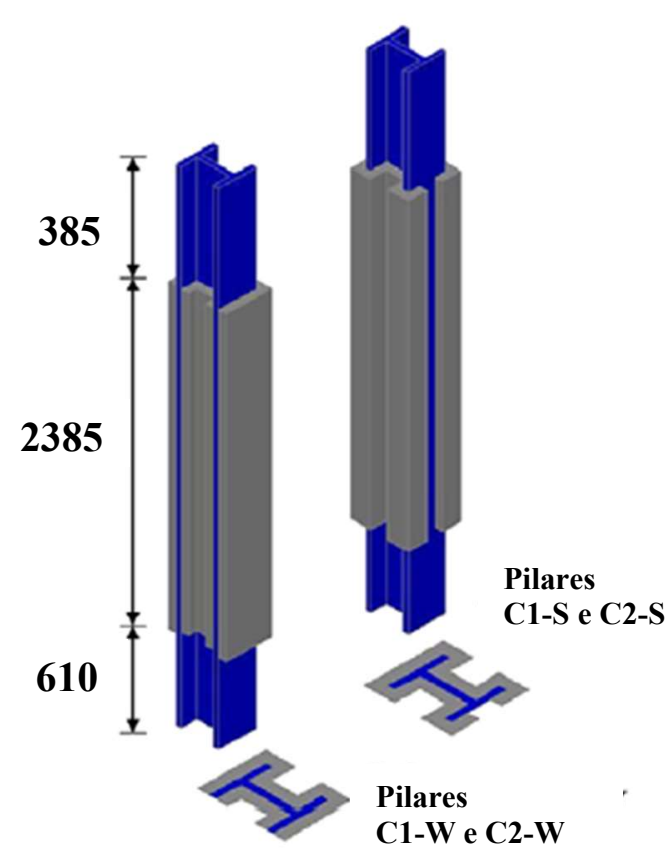

C1-W e C2-W

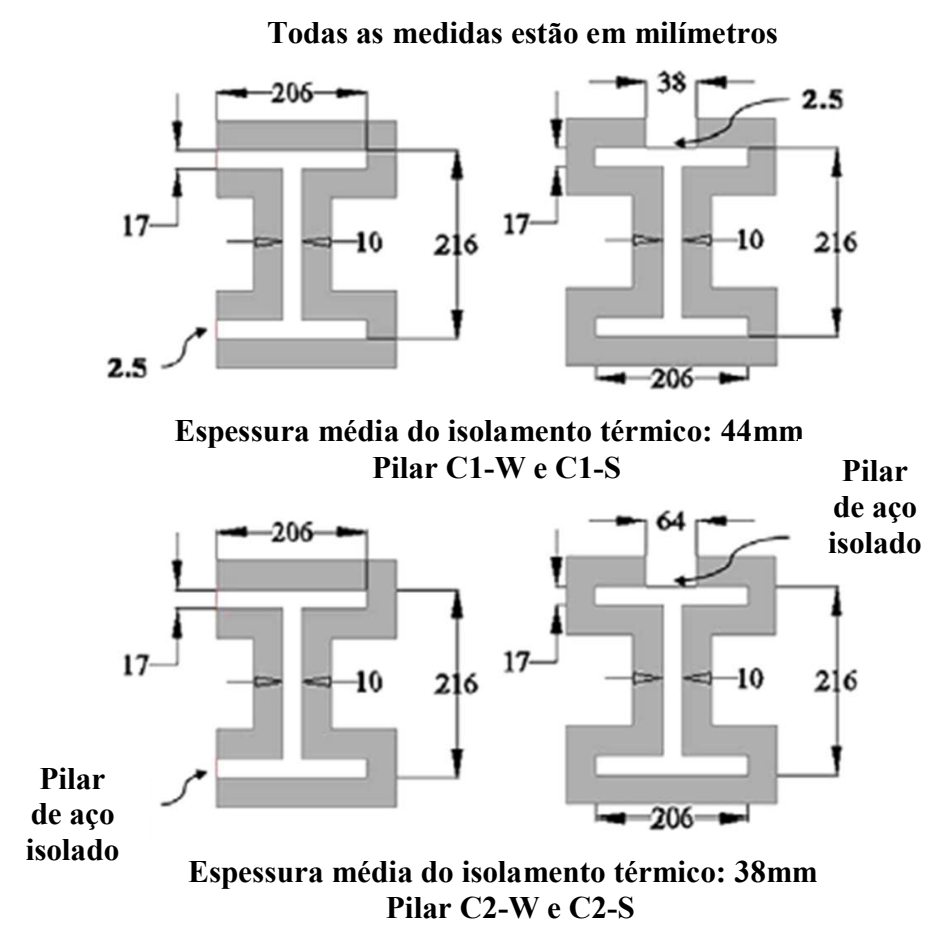

Todas as medidas estão em milímetros

Pilar C2-W e C2-S

Figura 2.14 - Cenários de isolamento térmico para os pilares estudados em Dwaikat et al. (2011)

Fonte: Dwaikat et al. (2011).

Os resultados apontaram a ocorrência do Thermal Bowing nos elementos estruturais. Além disso, em todos os ensaios a falha do pilar aconteceu pela plastificação total da seção transversal com maior temperatura média e menor momento resultante, devido aos efeitos combinados de momento fletor e esforço normal. 
No que concerne à análise numérica, utilizou-se o código computacional SAFIR para a criação dos modelos. Os resultados numéricos conseguiram representar satisfatoriamente a resposta termoestrutural dos ensaios experimentais de modo a reproduzir a inversão da curvatura do pilar devido ao fenômeno do Thermal Bowing e a determinar satisfatoriamente a capacidade resistente do elemento estrutural.

\subsubsection{Estudos numéricos}

\subsection{Garlock e Quiel (2006, 2007)}

A fim de comparar o comportamento de pilares metálicos com aquecimento uniforme e não uniforme na seção transversal, Garlock e Quiel $(2006,2007)$ realizaram estudos de caráter numérico e teórico, levando em consideração diferentes perfis de aço, variadas direções de aplicação do momento de flexão originado pelo gradiente térmico (eixo de maior inércia / eixo de menor inércia) e diversos níveis de carga aplicados.

Em relação aos elementos com aquecimento uniforme na seção transversal, os estudos identificaram menor capacidade de suporte em comparação com os demais pilares estudados. No que concerne aos elementos com aquecimento diferencial na seção, o foco do trabalho foi baseado nos parâmetros que influenciavam no fenômeno Thermal Bowing. Os resultados apontaram que quanto maior a força aplicada, maior será a magnitude da mudança do centroide efetivo e, consequentemente, do momento fletor produzido por essa excentricidade.

Ao comparar os pilares constituídos por perfis com diferentes orientações frente à ação do fogo, observou-se que aqueles em que o gradiente térmico é desenvolvido ao longo da mesa produz menor mudança do centroide efetivo, de modo que o momento total produzido chega a ser 50 a $60 \%$ do momento obtido em perfis com gradiente térmico em torno da alma.

\subsection{Dwaikat e Kodur (2010)}

Os autores propuseram um método simplificado para determinar a resistência de pilares metálicos submetidos a gradientes térmicos, através de diagramas de interação "esforço normal versus momento fletor", N-M. Nos códigos normativos atuais, existem diagramas específicos para pilares com aquecimento uniforme na seção transversal. Porém, quando o elemento é submetido a gradientes térmicos, as curvas N-M existentes se tornam inadequadas para a obtenção da resistência do pilar. 
O método proposto consiste basicamente em determinar o campo térmico na seção transversal e, em seguida, ajustar as curvas normatizadas por meio da temperatura média representativa do gradiente térmico, de modo que deve ser levado em conta a orientação do perfil de aço frente à ação do fogo.

A Figura 2.15 mostra a comparação entre as curvas "esforço normal versus momento fletor", recomendadas pelo método indicado nas normas atuais (linha cheia) e o método proposto pelos autores para os pilares com gradiente térmico na seção (linha tracejada).

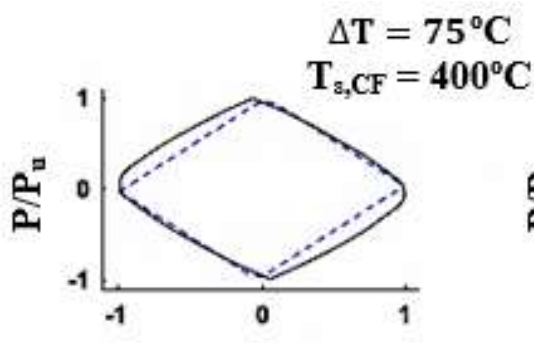

$\mathbf{M} / \mathbf{M}_{\mathbf{u}}$

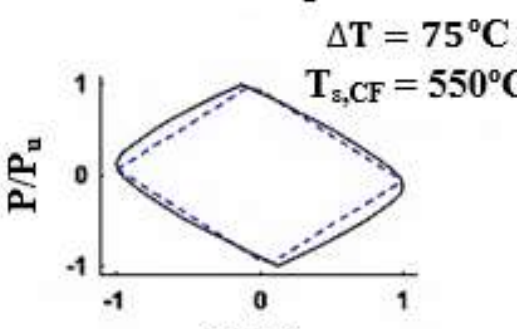

$\mathbf{M} / \mathbf{M}_{\mathbf{u}}$

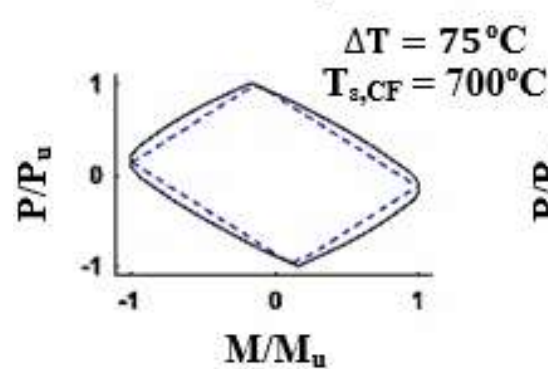

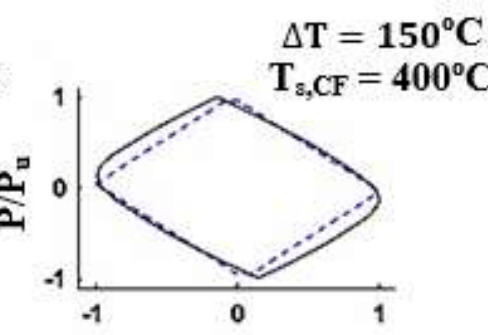

$\mathbf{M} / \mathbf{M}_{\mathbf{u}}$

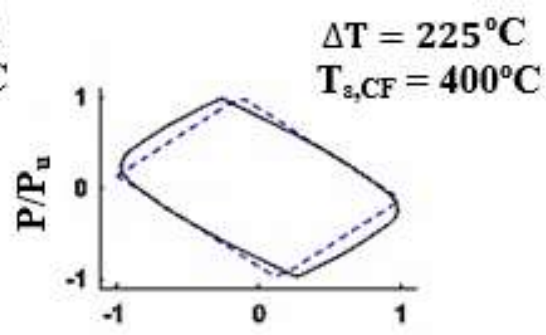

$\mathbf{M} / \mathbf{M}_{\mathbf{u}}$

$$
\Delta \mathrm{T}=150^{\circ} \mathrm{C}
$$$$
\Delta \mathrm{T}=225^{\circ} \mathrm{C}
$$

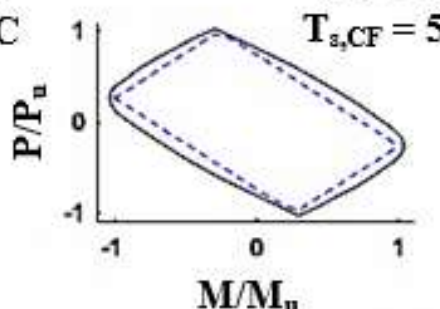

$T_{s, C F}=550^{\circ} \mathrm{C}$
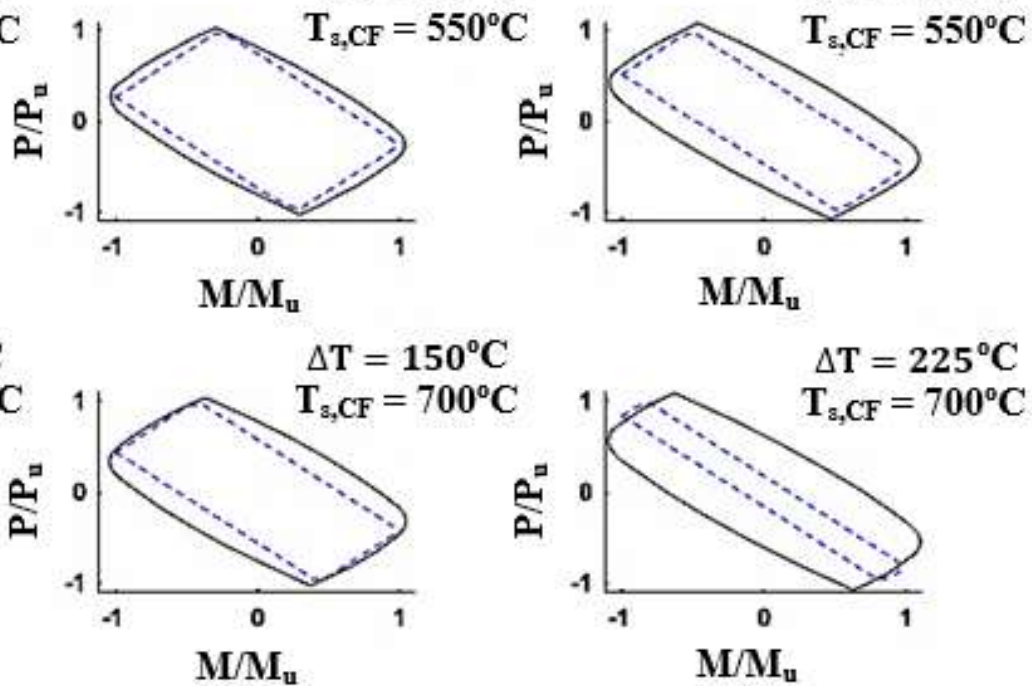

Figura 2.15 - Diagrama "N-M" para pilares sujeitos a gradientes térmicos ao longo das mesas Fonte: Dwaikat e Kodur (2010).

Os autores concluíram que as dimensões do perfil e as espessuras de suas chapas pouco influenciam o formato das curvas N-M dos pilares sujeitos a gradientes térmicos. Porém, quando o aquecimento diferencial se dá no eixo de maior inércia, há uma grande distorção nas curvas normatizadas existentes. 


\subsection{Agarwal, Choe e Varma (2014)}

Os autores realizaram análises numéricas sobre pilares metálicos submetidos a campos térmicos uniformes e não uniformes a partir da utilização do código computacional ABAQUS. A abordagem via elementos finitos possibilitou realizar estudos paramétricos para avaliar os efeitos de diferentes cenários de aquecimento no comportamento de falha dos pilares de aço em temperaturas elevadas.

De maneira geral, observou-se que a resistência ao fogo dos pilares com aquecimento uniforme foi atingida mais rapidamente em comparação aos casos em que a seção transversal do pilar apresentava aquecimento diferencial. Por outro lado, os elementos estruturais com aquecimento não uniforme apresentaram falha em temperaturas mais baixas quando comparados aos pilares com aquecimento nas quatro faces.

Em relação à orientação do perfil frente à ação térmica, pilares com gradiente térmico ao longo da alma falharam por instabilidade na direção do eixo forte ou por flexo torção. Já aqueles em que o gradiente térmico se desenvolve ao longo da mesa, a falha ocorreu por instabilidade na direção do eixo mais fraco.

A partir da análise numérica, o estudo ainda promoveu um método simplificado para o dimensionamento de pilares com aquecimento não uniforme da seção transversal. As equações propostas quantificam os efeitos relacionados à curvatura dos pilares, ao momento de segunda ordem gerado na extremidade do elemento estrutural e à assimetria da seção transversal.

\subsection{Quiel et al. (2014)}

Quiel et al. (2014) também realizaram um estudo numérico a respeito de pilares metálicos a fim de determinar sua capacidade plástica e avaliar seu comportamento quando expostos a um aquecimento diferencial. Para isso, foram aplicadas três diferentes metodologias para verificar a resposta desses pilares sob ação do fogo: a primeira baseada um estudo teórico considerando as equações fornecidas pelas normas americana e europeia e as outras duas foram realizadas por meio de uma abordagem numérica utilizando o código computacional SAFIR empregando elementos ora do tipo "fiber-beam" ora do tipo "shell".

Percebeu-se que os códigos normativos apresentam resultados conservadores por não considerarem devidamente todos os parâmetros envolvidos quando há gradientes térmicos nas seções transversais. Em contrapartida, o uso de elementos "fiber-beam" e "shell" foram capazes 
de prever de forma satisfatória os experimentos utilizados para validação, em especial quanto à capacidade plástica dos elementos estruturais.

\subsection{Zhang et al. (2015)}

Os autores realizaram uma investigação numérica sobre o comportamento de pilares de aço isolados submetidos a um incêndio localizado. Foram conduzidas simulações termoestruturais acopladas sequencialmente, utilizando elementos do tipo casca em sua representação numérica e considerando os efeitos das restrições axiais e rotacionais no desempenho dos pilares, como pode ser vista na Figura 2.16 que traz modelo proposto por Zhang et al. (2015).

a)

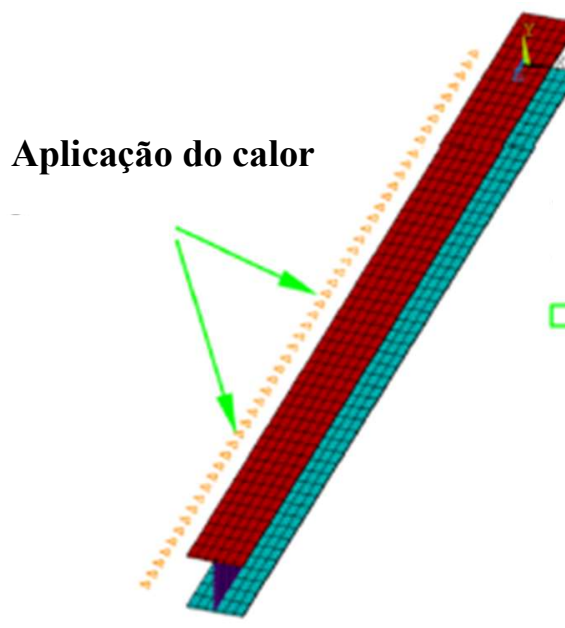

b)

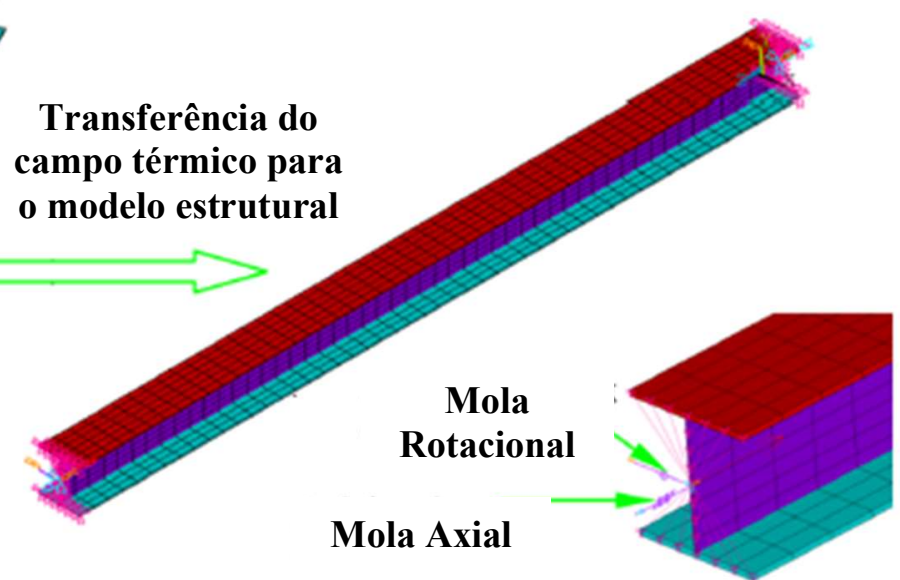

Figura 2.16 - Modelos numéricos propostos por Zhang et al. (2015): a) térmico; b) termoestrutural

Fonte: Zhang et al. (2015).

Os resultados apontaram que pilares cercados por um incêndio localizado falham por instabilidade local, enquanto aqueles sujeitos a um incêndio em suas quatro faces falham por instabilidade global. Em razão disso, as temperaturas que levam a falha dos pilares com gradiente térmico na seção transversal podem ser muito inferiores à dos pilares sujeitos a um aquecimento uniforme devido à presença de momentos fletores de segunda ordem. 


\subsubsection{Pesquisas científicas sobre pilares de aço inseridos em paredes}

\subsubsection{Estudos experimentais}

Como mencionado anteriormente, há uma carência de estudos sobre pilares inseridos em paredes no meio científico, principalmente em contexto experimental. O custo de experimentos que envolvem incêndio costuma ser elevado, o que muitas vezes inviabiliza sua execução. Foram encontrados na literatura somente três pesquisas que realizaram ensaios de pilares em contato com paredes, são elas: Correia (2011), Simões (2016) e Rocha (2016).

Todos eles foram desenvolvidos no Laboratório de Ensaio de Estruturas e Materiais da Universidade de Coimbra, Portugal, que possui um forno vertical elétrico com grandes dimensões o qual possibilita o desenvolvimento de ensaios de pilares inseridos em paredes.

O programa experimental foi basicamente o mesmo para todos os estudos. A única diferença encontrada nos aspectos referentes aos experimentos se volta ao posicionamento das vigas superiores do pórtico de restrição. Em Correia (2011), ver Figura 2.5, uma viga se apoiava na outra, enquanto que nos outros dois estudos elas apenas se cruzavam. Isso impacta somente a intensidade da restrição térmica imposta aos pilares. Maiores informações a respeito disso será descrito adiante.

Tendo em vista o exposto, a seguir são discutidos os aspectos mais relevantes sobre esses trabalhos, sendo dado destaque a pesquisa desenvolvida e apresentada em Rocha (2016), pois ela será utilizada para validação dos modelos numéricos propostos no presente trabalho.

\subsection{Correia (2011)}

A referida tese de doutorado, no que concerne a pilares de aço inseridos em paredes, deu origem a diversos artigos científicos, os quais serão descritos a seguir. Em Correia, Rodrigues e Real (2014), são discutidos os estudos experimentais e numéricos realizados para os pilares em contato com paredes. Foram avaliados dois tipos de perfis metálicos, orientados com a alma paralela e ortogonal à superfície da parede, e duas espessuras de blocos cerâmicos. Vale ressaltar que o procedimento dos ensaios foi o mesmo descrito em Correia e Rodrigues (2012), em concordância com o item 2.2.1.5.

$\mathrm{Na}$ modelagem numérica, foi utilizado o código computacional ABAQUS para o desenvolvimento de análises térmicas, estruturais e termoestruturais. Em geral, os resultados numéricos foram satisfatórios somente para a representação das temperaturas, de modo que os 
autores identificaram dificuldades de reprodução do comportamento das forças de restrição e dos deslocamentos axiais desenvolvidos nos pilares.

As principais conclusões do estudo foram:

a) a espessura da parede, dado um mesmo perfil de aço, influencia diretamente no tempo crítico dos pilares;

b) os deslocamentos axiais são maiores em elementos com aquecimento uniforme na seção transversal, uma vez que a parede fornece rigidez axial ao pilar;

c) a alvenaria contribuiu para a redução da temperatura média da seção transversal de modo a aumentar o tempo e a temperatura críticos dos pilares.

Alguns dos resultados apresentados já haviam sido elucidados nos estudos experimentais e numéricos descritos em Correia et al. (2009) e Correia, Rodrigues e Silva (2010).

\subsection{Simões (2016)}

Nessa referência foram desenvolvidos estudos numérico e experimental voltados a pilares com aquecimento diferencial na seção transversal promovido pelo contato dos mesmos com paredes. Nesse trabalho foi avaliada a influência da orientação do perfil de aço frente à ação térmica, índice de esbeltez e nível de carga. A análise numérica também foi realizada por meio do código computacional ABAQUS, empregando as não linearidades geométrica e do material para os modelos termoestruturais.

Os resultados confirmaram a presença do fenômeno Thermal Bowing que ocorre em elementos estruturais submetidos a gradientes térmicos, de modo que foi possível analisar a migração do centroide efetivo da seção transversal ao longo do tempo nas simulações numéricas. Percebeu-se que o deslocamento dessa grandeza é mais brusco em pilares com gradiente térmico ao longo da alma, como afirmado também em Garlock e Quiel (2007).

A autora constatou, assim como Correia (2011), que o aquecimento diferencial é mais intenso em pilares em que a alma do perfil de aço se encontra perpendicular às paredes. Apesar disso, a temperatura média para esse tipo de elemento estrutural é menor em comparação ao pilar com a alma paralela à ação térmica de modo que a perda de sua capacidade resistente foi mais lenta. 


\subsection{Rocha (2016)}

O estudo descrito em Rocha (2016) contou com análises experimentais e numéricas a serem descritas a seguir. Vale destacar, mais uma vez, que esse trabalho será utilizado para fins de validação dos modelos a serem propostos por essa dissertação e por isso, um maior número de detalhes será relatado.

O programa experimental de referência foi realizado no Laboratório de Ensaio de Estruturas e Materiais da Universidade de Coimbra, Portugal, e contou com um total de doze protótipos considerando pilares de aço e mistos de aço e concreto, inseridos ou não em paredes, de modo a compreender a influência de diversos parâmetros no desempenho de pilares em situação de incêndio, a citar: esbeltez do elemento estrutural, orientação do perfil frente ação térmica, espessura da parede, fator de carga e rigidez da estrutura circundante.

Os pilares foram construídos a partir de dois tipos de perfis de aço, HEA 100 e HEA 220, cujas características geométricas estão descritas na Tabela 2.1.

Tabela 2.1 - Características geométricas dos perfis de aço HEA 100 e HEA 220

\begin{tabular}{ccc}
\hline Parâmetros & HEA 100 & HEA 220 \\
\hline $\mathrm{d}(\mathrm{mm})$ & 96 & 210 \\
$\mathrm{~b}_{\mathrm{f}}(\mathrm{mm})$ & 100 & 220 \\
$\mathrm{f}(\mathrm{mm})$ & 8 & 11 \\
$\mathrm{t}_{\mathrm{w}}(\mathrm{mm})$ & 5 & 7 \\
$\mathrm{I}_{\mathrm{x}}\left(\mathrm{cm}^{4}\right)$ & 349 & 5410 \\
$\mathrm{I}_{\mathrm{y}}\left(\mathrm{cm}^{4}\right)$ & 134 & 1950 \\
Área $\left(\mathrm{cm}^{2}\right)$ & 21,2 & 64,3
\end{tabular}

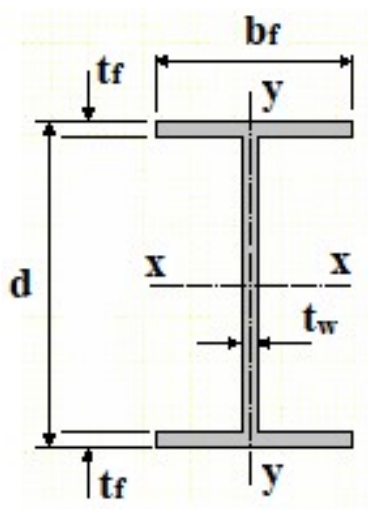

Fonte: Autor da Pesquisa (2018).

Em relação aos aspectos construtivos, as paredes foram idealizadas e construídas com blocos cerâmicos com o mesmo comprimento do pilar de aço, no caso, 2,94 m, bem como 1,2 $\mathrm{m}$ para cada lado do elemento estrutural. A ligação entre o pilar e as paredes se deu por meio de uma ancoragem da alvenaria. Para isso, foram soldados ganchos metálicos ao longo do comprimento do pilar, na alma ou na mesa, a depender da orientação desejada do perfil de aço frente à ação do fogo.

Para fixação das paredes a esses ganhos foram realizados cortes de $10 \times 10 \mathrm{~cm}^{2}$ no elemento de vedação que permitiu uni-los com o uso de argamassa. Essa ligação foi exitosa, 
haja vista que, nos ensaios em elevadas temperaturas, não houve descolamento do pilar da alvenaria, em virtude de os mesmos terem passado a trabalhar em conjunto. Maiores detalhes sobre a construção do elemento estrutural podem ser consultados em Rocha (2016).

Os ensaios realizados seguiram o mesmo padrão de execução desenvolvido em Correia e Rodrigues (2012), ou seja, os pilares foram inseridos em um sistema de restrição tridimensional que estabelecia uma restrição à deformação térmica, tanto em contexto de translação como de rotação das extremidades.

A única diferença entre ambos os ensaios se refere ao arranjo das vigas superiores da estrutura de restrição, como já foi mencionado, pois as vigas se cruzavam no ensaio de Rocha (2016), como pode ser visualizada na Figura 2.17, porém, sem que uma dada viga se apoiasse na outra. Tal fato alterou a intensidade das restrições pré-definida e considerada nas modelagens numéricas de Correia, Rodrigues e Gomes (2013). Apesar disso, não foram realizados ensaios para determinação da rigidez axial e rotacional da nova estrutura, o que dificultou a etapa da construção dos modelos termoestruturais realizados em Rocha (2016).

a)

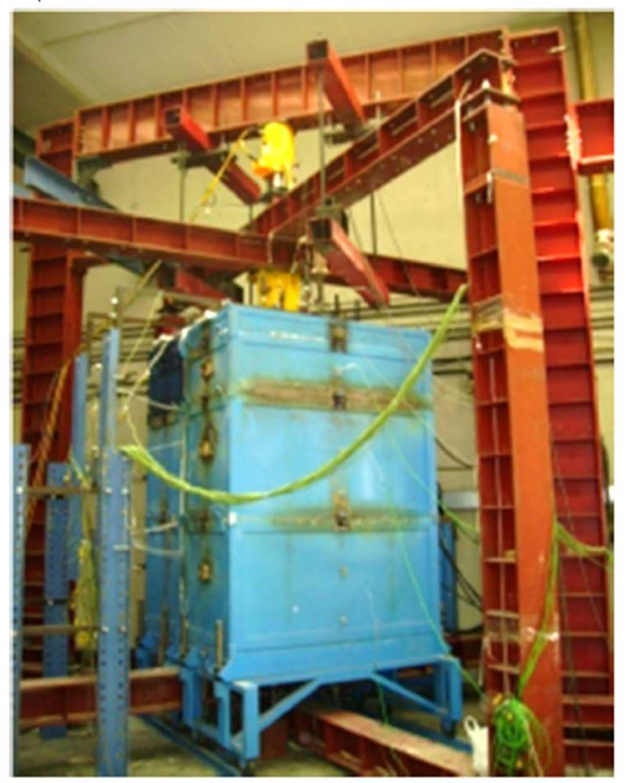

b)

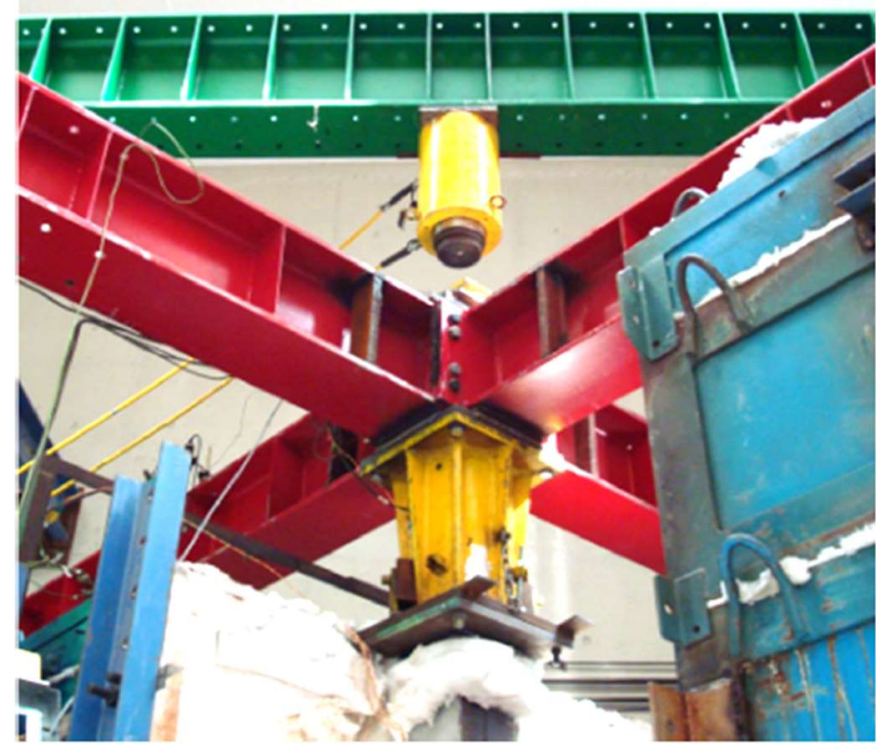

Figura 2.17 - Arranjo das vigas superiores da estrutura de restrição utilizada nos ensaios: a) Correia e Rodrigues (2012); b) Rocha (2016)

Fonte: Rocha (2016).

No que concerne aos procedimentos de ensaio, os pilares foram carregados com $30 \%$ da sua carga última teórica à temperatura ambiente, de acordo com as prescrições do Eurocode 3 Parte 1-1 (2005). Posteriormente, o sistema tridimensional de restrição foi devidamente travado para que, em seguida, os pilares fossem aquecidos. 
No caso dos pilares isolados, o aquecimento se deu nas quatro faces do perfil, enquanto que nos pilares inseridos em paredes, a ação do fogo se limitou a apenas uma face. O forno utilizado foi do tipo modular elétrico, composto por três módulos, sendo dois deles com 1,0 m de altura e o outro com 0,5 m. Quando unidos, formavam uma estrutura com dimensões 1,5 x $1,5 \times 2,5 \mathrm{~m}^{3}$, de maneira que apenas 2,5 m centrais do pilar eram aquecidos. A Figura 2.18 ilustra o sistema completo utilizado no ensaio experimental de um pilar em contato com paredes.

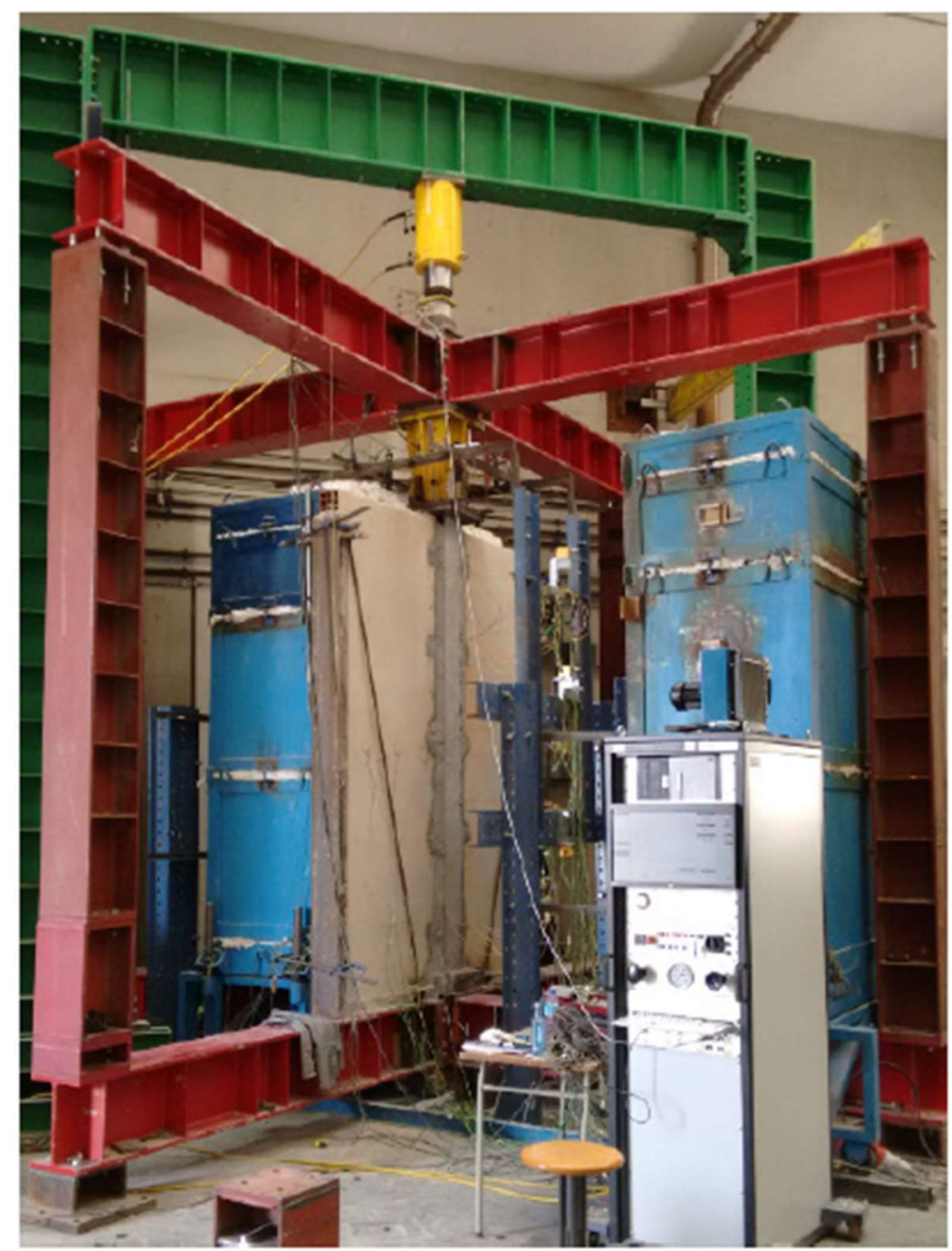

Figura 2.18 - Representação do sistema de ensaio utilizado em Rocha (2016)

Fonte: Rocha (2016).

A Figura 2.19 traz as representações esquemáticas da seção transversal de cada um dos pilares de aço estudados, indicando as posições dos termopares responsáveis por medir a evolução de temperatura em cada ponto, representados pela terminologia TX.Y, em que X indica a seção do pilar que está se estudando, enquanto $\mathrm{Y}$ indica a numeração do ponto de 
medição. Cita-se ainda que as temperaturas foram mensuradas em cinco seções ao longo do comprimento do elemento estrutural, conforme apresentadas na Figura 2.19d. Apesar disso, a apresentação dos resultados e a validação dos modelos propostos serão feitos tendo como referência a seção 3 (central).

a)

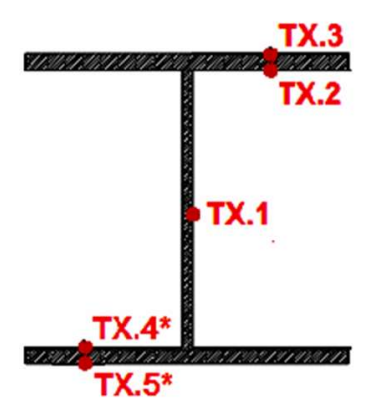

b)

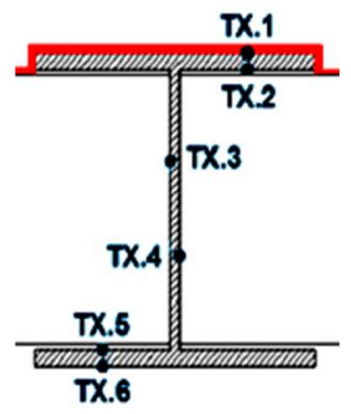

c)

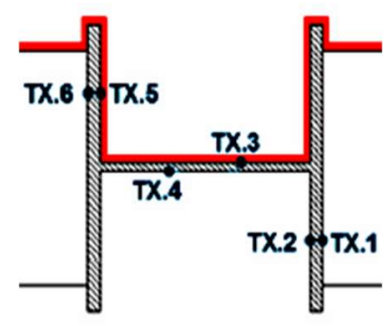

d)

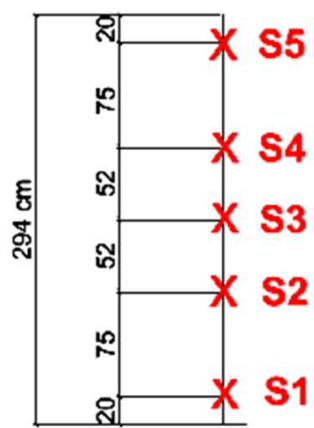

Figura 2.19 - Posições dos termopares utilizadas para os pilares no programa experimental: a) isolados; b) com alma ortogonal à superfície da parede; c) com alma paralela à superfície da parede; d) representação das seções para medição das temperaturas

Fonte: Rocha (2016).

Além da temperatura, foram medidos o deslocamento axial e a força de restrição durante os experimentos, pois representam parâmetros importantes em ensaios termoestruturais de pilares com restrição térmica.

Para a determinação do deslocamento axial, quatro transdutores do tipo LVDT foram instalados no topo e na base do pilar. A partir disso, essa grandeza foi obtida pela média aritmética dos quatro medidores seguido da diferença entre o deslocamento médio do topo e da base. Em relação à força, instalou-se uma célula de carga entre o pilar e o pórtico de restrição, responsável por medir as forças geradas pela expansão térmica do pilar restringido.

$\mathrm{O}$ estudo de referência ainda contou com uma abordagem numérica na tentativa de reprodução dos ensaios experimentais realizados. Os modelos desenvolvidos foram construídos por meio do código computacional ABAQUS com o objetivo de representar o sistema de restrição completo utilizado nos ensaios.

Diante disso, o modelo numérico foi constituído pelo pórtico de restrição (com as vigas superiores) associados ao pilar (com ou sem paredes), conforme mostra a Figura 2.20, similar ao que foi feito no estudo de Correia, Rodrigues e Gomes (2013), ver Figura 2.6. Todos esses componentes foram modelados com elementos finitos sólidos do tipo HT3D8R e C3D8R, para as análises térmica e termoestrutural, respectivamente. 
No âmbito da análise térmica, os pilares foram reproduzidos de modo que na face exposta ao fogo houvesse trocas de calor por convecção e radiação, enquanto na face não exposta ao fogo considerou-se apenas um coeficiente de convecção representativo para ambos os fenômenos. Portanto, foram utilizados os seguintes parâmetros de transferência de calor: emissividades da superfície do aço e da parede iguais a 0,9 e a 0,8 , respectivamente, e coeficiente de convecção igual a $25 \mathrm{~W} / \mathrm{m}^{2} .{ }^{\circ} \mathrm{C}$ para o lado em contato com as chamas, enquanto que para o lado não exposto ao fogo foi considerado apenas o coeficiente de convecção equivalente a $9 \mathrm{~W} / \mathrm{m}^{2} .{ }^{\circ} \mathrm{C}$.

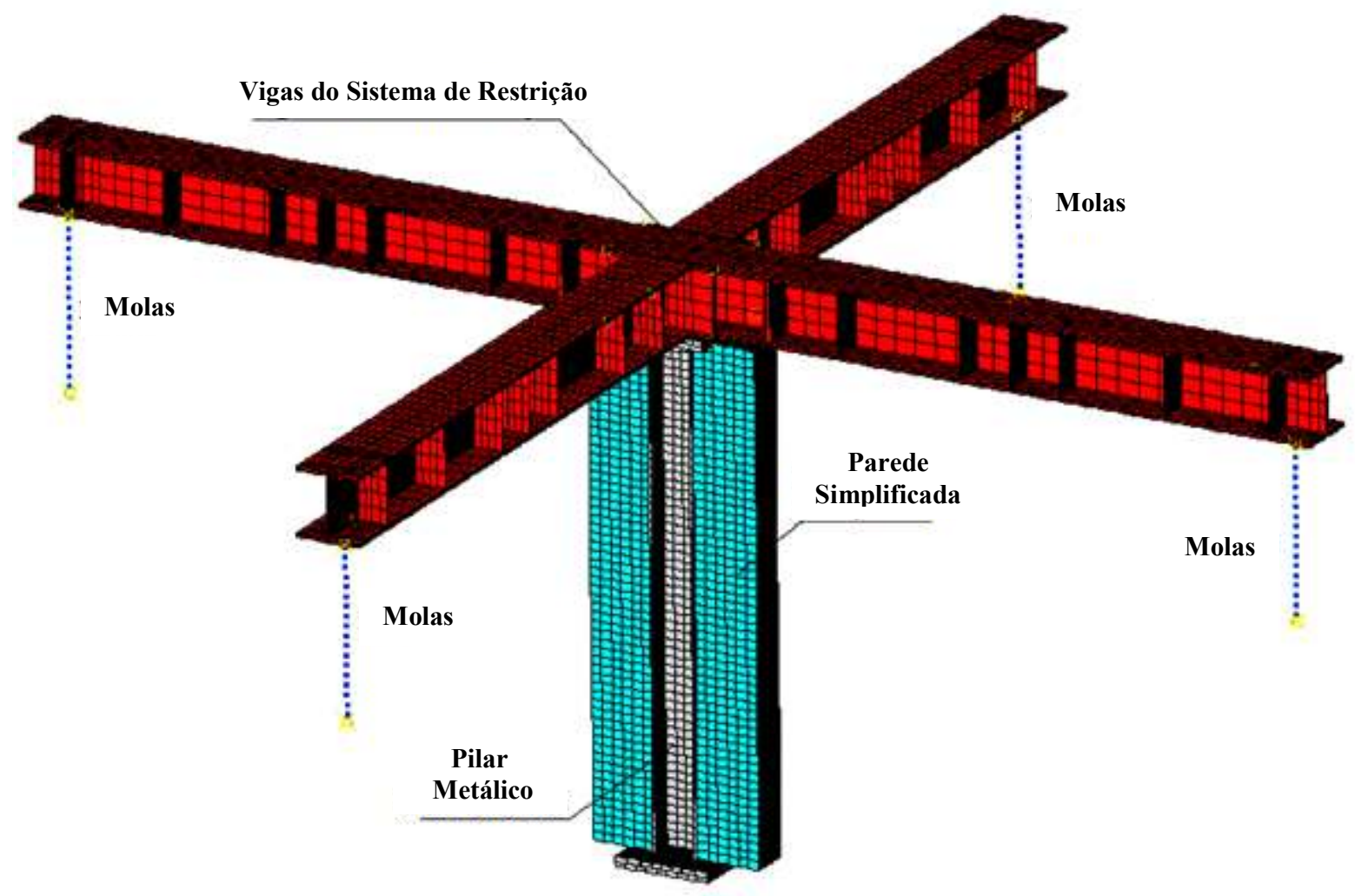

Figura 2.20 - Modelo numérico proposto por Rocha (2016)

Fonte: Rocha (2016).

Em relação às demais propriedades térmicas utilizadas no modelo, como o calor específico e a condutividade térmica, para o aço foi seguido o equacionamento descrito pela ABNT NBR 14323:2013, a qual possui basicamente as mesmas considerações do Eurocode 3 Parte 1-2 (2005).

Para as paredes, as propriedades térmicas foram consideradas constantes com o aumento da temperatura, seguindo os mesmos valores apresentados em Cadorin (2003) que, por sua vez, tratava de uma análise numérica no código computacional Ozone. Portanto, foram adotados os 
seguintes valores para as propriedades térmicas das paredes: $840 \mathrm{~J} / \mathrm{kg}^{\circ} \mathrm{C}$ para o calor específico, $1600 \mathrm{~kg} / \mathrm{m}^{3}$ para a massa específica e 0,7 para a condutividade térmica.

No que concerne à estratégia de modelagem termoestrutural proposta em Rocha (2016), destaca-se que houve grande dificuldade em encontrar um modelo que representasse todos os pilares ensaiados, tanto em contexto de forças de restrição quanto de deslocamentos. Por essa razão, três diferentes metodologias foram testadas, a citar:

a) representação do modelo de restrição tridimensional com molas;

b) representação do modelo de restrição tridimensional sem molas;

c) uso de elementos finitos do tipo casca (shell) para representação numérica dos perfis de aço associados a molas axiais e rotacionais nas extremidades dos pilares.

Os métodos "a" e "b" buscaram modelar a estrutura tridimensional completa do ensaio experimental, cujas propostas acarretaram em grande esforço computacional para obtenção dos resultados. A diferença entre ambos os métodos se voltava ao uso ou não das molas indicadas na Figura 2.20 de modo que em Rocha (2016), percebeu-se que a não utilização de tais molas aumentava a rigidez do sistema de restrição alterando substancialmente a resposta numérica.

Os resultados alcançados por cada metodologia representaram de forma satisfatória o comportamento termoestrutural de diferentes pilares. Diante disso, concluiu-se que a intensidade da restrição térmica proporcionada pelo sistema global consistia (e ainda consiste) em um fator determinante para o estudo dos pilares em situação de incêndio.

Tendo em vista o exposto, em Rocha (2016) se considerou utilizar o método "c", o qual, apesar de não ter sido abordado com detalhes nesse estudo, se mostrou ser um procedimento que poderia alcançar bons resultados na modelagem termoestrutural.

Nessa metodologia, o sistema de restrição dos ensaios foi representado por meio de molas axiais e rotacionais nas extremidades dos pilares desde que os perfis de aço fossem modelados por elementos de casca. A partir disso, o autor indicou que os resultados, enquanto forças e deslocamentos, podem ser mais representativos desde que se utilize valores de restrições axial e rotacional adequados para essas molas.

De forma complementar, o estudo de referência ainda chegou à conclusão que as paredes influenciam o comportamento termoestrutural dos pilares (mesmo não conseguindo mensurar tal influência) de modo a alterar a sua rigidez axial. Isso, de acordo com o autor, dificultou a obtenção de modelos numéricos consistentes.

Essa dissertação, portanto, também busca obter algumas das respostas não alcançadas em Rocha (2016), a partir do emprego do "método c", para melhor compreender o comportamento de pilares de aço isolados e inseridos em paredes sob ação do fogo. 


\subsubsection{Estudos numéricos}

\subsection{Silva, Correia e Rodrigues (2008)}

Trata-se de um estudo numérico em contexto térmico sobre pilares metálicos em contato com paredes. $\mathrm{O}$ trabalho buscou avaliar o efeito do gradiente térmico desenvolvido em pilares de aço com a alma paralela ou perpendicular à superfície da parede (Figura 2.21).
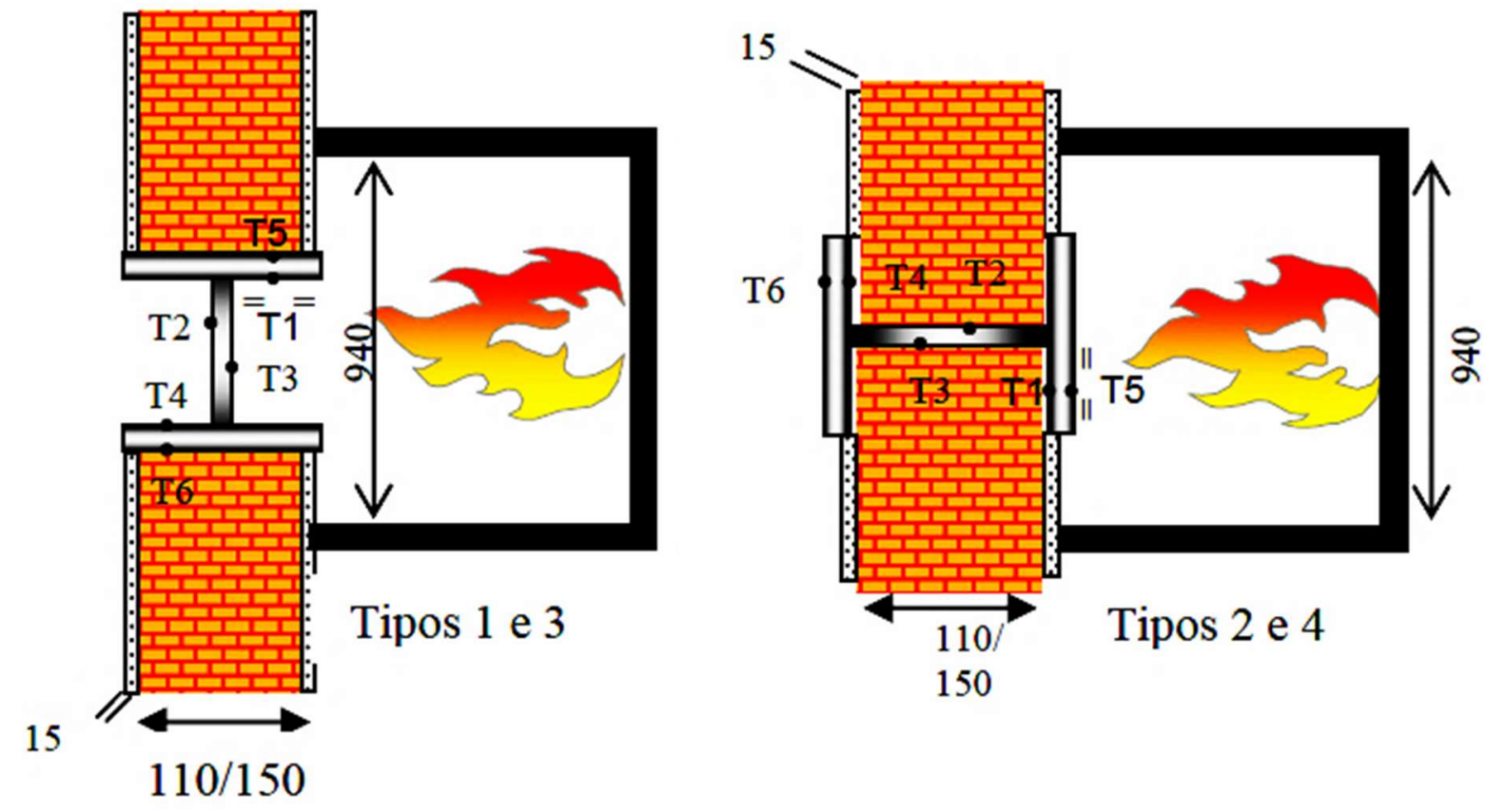

Figura 2.21 - Diferentes associações entre o perfil de aço e a alvenaria Fonte: Silva, Correia e Rodrigues (2008).

A análise numérica foi realizada por meio do código computacional Super Tempcalc (STC) em que foram reproduzidos pilares com dois tipos de seção transversal, HEB 160 e HEB 200. A alvenaria foi considerada sem função estrutural e as propriedades térmicas adotadas para ela foram consideradas constantes ao longo do aquecimento e estão também descritas em Cadorin (2003).

Em relação às propriedades térmicas do lado não exposto ao fogo, foram testadas as duas possibilidades recomendadas pelo Eurocode 1 Parte 1-2 (2005):

a) coeficiente de convecção $\left(\propto_{c}\right)$ equivalente a $9 \mathrm{~W} / \mathrm{m}^{2 \circ} \mathrm{C}$ e emissividade ( $(\varepsilon)$ igual a zero, considerando o efeito da convecção e radiação simultaneamente, e;

b) $\propto_{c}=4 \mathrm{~W} / \mathrm{m}^{2 \circ} \mathrm{C}$ e $\varepsilon=$ a definir, quando se considera separadamente os dois fenômenos. 
Quando aplicado o "teste b", os resultados foram mais satisfatórios para os modelos numéricos em que a alma é paralela à superfície da parede. Apesar disso, para a outra configuração do pilar, não houve diferenças significativas.

Os autores chegaram à conclusão que o gradiente térmico desenvolvido em pilares que possuem as paredes em contato com a alma é bastante superior àquele desenvolvido em elementos que possuem as mesas em contato com a alvenaria, em razão à menor exposição do perfil metálico a ação térmica. No que diz respeito aos resultados numéricos, para ambos os casos da orientação do perfil, as temperaturas dos modelos foram relativamente maiores que aquelas medidas nos ensaios experimentais, na maior parte dos casos, devido a não consideração do efeito shadow.

\subsection{Kimura (2009)}

A autora desenvolveu uma análise numérica com o uso do código computacional ANSYS v9.0 sobre pilares de aço em situação de incêndio, levando em conta sua interação com as paredes. Nesse estudo, houve variação da orientação do perfil de aço frente à ação térmica (ver Figura 2.22) e da direção das imperfeições geométricas iniciais em relação às chamas.

a)

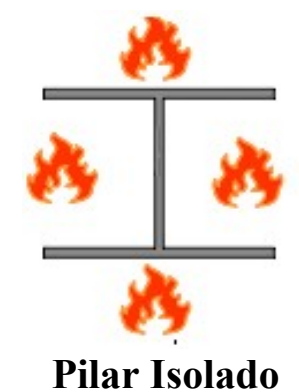

d) b)

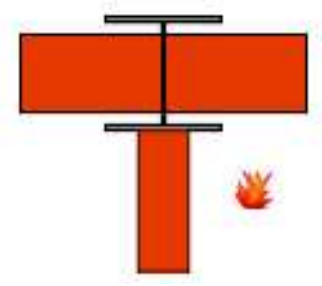

Pilar de borda

c)

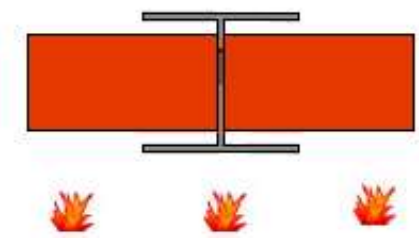

Pilar externo

e)

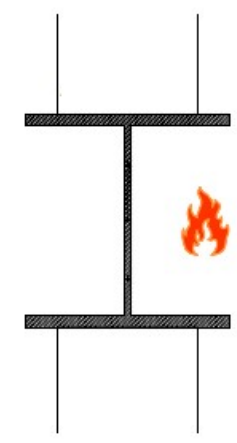

Pilar interno
Pilar de canto

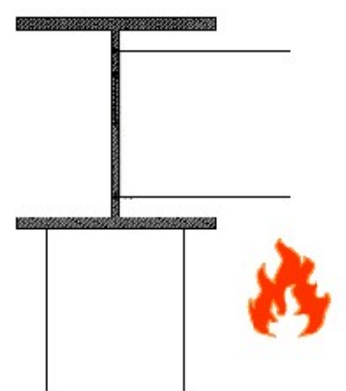

Figura 2.22 - Diferentes orientações dos perfis frente à ação térmica

Fonte: Kimura (2009). 
Constatou-se que esses dois parâmetros influenciam na determinação do campo de temperaturas na seção transversal. No que se refere à imperfeição geométrica, deslocamentos iniciais impostos de maneira contrária à ação térmica elevaram a resistência ao fogo dos pilares. Além disso, o estudo ainda contou com uma avaliação do método da ABNT NBR 14323:1999 no que diz respeito ao cálculo da evolução de temperatura na seção transversal. Resultados acerca dessa abordagem serão descritos na seção 2.4 por contemplar a temática da mesma.

\subsection{Dorr (2010)}

O autor elaborou um estudo numérico por meio da ferramenta computacional ANSYS, sobre pilares metálicos, isolados e inseridos em alvenaria, somente com restrição axial nas extremidades. A etapa inicial do trabalho consistiu em reproduzir os modelos propostos em Kimura (2009), adotando as mesmas considerações e simplificações, porém, substituindo o elemento finito do tipo sólido pelo de casca. O estudo comprovou a eficiência do elemento de casca que passou a ser utilizado em toda a pesquisa.

Os modelos numéricos criados para pilares isolados foram validados pelos estudos descritos em Rodrigues, Neves e Valente (2000) e Franssen (2000). Partindo dessa abordagem, foi desenvolvida a análise numérica para os pilares de aço inseridos em paredes. Com esse trabalho foi possível obter um provável comportamento das forças de restrição e dos deslocamentos axiais e laterais dos pilares quando estão em contato com a alvenaria, apesar de nenhuma validação numérica ter sido realizada, devido à carência de estudos experimentais.

Como resultado, o modelo proposto foi bem aceito e o estudo deu importante passo para representação de pilares em estruturas usuais em situação do incêndio, por considerar, além da alvenaria, as restrições axiais.

\subsection{MÉTODO SIMPLIFICADO PARA CÁLCULO DE TEMPERATURAS EM PERFIS DE AÇO PROPOSTO PELA ABNT NBR 14323:2013}

Nessa seção descreve-se, inicialmente, o método para cálculo da evolução da temperatura em perfis de aço proposto pela ABNT NBR 14323:2013 que é específico para distribuição uniforme da temperatura na seção transversal. Em seguida, discute-se sobre como a norma brasileira trata dos perfis de aço pertencentes a elementos de compartimentação no que diz respeito à determinação do campo térmico não uniforme que se desenvolve nos mesmos 
quando aquecidos. Esse item se encerra com as principais pesquisas científicas que avaliaram a eficiência do método a ser aqui discutido.

\subsubsection{Sobre o método simplificado}

A norma brasileira ABNT NBR 14323:2013, assim como a norma europeia Eurocode 3 Parte 1-2 (2005), define que, para uma distribuição uniforme de temperatura na seção transversal, aquecida pela curva de incêndio-padrão conforme a ISO 834:1999, a evolução de temperatura no perfil de aço sem revestimento será dada pela Equação 2.5:

$$
\Delta \theta_{a, t}=k_{s h} \frac{u / A_{g}}{c_{a} \rho_{a}} \varphi \Delta t
$$

Onde, valem:

- $\Delta \theta_{a, t}$ - é a variação da temperatura no elemento estrutural durante um intervalo de tempo $\Delta t$;

- $\quad k_{s h}$ - é definido como fator de correção de sombreamento e pode ser adotado um valor igual a 1,0 ou determinado pela Equação 2.6:

$$
k_{s h}=0,9 \frac{\left(u / A_{g}\right)_{b}}{u / A_{g}}
$$

- $\left(u / A_{g}\right)_{b}$ - é a relação entre o perímetro exposto ao incêndio de uma caixa hipotética que envolve o perfil de aço e a área da seção transversal;

- $u / A_{g}$ - é o fator de massividade definido pela relação entre o perímetro exposto ao fogo $(\mathrm{u})$ e a área da seção $\left(A_{g}\right)$;

- $C_{a}$ - calor específico do aço $\left(\mathrm{J} / \mathrm{kg} /{ }^{\circ} \mathrm{C}\right)$;

- $\rho_{a}$ - massa específica do aço $\left(\mathrm{kg} / \mathrm{m}^{3}\right)$;

- $\varphi$ - fluxo de calor por unidade de área $\left(\mathrm{W} / \mathrm{m}^{2}\right)$;

- $\Delta \mathrm{t}$ - intervalo de tempo que não pode ser adotado valor maior que $5 \mathrm{~s}$.

O fluxo de calor $(\varphi)$ presente na Equação 2.5 é dado pela soma da parcela do calor devido à convecção $\left(\varphi_{c}\right)$ e à radiação $\left(\varphi_{r}\right)$ e é calculado por meio da Equação 2.7: 


$$
\varphi=\varphi_{c}+\varphi_{r}=\alpha_{c}\left(\theta_{g}-\theta_{a}\right)+5,67 \times 10^{-8} \varepsilon_{r e s}\left[\left(\theta_{g}+273\right)^{4}-\left(\theta_{a}+273\right)^{4}\right]
$$

\section{Em que:}

- $\alpha_{c}$ - é o coeficiente de convecção, cujo valor é $25 \mathrm{~W} / \mathrm{m}^{2}{ }^{\circ} \mathrm{C}$ para exposição ao incêndio padrão ou $35 \mathrm{~W} / \mathrm{m}^{2}{ }^{\circ} \mathrm{C}$, para incêndio natural;

- $\theta_{g}$ - é a temperatura dos gases;

- $\theta_{a}$ - é temperatura do aço;

- $\varepsilon_{\text {res }}$ - é a emissividade resultante, adotada para efeitos práticos igual a 0,7.

\subsubsection{Elementos estruturais pertencentes a elementos de compartimentação}

Pilares inseridos em paredes (Figura 2.23), quando sujeitos à ação térmica, apresentam gradiente térmico na seção transversal, o que acarreta em um comportamento termoestrutural diferente de quando o mesmo possui um aquecimento uniforme em suas quatro faces.

A ABNT NBR 14323:2013 não fornece um método específico para essas situações, porém se admite utilizar o mesmo procedimento aplicado para pilares de aço isolados. Apesar disso, no cálculo do fator de massividade da Equação 2.5, deve-se adotar a área bruta correspondente apenas a parte delimitada pelo perímetro exposto ao fogo.

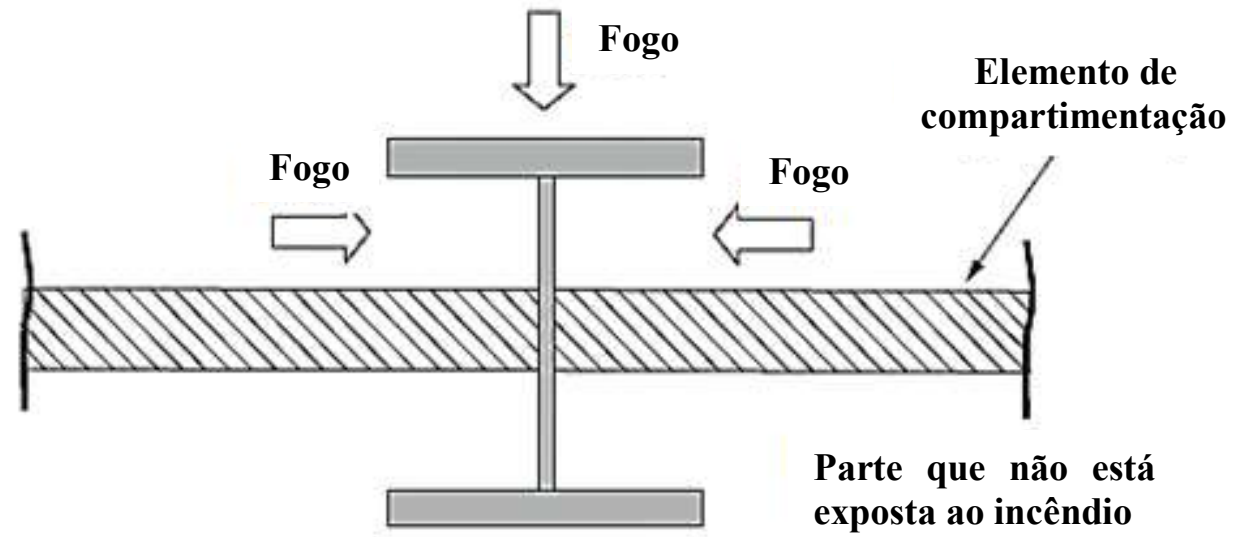

Figura 2.23 - Seção transversal de um pilar de aço inserido em parede Fonte: ABNT NBR 14323:2013. 


\subsubsection{Pesquisas científicas sobre a metodologia de cálculo de temperatura em perfis de aço proposta pelos códigos normativos}

\subsubsection{Regobello (2007)}

Estudo numérico desenvolvido por meio do código computacional ANSYS a fim de avaliar a evolução de temperatura em seções transversais metálicas e mistas para diferentes conformações de vigas, pilares, lajes e alvenaria com aquecimento uniforme e não uniforme. Em seguida, os resultados numéricos foram comparados àqueles obtidos com a aplicação do método simplificado da norma ABNT NBR 14323:1999, que leva em consideração apenas o fator de massividade para determinação da temperatura na seção transversal.

Os resultados foram satisfatórios somente para as seções transversais em que o fator de massividade era determinado pela norma brasileira, o que leva a concluir que há a necessidade de estudos avançados de cálculo para esse campo de pesquisa. Vale ressaltar que mesmo a norma avaliada nesse estudo ter sido atualizada em 2013, o método simplificado atualmente em vigor continua basicamente o mesmo daquele de 1999.

\subsubsection{Kimura (2009)}

Como descrito no item 2.3.3.2.2, Kimura (2009) também buscou verificar a eficiência do método de cálculo de temperaturas proposto pela norma brasileira, ainda em sua versão de 1999, para perfis de aço em contato com paredes. Ao comparar seus resultados numéricos com aqueles obtidos pela norma, pode-se constatar que o código normativo é conversador quando se trata de perfis que apresentam aquecimento diferencial na seção transversal, uma vez que norma brasileira considera apenas o fator de massividade para a determinação da temperatura no elemento estrutural.

\subsubsection{Correia (2011)}

A tese de doutorado apresentada em Correia (2011), além de desenvolver análises numéricas e experimentais a respeito de pilares isolados e inseridos em paredes sob ação do fogo, realizou um estudo sobre o método de cálculo de temperatura em perfis de aço proposto pelo Eurocode 3 Parte 1-2 (2005). Os artigos científicos mais relevantes sobre esse assunto originados por essa tese são Correia et al. (2009) e Correia, Rodrigues e Silva (2011). 
Correia et al. (2009) forneceram uma proposta de alteração do método de cálculo de temperatura da norma europeia atualmente vigente, de modo a adequá-lo para pilares com aquecimento diferencial, uma vez que essa metodologia é satisfatória somente para pilares que apresentam aquecimento uniforme em suas quatro faces.

Essa proposta consiste, inicialmente, em dividir a seção transversal do pilar em três zonas para o cálculo da temperatura. Em pilares com a alma paralela à superfície da parede, a seção foi dividida em: metade da mesa exposta, alma e metade da mesa não exposta. Já para pilares com a alma ortogonal à ação térmica, a seção foi segmentada em mesa exposta, alma e mesa não exposta.

O método sugere incluir coeficientes de redução aos resultados obtidos pelo método normatizado a cada faixa de 10 min do tempo de aquecimento para cada zona. Os autores apontaram que esse método pode ser útil para uma atualização da norma europeia.

Dando continuidade ao trabalho anterior, Correia, Rodrigues e Silva (2011) propuseram um novo método de cálculo para avaliar essas situações não abordadas pelas normas atuais. A metodologia foi baseada em resultados numéricos e experimentais e leva em consideração pilares de aço com duas orientações distintas em relação à superfície da parede: ortogonal e paralela.

Os autores novamente dividiram a seção transversal do pilar em zonas e para cada zona eles determinaram uma equação específica para o cálculo da temperatura. Quando a parede está em contato com a alma, independentemente de sua posição e espessura, são criadas três zonas para cálculo da temperatura $(\theta)$ como pode ser visto nas Figuras $2.24 \mathrm{a}-2.24 \mathrm{c}$, de modo que essa grandeza se comporta da seguinte maneira, $\theta_{3}>\theta_{2}>\theta_{1}$. Já para os pilares em que a parede está em contato com a mesa, apenas duas zonas são necessárias, ver Figuras $2.24 \mathrm{~d}$ e $2.24 \mathrm{e}$, uma vez que a $\theta_{2}=\theta_{3}$.

Isso se justifica pelo fato de o gradiente térmico ser mais intenso no primeiro caso (alma do perfil de aço ortogonal à alvenaria) e provocar uma maior heterogeneidade em relação à temperatura ao longo da seção transversal. O referido método foi validado e apresenta aplicabilidade garantida para os perfis de aço testados. Apesar disso, interpolações podem ser feitas para ampliar sua faixa de aplicação. 
a)

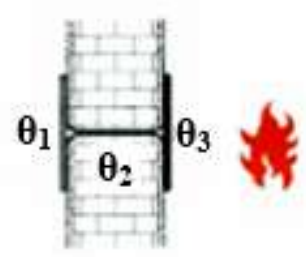

Modelo 1 b)

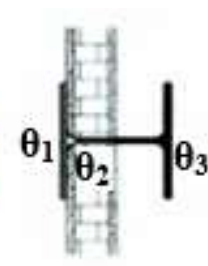

Modelo 2 c)

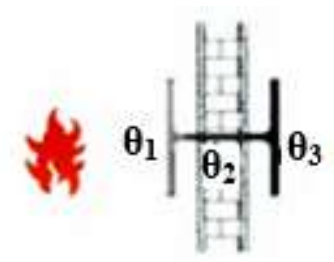

Modelo 3 d)

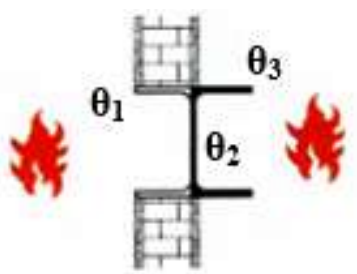

Modelo 4 e)

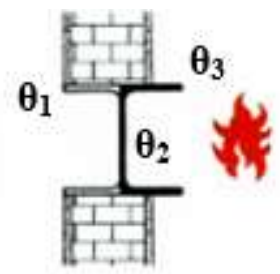

Modelo 5

Figura 2.24 - Zonas de temperatura para os perfis de aço definidas em Correia, Rodrigues e Silva (2011)

Fonte: Correia, Rodrigues e Silva (2011). 


\section{CAPÍTULO 3}

\section{3}

ANÁLISE NUMÉRICA TÉRMICA: MODELOS PROPOSTOS E VALIDAÇÃO

Neste capítulo serão discutidas as estratégias utilizadas para a realização da análise térmica desta pesquisa. Para isso, faz-se necessário retratar, a proposta de construção dos modelos numéricos, mencionando características como o tipo de elemento finito, as condições de contorno e as propriedades dos materiais empregados, assim como as características gerais dos modelos desenvolvidos.

\subsection{DEFINIÇÃO DO CAMPO DE ESTUDO}

Assim como foi discutido no Capítulo 2, o programa experimental de referência, presente em Rocha (2016), contou com um total de doze protótipos considerando pilares de aço e mistos de aço e concreto, inseridos ou não em paredes. Apesar disso, somente seis foram objeto de interesse deste trabalho, cujas características estão descritas na Tabela 3.1.

Os pilares ensaiados, para fins de identificação, apresentavam como referência informações como o tipo de perfil de aço (HEA 100 ou HEA 220), a orientação do perfil em relação à superfície da parede (paralela ou ortogonal) e a espessura do elemento de vedação (7 $\mathrm{cm}$ ou $15 \mathrm{~cm}$ ), conforme Tabela 3.1. Os pilares que receberam aquecimento nas quatro faces assumiram também como referência a palavra ISO.

Tabela 3.1 - Características dos pilares utilizados na modelagem numérica

\begin{tabular}{ccccc}
\hline Número & Referência & Perfil HEA & Orientação da alma & Espessura do bloco \\
\hline 1 & H100-PAR-T7 & 100 & Paralela & $7 \mathrm{~cm}$ \\
2 & H100-ORT-T7 & 100 & Ortogonal & $7 \mathrm{~cm}$ \\
3 & H220-PAR-T15 & 220 & Paralela & $15 \mathrm{~cm}$ \\
4 & H220-ORT-T15 & 220 & Ortogonal & $15 \mathrm{~cm}$ \\
5 & H100-ISO & 100 & - & - \\
6 & H220-ISO & 220 & - & - \\
\hline
\end{tabular}

Fonte: Autor da Pesquisa (2018). 


\subsection{CÓDIGO COMPUTACIONAL}

A análise numérica foi desenvolvida a partir do uso do código computacional ABAQUS versão 6.14, o qual utiliza o Método dos Elementos Finitos para resolução dos problemas de engenharia. Essa ferramenta permite desenvolver modelos térmicos, estruturais à temperatura ambiente e termoestruturais, os quais juntos representam as etapas necessárias para o estudo de elementos estruturais em situação de incêndio.

\subsection{ELEMENTOS FINITOS EMPREGADOS}

Seguindo a "metodologia c" utilizada na modelagem numérica de Rocha (2016) e descrita de forma sucinta no item 2.3.3.1.3 dessa dissertação, os perfis de aço foram modelados com o uso do elemento finito do tipo casca (shell) enquanto que as paredes foram reproduzidas com elementos sólidos. A seguir, são descritas as principais características desses elementos.

O elemento finito sólido adotado possui 4 nós em cada extremidade, resultando em oito nós no total, como representado na Figura 3.1. No caso da análise numérica térmica, a nomenclatura desse elemento é C3D8, definido pelo código computacional ABAQUS.

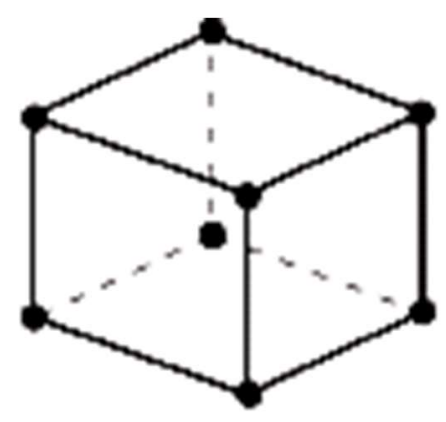

Figura 3.1 - Características do elemento sólido Fonte: ABAQUS (2013).

Em relação ao elemento finito do tipo casca, uma abordagem mais detalhada é realizada devido à complexidade em seu uso. Existem dois tipos de elemento de casca (shell), no caso, o convencional e o contínuo, como pode ser visualizado na Figura 3.2. São diferenciados pela quantidade de nós por elemento, graus de liberdade e forma de representação tridimensional. 


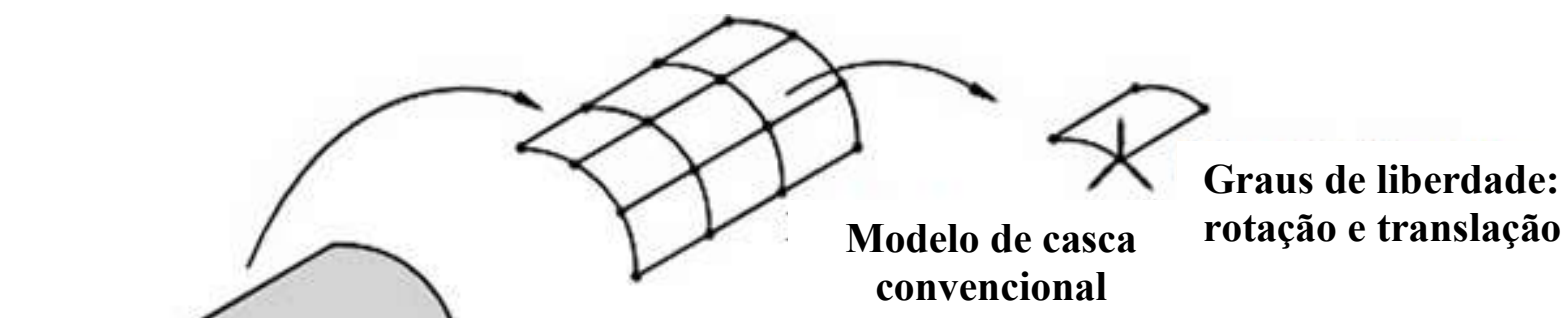

Corpo a ser modelado

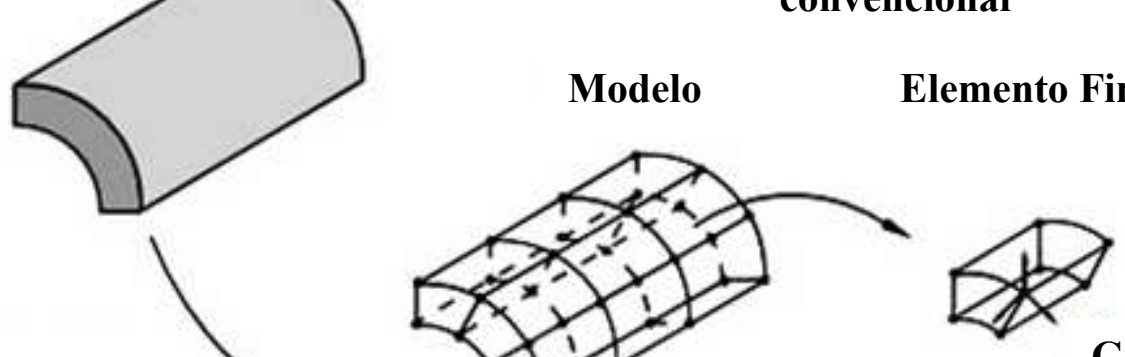

Grau de liberdade: translação

Modelo de casca contínuo

Figura 3.2 - Características do elemento de casca

Fonte: ABAQUS (2013).

Optou-se pelo elemento do tipo convencional, pois possui como graus de liberdade a rotação e o deslocamento nas três direções $\mathrm{X}, \mathrm{Y}$ e $\mathrm{Z}$, aspecto que será útil nos modelos termoestruturais, a serem discutidos no Capítulo 4, para representar as restrições axiais e rotacionais nas extremidades do pilar. Esse elemento finito foi empregado na modelagem dos perfis metálicos e possui como característica principal quatro nós na linha média da espessura da seção transversal. No caso dos modelos numéricos térmicos, a temperatura é o único grau de liberdade desse elemento.

Quando se trata do elemento de casca convencional e tridimensional em uma análise térmica, há a permissão de dividir sua espessura em camadas (layers). Essas camadas são úteis quando a estrutura que se quer representar possui diferentes materiais, ou ainda quando se deseja obter um maior número de informações da temperatura ao longo da espessura. Foram testadas mais de uma camada para o elemento, porém houve um aumento do tempo de processamento.

Além disso, a variação da temperatura com o uso de quantidades diferentes de camada, por exemplo, foi desprezível, o que já era de se esperar uma vez que em estruturas metálicas, de acordo com Dorr (2010), a variação de temperatura ao longo da espessura dos elementos que compõem a seção transversal é insignificante em resposta às reduzidas espessuras das chapas e à elevada condutividade térmica do aço. Por esta razão, adotou-se apenas por uma camada para o elemento. 
Outro parâmetro a ser informado é a quantidade de pontos de integração definidos ao longo da espessura, o que também irá auxiliar na determinação da variação da temperatura. Quanto maior esse valor, mais detalhado será a distribuição de temperatura na espessura. Mais uma vez, foram testados diferentes valores de pontos de integração. A variação foi pequena entre eles, razão pela qual decidiu-se adotar cinco pontos de integração.

Como já foi citado, a representação tridimensional das chapas do perfil de aço ocorre pela linha média quando se utiliza o elemento de casca convencional. Assim, ao inserir alguma propriedade ou quando se deseja obter algum resultado com esse tipo de elemento, necessitase saber qual a face que se quer considerar, a superior ou a inferior. O ABAQUS nomeia essas faces em: superfície positiva (SPOS) e superfície negativa (SNEG). A definição de qual superfície é positiva ou negativa se dá a partir da regra da mão direita, como pode ser vista na Figura 3.3.

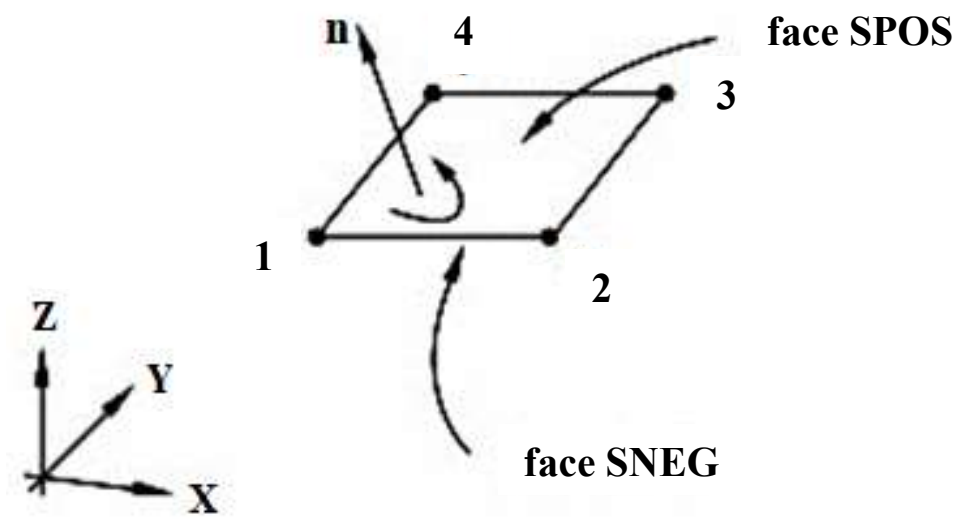

Figura 3.3 - Tipos de superfície para o elemento finito do tipo casca convencional Fonte: ABAQUS (2013).

Diante disso, para determinar a temperatura, nos pontos extremos da espessura, faz-se necessário buscar os resultados correspondentes ao grau de liberdade 11 para a SNEG, bem como o grau de liberdade $10+n s$ para a SPOS, em que $n s$ é o número de pontos de integração, que no caso dessa pesquisa foi 5. Portanto, o SPOS tem como grau de liberdade o número 15, como detalhado na documentação do código computacional.

Na modelagem numérica térmica, a nomenclatura correspondente ao elemento de casca, definido pelo código computacional ABAQUS, é DS4. 


\subsection{ASPECTOS GERAIS DA MODELAGEM NUMÉRICA}

Em todos os modelos propostos não foi reproduzido o sistema de restrição tridimensional dos ensaios, uma vez que a representação simplificada foi suficiente para obtenção de bons resultados. Em relação ao contato entre o aço e a parede, esse foi modelado com o uso da função tie constraint do tipo master-slave surfaces que une os graus de liberdade dos nós das superfícies em contato. Além disso, no processo de geração de malhas foi feito um refinamento que permitiu a adoção de elementos finitos com tamanho de $30 \mathrm{~mm}$ para todos os componentes estruturais (ver Apêndice A).

A modelagem numérica das paredes consistiu em uma macromodelagem, a qual permite considera-las como um bloco maciço de mesma altura do pilar de aço e com comprimento igual a com 0,5 metros, o qual se refere a dimensão lateral que recebeu carga térmica (calor) quando da realização dos experimentos.

A Figura 3.4 mostra a representação dos modelos térmicos para alguns elementos estruturais estudados. Nela estão indicados apenas um pilar para cada orientação da alma em relação à superfície da parede, uma vez que os modelos são construídos de maneira semelhante, alterando apenas as dimensões da seção transversal, a espessura dos elementos de vedação e a presença ou não da alvenaria. Ressalta-se que os modelos são apresentados em perspectiva e na horizontal para melhor visualização.

a)

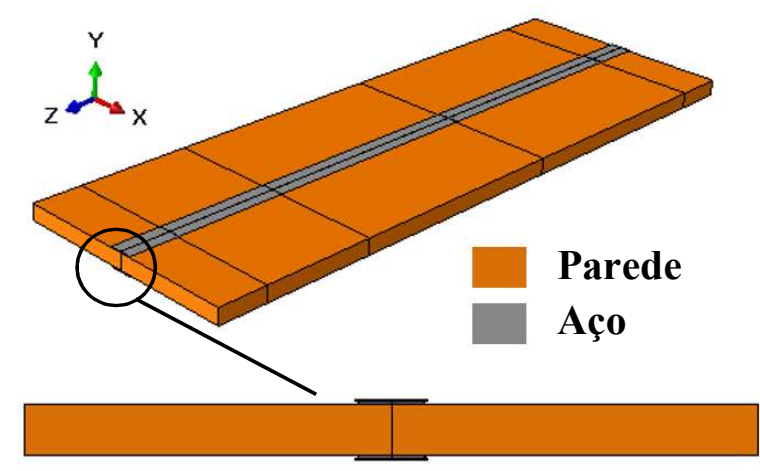

H100 - ORT - T7 b)

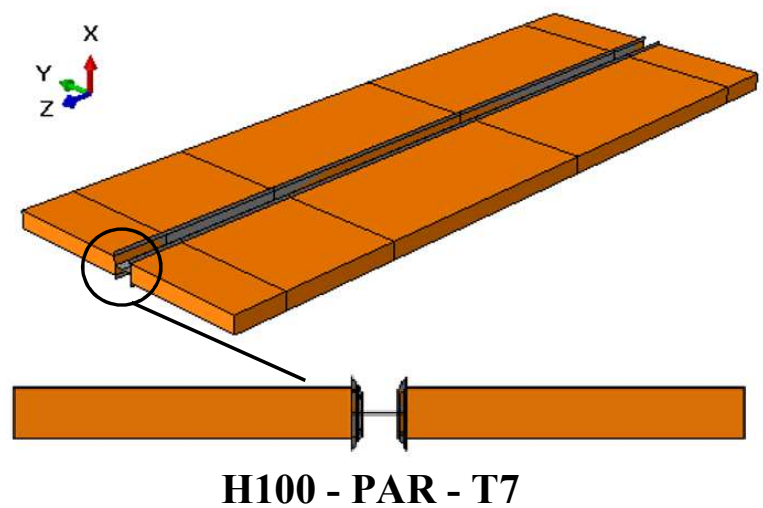

Figura 3.4 - Representação dos modelos térmicos para os pilares: a) H100-ORT-T7; b) H100PAR-T7

Fonte: Autor da Pesquisa (2018). 
Outra consideração importante no processo de modelagem pode ser observada novamente na Figura 3.4 e diz respeito às cinco divisões presentes nos pilares e nas paredes ao longo de sua altura (eixo z). Tais divisões foram empregadas para inserir as curvas de aquecimento dos gases verificadas nas três regiões centrais $(2,5 \mathrm{~m})$ do modelo, sendo que cada uma delas representava a área de influência de cada módulo do forno. Cita-se ainda que essas curvas não coincidiram com aquela referente ao incêndio padrão definida pela ISO 834:1999, uma vez que o uso das paredes como forma de isolamento do forno resultou em uma grande perda de calor do sistema.

A diferença entre as curvas obtidas nos ensaios experimentais e aquela correspondente a ISO 834:1999 está representada na Figura 3.5. Observa-se que a máxima distinção entre elas ocorre nos primeiros minutos, sendo que as diferenças encontradas chegam, em alguns casos, a ser superiores a $300^{\circ} \mathrm{C}$. Isso garante que as curvas experimentais se encontrem fora do limite de tolerância estabelecido pela ISO 834:1999, pois de acordo com a referida norma, não é permitido que haja uma diferença superior a $100{ }^{\circ} \mathrm{C}$ entre as curvas de aquecimento e de incêndio-padrão após 10 min de exposição. Maiores detalhes a respeito da diferença entre as curvas experimentais e normativa nos primeiros minutos da ação térmica podem ser vistas no Apêndice $A$.

a)

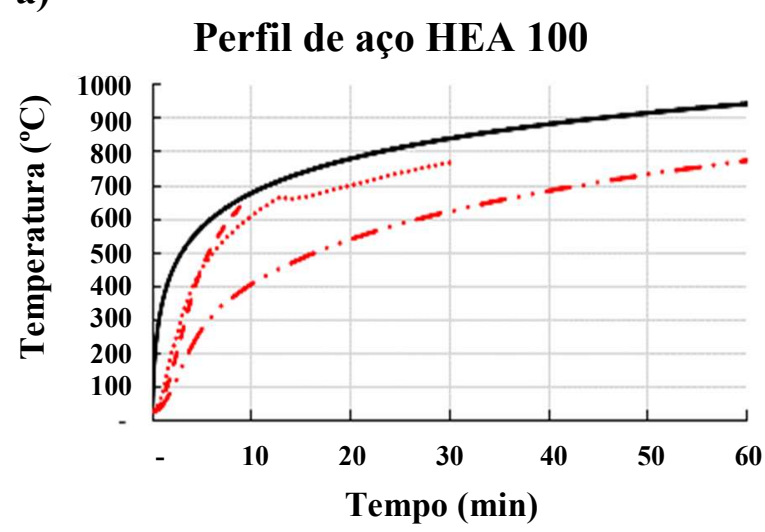

ISO 834:1999

- - - Curva de Aquecimento - H100-ISO

- $\cdots$ Curva de Aquecimento - H100-ORT-T7

Curva de Aquecimento - H100-PAR-T7 b)

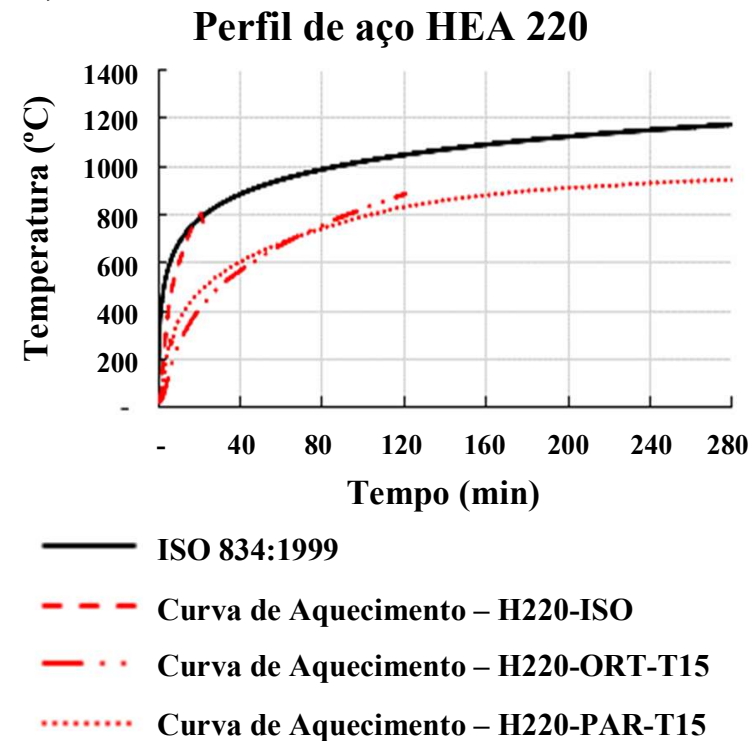

Figura 3.5 - Comparação entre as curvas experimentais e a curva de incêndio-padrão ISO 834:1999 para os pilares estudados

Fonte: Autor da Pesquisa (2018). 
Além disso, destaca-se que apesar de, durante os ensaios experimentais, ter sido aplicada uma camada de argamassa do lado da parede não exposta ao fogo, no modelo numérico definitivo essa mesma não foi considerada. Tal abordagem foi escolhida tendo em vista a ocorrência de aumento do custo computacional durante o processamento sem nenhum ganho significativo em termos de precisão dos resultados, como pode ser constatado também no Apêndice A.

\subsection{CONDIÇÕES DE CONTORNO E PROPRIEDADE DOS MATERIAIS}

O ABAQUS adota o princípio da conservação da energia para realização de suas análises térmicas. Com relação à forma de análise, adotou-se, nessa pesquisa, aquela do tipo transiente, em que as propriedades térmicas dos materiais e a distribuição da temperatura variam com o tempo. As condições de contorno necessárias para realização de uma análise térmica se referem aos três mecanismos de transferência de calor (convecção, radiação e condução) os quais são discutidos com maiores detalhes no Anexo $\boldsymbol{A}$.

Na modelagem numérica, para consideração da convecção e da radiação inserem-se as grandezas coeficiente de convecção $\left(\alpha_{c}\right)$ para o primeiro mecanismo, bem como a emissividade do material $(\varepsilon)$ e a constante Stefan-Boltzmann $\left(5,67 \times 10^{-8} \mathrm{~W} / \mathrm{m}^{2} \mathrm{~K}^{4}\right)$ para o segundo. A consideração da condução do calor se dá a partir da inclusão, no modelo numérico, de parâmetros relativos ao próprio material da seção, como a densidade, condutividade térmica e calor específico.

No caso dos pilares inseridos em paredes, deve-se considerar os lados exposto e não exposto ao fogo na construção do modelo térmico. O Eurocode 1 Parte 1-2 (2002) no item 3.1 (5) traz, para esse tipo de análise, duas opções para levar em conta os fenômenos de transferência de calor para o lado não exposto. Pode-se adotar um coeficiente de convecção equivalente a $9 \mathrm{~W} / \mathrm{m}^{2 \circ} \mathrm{C}$, para representar os efeitos de convecção e radiação juntos, ou se admite esses fenômenos separadamente, de modo que o coeficiente de convecção seja igual a $4 \mathrm{~W} / \mathrm{m}^{2 \circ} \mathrm{C}$, com o valor da emissividade dependente do material empregado. A norma brasileira ABNT NBR 14323:2013 não faz referência a esse assunto. Para a face exposta, tanto a norma brasileira citada anteriormente quanto a norma europeia (Eurocode 3 Parte 1-2, 2005) consideram o coeficiente de convecção igual a $25 \mathrm{~W} / \mathrm{m}^{2 \circ} \mathrm{C}$ e emissividade de 0,7 para a superfície do aço. 
Apesar disso, durante o processamento dos modelos numéricos para fins de calibração e validação, os mesmos não apresentaram resultados satisfatórios utilizando as sugestões normatizadas. Por essa razão, apenas com vistas a uma análise de sensibilidade dos parâmetros mencionados foram determinados aqueles que melhor representavam o ensaio experimental. A Tabela 3.2 apresenta os parâmetros testados na calibração do modelo numérico, com destaque para aqueles empregados na representação final.

Tabela 3.2 - Parâmetros testados para calibração do modelo numérico térmico

\begin{tabular}{|c|c|c|c|c|}
\hline \multirow[b]{2}{*}{ Superfície } & \multicolumn{2}{|c|}{ Lado exposto } & \multicolumn{2}{|c|}{ Lado não exposto } \\
\hline & Emissividade & $\begin{array}{c}\text { Coeficiente de } \\
\text { Convecção } \\
\text { W.m }{ }^{2} /{ }^{\circ} \mathrm{C}\end{array}$ & Emissividade & $\begin{array}{c}\text { Coeficiente de } \\
\text { Convecção } \\
\text { W.m }{ }^{2}{ }^{\circ} \mathbf{C}\end{array}$ \\
\hline Aço & $0.6,0.7, \underline{\mathbf{0 . 8}}, 0.9$ & $\underline{25}$ & $\underline{\mathbf{0 . 6}}, 0.7,0.8,0.9$ & $\underline{4}, 9$ \\
\hline Parede & $\underline{\mathbf{0 . 7}}, 0.8$ & $\underline{25}$ & $\underline{\mathbf{0 . 7}}, 0.8$ & $\underline{4}, 9$ \\
\hline
\end{tabular}

Fonte: Autor da Pesquisa (2018).

Vale ressaltar que a mudança dos valores de emissividade é justificável, pois a situação de aquecimento que se obtém em um ensaio realizado em forno elétrico é diferente daquela que é verificada em um incêndio real. Em relação ao coeficiente de convecção, o valor fornecido pelas normas se mostrou razoável.

Sobre as propriedades térmicas utilizadas nessa pesquisa, para o aço foram empregadas aquelas descritas pela ABNT NBR 14323:2013 (ver Anexo B) enquanto que para as paredes, foram empregadas as mesmas relatadas em Rocha (2016) e mencionadas no item 2.3.3.1.3.

Finaliza-se esse subitem abordando o modo em que foi realizado a validação da modelagem térmica. Ela consistiu em identificar se as temperaturas obtidas numericamente apresentavam boa concordância com aquelas medidas nos ensaios experimentais. Os resultados da validação serão apresentados na seção 3.7 .

\subsection{ANÁLISE DA EFICIÊNCIA DO ELEMENTO FINITO DE CASCA EM CONTEXTO TÉRMICO}

A primeira abordagem numérica realizada em contexto de análise térmica consistiu em comparar os resultados descritos em Rocha (2016), nos quais foram empregados apenas 
elementos finitos do tipo sólido para representação de pilares de aço isolados e inseridos em paredes, com os resultados obtidos na presente pesquisa, em que foram utilizados elementos finitos do tipo casca, ou shell. Para que houvesse coerência nas comparações foram adotados os mesmos parâmetros de modelagem do estudo de referência (condições de contorno e propriedades dos materiais), os quais já foram mencionados no item 2.3.3.1.3.

As Figuras 3.6, 3.7 e 3.8 ilustram a comparação dos resultados obtidos por meio dos modelos numéricos que utilizaram elementos de casca com aqueles que empregaram elementos sólidos. É importante destacar que esse estudo será apresentado apenas para os pilares constituídos pelo perfil metálico HEA 220, uma vez que em Rocha (2016) não foram realizadas modelagens numéricas para os pilares formados pelo perfil de aço HEA 100. Os termopares das seções transversais não mostrados nos gráficos são aqueles que apresentaram danos no ensaio e, portanto, não foi possível obter a medição.

No caso do pilar metálico isolado, conforme Figura 3.6, apenas dois pontos de leitura foram representados, sendo um para a alma do perfil (termopar T3.1) e outro para a mesa superior (termopar T3.3). Como a temperatura na seção é praticamente uniforme, há apenas uma pequena diferença dessa grandeza entre alma e mesa, sendo a alma com temperaturas ligeiramente superiores devido à maior esbeltez e maior área de contato com o calor.
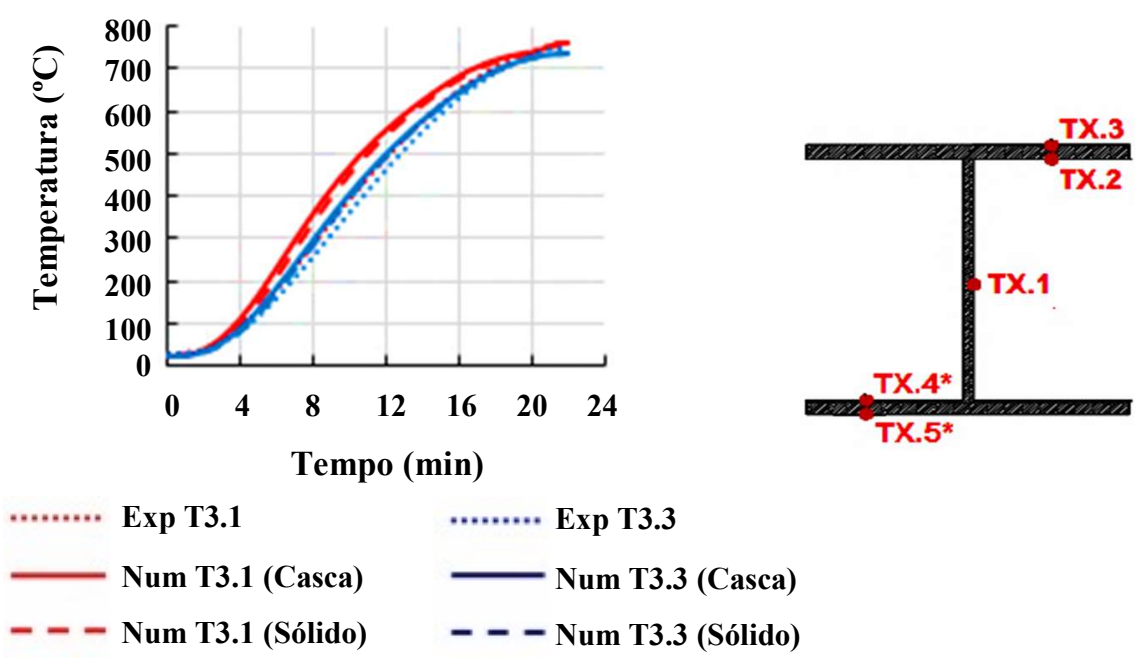

Figura 3.6 - Comparação entre os resultados dos modelos térmicos constituídos por elementos de casca e sólido para o pilar H220-ISO

Fonte: Autor da Pesquisa (2018).

Em relação aos pilares inseridos em paredes, as Figuras 3.7 (pilar H220-ORT-T15) e 3.8 (pilar H220-PAR-T15) trazem as curvas que representam o estudo comparativo realizado. 
a)

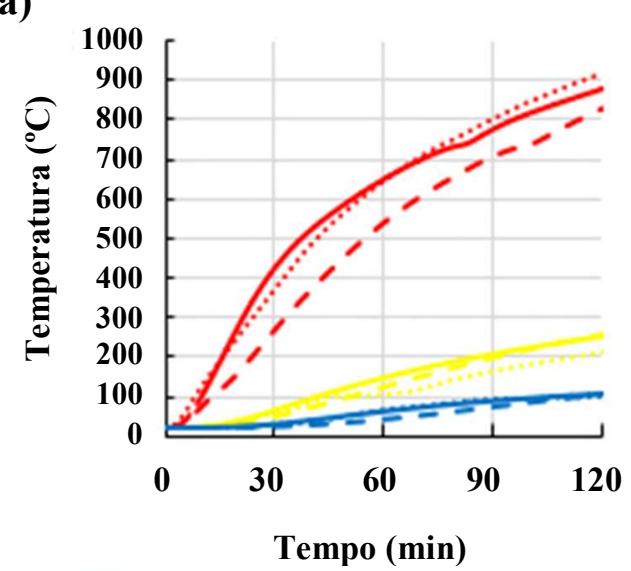

b)

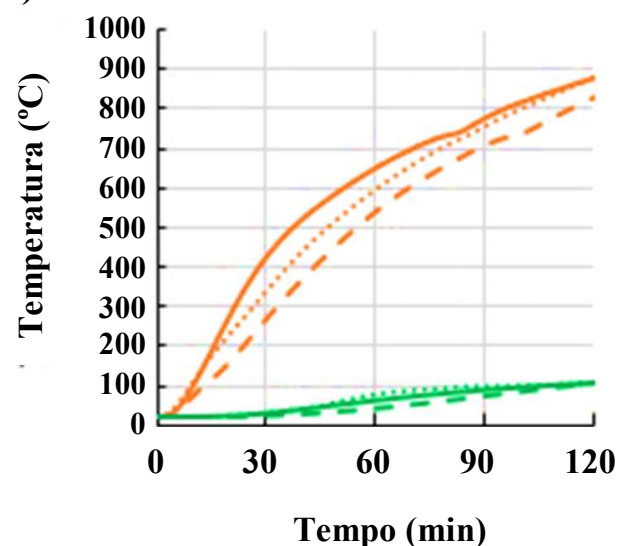

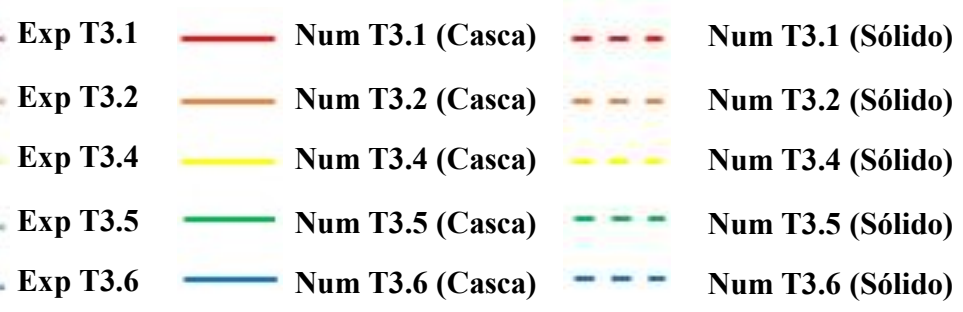

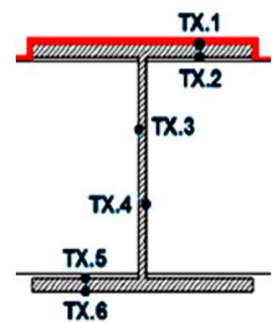

Figura 3.7 - Comparação entre os resultados dos modelos térmicos constituídos por elementos de casca e sólido para o pilar H220-ORT-T15

Fonte: Autor da Pesquisa (2018).

a)

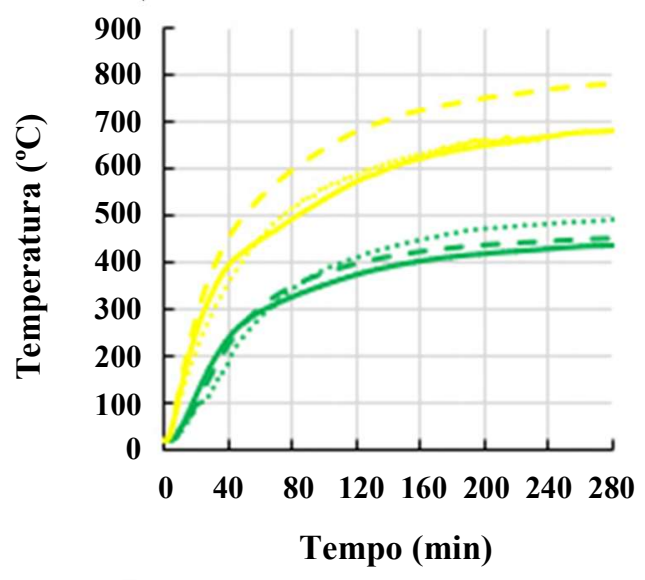

b)

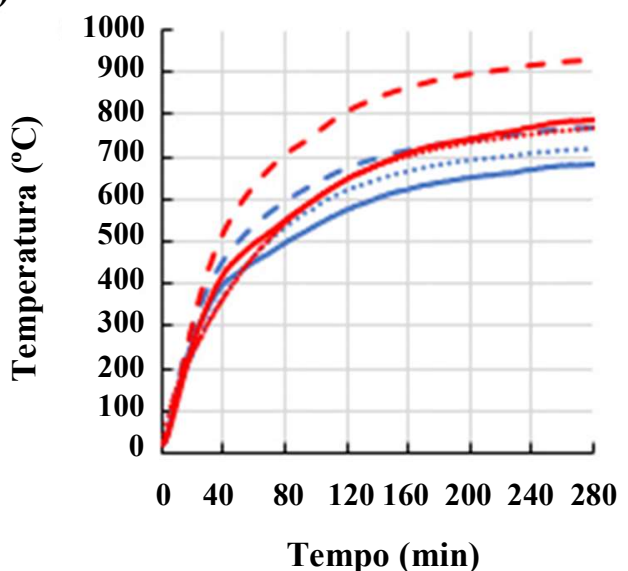

Exp T3.1 — Num T3.1 (Casca) - - - Num T3.1 (Sólido)

$\operatorname{Exp}$ T3.3 Num T3.3 (Casca) -- Num T3.3 (Sólido)

Exp T3.4 - Num T3.4 (Casca)

Exp T3.5 Num T3.5 (Casca) - - N N Num T3.5 (Sólido)

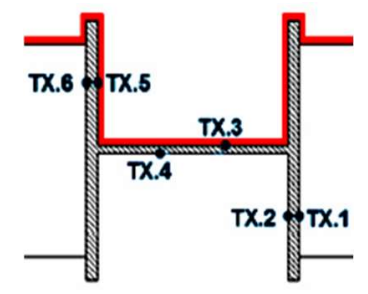

Figura 3.8 - Comparação entre os resultados dos modelos térmicos constituídos por elementos de casca e sólido para o pilar H220-PAR-T15

Fonte: Autor da Pesquisa (2018). 
A análise gráfica por meio das Figuras 3.6, 3.7 e 3.8 permite concluir que o uso do elemento finito do tipo casca para representar o perfil de aço, em substituição ao elemento finito do tipo sólido, resultou em melhor resposta dos modelos numéricos, pois se nota maior aproximação da curva numérica "Tempo versus Temperatura" quando comparadas àquelas obtidas nos ensaios experimentais para a grande maioria dos casos. Diante do apresentado, comprova-se, como era de se esperar, a eficiência do elemento shell na representação dos pilares em análise na presente pesquisa.

\subsection{VALIDAÇÃO DOS MODELOS TÉRMICOS PROPOSTOS}

A partir da avaliação da eficiência do elemento de casca para representação do perfil de aço, descrito na seção anterior, decidiu-se verificar se os valores de emissividade e coeficiente de convecção adotados em Rocha (2016) eram, de fato, os mais adequados para melhor reproduzir os ensaios experimentais de todos os elementos estruturais.

Para tanto, foram desenvolvidas análises de sensibilidade a partir da variação desses parâmetros, como relatado no item 3.5, concluindo-se que os valores mais representativos são aqueles apresentados na Tabela 3.3.

Tabela 3.3 - Parâmetros adotados para calibração do modelo numérico térmico

\begin{tabular}{|c|c|c|c|c|}
\hline \multirow{4}{*}{ Superfície } & \multicolumn{2}{|c|}{ Lado exposto } & \multicolumn{2}{|c|}{ Lado não exposto } \\
\hline & & Coeficiente de & & Coeficiente de \\
\hline & Emissividade & Convecção & Emissividade & Convecção \\
\hline & & $\mathbf{W} \cdot \mathrm{m}^{2} /{ }^{\circ} \mathrm{C}$ & & $\mathbf{W} \cdot \mathbf{m}^{2} /{ }^{\circ} \mathrm{C}$ \\
\hline Aço & 0,8 & 25 & 0,6 & 4 \\
\hline Parede & 0,7 & 25 & 0,7 & 4 \\
\hline
\end{tabular}

Fonte: Autor da Pesquisa (2018).

Seguindo a estratégia numérica já mencionada ao longo desse capítulo para a análise térmica, associada aos procedimentos do programa experimental de referência citados no Capítulo 2, foi possível desenvolver seis modelos numéricos térmicos correspondentes aos pilares estudados. As Figuras 3.9 a 3.13 apresentam a validação da proposta de modelagem a partir da comparação entre as curvas de evolução de temperatura numéricas e experimentais na seção localizada na meia altura do pilar metálico (Seção 3). 
a)

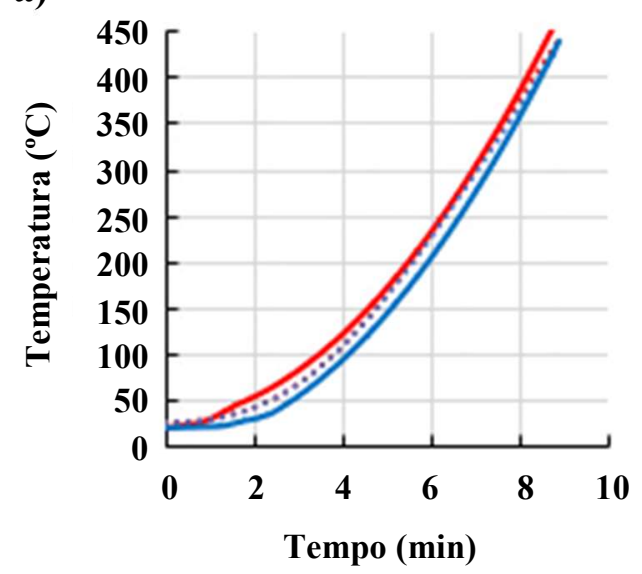

Exp T3.1

Num T3.1

$\operatorname{Exp}$ T3.2

Num T3.2 b)
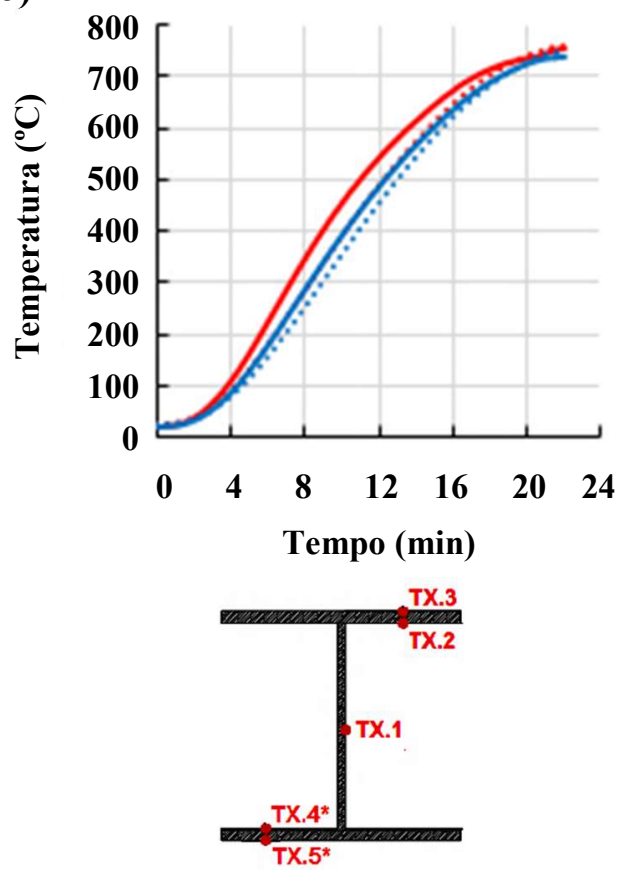

Figura 3.9 - Validação dos modelos numéricos térmicos para os pilares isolados: a) H100ISO; b) H220-ISO

Fonte: Autor da Pesquisa (2018).

a)

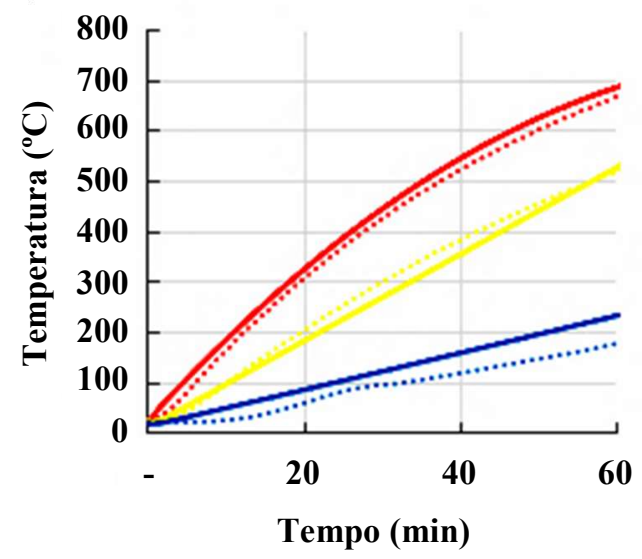

b)

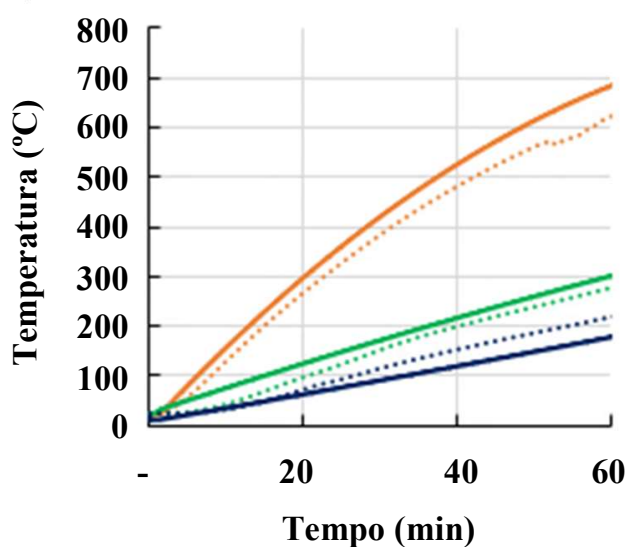

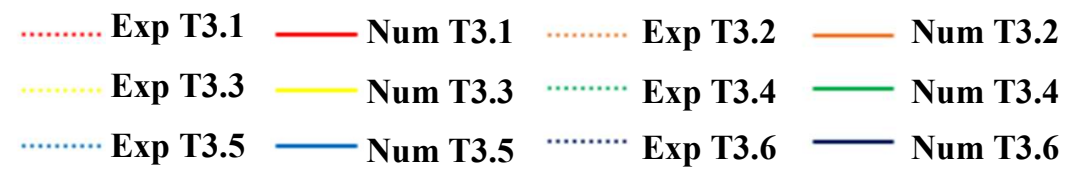

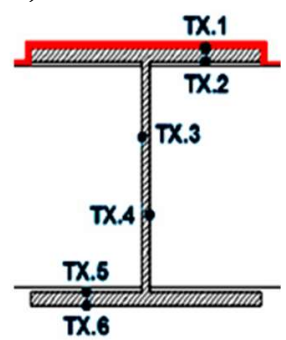

Figura 3.10 - Validação dos modelos numéricos térmicos para o pilar H100-ORT-T7 Fonte: Autor da Pesquisa (2018). 
a)

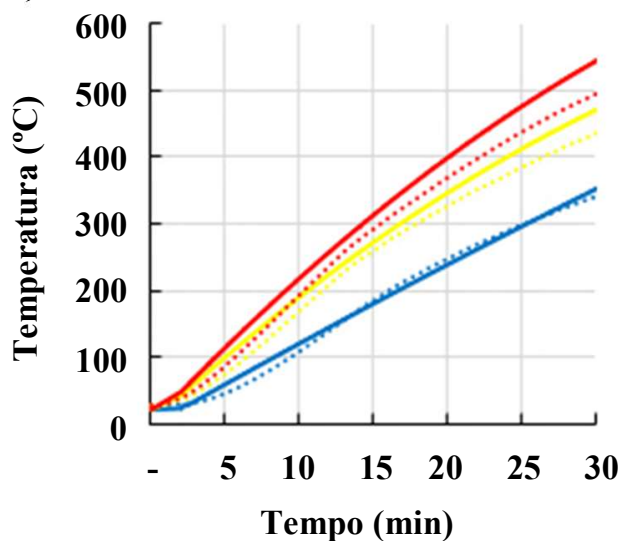

b)

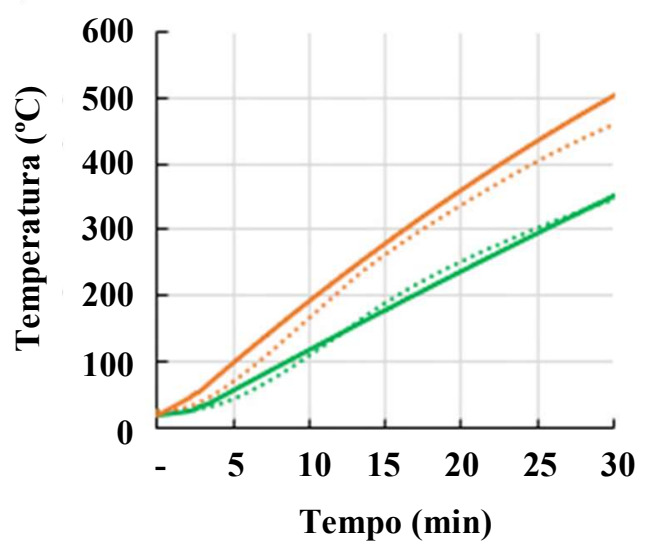

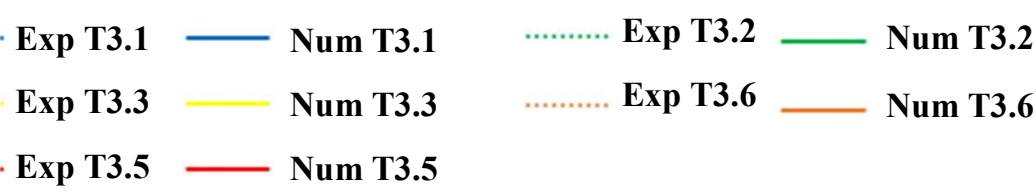

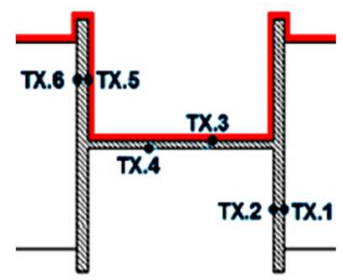

Figura 3.11 - Validação dos modelos numéricos térmicos para o pilar H100-PAR-T7

Fonte: Autor da Pesquisa (2018).

a)

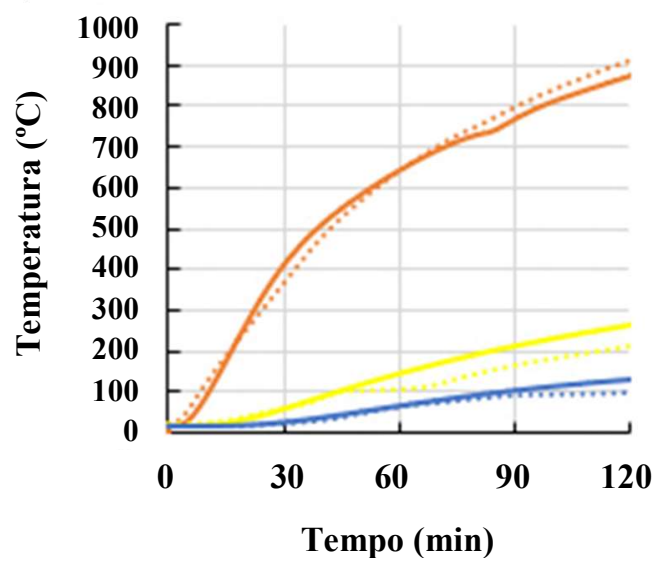

b)

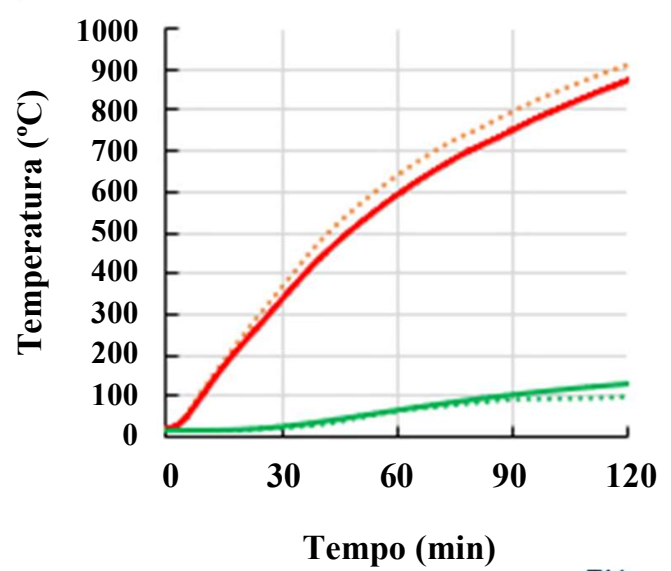

$\begin{array}{rr}\text { Exp T3.1 } & \text { Num T3.1 } \\ \text { Exp T3.4 } & \text { Num T3.4 } \\ \text { Exp T3.5 } & \text { Num T3.5 }\end{array}$

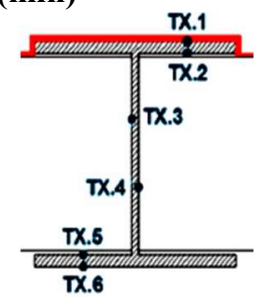

Figura 3.12 - Validação dos modelos numéricos térmicos para o pilar H220-ORT-T15

Fonte: Autor da Pesquisa (2018). 


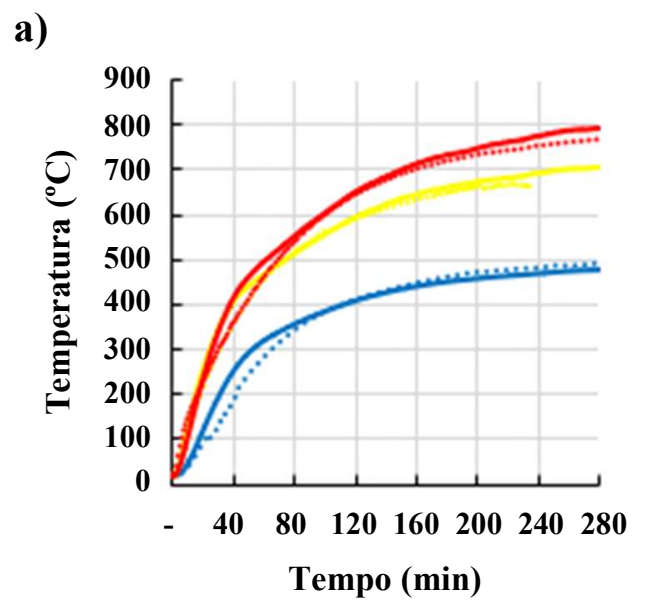

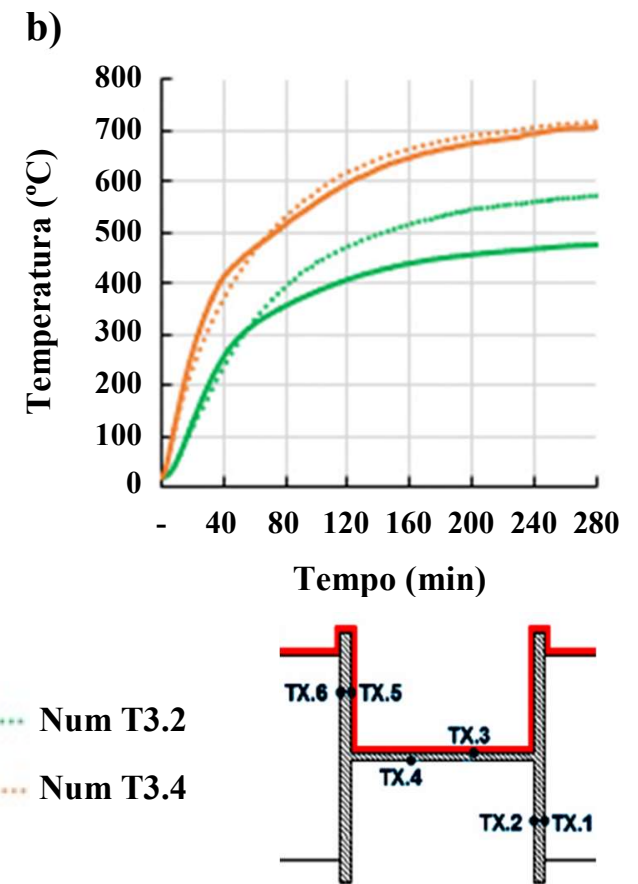

b)

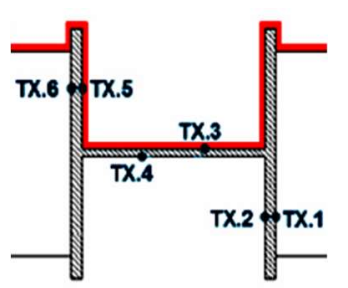

Figura 3.13 - Validação dos modelos numéricos térmicos para o pilar H220-PAR-T15

Fonte: Autor da Pesquisa (2018).

Como observado por meio da análise das Figuras 3.9 a 3.13, as temperaturas obtidas numericamente, para a grande maioria dos casos analisados, se encontram próximas daquelas identificadas experimentalmente, o que permite considerar a consistência dos modelos numéricos térmicos propostos. Ressalta-se ainda que os parâmetros apresentados na Tabela 3.3 promoveram uma melhora na resposta dos resultados numéricos quando comparados àqueles mostrados nas Figuras 3.6 a 3.8.

A partir dos modelos térmicos validados, no Capítulo 4, a ser descrito adiante, será desenvolvido um conjunto de análises numéricas termoestruturais na tentativa de reprodução dos ensaios experimentais de referência, em contexto da evolução das forças de restrição e dos deslocamentos axiais. Para isso, o campo das temperaturas aqui proposto é transferido como carregamento para o modelo estrutural dos pilares estudados. Maiores informações são encontradas a seguir. 


\section{CAPÍTULO 4}

\section{ANÁLISE NUMÉRICA TERMOESTRUTURAL: ESTRATÉGIAS DE MODELAGEM, MODELOS PROPOSTOS E VALIDAÇÃO}

Neste capítulo serão discutidas as estratégias utilizadas para construção dos modelos numéricos termoestruturais utilizados nessa pesquisa. Destaca-se ainda que, ao longo do corpo do texto, serão feitas considerações a respeito da modelagem estrutural à temperatura ambiente que envolve a inserção das imperfeições geométricas iniciais nos elementos em análise, no caso, os pilares. Além disso, serão retratados todos os testes realizados para calibração e validação dos modelos propostos.

\subsection{ELEMENTOS FINITOS UTILIZADOS}

A modelagem numérica foi desenvolvida utilizando os mesmos tipos de elementos finitos em todas as análises (térmica, estrutural e termoestrutural), alterando somente a identificação do elemento finito pelo ABAQUS, como pode ser vista na Tabela 4.1.

Tabela 4.1 - Nomenclatura dos elementos finitos utilizados na modelagem numérica

\begin{tabular}{cccc}
\hline $\begin{array}{c}\text { Componente } \\
\text { Estrutural }\end{array}$ & $\begin{array}{c}\text { Elemento Finito: } \\
\text { Modelo Térmico }\end{array}$ & $\begin{array}{c}\text { Elemento Finito: } \\
\text { Modelo Estrutural }\end{array}$ & $\begin{array}{c}\text { Elemento Finito: Modelo } \\
\text { Termoestrutural }\end{array}$ \\
\hline $\begin{array}{c}\text { Perfil de aço } \\
\text { Parede }\end{array}$ & DS4 & S4R & S4R \\
C3D8 & C3D8R & C3D8R \\
\hline
\end{tabular}

Fonte: Autor da Pesquisa (2018).

\subsection{ASPECTOS GERAIS SOBRE A MODELAGEM TERMOESTRUTURAL}

No âmbito da análise termoestrutural, que envolve fenômenos térmicos e estruturais em conjunto, foi adotado o método sequencial para realização da modelagem numérica. Esse método consiste em desenvolver modelos térmico e termoestrutural inicialmente independentes e, posteriormente, conectá-los por meio da transferência do campo térmico como carregamento 
para o modelo estrutural. Para facilitar o processamento de dados, utilizou-se a mesma malha, ou seja, a quantidade e a posição dos nós e dos elementos foram iguais em ambos os modelos.

De maneira geral, a análise numérica completa consiste em três etapas. A primeira, chamada de análise térmica, é responsável por determinar o campo de temperaturas obtido no ensaio experimental de referência em todo o tempo de aquecimento (ver Capítulo 3). A segunda fundamenta-se na inserção das imperfeições geométricas iniciais como um deslocamento no meio do vão do pilar. E na última etapa, denominada análise termoestrutural, o elemento estrutural imperfeito é carregado e recebe gradualmente o campo térmico previamente determinado visando então representar o comportamento do pilar em situação de incêndio.

No presente trabalho, quando for citado o termo "modelagem estrutural", esse mesmo termo deverá ser entendido como a etapa em que ocorre o carregamento do pilar à temperatura ambiente, uma vez que esse elemento não foi modelado para obtenção de sua capacidade de carga, pois no estudo de referência não foram realizados experimentos com esse propósito. Nesse caso, a força aplicada correspondeu aquela empregada no ensaio experimental.

$\mathrm{Na}$ etapa de carregamento, o pilar foi modelado com imperfeições geométricas iniciais, as quais foram inseridas como deslocamento lateral no meio do pilar em todos os nós localizados nessa posição. Para determinação da amplitude desse parâmetro, foram realizadas análises de sensibilidade testando, enquanto valores, L/1500, L/1000 e L/500 na direção exposta e não exposta ao fogo para os casos de pilares inseridos em paredes, bem como nos eixos fraco e forte para os casos de pilares isolados. Nos valores citados, vale destacar que L é o termo que corresponde ao comprimento do pilar.

Em relação às propriedades mecânicas empregadas para construção dos modelos, o aço seguiu o critério de plastificação de von Mises em conjunto com os diagramas tensão versus deformação em função da temperatura, apresentados pela ABNT NBR 14323:2013. Já para as propriedades mecânicas das paredes, foi considerado somente o módulo de elasticidade com o valor igual a 30.672 MPa como recomendado em Rocha (2016), sem redução pela ação térmica, uma vez que no meio científico há uma carência de estudos acerca do comportamento desse elemento de vedação em situação de incêndio.

No que diz respeito à validação do modelo termoestrutural, foram avaliados o deslocamento axial e a força axial relativa como parâmetros de comparação entre resultados numérico e experimental. A força axial relativa foi obtida por meio da relação entre a força axial em determinado instante do aquecimento por aquela medida antes de iniciar o aquecimento. O uso da força, em termos relativos, facilita a discussão dos resultados, uma vez que o carregamento aplicado em cada um dos pilares foi diferente. 
Após o estabelecimento das características e propriedades gerais dos modelos numéricos termoestruturais propostos, parte-se então para a descrição das estratégias empregadas.

\subsubsection{Estratégia numérica I}

A Estratégia Numérica I consistiu em inserir uma mola com rigidez axial e rotacional na extremidade superior do elemento estrutural de modo a simular a estrutura tridimensional de restrição do ensaio experimental como indicado na Figura 4.1, para o pilar isolado H220-ISO, e na Figura 4.2, para o pilar inserido em paredes H100-ORT-T7.

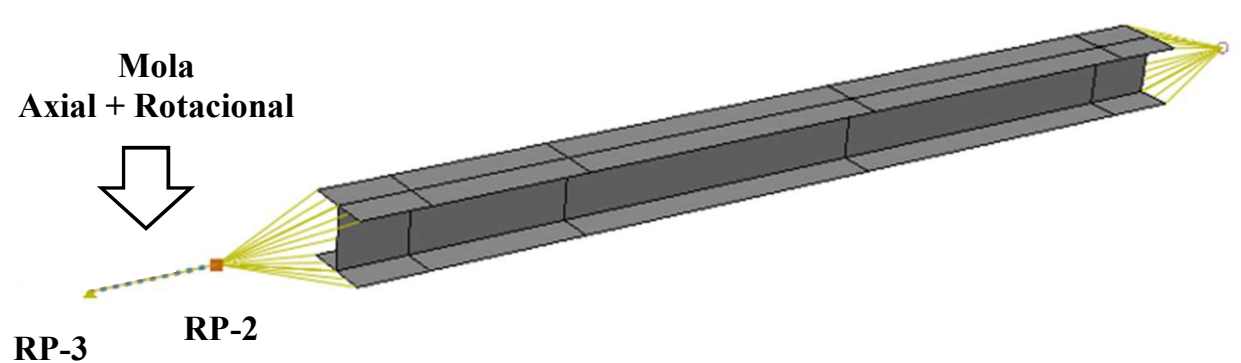

RP-1

Figura 4.1 - Representação do modelo numérico baseado na estratégia numérica I para o pilar isolado H220-ISO

Fonte: Autor da Pesquisa (2018).

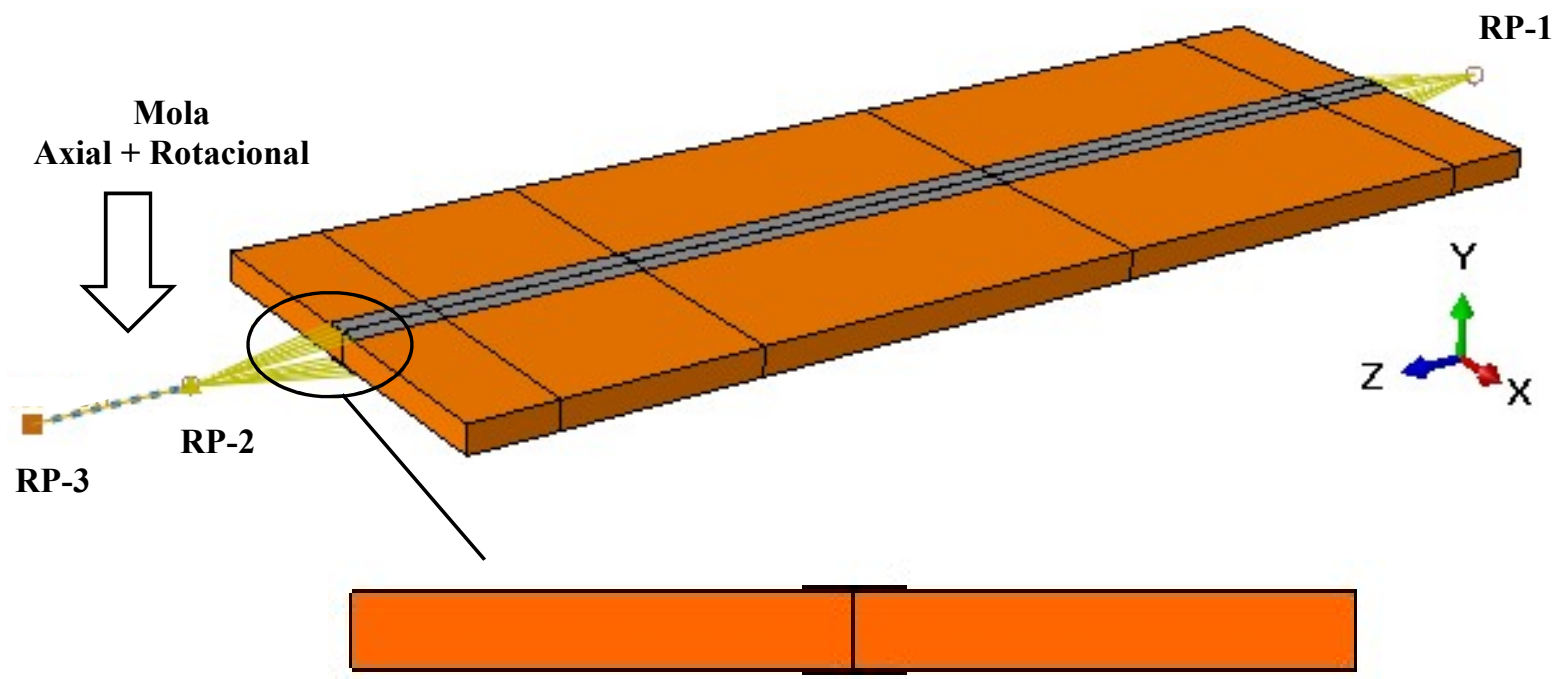

Figura 4.2 - Representação do modelo numérico baseado na estratégia numérica I para o pilar H100-ORT-T7

Fonte: Autor da Pesquisa (2018). 
Como mencionado em Neves (1995), a reação da estrutura circundante ao aquecimento do pilar pode ser comparada a ação de uma mola, cuja rigidez depende das características físicas e geométricas da própria estrutura que envolve o elemento ensaiado. Dessa maneira, a mola foi construída de modo a apresentar as rigidezes axial e rotacional da estrutura de restrição, sendo os valores para essas grandezas definidos a partir de calibrações numéricas.

Para isso, como pode ser vista ainda nas Figuras 4.1 e 4.2, foram criados nós de referência nas extremidades dos pilares para os quais foram acoplados os graus de liberdade das partes superior e inferior do elemento estrutural. Na parte inferior foi criado o nó RP-1 e na parte superior foram criados os nós RP-2 e RP-3 que receberam graus de liberdade do topo do pilar e representaram o comportamento de uma mola.

O desenvolvimento do modelo termoestrutural foi realizado em 2 passos, ou 2 steps, forma na qual o ABAQUS atribui cada um dos passos de uma análise. O primeiro step consistiu na etapa de carregamento do pilar imperfeito (considerando sua imperfeição geométrica inicial) a partir da inserção da força axial no nó RP-2. Além disso, como condição de contorno, adotouse engaste para o nó RP-1, bem como foram fixados os deslocamentos na direção X e Y e a rotação em torno do eixo $\mathrm{Z}$ para o nó RP-2, de modo que os demais graus de liberdades resultassem livres para se manifestar. No nó RP-3 não foi aplicada restrição alguma, pois nessa etapa não houve a participação da mola.

O segundo step representou a fase de aquecimento do elemento estrutural e se baseou na transferência do campo térmico para o pilar carregado de modo que fossem calculados novos deslocamentos por meio da consideração da expansão térmica e da degradação das propriedades dos materiais, agora em função do tempo de aquecimento. Portanto, as temperaturas do modelo numérico previamente definidas foram transmitidas para essa etapa, de modo a simular o aquecimento da peça estrutural. Além disso, foi inserida a participação da mola na extremidade superior como condição de contorno do nó RP-3. Assim, ela atuou restringindo as deformações longitudinais (eixo $\mathrm{Z}$ ) e as rotações em torno do eixo $\mathrm{X}$ e $\mathrm{Y}$, as quais, no passo anterior, estavam livres para se deformar.

Os modelos numéricos foram processados até o instante correspondente à duração dos ensaios experimentais de cada pilar. Vale destacar que os níveis de força e de deslocamento axiais foram medidos pelos nós de referência RP-1 e RP-2, respectivamente.

Apesar da estratégia numérica anterior ter se mostrado satisfatória, principalmente para os pilares isolados, ela não representou adequadamente os pilares inseridos em paredes. Tendo em vista o exposto associado aos resultados descritos em Rocha (2016) sobre seus experimentos (ver item 2.1.3), chegou-se à conclusão que o elemento de compartimentação apresentava 
influência no comportamento termoestrutural dos pilares no que diz respeito à rigidez total da estrutura circundante o que ocasionou o surgimento de uma nova estratégia.

\subsubsection{Estratégia numérica II}

A partir dos resultados alcançados, fez-se necessário inserir molas na direção axial das paredes com o intuito de controlar seu deslocamento nessa direção como pode ser vista na Figura 4.3.

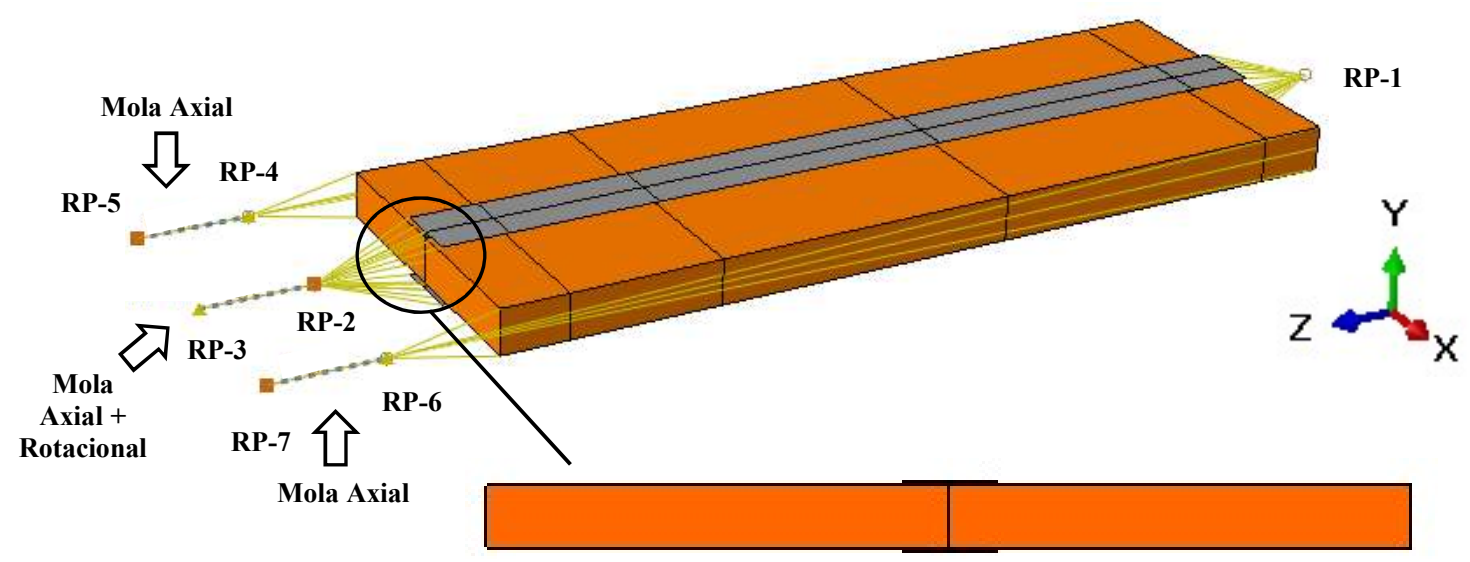

Figura 4.3 - Representação do modelo numérico baseado na estratégia numérica II para o pilar H220-PAR-T15

Fonte: Autor da Pesquisa (2018).

A rigidez dessas molas foi determinada a partir de calibrações numéricas. É importante destacar que as condições de contorno dos nós de referência dessas novas molas, para cada step, foram idênticas àquelas adotadas na mola que representava o pórtico de restrição. Maiores informações a respeito serão abordadas no que segue.

\subsection{VALIDAÇÃO DA MODELAGEM TERMOESTRUTURAL}

A apresentação dos resultados acerca da validação dos modelos numéricos termoestruturais será dividida em função da estratégia de modelagem adotada e do tipo de pilar analisado. Ressalta-se ainda que essa validação foi realizada basicamente por meio do parâmetro força axial relativa. Considerações a respeito do deslocamento axial serão descritas ao final desse mesmo capítulo. 


\subsubsection{Utilização da estratégia numérica I}

Como já mencionado, a estratégica numérica I não considera a influência da parede no comportamento termoestrutural do pilar, de modo que a mesma atue somente como elemento de compartimentação no caso dos pilares em contato com alvenaria.

$\mathrm{Na}$ etapa termoestrutural referente a essa metodologia, a modelagem consistiu em inserir a intensidade da rigidez axial e da rigidez rotacional da mola localizada no topo do elemento estrutural (Figuras 4.1 e 4.2), ambas responsáveis por simular nos modelos numéricos o sistema de restrição tridimensional utilizado nos experimentos. Como discutido no Capítulo 2, as intensidades das rigidezes desse sistema não foram mensuradas experimentalmente o que acabou por impor a necessidade de calibração dessa mola.

A calibração numérica referida foi feita somente para os pilares isolados. A descrição do estudo realizado para obtenção dos valores das rigidezes axial e rotacional se encontra detalhada no Apêndice B. A partir dessa abordagem, definiu-se que o valor correspondente à rigidez axial e à rigidez rotacional resultam iguais a $30 \mathrm{kN} / \mathrm{mm}$ e $5000 \mathrm{kN} . \mathrm{m} / \mathrm{rad}$, respectivamente. Tais valores serão utilizados em todos os modelos dessa pesquisa, não apenas para os pilares isolados, em razão de os ensaios experimentais terem sido desenvolvidos em um único sistema de restrição. A seguir, estão descritos os resultados obtidos para cada tipo de pilar de acordo com essa metodologia.

\subsubsection{Pilares isolados}

Definidas as restrições impostas, bem como as respectivas intensidades, passou-se a considerar a validação dos modelos termoestruturais, inicialmente para os casos de pilares isolados, os quais foram analisados numericamente levando em consideração a imperfeição geométrica inicial com amplitude igual a L/500 na direção do eixo de menor inércia. Os resultados estão representados na Figura 4.4.

Testes foram realizados com outros valores de amplitudes, no caso, L/1000 e L/1500, porém, como pode ser observado no Apêndice B do presente texto, esse parâmetro pouco afetou o comportamento termoestrutural dos pilares isolados. Por essa razão, foi adotada a amplitude $\mathrm{L} / 500$, pois foi a que melhor representou os pilares inseridos em paredes, como será visualizado posteriormente. 
a)

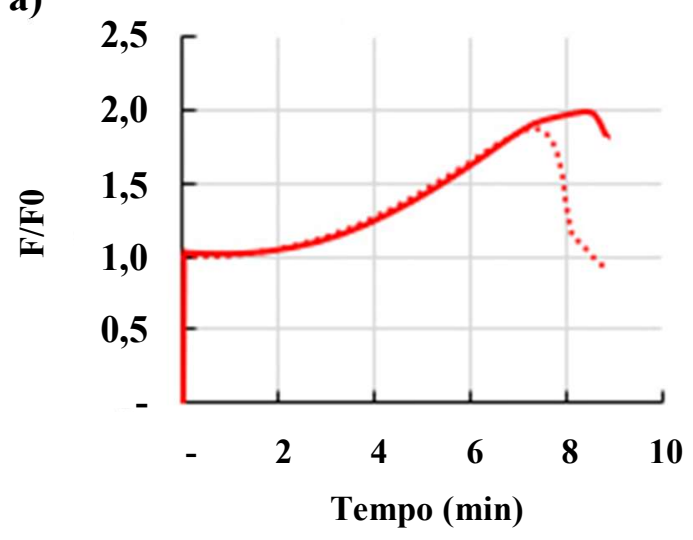

Experimental b)

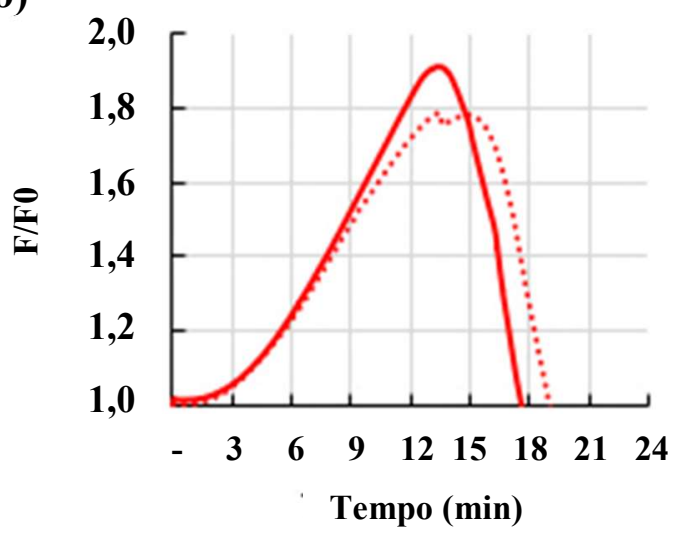

Numérico

Figura 4.4 - Validação dos modelos numéricos dos pilares isolados: a) H100-ISO; b) H220ISO

Fonte: Autor da Pesquisa (2018).

Analisando a Figura 4.4, observa-se que os resultados numéricos representaram de forma adequada os ensaios experimentais, principalmente o comportamento ascendente da curva "força axial relativa versus tempo". No caso do pilar H100-ISO (Figura 4.4a) houve uma reprodução consistente do resultado experimental até próximo de atingir o pico da curva. Já em relação ao pilar H220-ISO (Figura 4.4b), a partir de 10 minutos a curva começa a se distanciar daquela experimental, apresentando uma diferença da ordem de $5 \%$ do valor máximo atingido nos experimentos.

Com relação ao trecho descendente, os modelos apresentaram ajuste não muito satisfatório, sendo que para o pilar mais robusto houve uma pequena separação entre curvas numérica e experimental, enquanto que para o pilar H100-ISO esse trecho não é reproduzido como desejado. Tal fato pode ser consequência da forte instabilidade verificada nos ensaios dos perfis de aço com aquecimento uniforme a partir do instante que o pilar atinge a força máxima de restrição, aspecto que dificultou a representação numérica nas fases de pós-pico das forças existentes.

\subsubsection{Pilares inseridos em paredes}

\subsection{Formados pelo perfil de aço HEA 100}

Os pilares de aço H100-ORT-T7 e H100-PAR-T7 foram modelados seguindo a estratégia numérica $I$, de modo que as intensidades das rigidezes da mola situada na 
extremidade desses elementos estruturais continuam sendo as mesmas determinadas no item 4.3.1. O mesmo se verifica no que diz respeito à imperfeição geométrica inicial inseridas nesses pilares, com amplitude igual a L/500 na direção do fogo. A calibração numérica dessa grandeza também está demonstrada no Apêndice B. A comparação entre resultados numéricos e experimentais para esses pilares estão representados na Figura 4.5.

a)

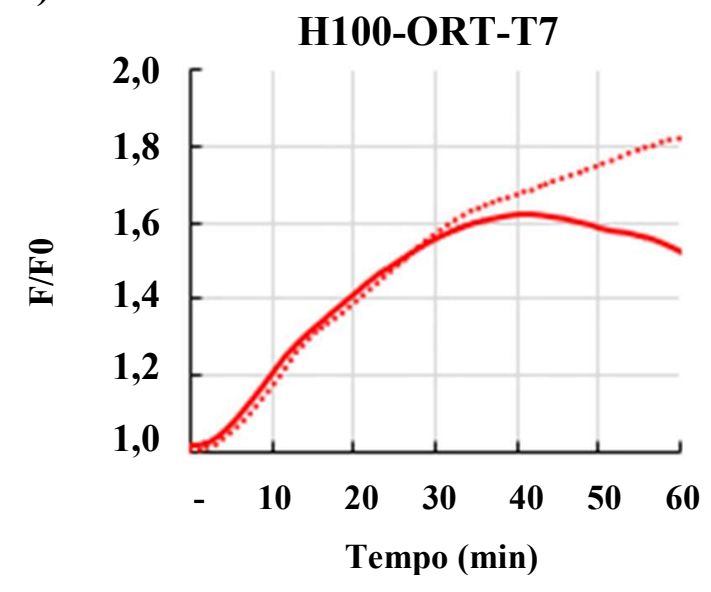

Experimental b)

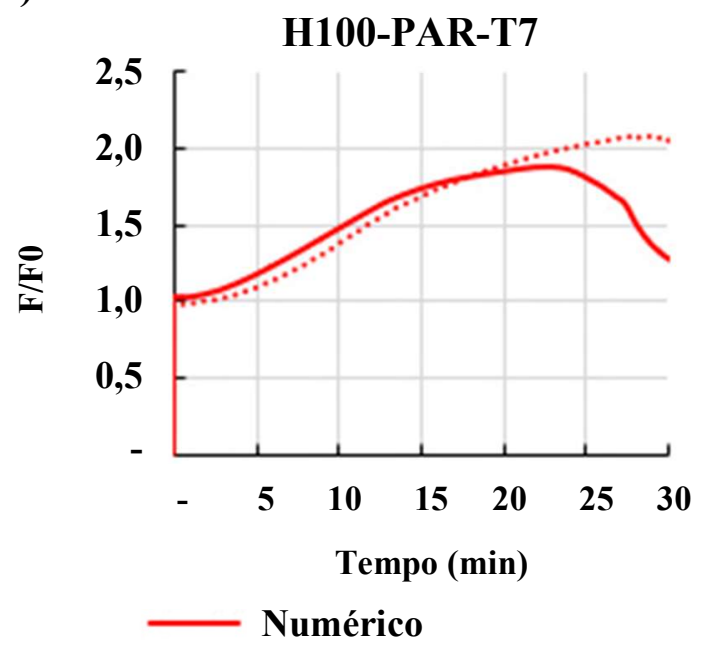

Figura 4.5 - Comparação entre os resultados numéricos e experimentais para os pilares inseridos em paredes formados pelo perfil de aço HEA 100

Fonte: Autor da Pesquisa (2018).

A análise gráfica mostra que para ambos os elementos estruturais ocorre boa consistência na maior parte do tempo de exposição ao fogo, uma vez que a diferença entre as curvas apresentadas foi mínima. No entanto, a partir de certo instante de tempo, os resultados numéricos começaram a se distanciar dos obtidos experimentalmente, ou seja, em 30 min e em 20 min para os pilares com paredes em contato com a alma (Figura 4.5a) e com a mesa (Figura $4.5 b)$, respectivamente. Discussões a respeito dessas diferenças entre as curvas serão descritas mais adiante.

\subsection{Formados pelo perfil de aço HEA 220}

Os pilares de aço H220-ORT-T15 e H220-PAR-T15 foram modelados pelo mesmo procedimento abordado no item 4.3.1.2.1, ou seja, com amplitude da imperfeição geométrica adotada para representação dos modelos numéricos igual a L/500 na direção do fogo (maiores informações são encontradas no Apêndice B), bem como rigidez axial igual a $30 \mathrm{kN} / \mathrm{mm}$ e 
rotacional igual a $5000 \mathrm{kN} . \mathrm{m} / \mathrm{rad}$. A comparação entre os resultados numéricos e experimentais se encontra ilustrada na Figura 4.6.

a)

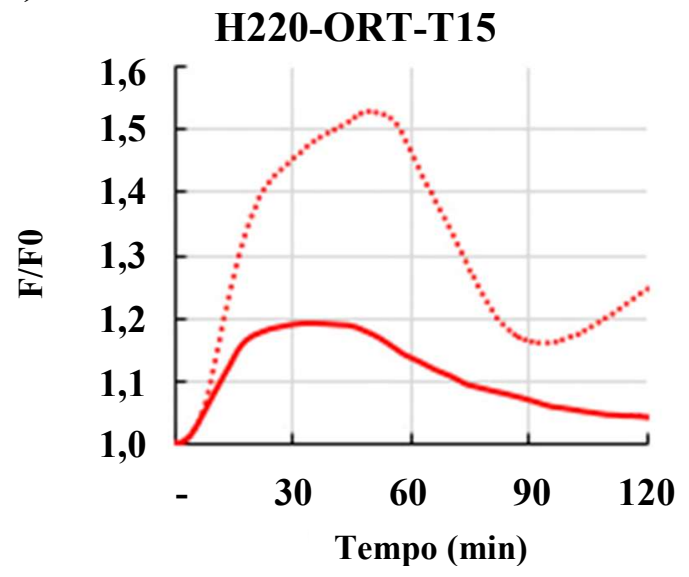

Experimental b)

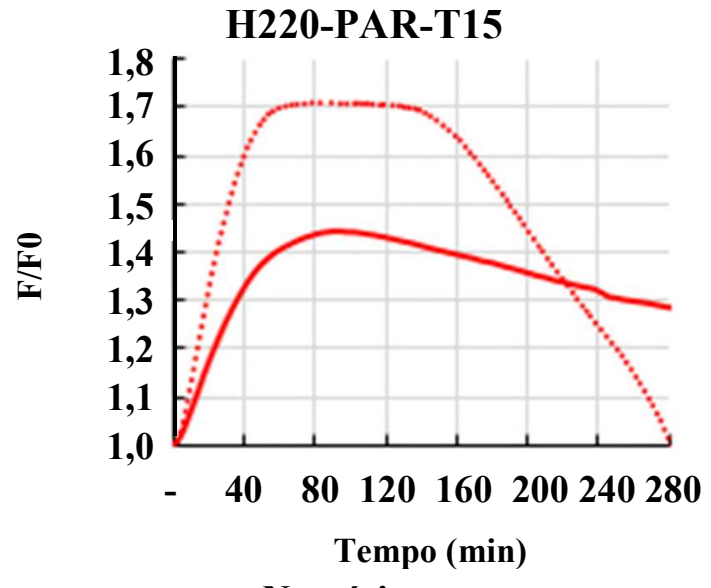

Numérico

Figura 4.6 - Comparação entre os resultados numéricos e experimentais para os pilares inseridos em paredes formados pelo perfil de aço HEA 220

Fonte: Autor da Pesquisa (2018).

A análise dos gráficos da Figura 4.6 permite identificar que os resultados dos modelos referentes aos pilares H220-ORT-T15 e H220-PAR-T15 não foram satisfatórios, pois não conseguiram representar os ensaios experimentais. Para o elemento estrutural com gradiente térmico ao longo da alma (Figura 4.6a), houve uma diferença da ordem de $22 \%$ entre os valores máximos da força de restrição, enquanto que para o pilar com aquecimento diferencial ao longo das mesas (Figura 4.6b), essa diferença resulta da ordem de $15 \%$. Observa-se ainda que em ambos os modelos numéricos, desde o início do aquecimento, houve uma baixa rigidez global o que promoveu a formação de forças axiais relativas menores.

4.3.1.3 Considerações referentes aos resultados numéricos proporcionados pela estratégia numérica I

A estratégia numérica I apresentou resultados de certa forma adequados para os pilares isolados e boa representação, em parte do tempo de exposição ao fogo, para os pilares inseridos em paredes H100-ORT-T7 e H100-PAR-T7.

Por outro lado, para os pilares em contato com alvenaria formados pelo perfil HEA 220 (H220-ORT-T15 e H220-PAR-T15) os resultados numéricos não se apresentaram satisfatórios. 
Uma possível causa para essa representação numérica não satisfatória pode estar associada a não consideração da influência da parede no comportamento termoestrutural dos pilares.

Como descrito no Capítulo 2, na seção referente às restrições térmicas, a inserção de paredes em pilares aumenta a rigidez axial do elemento estrutural de modo a interferir no parâmetro rigidez axial relativa $(\alpha)$ alterando o desenvolvimento de forças e deslocamentos axiais durante o incêndio. É importante destacar novamente que os ensaios de referência utilizados nessa pesquisa constataram a influência da parede na resposta estrutural dos pilares de aço em elevadas temperaturas.

Por essa razão, uma vez que na estratégia numérica adotada até o momento a alvenaria se comportou apenas como elemento de compartimentação, os resultados podem ter sido comprometidos, principalmente para os pilares H220-ORT-T15 e H220-PAR-15, os quais são associados a uma parede mais robusta e, possivelmente, com maior influência no comportamento do elemento sob a ação do fogo.

Diante do exposto, o item a seguir apresenta um estudo de caráter inicial sobre a influência da parede no desempenho termoestrutural dos pilares na tentativa de propor uma estratégia de modelagem que represente satisfatoriamente todos os elementos inseridos em alvenaria.

\subsubsection{Influência das paredes no comportamento termoestrutural de pilares}

Como já mencionado, os modelos numéricos para os pilares formados pelos perfis HEA 100 e HEA 220 apresentam diferentes respostas, uma vez que os perfis HEA 100 tiveram um resultado numérico satisfatório até da ordem da metade do tempo de exposição ao fogo, enquanto os perfis HEA 220 apresentaram resultados não consistentes ao longo de todo o tempo de exposição ao fogo, supostamente em resposta à influência das dimensões da seção transversal dos perfis, da espessura da parede, do gradiente térmico e da contribuição da alvenaria.

Os pilares constituídos pelos perfis HEA 100 possuem pequenas dimensões e estão inseridos em paredes de espessura igual a $7 \mathrm{~cm}$, essa bastante reduzida se comparadas às paredes embutidas nos pilares formados pelo perfil de aço HEA 220, no caso $15 \mathrm{~cm}$. Por essa razão, os pilares HEA 100 se aquecem mais rapidamente, apresentando temperatura média superior aos pilares HEA 220, para o mesmo tempo de exposição ao fogo e mesma orientação do perfil em relação à superfície da parede, como pode ser observado na Figura 4.7. 
A Figura 4.7a mostra as curvas de evolução da temperatura média de todos os pilares em função do tempo de exposição ao fogo. Porém para melhor visualização do comportamento daquelas que apresentaram um tempo de duração menor, a Figura $4.7 \mathrm{~b}$ foi criada, apresentando tais curvas até um intervalo igual a $60 \mathrm{~min}$.

a)

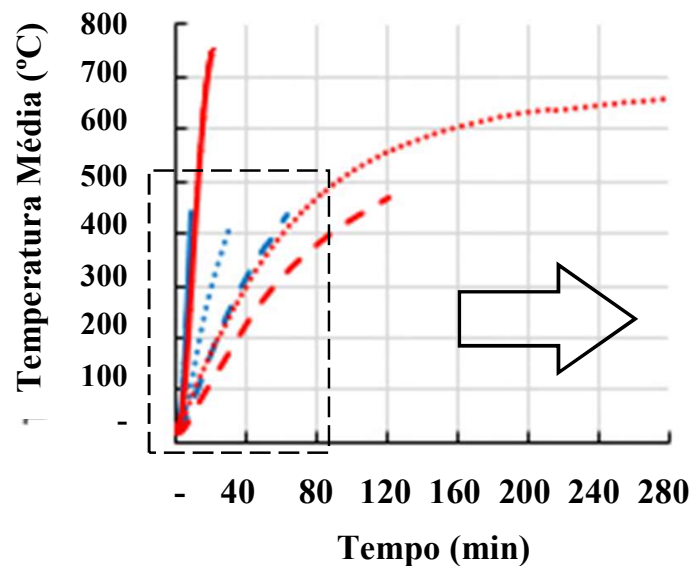

H100-ISO b)

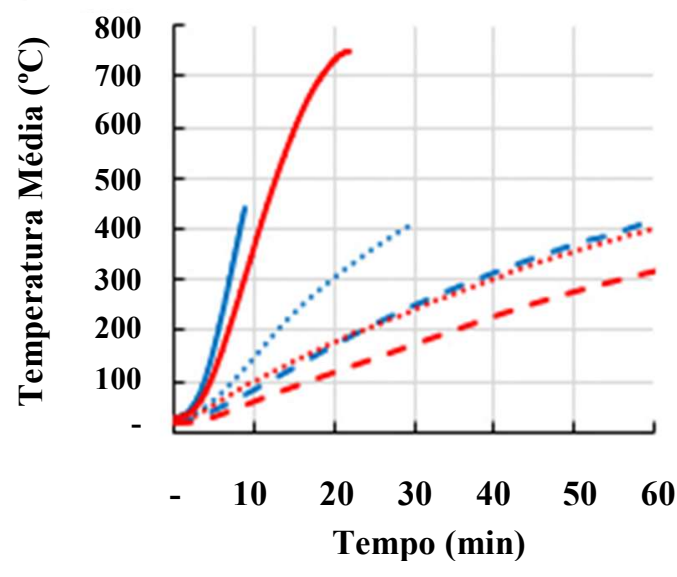

H220-ISO

H220-ORT-T15

H220-PAR-T15

Figura 4.7 - Curva referente à temperatura média em função do tempo para os pilares formados pelos perfis $\mathrm{H} 100$ e H220, isolados ou inseridos em paredes

Fonte: Autor da Pesquisa (2018).

Adicionalmente, por se aquecer mais rapidamente, os pilares formados pelo perfil HEA 100 desenvolvem menor gradiente térmico na seção transversal, de modo que seus resultados acabam por apresentar certa semelhança com os pilares aquecidos em todas as faces, conforme ilustra a Figura 4.8 .

A Figura 4.8 é dividida em "a" e "b" pelos mesmos motivos já mencionados para a realização da Figura 4.7. Vale ressaltar que o gradiente térmico foi determinado a partir da diferença de temperatura entre os nós mais expostos e menos expostos dos modelos numéricos para cada instante de tempo de exposição ao fogo. 
a)

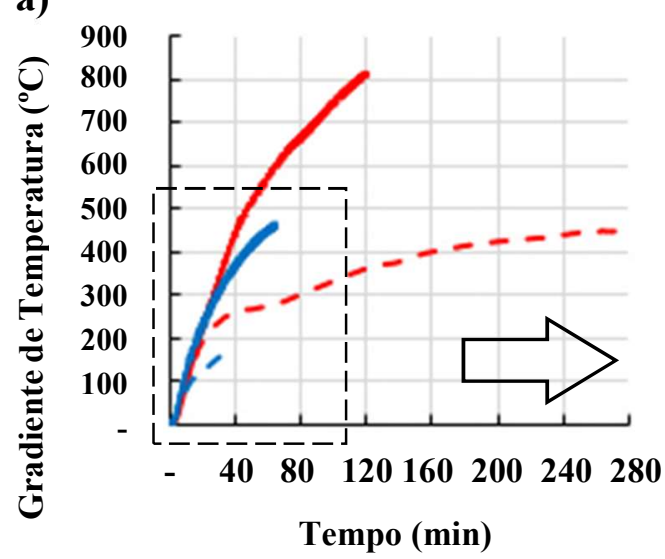

b)

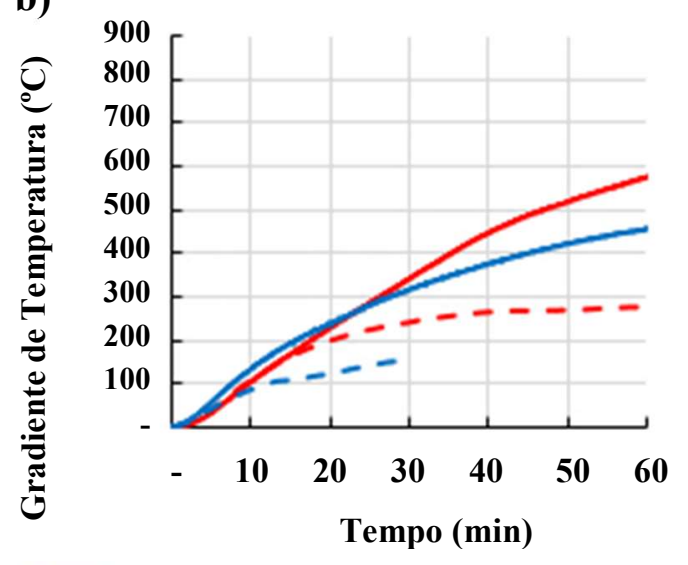

\section{- H220-ORT-T15
- H100-ORT-T7
--- H220-PAR-T15 - - H100-PAR-T7}

Figura 4.8 - Curva referente ao gradiente térmico em função do tempo para os pilares

Fonte: Autor da Pesquisa (2018).

Diante do exposto, é possível considerar que os pilares formados pelo perfil HEA 100 sofrem menor influência das paredes em comparação com aqueles formados pelo perfil HEA 220. Tal aspecto parece explicar a aproximação das curvas numérica e experimental dos modelos da Figura 4.5 até a metade do tempo de exposição, uma vez que inicialmente, como o gradiente térmico é pouco evidenciado, esses pilares basicamente se deslocam axialmente, similar aos pilares isolados.

A partir do momento que o gradiente térmico se torna mais evidente, a ponto de interferir na estrutura por meio do fenômeno Thermal Bowing, nota-se um maior distanciamento das respectivas curvas e, neste caso, acredita-se que as paredes devam exercer maior influência no comportamento termoestrutural.

Considerando que a parede interfere no comportamento termomecânico dos pilares, necessita-se determinar de que forma ela atua nos modelos numéricos termoestruturais. Assim, a lateral das paredes foi travada, tanto à rotação quanto ao deslocamento, em diversas direções, de modo a avaliar tal impacto nos resultados numéricos. Vale ressaltar que, no ensaio experimental, essa região se encontrava em contato com um quadro metálico conectado ao pórtico de restrição do ensaio, como pode ser vista na Figura 4.9 e, portanto, provavelmente exercendo influência nos resultados obtidos. 


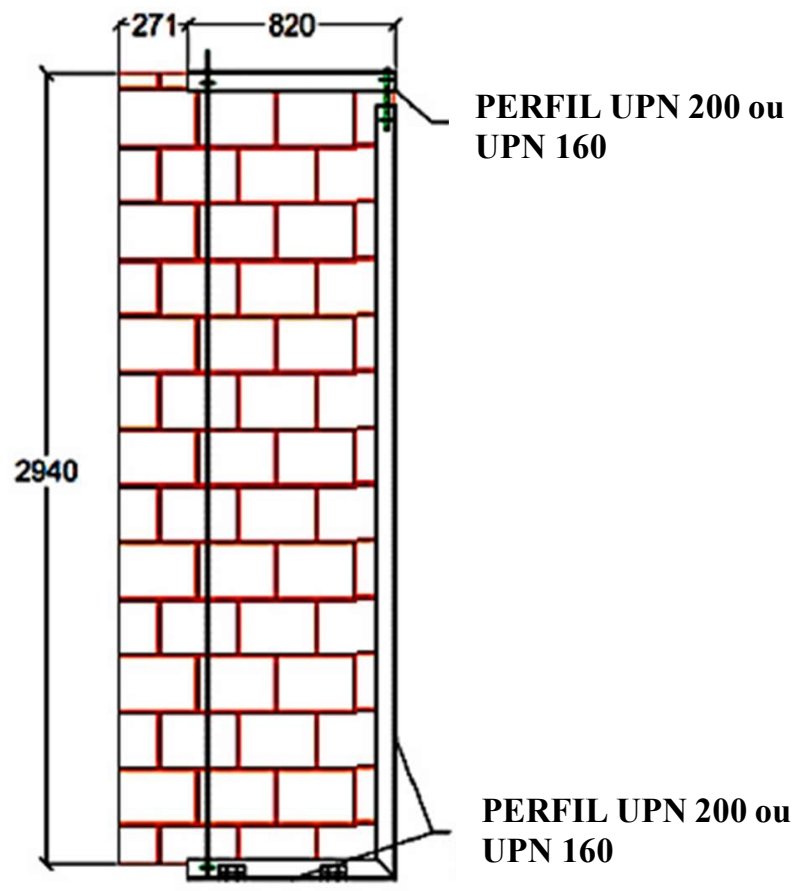

Dimensões em [mm]

Figura 4.9 - Representação das paredes no ensaio experimental Fonte: Rocha (2016).

Nas análises que se seguem, as nomenclaturas U1, U2 e U3 indicam travamento do deslocamento na direção de $\mathrm{X}, \mathrm{Y}$ e Z, respectivamente. Como pode ser observado na Figura 4.10, as direções X e Y se alteram de acordo com a orientação do perfil em relação à superfície do elemento de vedação.

a) Pilar com a alma ortogonal à parede

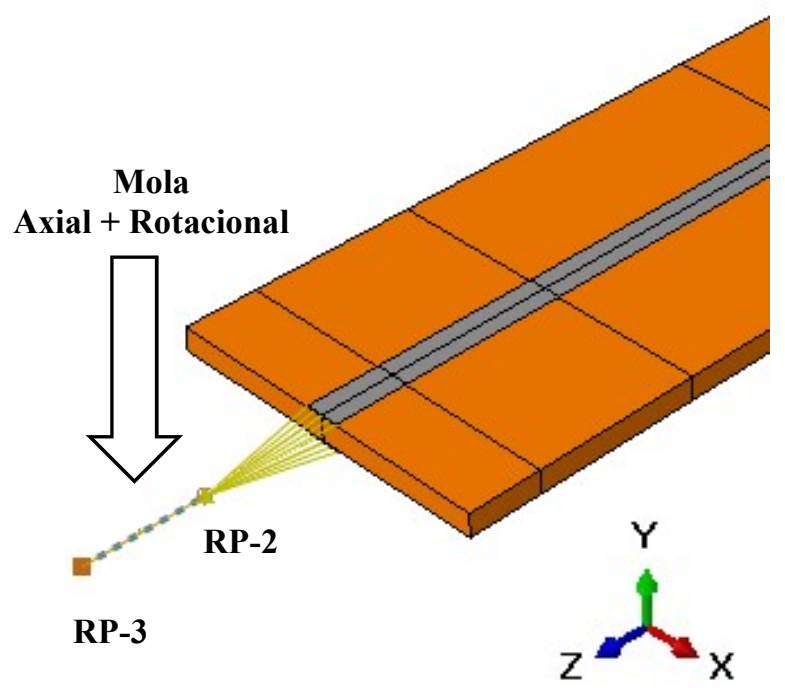

b) Pilar com a alma paralela à parede

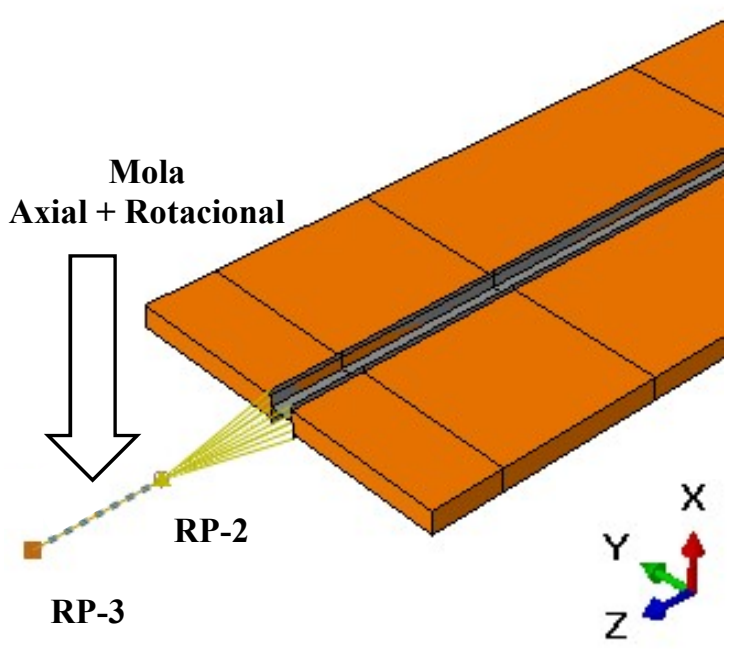

Figura 4.10 - Representação numérica dos pilares inseridos em paredes Fonte: Autor da Pesquisa (2018). 
A Figura 4.11 mostra os resultados dos testes realizados nos modelos numéricos para os pilares inseridos em parede. Destaca-se que não serão representados os resultados referentes ao travamento à rotação na lateral da alvenaria, uma vez que esse tipo de travamento, após análise dos resultados, não afetou o comportamento termomecânico dos pilares.

a)

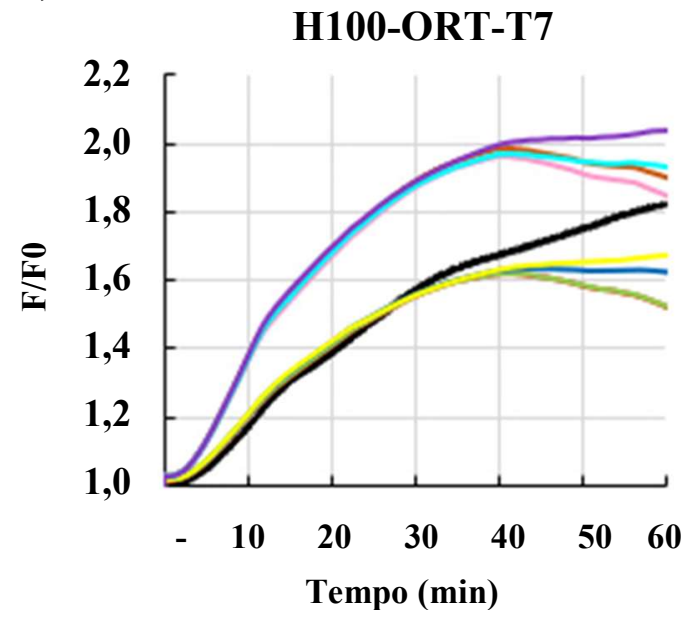

c)

H220-ORT-T15

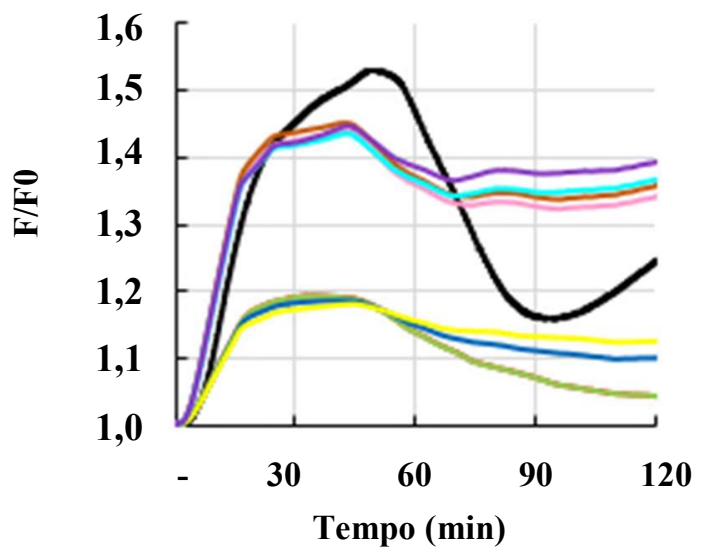

b)

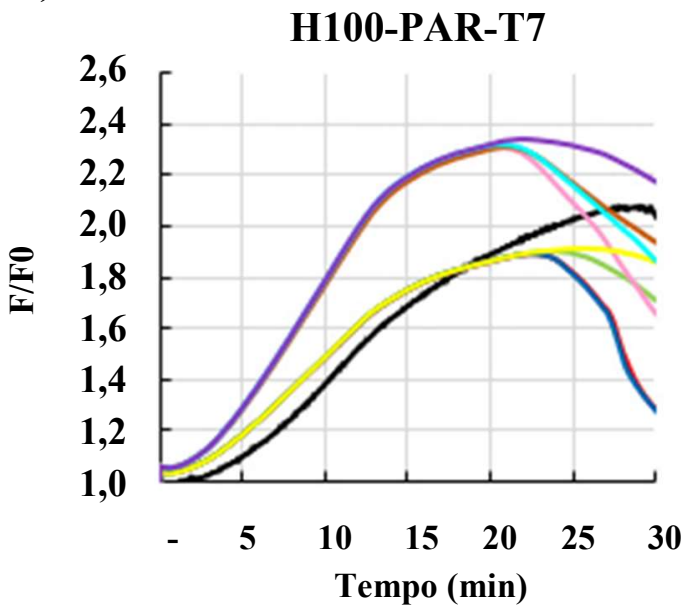

d)

\section{H220-PAR-T15}

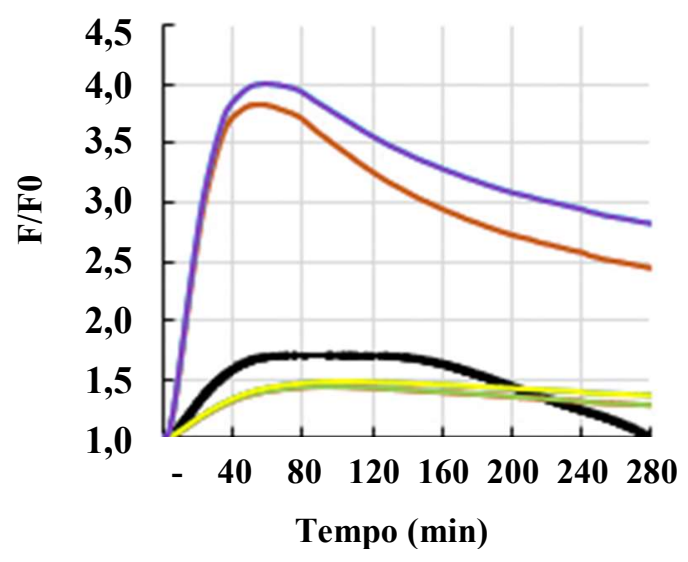

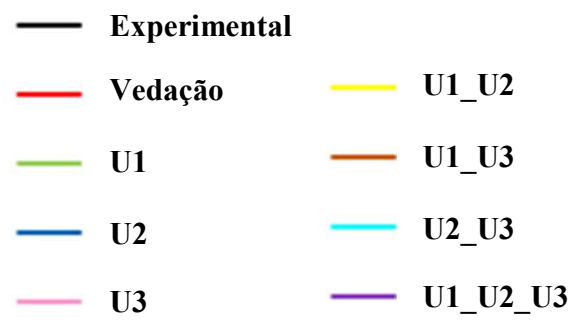

Figura 4.11 - Comparação entre os resultados numéricos e experimental para diferentes travamentos da lateral das paredes

Fonte: Autor da Pesquisa (2018). 
Analisando inicialmente o travamento na direção paralela à superfície da parede, no caso, U1 (eixo X) para os pilares com alma ortogonal ao plano da alvenaria (Figuras 4.11a e 4.11c), bem como U2 (eixo Y) para os pilares com alma paralela ao plano da alvenaria (Figuras 4.11 b e $4.11 \mathrm{~d}$ ), nota-se que o travamento total dessa direção pouco altera o comportamento termoestrutural dos pilares, uma vez que as curvas para essa situação coincidiram com aquela em que a parede é tratada apenas como elemento de vedação, de modo que houve sobreposição de curvas. Tal resposta provavelmente está atrelada ao fato de nessa direção os esforços gerados nos pilares resultarem reduzidos, o que torna a influência da parede pequena.

Em contrapartida, para o travamento total na direção ortogonal à superfície da parede, no sentido em que o gradiente térmico se mostra mais evidente, nota-se uma elevação da força axial relativa para todos os quatro pilares estudados, pois nesse sentido os esforços passam a ser significantes, devido ao fenômeno Thermal Bowing, de modo que a parede parece influenciar mais significativamente nesse comportamento.

Quando se impõe travamentos nas duas direções simultaneamente foi alcançado o melhor resultado para os pilares H100-ORT-T7 e H100-PAR-T7. Observa-se que para esses elementos estruturais, por meio dos testes realizados, ocorreu a elevação da força axial numérica somente no trecho que estava distante da curva experimental, apresentado na Figura 4.5, o que sugere, como esperado, que as paredes apresentaram influência no comportamento desses pilares após certo tempo de exposição ao fogo.

Já para os pilares formados pelo perfil HEA 220, esse mesmo travamento simultâneo proporcionou apenas discreta melhora, principalmente para tempos mais longos de exposição ao fogo, porém os resultados ainda continuaram a se apresentar pouco eficazes para esses elementos estruturais.

No caso da direção U3 (sentido axial do pilar) e suas combinações com U1 e/ou U2, ao ser totalmente travado, a rigidez do sistema global se elevou de tal forma que as forças de restrição desenvolvidas no modelo cresceram substancialmente, possibilitando ao modelo H220-ORT-T15 reproduzir resultados que se aproximassem do experimental satisfatoriamente. No entanto, para os demais três pilares essa mesma proposta não se mostrou adequada, uma vez que as forças cresceram além do desejado.

As análises aqui apresentadas sinalizam que a associação pilar-parede apresenta um comportamento em conjunto quando analisado em situação de incêndio e, de certo modo, com grande complexidade para o correto entendimento. É importante destacar que nos ensaios experimentais foi observado que em pilares onde o gradiente térmico se evidenciou ao longo 
da mesa, a alvenaria manifestou maior deterioração apresentando deslocamento relativo entre os blocos cerâmicos em virtude de um elevado deslocamento axial do pilar.

Os aspectos citados anteriormente sugerem que o conjunto pilar-parede pode ser interpretado como um sistema de seção equivalente de aço responsável por suportar o carregamento aplicado no eixo do elemento estrutural (direção axial U3), o que pode justificar o fato desse travamento influenciar mais fortemente no comportamento termoestrutural do pilar. A intensidade dessa influência, a qual parece estar atrelada ao nível de travamento dessa direção, é de difícil identificação (difícil de ser mensurada) uma vez que envolve a degradação das propriedades dos materiais, a temperatura média do pilar e o respectivo gradiente térmico desenvolvido na seção transversal.

De certo modo, uma vez que o pilar H220-ORT-T15 se desloca menos axialmente e apresenta uma temperatura média menor, em resposta ao elevado gradiente térmico, nota-se que as paredes fornecem maior rigidez axial ao sistema. O exposto não se aplica ao pilar H100ORT-T7, pois apesar de o gradiente térmico formado ser ao longo da alma, o perfil apresenta pequenas dimensões e, como já mencionado anteriormente, ele se aquece mais rapidamente elevando sua temperatura média (ver Figura 4.7).

Diante do exposto, pode-se observar que os testes de travamento lateral das paredes indicaram que esse elemento de vedação parece realmente influenciar o comportamento termoestrutural dos pilares. Apesar disso, ainda que tais testes não tenham sido capazes de representar todos os elementos estruturais, certamente permitiram indicar uma nova estratégia numérica, como discutida a seguir.

\subsubsection{Utilização da estratégia numérica II}

Considerando os resultados apresentados no item 4.3.2 ao retratar os travamentos na alvenaria, para as direções ortogonal e paralela à superfície da parede, nota-se melhora na resposta numérica de todos pilares, principalmente para aqueles formados pelo perfil de aço HEA 100. Por outro lado, foi possível constatar que o travamento da direção axial elevava substancialmente a rigidez do modelo e, consequentemente, a força axial relativa. Tal fato permitiu a obtenção de resultados numéricos satisfatórios somente para o pilar H220-ORT-T15, enquanto que para os outros, a força de restrição resultou bem superior às identificadas experimentalmente. 
Neste sentido, propõe-se uma nova estratégia, aqui denominada estratégia numérica II, a qual se apresenta como alternativa em resposta aos resultados obtidos considerando travamento lateral das paredes, proposto no item 4.3.2.

A estratégia proposta no que segue consiste em manter o travamento total da lateral da alvenaria nas direções paralela e ortogonal à sua superfície, mas agora inserindo molas que permitam controlar a sua rigidez na direção axial (U3), de modo a encontrar uma dada rigidez para as mesmas que seja adequada para todos os modelos estudados, como ilustrado anteriormente na Figura 4.3, visto que o travamento total, similar a uma mola com rigidez infinita, não foi satisfatório.

Como o presente estudo trata de pilares com consideráveis diferenças de dimensões de perfis metálicos e, consequentemente, de espessuras de paredes, a influência desses últimos em cada elemento estrutural é distinta, como já discutido, razão pela qual a rigidez das molas presentes na lateral das paredes correspondentes aos pilares formados pelo perfil de aço HEA 100 será diferente daquelas com perfil HEA 220.

Em relação as propriedades da mola axial inserida na lateral das paredes, considerar-seá comportamento elastoplástico perfeito de modo a se deformar inicialmente de maneira elástica até um dado deslocamento. A partir do momento em que a mola atinge a força axial correspondente a esse deslocamento, essa mesma apenas irá se deformar sem apresentar qualquer ganho de força, conforme Figura 4.12.

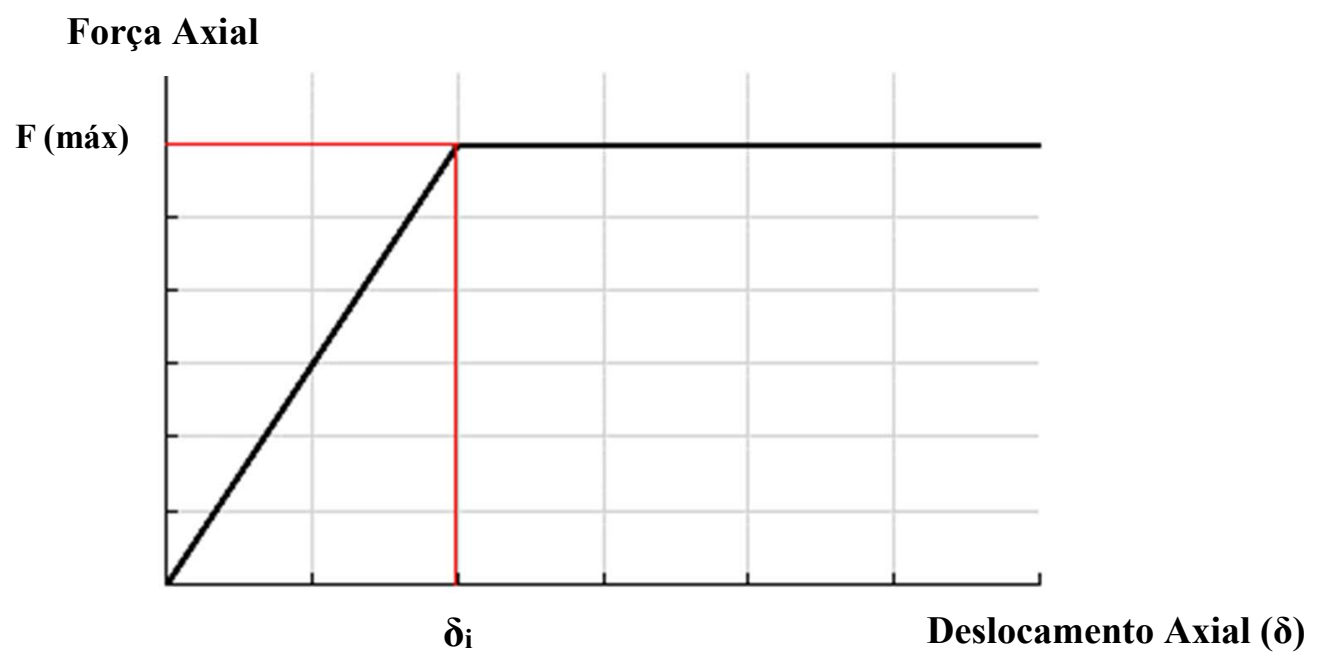

Figura 4.12 - Representação gráfica do modelo elastoplástico perfeito Fonte: Autor da Pesquisa (2018) 
Basicamente, tal ideia busca capturar (ou simular) com qual intensidade o deslocamento axial do pilar leva a parede a se deformar e a perder a ligação entre seus elementos, juntamente com a perda da rigidez dos pilares em resposta à degradação das propriedades mecânicas dos materiais. Vale notar que, para os pilares em que a alma é paralela à superfície das paredes, a perda de rigidez se apresenta mais rápida em resposta à temperatura média da seção transversal resultar sempre mais elevada.

Diante do exposto, calibrações das molas axiais foram realizadas considerando variação da força máxima por ela atingida e seu correspondente deslocamento axial. Todos os testes realizados para os quatro pilares inseridos em paredes estão disponíveis no Apêndice $\boldsymbol{B}$.

Iniciando a análise dos resultados para os pilares formados pelo perfil HEA 100, a calibração numérica definiu uma rigidez de mola equivalente a $5 \mathrm{kN} / \mathrm{mm}$, sendo a força axial máxima igual a $10 \mathrm{kN}$ com deslocamento axial de $2 \mathrm{~mm}$. A Figura 4.13 traz os resultados para esses pilares, em que se pode constatar que a modelagem numérica gerou resultados numéricos próximos dos experimentais. As maiores diferenças entre as curvas numéricas e experimentais resultaram iguais a 5\% e 7\% para os pilares H100-ORT-T7 (Figura 4.13a) e H100-PAR-T7 (Figura 4.13b), respectivamente.

a)

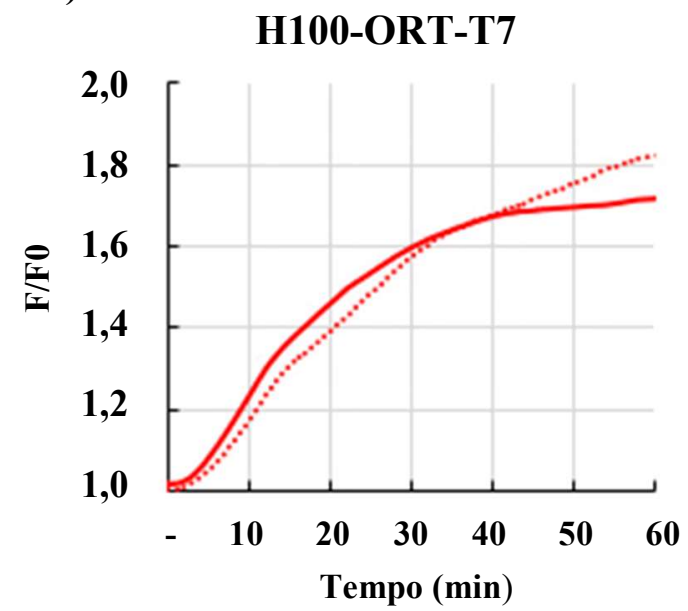

b)

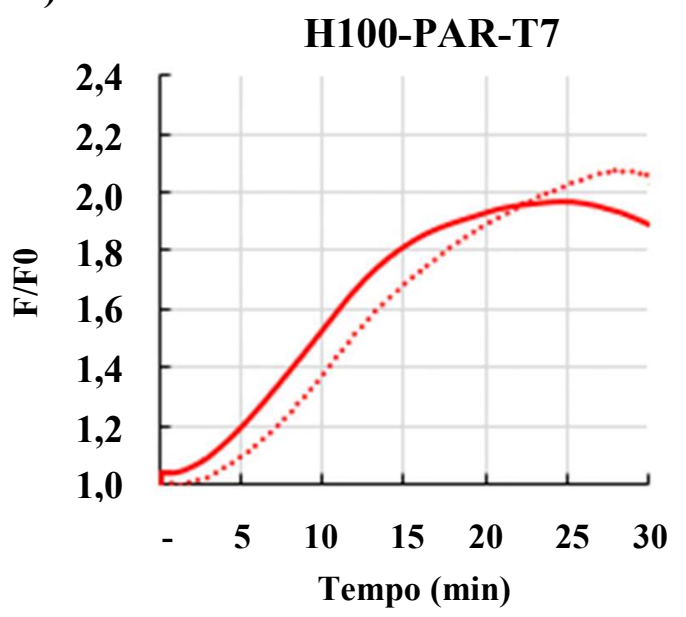

Experimental

Numérico

Figura 4.13 - Validação da modelagem numérica para os pilares de aço formados pelo perfil de aço HEA 100

Fonte: Autor da Pesquisa (2018).

De modo análogo, em relação aos pilares constituídos por perfis HEA 220, H220-ORTT15 e H220-PAR-T15, a calibração numérica definiu para a mola uma rigidez igual a 180 
$\mathrm{kN} / \mathrm{mm}$, sendo a força axial máxima igual a $90 \mathrm{kN}$ e deslocamento axial igual a $0,5 \mathrm{~mm}$. Tais valores foram responsável por gerar os resultados mais adequados para ambos os pilares.

A Figura 4.14 traz os resultados para esses pilares. Observa-se que os resultados experimentais passaram a ser melhor representados em comparação a resposta numérica da estratégia de modelagem I (ver Figura 4.6), uma vez que as curvas numéricas e experimentais resultaram mais próximas. A diferença entre os pontos de pico das curvas numéricas e experimentais reduziu de $25 \%$ para aproximadamente $10 \%$, para o pilar com gradiente térmico ao longo da alma (Figura 4.14a), bem como em 5\% para o elemento com aquecimento diferencial ao longo da mesa (Figura 4.14b).

Além disso, como pode ser vista na Figura 4.14b, essa nova estratégia possibilitou para a curva numérica praticamente o mesmo aspecto da curva experimental, representando de forma satisfatória o experimento, antes não identificado quando do uso da estratégia numérica I. Em relação ao pilar H220-ORT-T15 (Figura 4.14a), o esboço da curva numérica resultou, com alguma similaridade, os valores experimentais, porém, após 15 minutos, a rigidez do sistema global ainda se encontrou um pouco inferior àquela encontrada nos ensaios, devido à diferença entre o pico das curvas citada anteriormente. Mesmo assim, por se tratar de um estudo inicial sobre a influência das paredes no comportamento termoestrutural dos pilares, pode-se considerar os modelos numéricos adequados.

a)

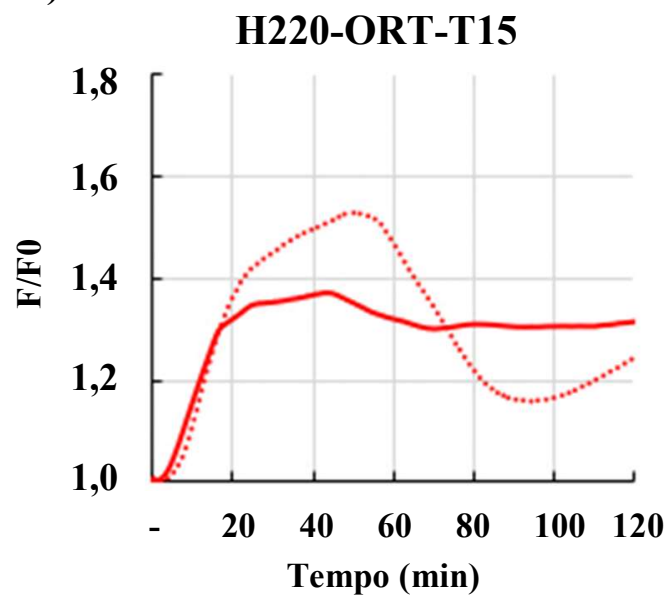

b)

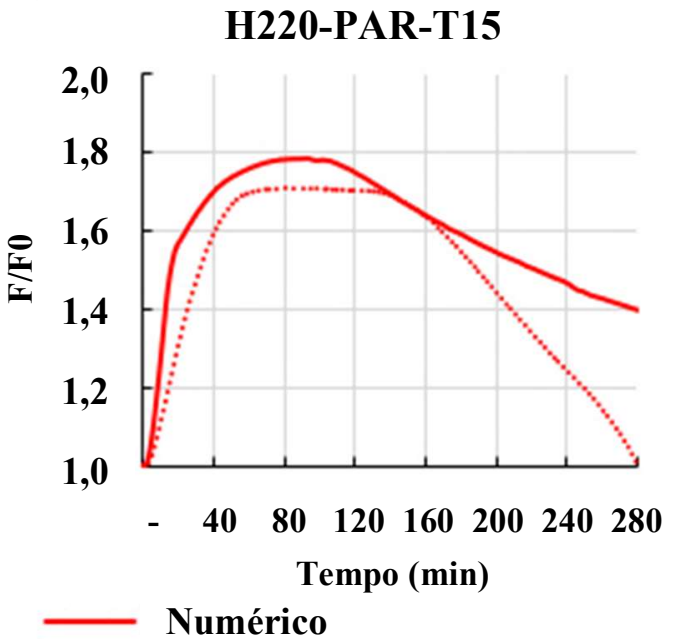

Figura 4.14 - Validação da modelagem numérica para os pilares de aço formados pelo perfil de aço HEA 220

Fonte: Autor da Pesquisa (2018). 
Ainda com relação a Figura 4.14, observa-se que, adotando a mesma rigidez axial da mola presente na lateral das paredes, não foi possível recuperar com precisão desejada a coincidência entre curvas numéricas e experimentais para os casos em que os pilares apresentavam gradiente térmico ao longo da alma e da mesa.

Possivelmente, tal aspecto, por hipótese, parece ser justificado pela influência da orientação do perfil metálico na rigidez equivalente do conjunto pilar-parede em situação de incêndio. No caso do pilar H220-ORT-T15, tal orientação parece fornecer maior rigidez a esse conjunto, uma vez que o momento fletor secundário gerado pelo gradiente térmico se dará em torno do eixo de maior inércia do perfil de aço associado a uma menor temperatura média do pilar, se comparado aos casos em que esse perfil se encontra paralelo à superfície da parede. Isso pode justificar a adoção de diferentes valores de rigidez para as molas axiais das paredes no que diz respeito às duas orientações dos pilares, de modo a melhorar os resultados numéricos.

4.3.3.1 Considerações referentes aos resultados numéricos proporcionados pela estratégia numérica II

Ao utilizar a estratégia numérica II, os resultados numéricos apresentaram uma melhora com a consideração das paredes no comportamento termoestrutural dos pilares. A restrição da lateral da parede possibilitou um ganho da rigidez global do sistema, aumentando, dessa maneira, a força axial relativa desenvolvida. Comparando a calibração numérica da mola axial das paredes para os pilares formados pelos perfis HEA 100 e HEA 220, percebe-se uma considerável diferença de rigidez.

De modo geral, para os pilares mais robustos, formados por perfil com grandes dimensões e inseridos em paredes com espessura elevada, como é o caso do H220-ORT-T15 e H220-PAR-T15, a alvenaria proporciona maior rigidez axial aos pilares, o que influencia diretamente na rigidez axial relativa, alterando, dessa forma, o comportamento das forças axiais desenvolvidas durante a ação do fogo.

\subsubsection{Análise do deslocamento axial}

No presente item, discute-se o deslocamento axial alcançado pelos modelos numéricos. Os resultados ilustrados a seguir são aqueles obtidos pelas estratégias numéricas que validaram 
os pilares de aço, ou seja, estratégia numérica I para os pilares considerados isolados, bem como estratégia numérica II para os pilares inseridos em paredes.

Iniciando a análise para os pilares isolados, a Figura 4.15 traz os resultados da comparação entre as curvas numéricas e experimentais. Para o pilar H220-ISO, houve uma boa correlação entre as curvas, de modo que o trecho ascendente conseguiu ser bem representado. Para o trecho descendente, apesar de ter ocorrido um maior distanciamento entre essas curvas, considera-se o resultado como satisfatório. Em relação ao pilar H100-ISO, o modelo gerou um deslocamento superior àquele medido nos ensaios experimentais desde o início do aquecimento.

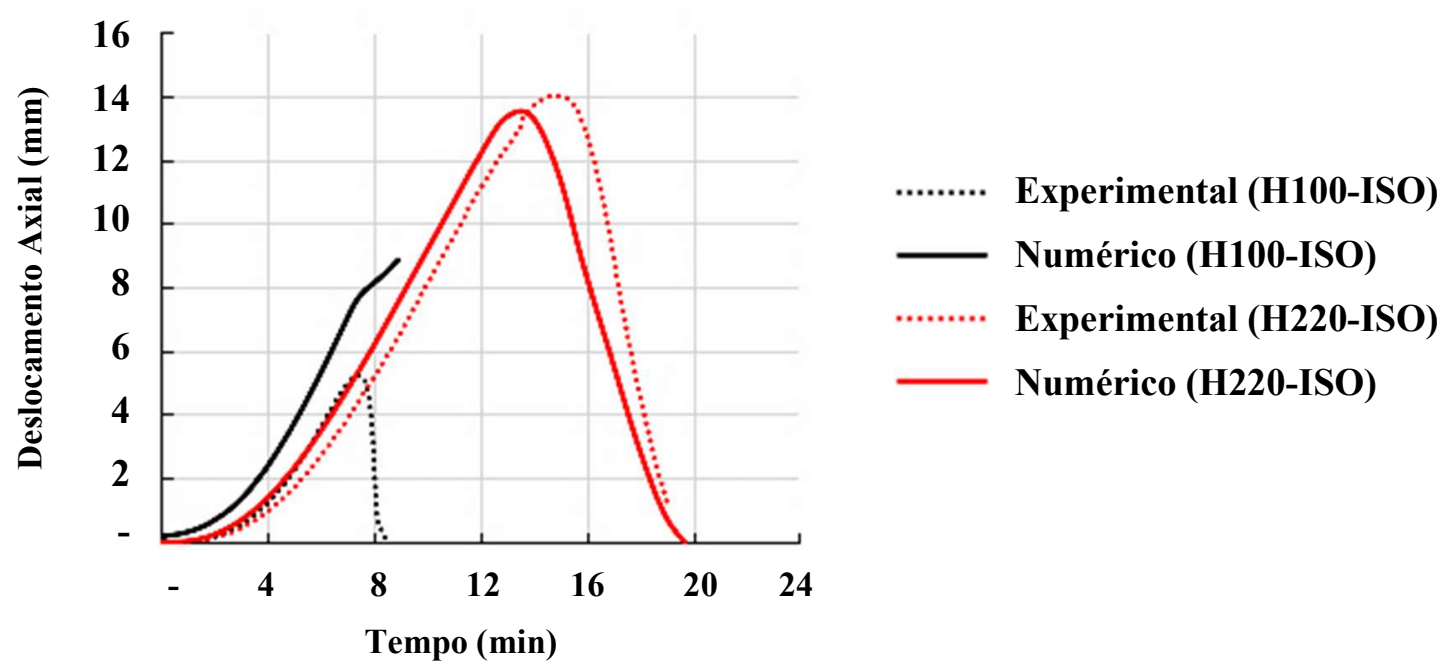

Figura 4.15 - Análise do deslocamento axial para os pilares isolados Fonte: Autor da Pesquisa (2018).

Situação similar ocorreu para os pilares inseridos em paredes, como pode ser vista na Figura 4.16. Com exceção do modelo H220-PAR-T15, todos os demais resultados numéricos não permitiram recuperar àqueles desenvolvidos nos experimentos quanto ao deslocamento axial, apesar de o comportamento da curva numérica referente à evolução das forças axiais relativas ter resultado similar à experimental.

Em relação ao pilar H220-PAR-T15, o trecho ascendente da curva dos ensaios conseguiu ser reproduzida pelo modelo numérico de forma minimamente satisfatória. Uma pequena diferença foi constatada no pico da curva equivalente a $1 \mathrm{~mm}$, o que não invalida os resultados. Apesar disso, o trecho descendente da curva experimental não foi bem retratado, pois o modelo numérico não apresentou uma queda brusca após ter atingido o deslocamento máximo. 
a)

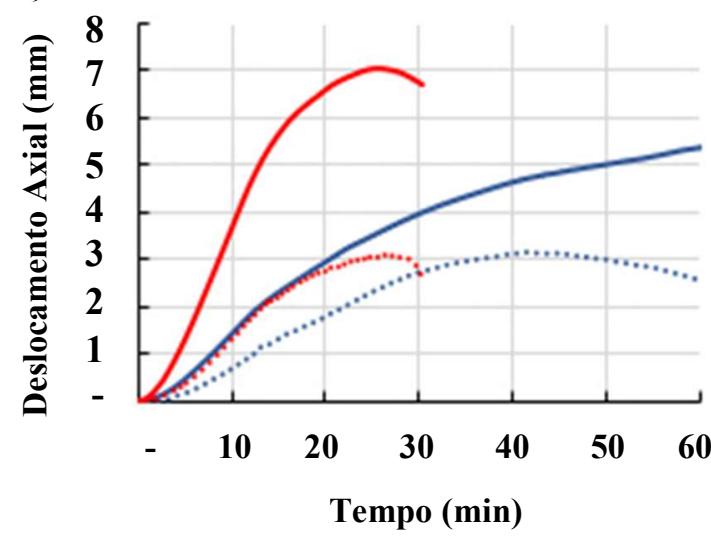

Experimental (H100-ORT-T7)

— Numérico (H100-ORT-T7)

Experimental (H100-PAR-T7)

Numérico (H100-PAR-T7) b)

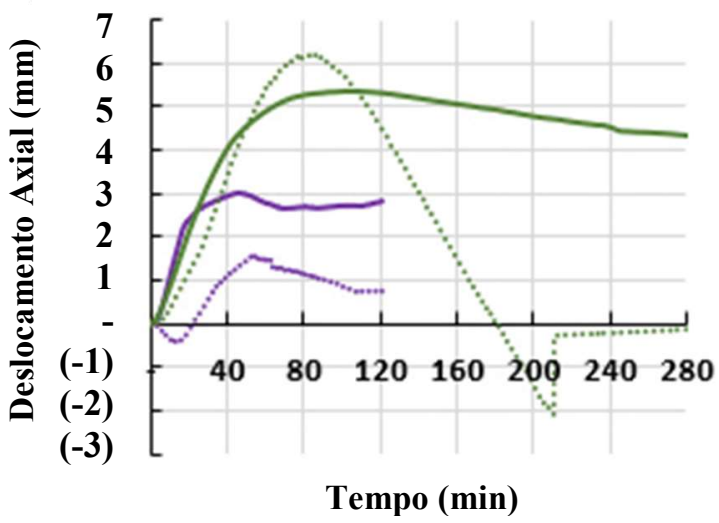

Experimental (H220-ORT-T15)

Numérico (H220-ORT-T15)

Experimental (H220-PAR-T15)

— Numérico (H220-PAR-T15)

Figura 4.16 - Análise do deslocamento axial para os pilares inseridos em paredes: a) formados pelo perfil HEA 100; b) formados pelo perfil HEA 220

Fonte: Autor da Pesquisa (2018).

Diante dos resultados apresentados e analisando os procedimentos de ensaio, acreditase que, possivelmente, houve erros de medição dessa grandeza, principalmente para os pilares inseridos em paredes. Como discutido no Capítulo 2, o deslocamento axial foi medido nos ensaios experimentais de referência a partir da média dos valores encontrados em quatro transdutores fixados em uma placa situada no topo e na base dos pilares, como pode ser vista na Figura 4.17.

A diferença obtida entre os resultados médios da base e do topo correspondia ao deslocamento axial do pilar. É importante destacar que o deslocamento medido na base foi bastante pequeno, de modo que quase não afetava o valor final. Diante disso, na modelagem numérica, a base do pilar foi considerada engastada, como descrito nesse capítulo, e o deslocamento axial foi captado por meio do nó RP-2 em todos os modelos numéricos (ver Figura 4.1, Figura 4.2 e Figura 4.3).

Como descrito em Rocha (2016), pilares inseridos em paredes apresentam gradientes térmicos na seção transversal devido ao seu aquecimento diferencial, o que promove rotação em suas extremidades. Por essa razão, a média entre os quatro transdutores situados no topo do pilar pode não representar precisamente o deslocamento axial do mesmo. 


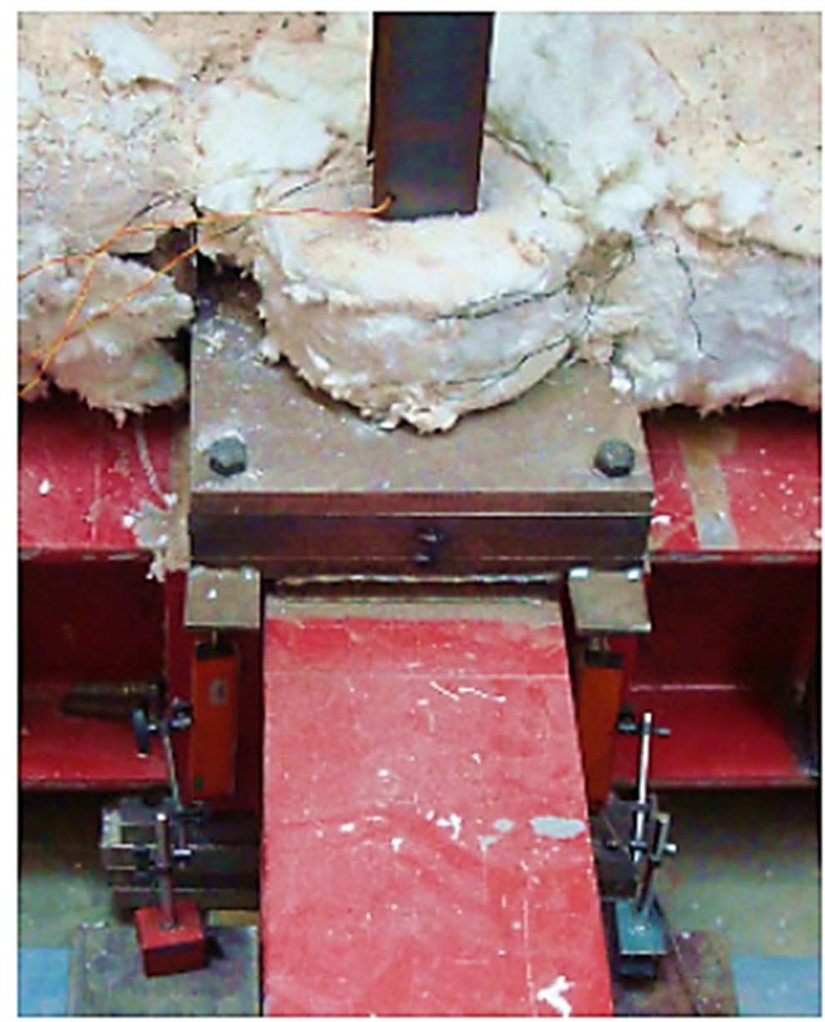

Figura 4.17 - Posicionamento dos transdutores de deslocamento no ensaio experimental Fonte: Rocha (2016).

Ainda segundo a última referência, principalmente nos pilares com maior gradiente térmico, como por exemplo, o pilar H220-ORT-T15, os resultados obtidos pelos transdutores quanto aos deslocamentos axiais apresentaram sinais opostos, em virtude das rotações às quais os elementos estão sujeitos, de maneira que a média resultou em um valor possivelmente não representativo. Por essa razão, essa grandeza, ainda que tenha sido aqui considerada e analisada, não foi utilizada para fins de validação dos modelos numéricos termoestruturais.

\subsubsection{Comparação entre os resultados numéricos obtidos e aqueles apresentados na literatura}

No meio científico, há uma certa carência de estudos a respeito do comportamento de pilares associados a alvenaria em situação de incêndio e, adicionalmente, foi possível constatar que as pesquisas já desenvolvidas focaram basicamente na influência da orientação do perfil de aço frente à ação térmica na resistência ao fogo dos pilares.

No presente trabalho foi observado que somente essas grandezas não são suficientes para compreender o comportamento termoestrutural desse tipo de elemento estrutural, de modo 
que a parede e sua respectiva vinculação, bem como o tipo de seção transversal em contato com a alvenaria, também influenciam no desempenho dos pilares em elevadas temperaturas. No que diz respeito aos estudos numéricos já realizados sobre pilares embutidos em alvenarias, a seguir se procedem comparações entre esses e os resultados obtidos no presente trabalho no desempenho termoestrutural desses elementos estruturais.

Conforme mencionado no Capítulo 2, em Correia (2011) foram realizados ensaios experimentais e estudos numéricos sobre pilares de aço e mistos de aço e concreto isolados e inseridos em parede. Com ênfase nos protótipos de interesse para esse trabalho, a Figura 4.18 e a Figura 4.19 trazem os resultados numéricos de alguns dos vários elementos estruturais estudados em Correia (2011).
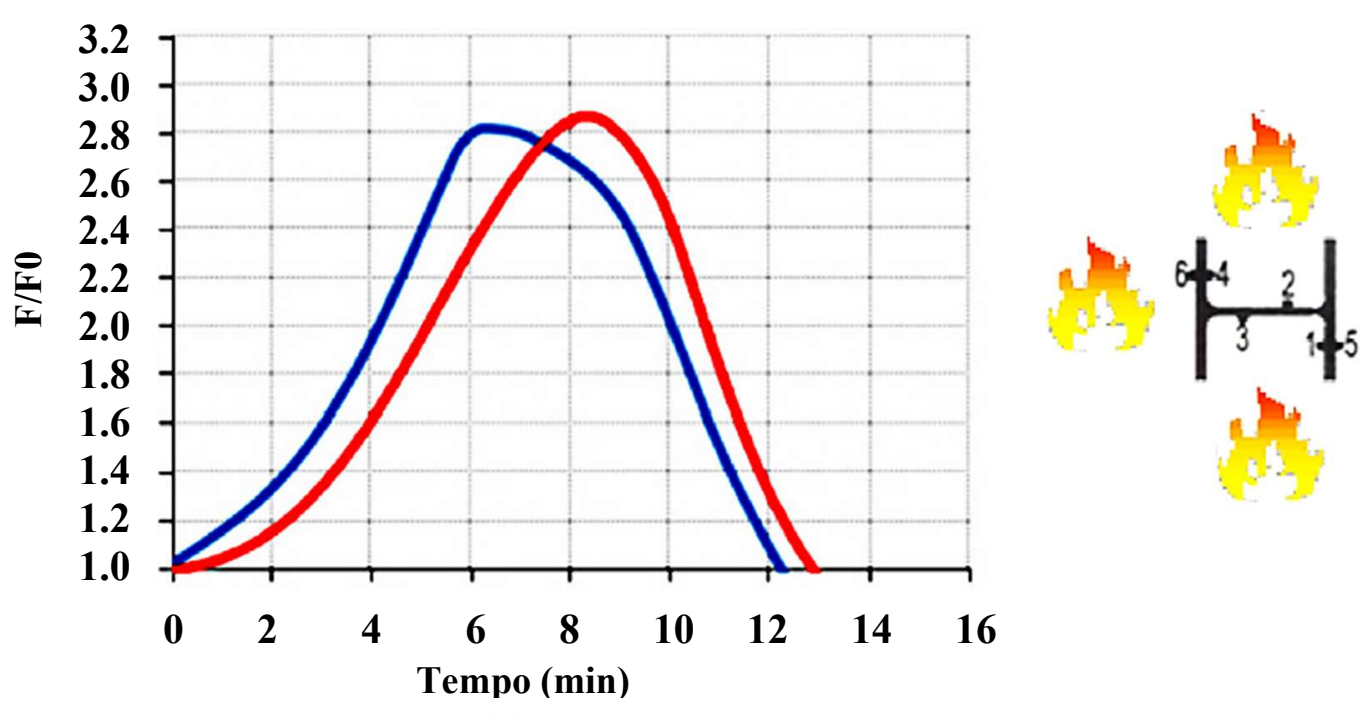

NUM-HEA 160 EXP-HEA 160

Figura 4.18 - Resultado numérico para o pilar isolado formado pelo perfil HEA 160 Fonte: Correia (2011).

Por meio da análise com relação à Figura 4.18, percebe-se que, para os pilares isolados, foi possível gerar modelos que representaram de forma satisfatória os ensaios experimentais do ponto de vista de força axial relativa, assim como também obtido na presente pesquisa conforme Figura 4.4. No entanto, é possível notar que a modelagem numérica não gerou resultados próximos ao experimental para os pilares embutidos em paredes com qualquer orientação do perfil de aço frente à ação térmica, como pode ser vista na Figura 4.19. 

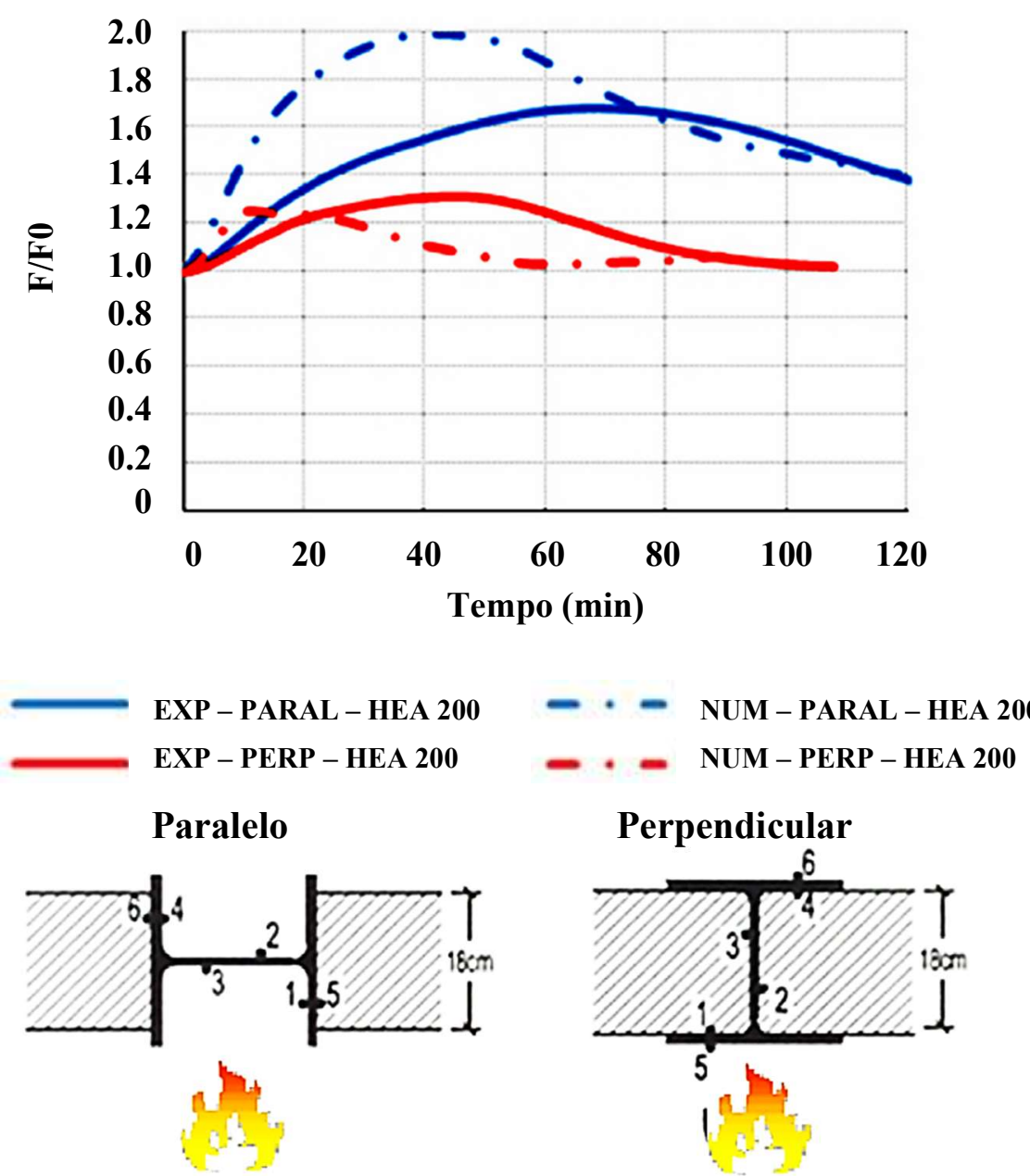

Figura 4.19 - Resultados numéricos para os pilares inseridos em paredes formados pelo perfil HEA 200

Fonte: Correia (2011).

As curvas numérica e experimental, como mostra a Figura 4.19, também apresentam certa distância, de maneira similar aos resultados obtidos por essa pesquisa quando não se considerou a influência da parede (ver Figura 4.6). Tal aspecto pode ser, possivelmente, a razão para a diferença encontrada entre essas curvas na análise numérica do estudo de Correia (2011).

Em Rocha (2016), cujos resultados foram utilizados para validação dos resultados numéricos dessa pesquisa, também foi realizado um trabalho similar ao citado anteriormente em contextos experimental e numérico, de modo a compreender a influência de diversos parâmetros no desempenho de pilares em situação de incêndio. Em relação à modelagem numérica, como foi descrito no Capítulo 2, as duas metodologias testadas não foram suficientes para gerar resultados suficientemente satisfatórios para todos os pilares, isolados e ou não, como pode ser visto na Figura 4.20 e na Figura 4.21. 


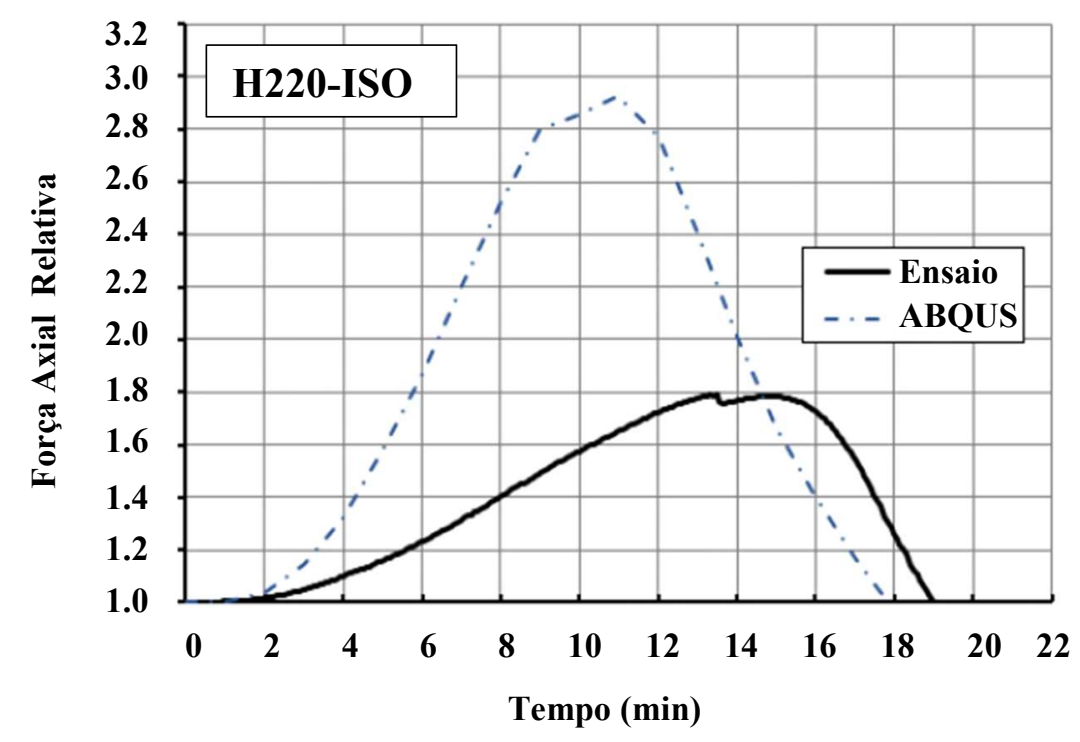

Figura 4.20 - Resultado numérico para o pilar de aço isolado Fonte: Rocha (2016).

No caso dos pilares isolados (Figura 4.20), a grande dificuldade encontrada ao proceder a modelagem numérica estava associada à definição da rigidez da estrutura de restrição utilizada nos ensaios experimentais. Já no caso dos pilares inseridos em alvenarias (Figura 4.21), a imprecisão dos resultados da estratégia numérica proposta em Rocha (2016) pode estar atrelada principalmente à influência das paredes.

a)

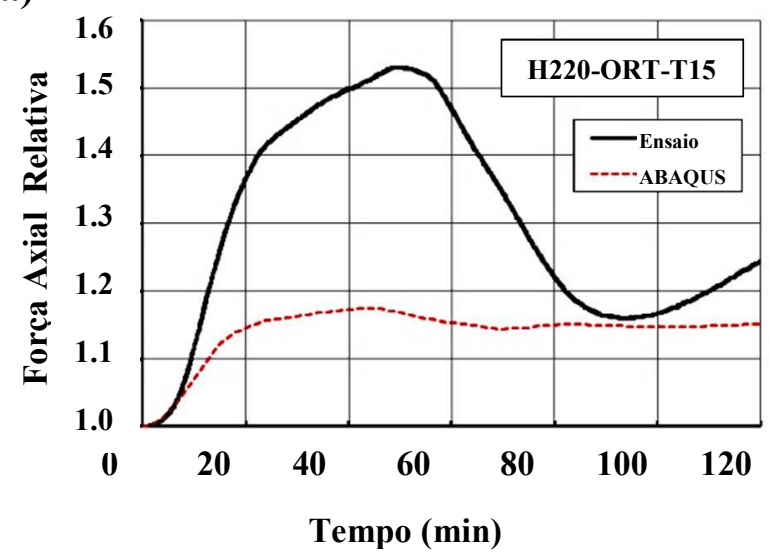

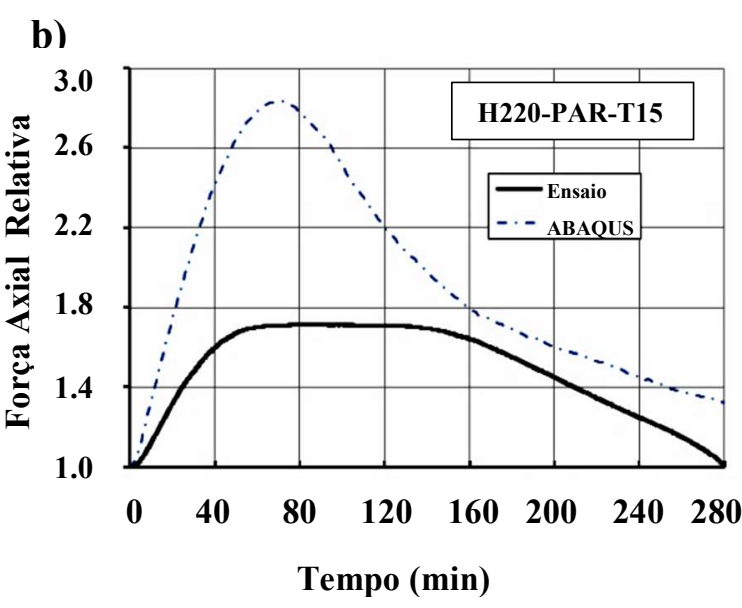

Figura 4.21 - Resultados numéricos para os pilares de aço inseridos em paredes descritos em Rocha (2016)

Fonte: Rocha (2016). 
Por fim, como último estudo a ser abordado nessa seção, vale mencionar aquele desenvolvido e apresentado em Simões (2016), no qual foram consideradas abordagens numéricas e experimentais para pilares isolados e inseridos em paredes formados pelo perfil HEA 100. Os modelos numéricos, como mostrado na Figura 4.22, apresentam resultados substancialmente diferentes daqueles medidos experimentalmente para os três tipos de pilar analisados.

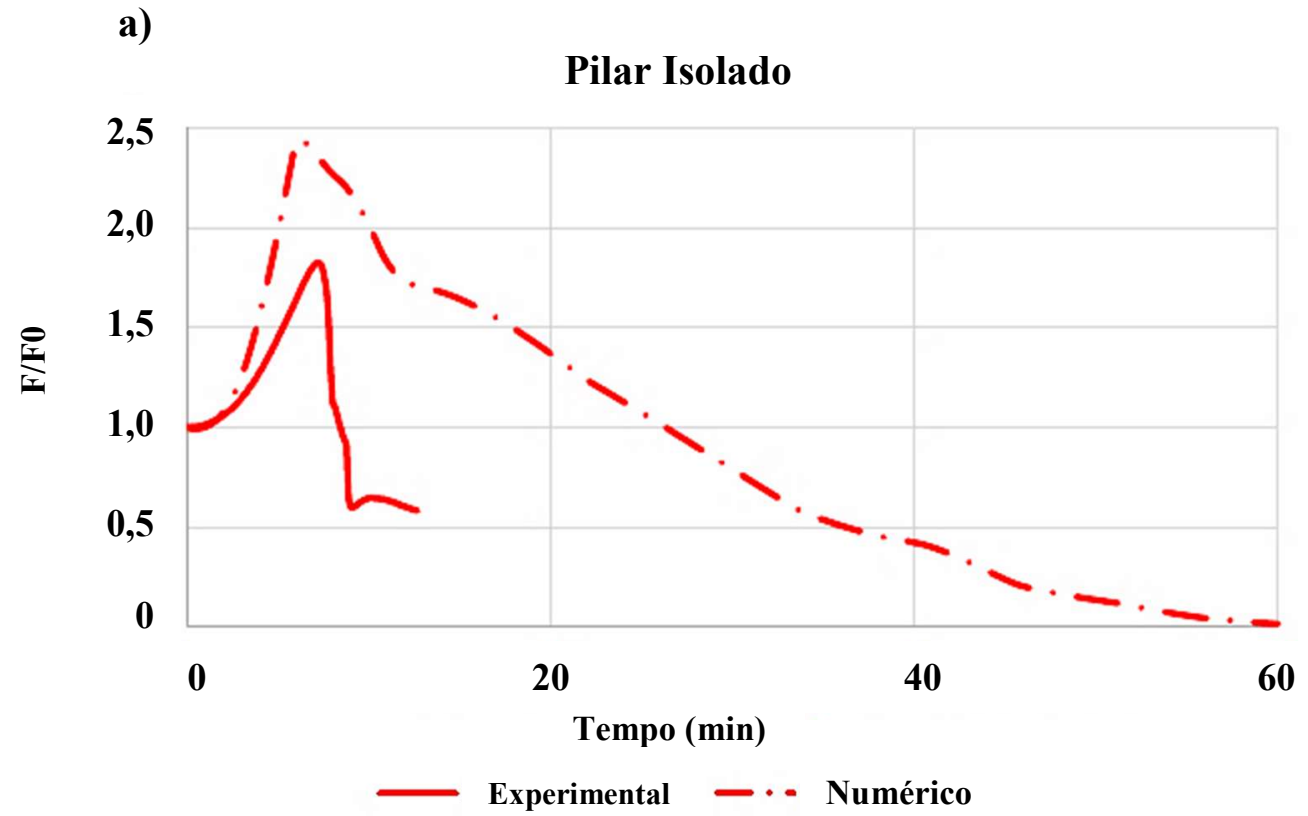

b)

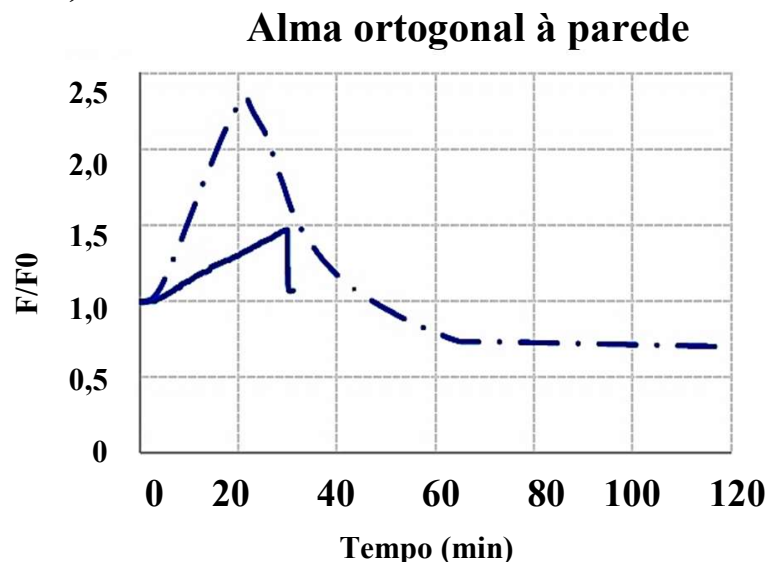

Experimental - - Numérico c)

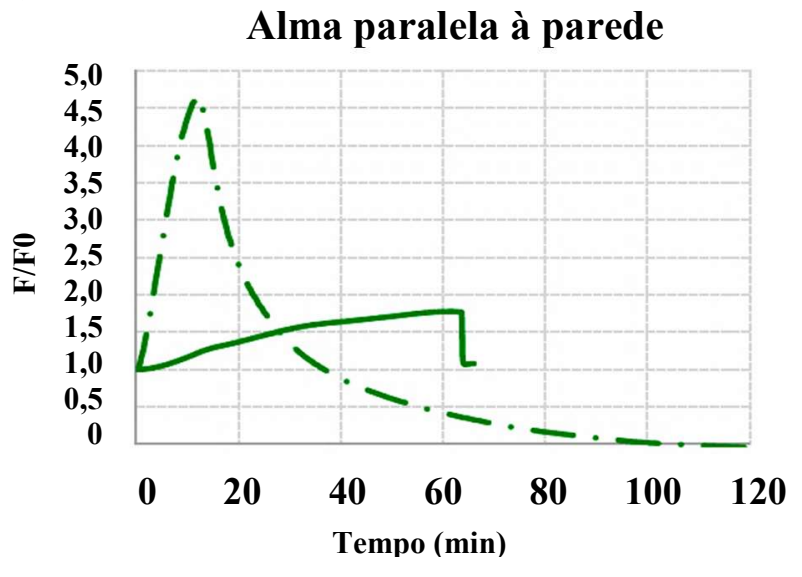

Experimental - - Numérico

Figura 4.22 - Resultados numéricos para os pilares de aço descritos em Simões (2016) Fonte: Simões (2016).

Diante do exposto, percebe-se a complexidade em se representar numericamente o comportamento de pilares em situação de incêndio, principalmente quando esses elementos 
estão inseridos em paredes. Os resultados numéricos para pilares em contato com alvenarias nas três referências mencionadas se apresentaram bastante diferentes dos seus respectivos ensaios experimentais, aspectos que demonstram a forte necessidade de mais pesquisas na área para melhor compreender o comportamento dos mesmos em situação de incêndio.

Quando os resultados das três referências mencionadas são comparados com os resultados obtidos na presente pesquisa para os pilares de estudo, em que se considera a forte influência das paredes no comportamento dos pilares inseridos nas mesmas, observa-se a efetividade da estratégia numérica aqui apresentada enquanto contribuição trazida para o correto entendimento do conjunto pilar-alvenaria dentro do contexto da Segurança das Estruturas em Situação de incêndio.

\subsection{RESUMO DOS RESULTADOS NUMÉRICOS TERMOESTRUTURAIS}

A realização da análise termoestrutural contou com duas estratégias de modelagem. A primeira, denominada "estratégia numérica I", consistiu em inserir molas axiais e rotacionais nas extremidades dos pilares de modo a simular o sistema de restrição utilizado nos ensaios experimentais. Tal metodologia gerou resultados adequados somente para os pilares isolados, uma vez que para os pilares que apresentavam contato com paredes, essas mesmas apresentavam apenas função de compartimentação.

A partir de um primeiro teste considerando vinculação na lateral das paredes, percebeuse que essas apresentavam forte influência no comportamento termoestrutural dos pilares. Os travamentos da alvenaria nas direções laterais e ortogonais à sua superfície apresentaram pouca relevância para os pilares mais robustos (H220-ORT-T15 e H220-PAR-T15), entretanto a resposta numérica para os pilares mais esbeltos (H100-ORT-T7 e H100-PAR-T7) resultou melhorada.

Já para a direção axial da parede, quando totalmente travada, notava-se substancial elevação da rigidez do sistema global aumentando as forças axiais desenvolvidas nos pilares. Apenas para o modelo H220-ORT-T15 tal verificação foi satisfatória, o que indica que essa configuração da parede frente à ação térmica, por apresentar uma temperatura média menor do conjunto pilar-parede e, consequentemente, menor deslocamento axial, promove uma maior rigidez axial ao sistema por um tempo de exposição maior ao fogo.

O conjunto pilar-parede pode ser convertido em um sistema de rigidez equivalente responsável por suportar a força aplicada na direção axial (U3) do elemento estrutural, o que parece justificar o travamento dessa grandeza influenciar de forma considerável o 
comportamento termoestrutural dos pilares. A intensidade dessa rigidez, ou ainda o nível de travamento dessa direção, é de difícil mensuração, uma vez que envolve a degradação das propriedades dos materiais, temperatura média do pilar e o gradiente térmico desenvolvido, o que torna a análise não linear.

Diante do exposto, passou a ser proposta uma segunda estratégia, denominada “estratégia numérica II”, em que foram inseridas molas nas laterais das paredes que permitiam controlar a sua rigidez na direção axial (U3), com o intuito de encontrar uma dada rigidez adequada para todos os modelos estudados, considerando, é claro, as diferentes proporções das seções transversais dos pilares.

A partir da calibração numérica das molas axiais das paredes, foi possível obter os quatro modelos de pilares inseridos em elementos de compartimentação minimamente consistentes para essa abordagem de caráter inicial, permitindo que o comportamento termoestrutural dos pilares estudados fosse melhor compreendido e, consequentemente, melhor representado.

Diante dos modelos numéricos validados, no Capítulo V, a ser descrito no que segue, será realizado um conjunto de análises paramétricas com o intuito de verificar a influência de fatores como a restrição térmica e o nível de carregamento no desenvolvimento das forças que surgem ao longo do aquecimento, tendo como foco também a resistência ao fogo do elemento estrutural. 


\section{CAPÍTULO 5}

Tomando por base a proposta de modelagem numérica termoestrutural apresentada no Capítulo 4, para pilares de aço isolados e inseridos em paredes, aquela mesma estratégia será aqui utilizada com o intuito de estender as análises desenvolvidas no capítulo citado para casos diferentes daqueles expressos no programa experimental de referência, Rocha (2016).

É importante ressaltar que as curvas de aquecimento identificadas na análise experimental e utilizadas no processo de validação dos modelos numéricos não resultaram em concordância com a curva de incêndio-padrão proposta pela ISO 834:1999, recomendada pela ABNT NBR 14323:2013. Adicionalmente, também merece destaque o fato de os coeficientes utilizados para representar os fenômenos de radiação dos ensaios também não coincidirem com os recomendados por essa mesma norma brasileira.

Considerando o exposto nos dois últimos parágrafos, e como a ideia é verificar a coerência de resultados obtidos com base nas prescrições da ABNT NBR 14323:2013, para fins de contribuições futuras, no presente capítulo serão realizadas análises paramétricas para avaliar o comportamento estrutural de pilares de aço isolados e, principalmente, inseridos em paredes, considerando as disposições previstas na norma. Assim, os pilares serão modelados utilizando a curva de incêndio-padrão em concordância com a ISO 834:1999, com os parâmetros térmicos definidos pela norma brasileira. Portanto, para os pilares isolados e para a face exposta ao fogo dos pilares em contato com paredes serão adotados o valor de emissividade resultante da superfície de aço igual a 0,7 e valor do coeficiente de convecção igual a $25 \mathrm{Wm}^{2} /{ }^{\circ} \mathrm{C}$.

Em relação às propriedades térmicas para o lado não exposto e aquelas correspondentes às paredes na face aquecida, a norma brasileira não traz informações a respeito. Portanto, serão empregados os parâmetros fornecidos pelos códigos normatizados europeus conforme descritos no Capítulo 3 juntamente com aqueles utilizados em Correia, Rodrigues e Real (2014). Assim, para a face não exposta, adotou-se emissividade igual a 0,7 e coeficiente de convecção igual a $4 \mathrm{Wm}^{2} /{ }^{\circ} \mathrm{C}$. O tempo de análise do modelo térmico, a princípio, foi limitado ao instante em que a força axial que atua no pilar volta ao seu valor inicial, caracterizando a resistência ao fogo, conforme descrito em Neves (1995). 
Dentre os parâmetros monitorados nas análises numéricas realizadas, foram considerados o fator de carregamento do pilar e o nível de restrição térmica imposta ao elemento estrutural. Como níveis de carregamento, foram adotados valores correspondentes a $25 \%, 50 \%$ e 75\% da força normal resistente do pilar à temperatura ambiente, cuja determinação da força última desse mesmo elemento seguiu as prescrições disponibilizadas pela ABNT NBR 8800:2008, descrita no Apêndice $\boldsymbol{C}$.

No que concerne às restrições térmicas, essas se dividem em restrição axial e restrição rotacional. O foco dessa pesquisa está direcionado principalmente na influência do nível de restrição axial no comportamento termomecânico dos pilares, de modo que foram avaliados os seguintes valores adimensionais: $0,0,05,0,1,0,3,0,75$ e 1 , correspondentes à relação entre a rigidez da estrutura circundante e a rigidez do pilar. $\mathrm{O}$ valor da rigidez axial dos pilares foi calculado por meio da Equação 2.2, apresentada no Capítulo 2 desta dissertação.

Tendo em vista o fato de os pilares metálicos formados pelos perfis HEA 100 e HEA 220 possuírem diferentes capacidades de carga e de rigidez, os valores absolutos do carregamento aplicado e da rigidez da estrutura circundante resultaram diferentes para cada caso, conforme Tabela 5.1, porém os níveis de carregamento e de rigidez relativa fixados anteriormente foram respeitados. Outras abordagens, de caráter inicial e exploratório, sobre a atuação da restrição rotacional também foram realizadas.

Tabela 5.1 - Força normal resistente e rigidez axial dos pilares estudados

\begin{tabular}{ccc}
\hline & Perfil HEA 100 $^{\mathbf{a}}$ & Perfil HEA 220 $^{\mathbf{a}}$ \\
\hline Força normal resistente $(\mathrm{kN})$ & 335 & 1785 \\
Rigidez axial do pilar $(\mathrm{kN} / \mathrm{mm})$ & 123,7 & 375,1 \\
\hline
\end{tabular}

\footnotetext{
${ }^{\text {a }}$ Perfil de aço formador do elemento estrutural

Fonte: Autor da Pesquisa (2018).
}

Nos itens que seguem, será apresentada a forma como cada um dos parâmetros citados anteriormente deverá influenciar no comportamento termoestrutural dos pilares em situação de incêndio, analisando, principalmente, a contribuição no desenvolvimento das forças axiais relativas ao longo do aquecimento. Para isso, a abordagem será dividida em pilares isolados e pilares inseridos em paredes. 


\subsection{PILARES DE AÇO ISOLADOS}

\subsubsection{Análises paramétricas com relação à influência do fator de carga}

Nas Figuras 5.1a - 5.1f são apresentadas as curvas de evolução da força axial relativa considerando para a rigidez axial os parâmetros adimensionais iguais a 0,05, 0,3 e 1,0. Para os demais valores estudados, as curvas podem ser encontradas no Apêndice D. Na apresentação dos resultados referentes a influência do fator de carga, considera-se fixo um dado nível de rigidez axial relativa, de forma separada para os pilares H100-ISO e H220-ISO. Nessa análise, a modelagem numérica foi realizada sem considerar a rigidez rotacional do pilar.

De modo geral, observa-se por meio dos resultados obtidos, que quanto maior o nível de carga aplicado antes do aquecimento, menor será o valor atingido da força axial relativa. Analisando primeiramente a Figura 5.1a correspondente ao modelo H100-ISO, os resultados mostram que para os pilares de aço com $\alpha_{A}=0,05$, as forças axiais relativas máximas para os fatores de carga de $25 \%, 50 \%$ e $75 \%$ resultaram iguais a 2,21, 1,53 e 1,29, respectivamente. Já para o pilar H220-ISO, como pode ser visto na Figura 5.1b, para o mesmo parâmetro $\alpha_{\mathrm{A}}=0,05$, os valores de pico para força axial foram iguais a 1,59, 1,21 e 1,08, respectivamente.

Além disso, tais picos foram observados em tempos distintos, sendo que quanto menor o fator de carga, mais tempo se fez necessário para atingi-lo, aspecto que se mostra coerente pois o aumento de força se dá de forma gradual com o aumento de temperatura. Sendo assim, quanto menor a carga aplicada ao pilar no início do aquecimento, mais força axial será possível absorver e, consequentemente, mais tempo para atingir a sua capacidade de carga.

Após o pico, as forças apresentam uma queda até o instante de tempo em que elas voltam a apresentar a mesma intensidade aplicada antes do aquecimento, o qual é aqui considerado como o tempo de resistência ao fogo. É importante relembrar ao leitor que os resultados dos modelos numéricos para pilar H100-ISO, quando de sua validação numérica no Capítulo 4, resultaram consistentes somente até a carga máxima atingida, enquanto que para o trecho descendente esse mesmo modelo numérico não representou de forma satisfatória os resultados experimentais (ver Figura 4.4) e, portanto, não é possível medir o tempo crítico para esse pilar. 
H100-ISO

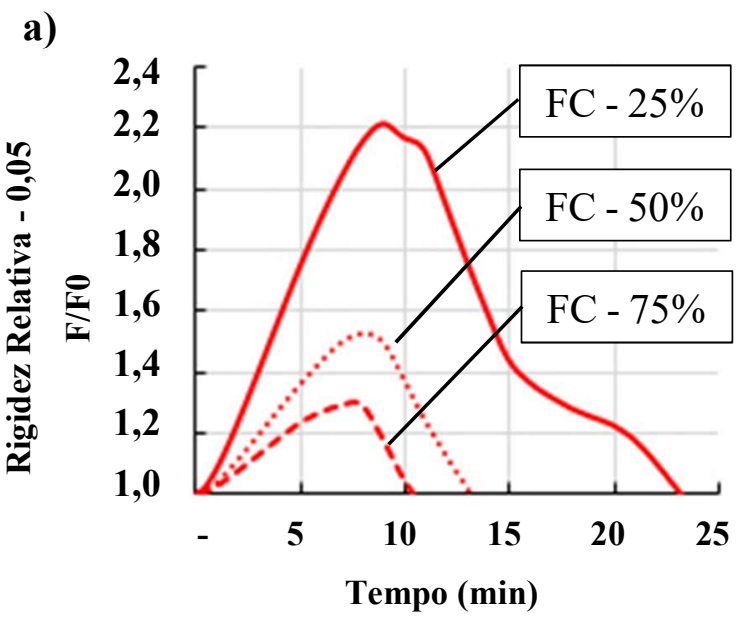

c)

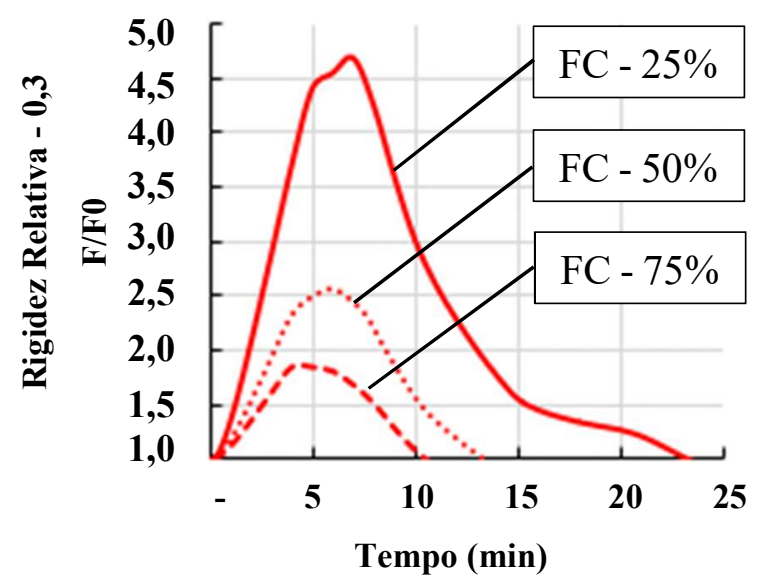

e)

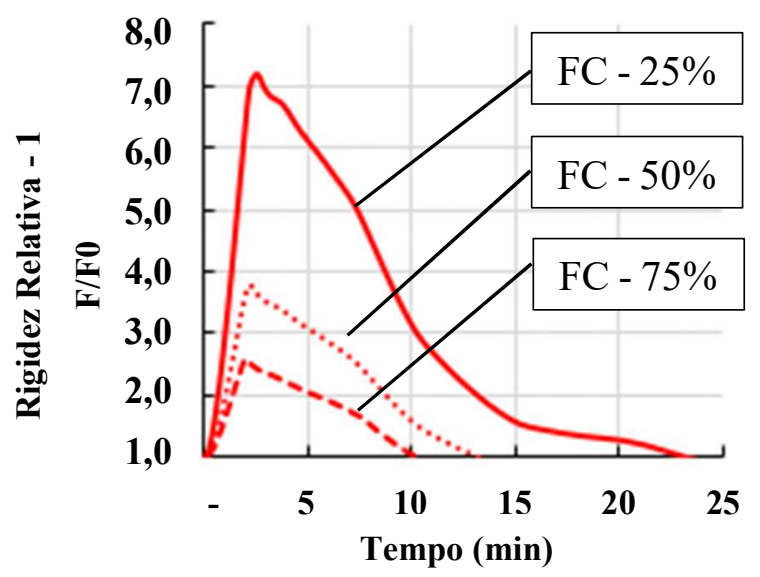

b)

H220-ISO

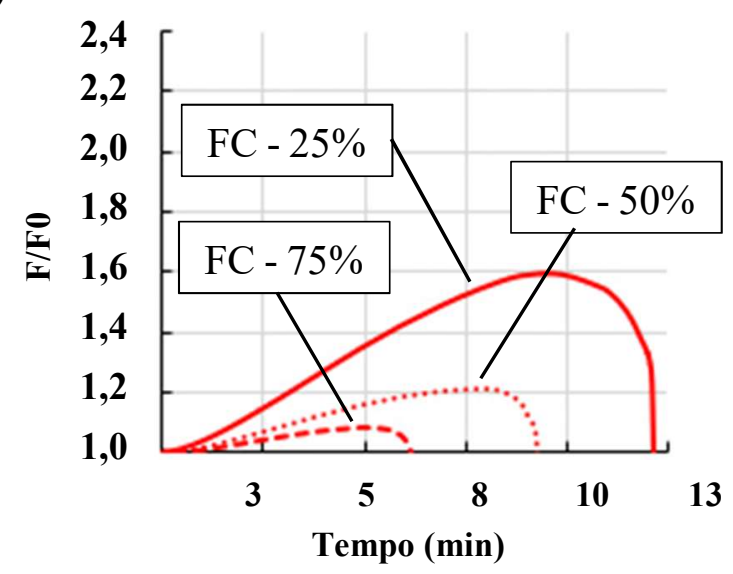

d)

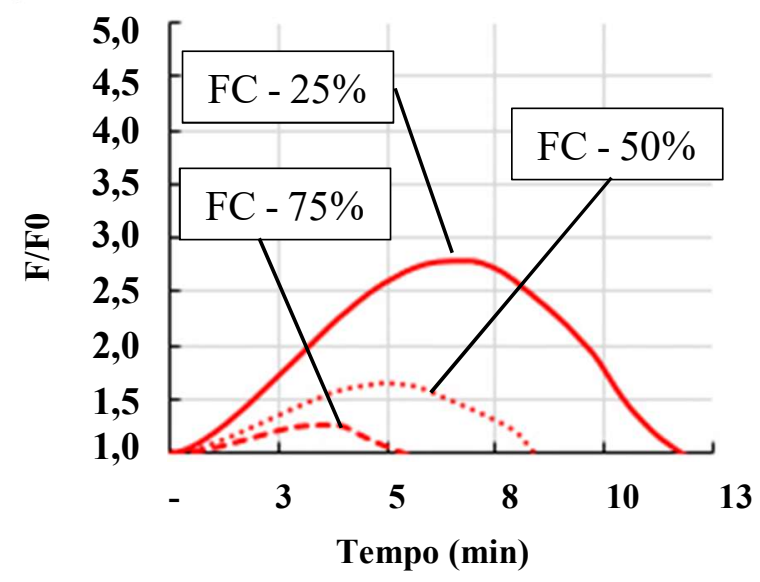

f)

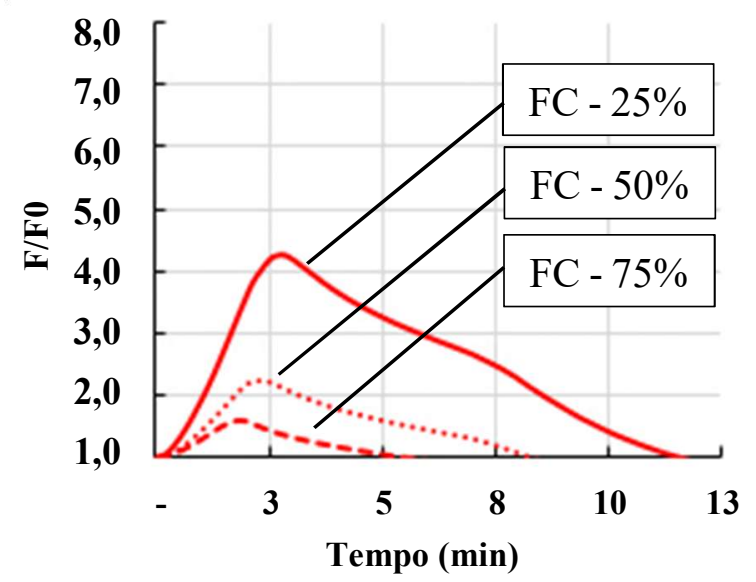

Figura 5.1 - Influência da variação do fator de carga no desenvolvimento das forças axiais relativas para os pilares de aço isolados

Fonte: Autor da Pesquisa (2018). 
Apesar disso, no caso da Figura 5.1b, os tempos críticos encontrados para o pilar H220ISO resultaram iguais a $12,16,9,24$ e 6,14 minutos para fatores de carga iguais a $25 \%, 50 \%$ e $75 \%$, respectivamente, o que permite estabelecer, assim como para os valores de pico, que os tempos críticos observados são sempre maiores quanto menor for o fator de carga empregado.

Vale ressaltar que o fato de as forças axiais relativas para os pilares H220-ISO apresentarem valores menores está relacionado às intensidades das forças iniciais aplicadas antes do aquecimento que, por sua vez, são os divisores para o cálculo da Força Axial Relativa, maiores que no caso dos pilares H100-ISO. Dessa forma, a força absoluta atuante no pilar durante o aquecimento pode, em muitos casos, ser maior no pilar metálico mais robusto, mesmo tendo uma força axial relativa menor.

De qualquer forma, a análise pela força relativa é bastante significativa para comparar o comportamento termoestrutural entre elementos com características diferentes, bem como para verificar a quantidade de carregamento adicional que este elemento estará sujeito ao longo do incêndio.

\subsubsection{Análises paramétricas com relação à influência à restrição térmica}

\subsubsection{Quanto à rigidez axial}

De forma semelhante ao que foi realizado no item anterior, são apresentadas nas Figuras 5-2a - 5.2f o comportamento da força axial relativa para um dado nível de carregamento, de forma separada para os pilares H100-ISO e H220-ISO, com relação à variação da rigidez axial da estrutura circundante. Mais uma vez, destaca-se o fato de a modelagem numérica ter sido realizada sem considerar a rigidez rotacional do pilar.

Dentre as principais considerações, atenções especiais devem ser direcionadas ao fato de a variação da rigidez axial da estrutura circundante pouco (ou quase nada) ter afetado o tempo crítico dos pilares dado um mesmo nível de carregamento, aspecto esse que apresenta coincidência com as observações identificadas e apresentadas em Neves (1995). 


\section{H100-ISO}

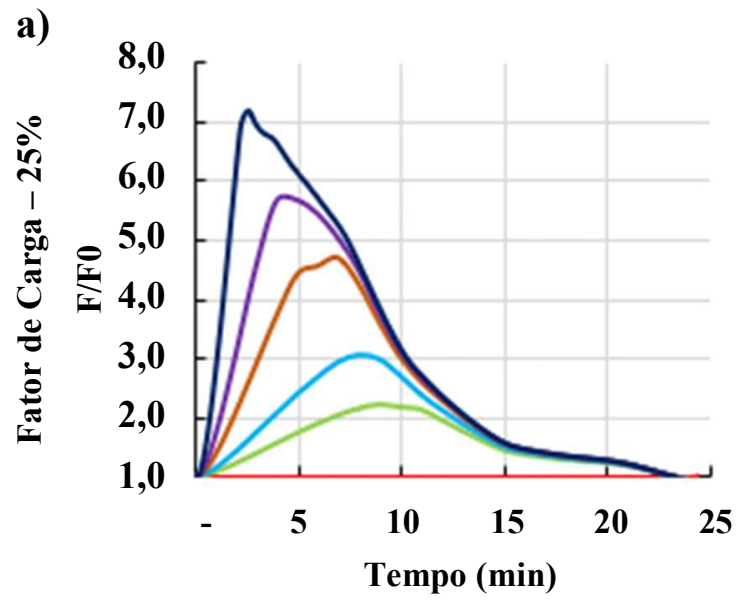

c)

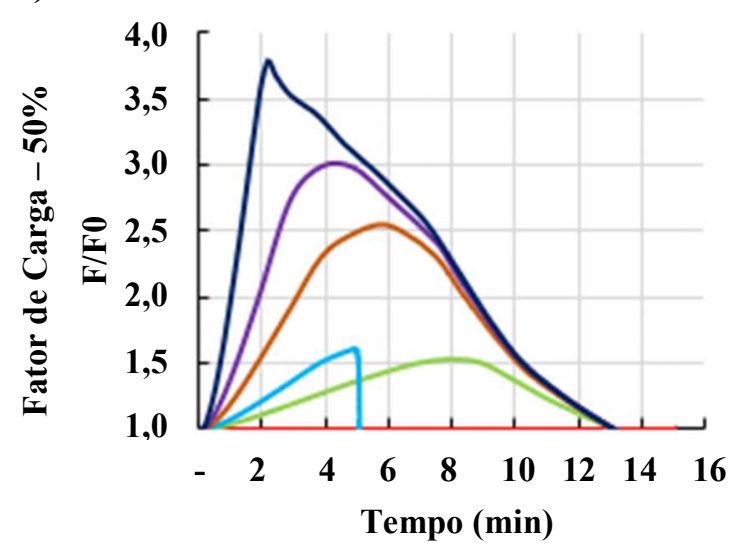

e)

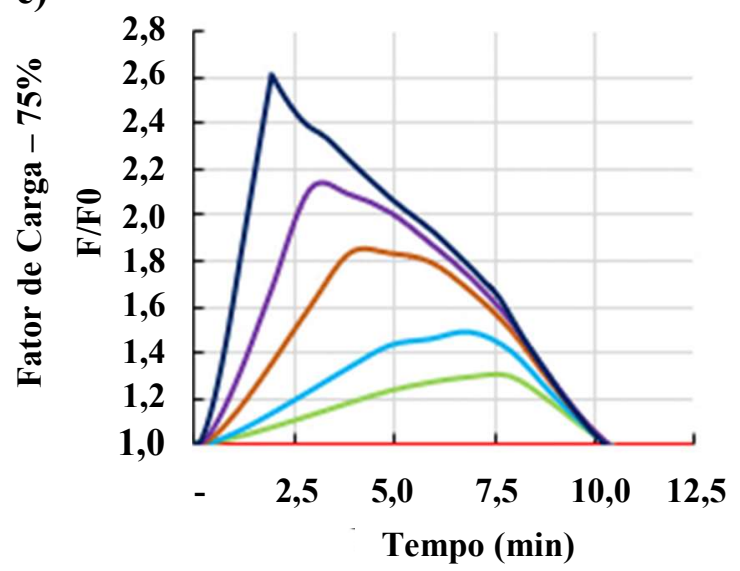

H220-ISO

b)

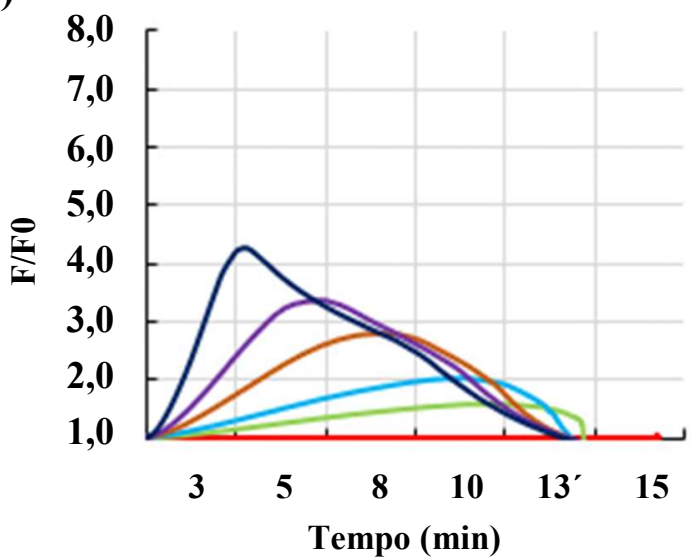

d)

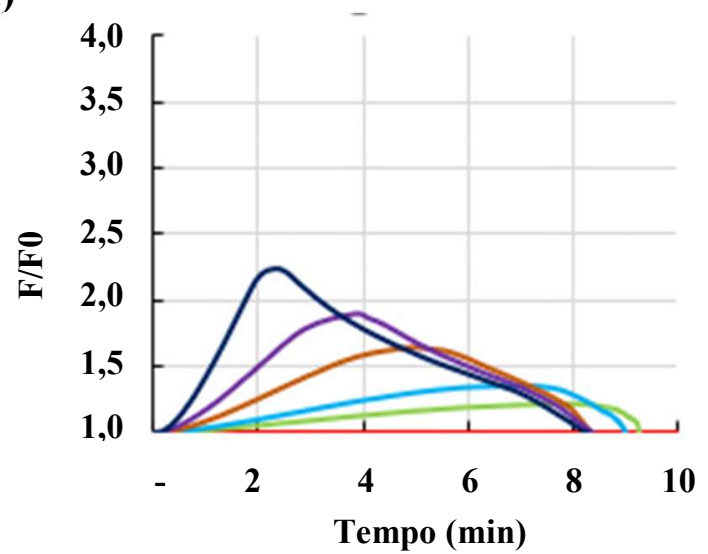

f)

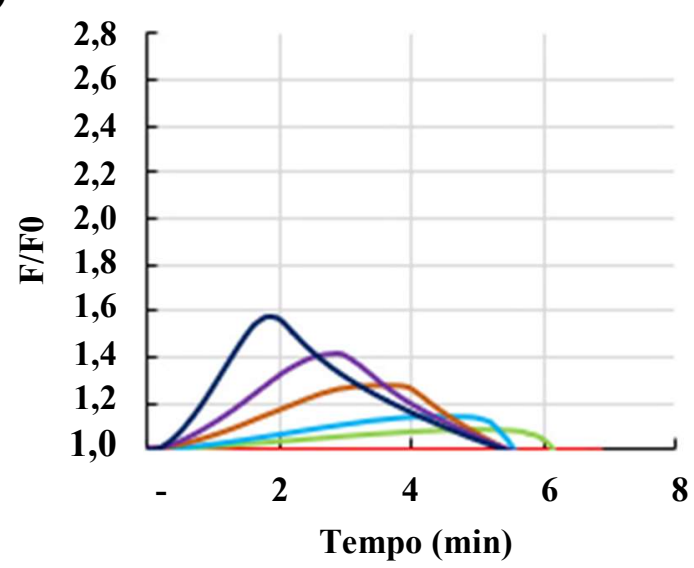

Rigidez Relativa

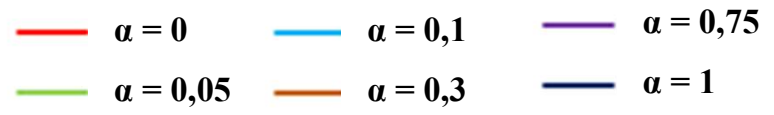

Figura 5.2 - Influência do nível de rigidez axial no desenvolvimento das forças axiais relativas para os pilares de aço isolados

Fonte: Autor da Pesquisa (2018). 
Vale aqui estabelecer análise particular com relação o pilar H220-ISO, para o qual a maior diferença entre tempos críticos foi observada principalmente entre as rigidezes adimensionais mais baixas, ou seja, iguais a 0,0,05 e 0,1, o que permite, de maneira geral, estabelecer como entendimento que a presença de restrição térmica é muito mais impactante do que sua própria intensidade na resistência ao fogo do elemento estrutural.

Ainda por meio da Figura 5.2, é possível notar o modo como a mudança da rigidez da estrutura circundante afeta a intensidade da força gerada no pilar. Observa-se que quanto maior a rigidez axial, maior será a restrição à expansão térmica, gerando assim um esforço maior nos pilares.

\subsubsection{Quanto à restrição rotacional}

Esse subitem busca identificar a influência da restrição rotacional no comportamento termomecânico dos pilares de aço. Adotou-se o fator de carga equivalente a $25 \%$ e a rigidez axial relativa igual a 0,3 para os dois pilares de aço isolados. Vale ressaltar que esse estudo possui apenas um caráter preliminar, visto que poucas análises foram realizadas com o intuito de avaliar essa grandeza.

Diante do proposto, buscou-se verificar o quanto a presença da restrição rotacional impacta no desenvolvimento das forças axiais do elemento estrutural. Para tanto, foram testados quatro valores de rigidez: 500, 5000, 50000 e 500000 kN.m/rad. A Figura 5.3 traz os resultados numéricos para o pilar H100-ISO e H220-ISO.

H100-ISO

a)

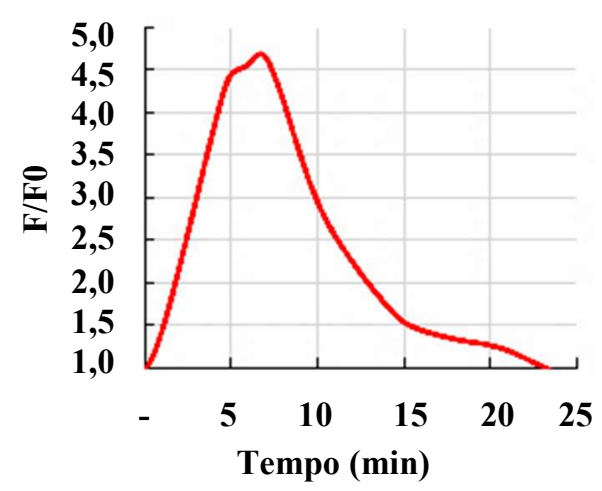

H220-ISO

\section{b)}

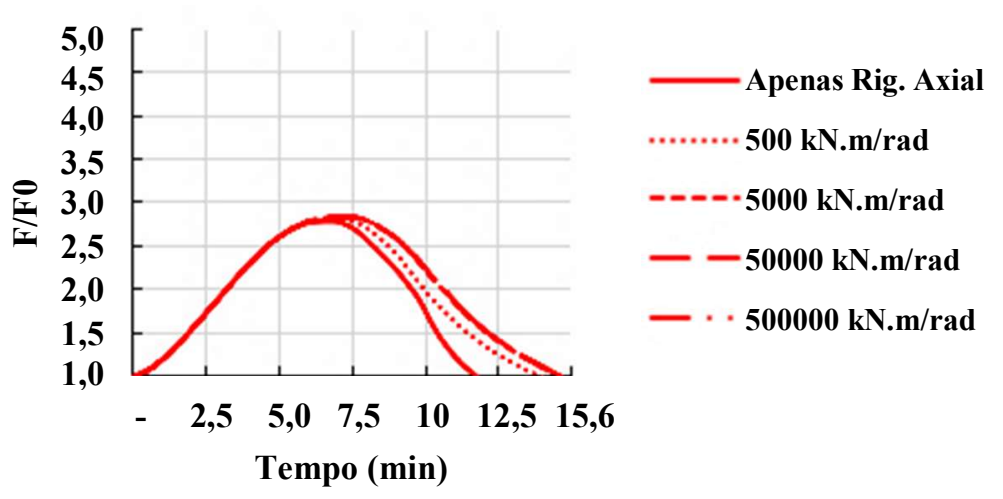

Figura 5.3 - Influência do nível de rigidez rotacional no desenvolvimento das forças axiais relativas para os pilares de aço isolados

Fonte: Autor da Pesquisa (2018). 
$\mathrm{Na}$ parte da curva numérica referente ao crescimento das forças axiais é possível notar que ambos os pilares não sofreram alterações significativas com a inserção da restrição rotacional em suas extremidades uma vez que todas as curvas numéricas se encontram sobrepostas.

Por outro lado, quando se trata do tempo de resistência ao fogo, para o pilar H220-ISO (Figura 5.3b), a presença desse tipo de restrição aumentou o tempo crítico em mais de dois minutos, constatando seu o efeito benéfico, como usualmente relatado em diversos trabalhos de caráter científico. Apesar disso, a partir de um dado valor de restrição rotacional, o tempo crítico se estabilizou.

Em relação ao pilar H100-ISO (Figura 5.3a), novamente nada se pode afirmar sobre o comportamento do trecho descendente da curva, tendo em vista a não validação numérica do modelo para o mesmo, como mencionado em itens anteriores.

\subsection{PILARES INSERIDOS EM PAREDES}

\subsubsection{Análises com relação aos pilares formados pelo perfil HEA 100}

\subsubsection{Análises paramétricas com relação à influência do fator de carga}

Assim como foi realizado para os pilares isolados, nas Figuras 5.4a - 5.4f são apresentadas as curvas de evolução da força axial relativa para os parâmetros adimensionais de rigidez axial iguais a 0,05, 0,3 e 1,0. Para os demais valores estudados, as curvas numéricas se encontram apresentadas no Apêndice D. Na apresentação dos resultados, considera-se fixo um dado nível de rigidez axial relativa de forma separada para os pilares H100-ORT-T7 e H100PAR-T7 e varia-se o nível de carga aplicado ao elemento estrutural.

Dentre as abordagens a serem realizadas nesse item, inicia-se com a diferença entre o formato, no caso, o esboço, das curvas numéricas para os pilares com a alma ou paralela ou ortogonal ao plano da parede. Para o pilar H100-PAR-T7, a evolução das forças axiais se desenvolve de modo equivalente ao do pilar isolado, aspecto que parece apresentar coerência uma vez que esse pilar apresenta dimensões reduzidas, principalmente se comparado ao perfil HEA 220, bem como uma maior área de exposição ao calor, o que acaba por impor um gradiente térmico menos evidenciado na seção transversal. 


\section{H100-ORT-T7}

a)

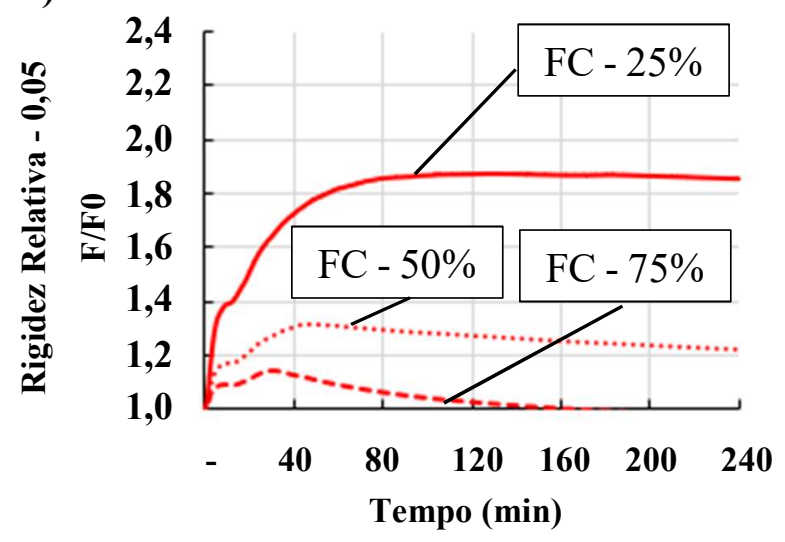

c)

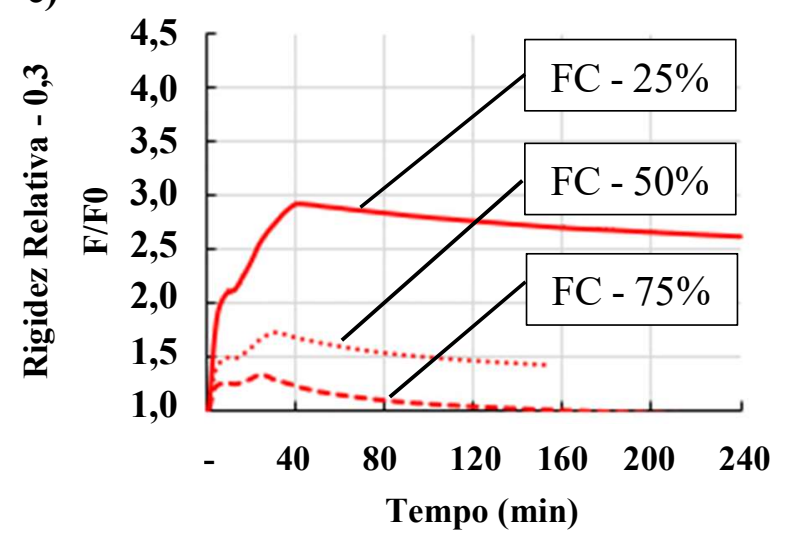

e)

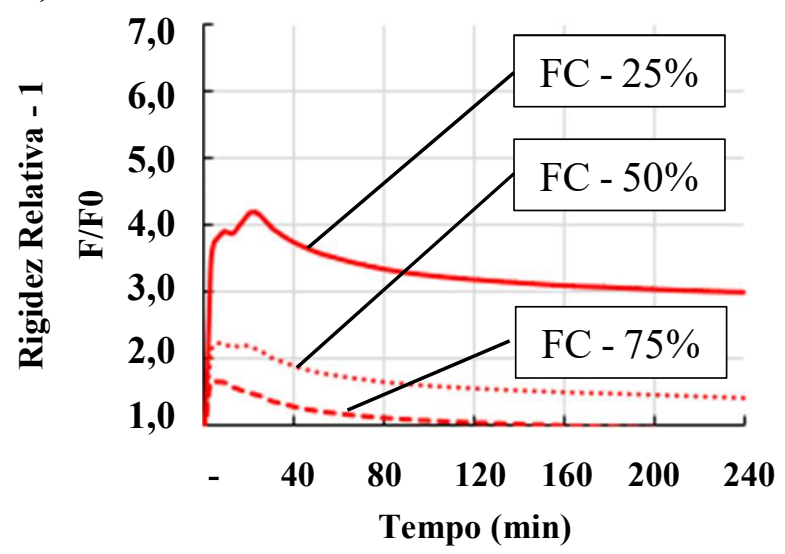

H100-PAR-T7

b)

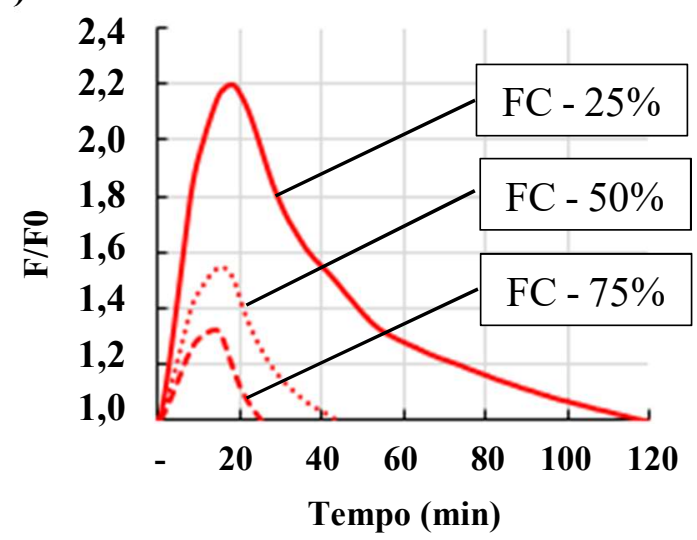

d)

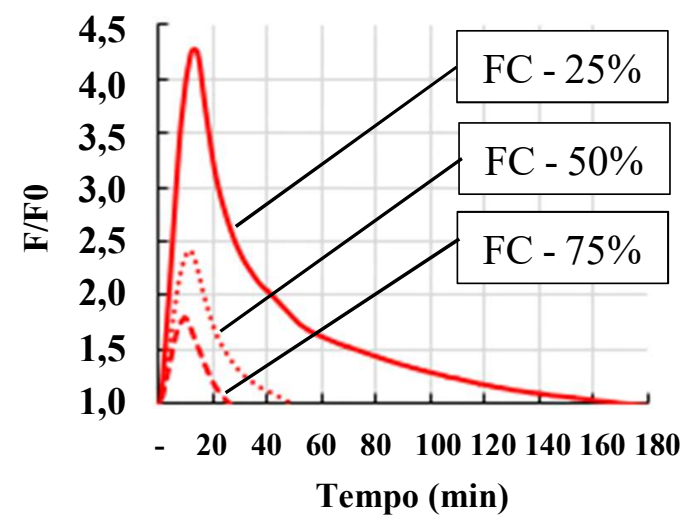

f)

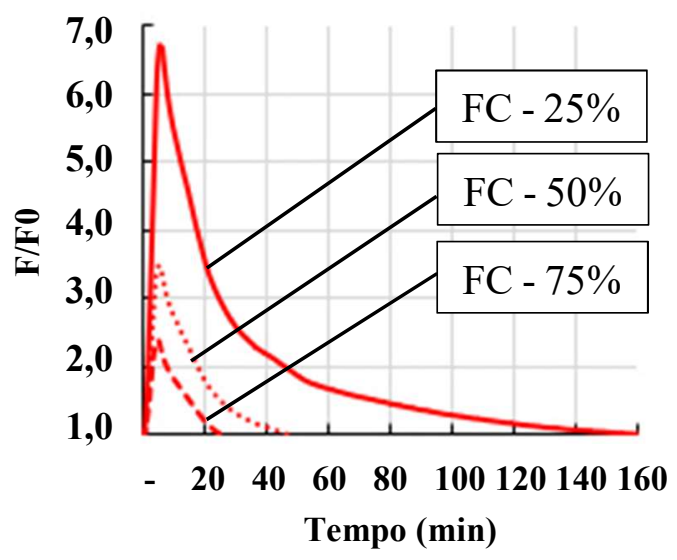

Figura 5.4 - Influência da variação do fator de carga no desenvolvimento das forças axiais relativas para os pilares de aço H100-ORT-T7 e H100-PAR-T7

Fonte: Autor da Pesquisa (2018).

Em relação ao pilar H100-ORT-T7, observa-se rápida elevação da força axial no início do aquecimento, proveniente da expansão do pilar devido ao acelerado crescimento da temperatura da mesa exposta ao fogo. A partir de certo instante, a elevação da força axial cessa e esse parâmetro apresenta um leve caimento, pois nesse momento a mesa exposta entra em escoamento associado à redução de suas propriedades mecânicas. Em seguida, essa mesma 
grandeza volta a crescer em virtude do aquecimento da alma e da mesa não exposta à ação térmica que, até então, se encontram com baixas temperaturas. O gradual aumento da temperatura da alma e da mesa não exposta gera nova expansão axial do pilar e, consequentemente, a elevação das forças de restrição. Portanto, quando essas partes atingem o escoamento, a curva novamente volta a decrescer até a força inicialmente aplicada no pilar.

Para esses pilares, como pode ser observado nas Figuras 5.4a, 5.4c e 5.4e, o aumento do fator de carga faz com que o comportamento redução-aumento, descrito no último parágrafo, seja cada vez menos acentuado, uma vez que quanto maior a carga aplicada ao pilar no início do aquecimento, menor será a força axial a ser incorporada à força inicial e, consequentemente, menor o tempo necessário para que seja atingida a capacidade de carga dos elementos da seção transversal.

Além disso, assim como foi obtido para os pilares isolados, quanto maior o nível de carga aplicado antes do aquecimento, menor será o valor atingido para a força axial relativa. Esse aumento também resultou na diminuição do tempo crítico dos elementos estruturais como pode ser visto nas Figuras 5.4b, 5.4d e 5.4f. De acordo com a Figura 5.4b, por exemplo, os tempos críticos encontrados para o pilar H100-PAR-T7 foram de 117,88, 43,88 e 25,88 minutos para os fatores de carga de $25 \%, 50 \%$ e $75 \%$, respectivamente, para uma rigidez axial relativa de 0,05 .

A análise do tempo de resistência ao fogo para o pilar H100-ORT-T7 não foi possível ser realizada, uma vez que poucas curvas voltaram para o nível de carga aplicado inicialmente, dado o tempo de exposição máximo adotado de $240 \mathrm{~min}$. Nesses casos, o tempo crítico foi superior a esse instante. Apesar disso, a análise gráfica permite concluir, de forma intuitiva, que a resistência ao fogo também será impactada de forma negativa pela elevação do fator de carga para esse pilar.

Vale ressaltar que, no caso específico na Figura 5.4c, a curva referente ao fator de carga de 50\% foi interrompida próxima aos 160 minutos devido a uma perda de convergência numérica, que impossibilitou a obtenção do seu comportamento até os 240 minutos.

\subsubsection{Análises paramétricas com relação à influência da restrição térmica}

\subsection{Restrição axial}

De forma semelhante ao que foi realizado no item anterior, nessa seção será analisada a variação da força axial relativa que se desenvolverá nos pilares inseridos em paredes, H100- 
ORT-T7 e H100-PAR-T7, considerando a influência da restrição axial para um determinado nível de carregamento. Os resultados estão apresentados nas Figuras 5.5a - 5.5f que seguem.

\section{H100-ORT-T7}

a)

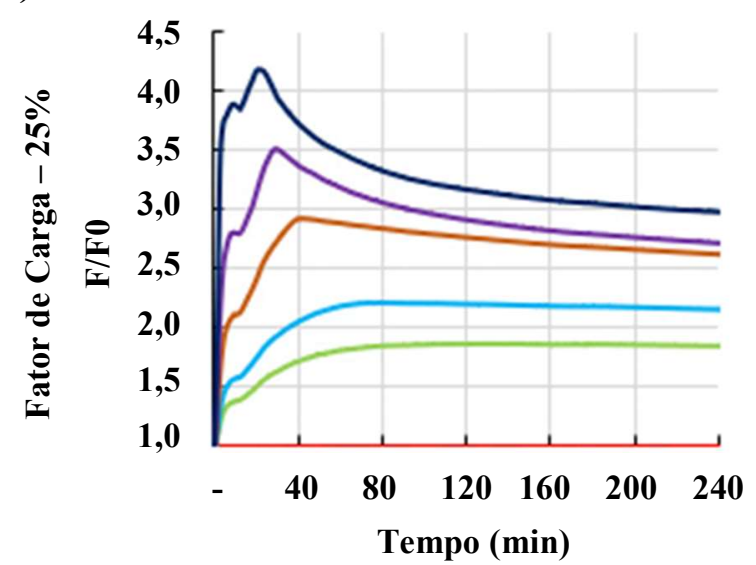

c)

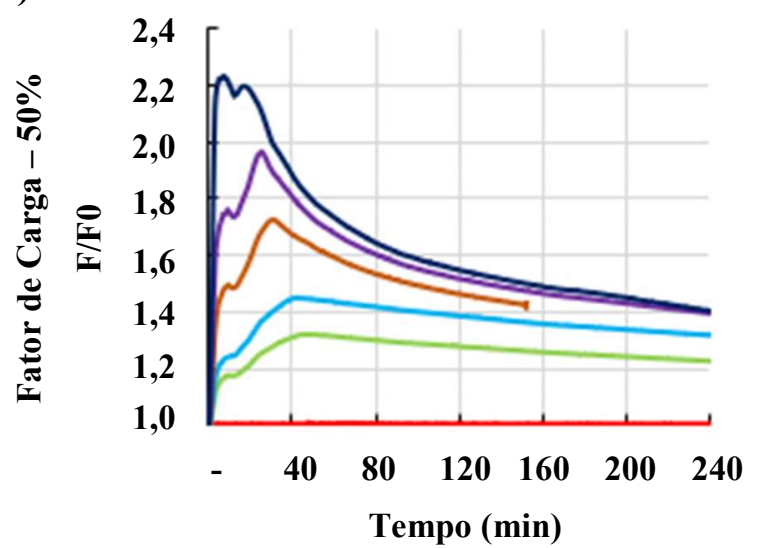

e)

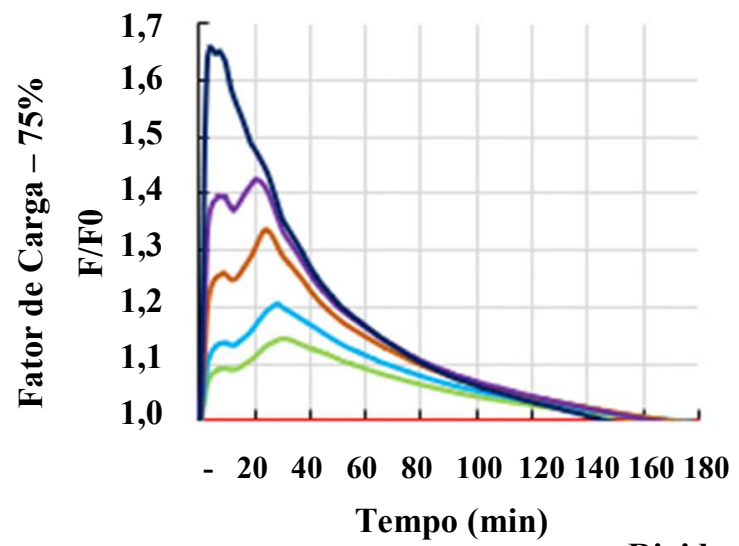

b)

H100-PAR-T7

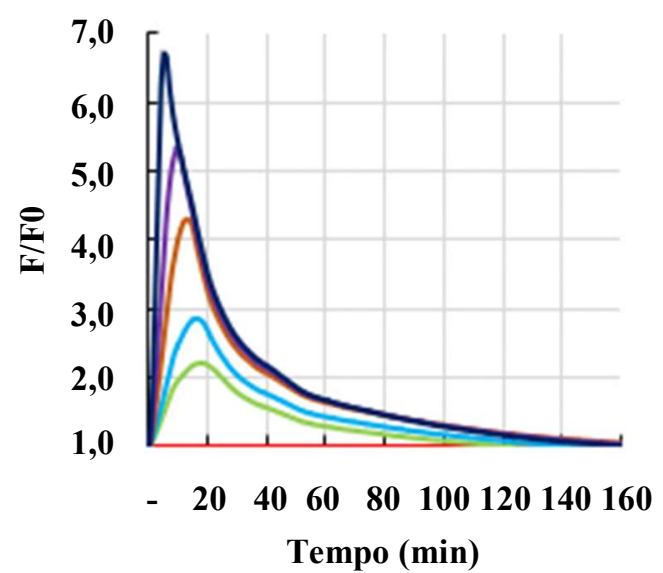

d)

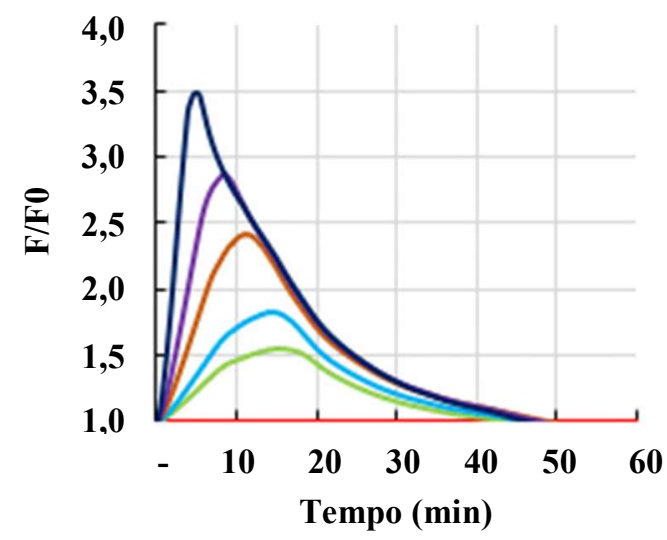

f)

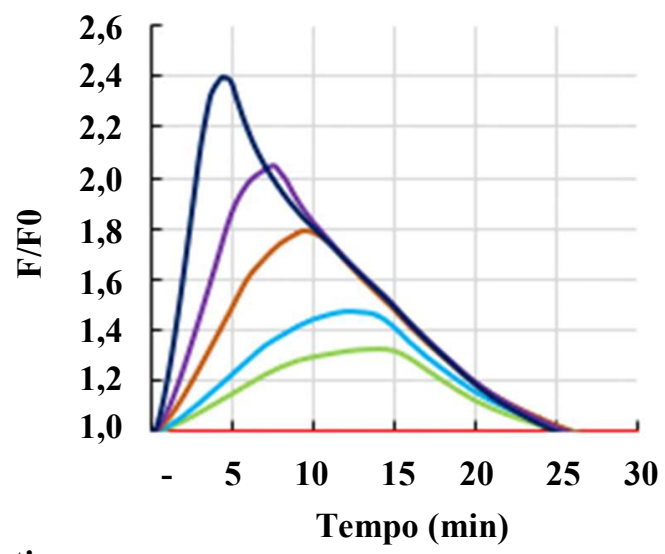

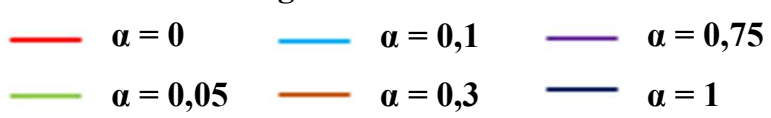

Figura 5.5 - Influência do nível de rigidez axial no desenvolvimento das forças axiais relativas para os pilares de aço H100-ORT-T7 e H100-PAR-T7

Fonte: Autor da Pesquisa (2018). 
Com base em análises com relação às Figuras 5.5a e 5.5b se observa que a mudança da rigidez axial da estrutura circundante afeta a intensidade da força gerada nos pilares, sendo que quanto maior a rigidez maior será a intensidade das forças axiais desenvolvidas.

No que concerne à resistência ao fogo desses elementos estruturais, de maneira similar ao que foi discutido para os pilares isolados, a variação da restrição axial pouco afeta o tempo crítico do pilar quando se considera um mesmo nível de carregamento, na maioria dos casos. Isso pode ser comprovado para alguns dos pilares com a alma ortogonal e paralela à ação térmica, no caso, nas Figuras 5.5b, 5.5d, 5.5e e $5.5 \mathrm{f}$. No entanto, quando o pilar é considerado livre de restrições, ou seja, $\alpha_{\mathrm{A}}=0$, o tempo crítico é substancialmente maior que os demais casos, de modo que o fator que mais impacta na resistência ao fogo desses elementos estruturais é a presença da restrição axial e não a sua intensidade.

\subsection{Rigidez rotacional}

No presente item são apresentados estudos preliminares voltados à influência da rigidez rotacional no comportamento de pilares de aço inseridos em paredes. Para isso, adotou-se o fator de carga equivalente a $75 \%$ e a rigidez axial relativa igual a 0,3 para os dois pilares de aço inseridos em alvenaria formados pelo perfil HEA 100. Foram testados quatro valores para a consideração da rigidez rotacional, no caso, 500, 5000, 50000 e 500000 kN.m/rad. A Figura 5.6 apresenta graficamente os resultados numéricos para os pilares H100-ORT-T7 e H100-PART7.

H100-ORT-T7

a)

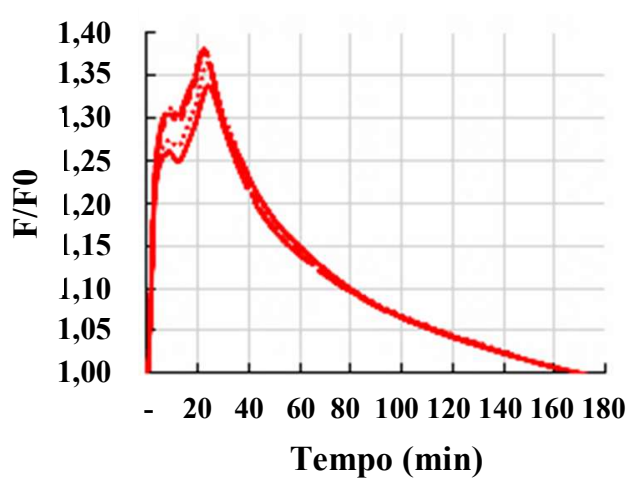

H100-PAR-T7

b)

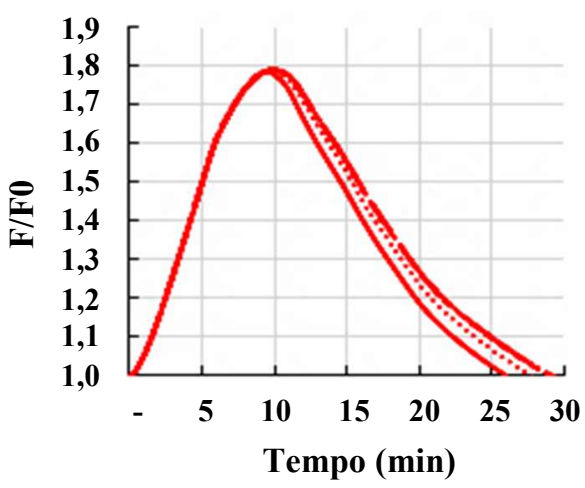

- Apenas Rig. Axial $500 \mathrm{kN} . \mathrm{m} / \mathrm{rad}$ $----5000 \mathrm{kN} . \mathrm{m} / \mathrm{rad}$ $--50000 \mathrm{kN} . \mathrm{m} / \mathrm{rad}$ - $500000 \mathrm{kN} . \mathrm{m} / \mathrm{rad}$

Figura 5.6 - Influência do nível de rigidez rotacional no desenvolvimento das forças axiais relativas para os pilares de aço H100-ORT-T7 e H100-PAR-T7

Fonte: Autor da Pesquisa (2018). 
Por meio de análises com relação à rigidez rotacional e iniciando o estudo pelo tempo de resistência ao fogo é possível observar que o pilar H100-ORT-T7 (Figura 5.6a) manteve seu tempo crítico praticamente invariável em torno de 165 minutos, independente da intensidade adotada para a rigidez rotacional.

Por outro lado, diferentemente do pilar H100-ORT-T7, para o pilar H100-PAR-T7 (Figura 5.6b), a consideração dessa restrição impôs um aumento, ainda que discreto, no tempo de resistência ao fogo, de 26 para 29 minutos, evidenciando a influência benéfica desse tipo de rigidez na resistência ao fogo de pilares. Adicionalmente, vale ressaltar que a partir do momento que a rigidez rotacional apresentou valores substancialmente elevados, o tempo crítico se estabilizou, assim como foi obtido para os pilares isolados.

No que diz respeito à evolução das forças de restrição considerando a relação $F / F_{0}$, a rigidez rotacional pouco (ou quase em nada) alterou a parte da curva numérica referente ao crescimento das forças axiais para o pilar H100-PAR-T7 (Figura 5.6b), assim como ocorreu nos pilares com aquecimento uniforme. Já para o caso do pilar H100-ORT-T7, ao analisar a Figura 5.6a, a princípio, a consideração da rigidez rotacional indica a elevação das forças axiais relativas máximas desenvolvidas no pilar em análise. Isso parece estar associado à escala do eixo vertical utilizada no gráfico. A diferença entre os valores de pico para o pilar modelado com a maior rigidez rotacional e aquele reproduzido sem a presença desse tipo de rigidez é em torno de $3 \%$, o que implica dizer que a influência do parâmetro analisado nas forças máximas é pouco significativa.

\subsubsection{Análises com relação aos pilares formados pelo perfil HEA 220}

\subsubsection{Influência do fator de carga}

Dentro do mesmo contexto das discussões anteriores, no que se refere à influência do fator de carga no comportamento termoestrutural de pilares de aço, nas Figuras 5.7a - 5.7f são apresentadas as curvas de evolução da força axial relativa, considerando novamente como valores os parâmetros adimensionais de rigidez axial iguais a 0,05, 0,3 e 1,0. Demais análises complementares realizadas podem ser encontradas no Apêndice D. Na apresentação dos resultados, considera-se fixo um dado nível de rigidez axial relativa, de forma separada para os pilares H220-ORT-T15 e H220-PAR-T15. 
H220-ORT-T15

a)

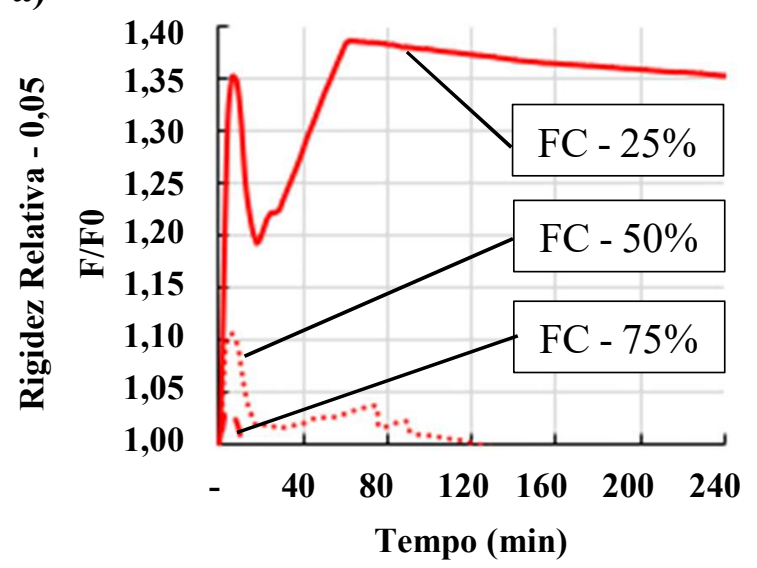

c)

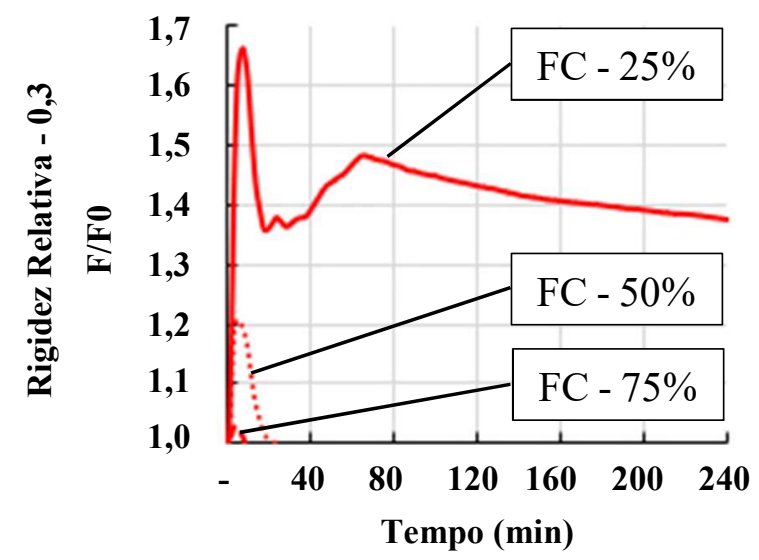

e)

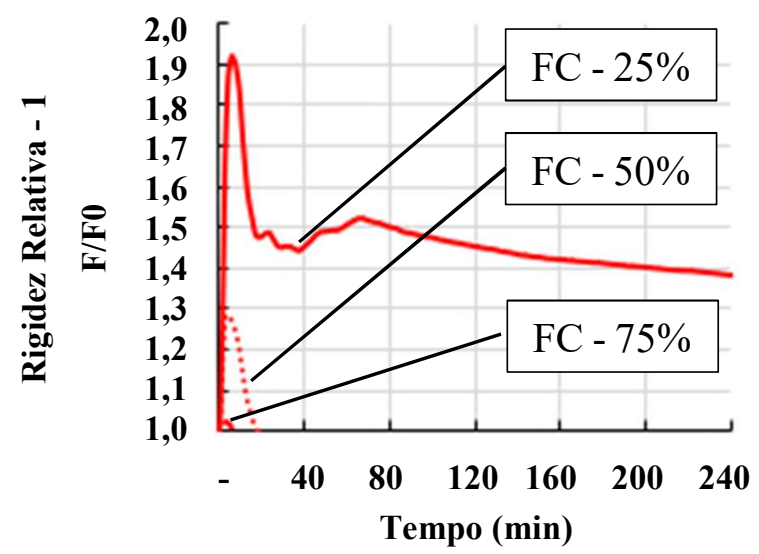

H220-PAR-T15

b)

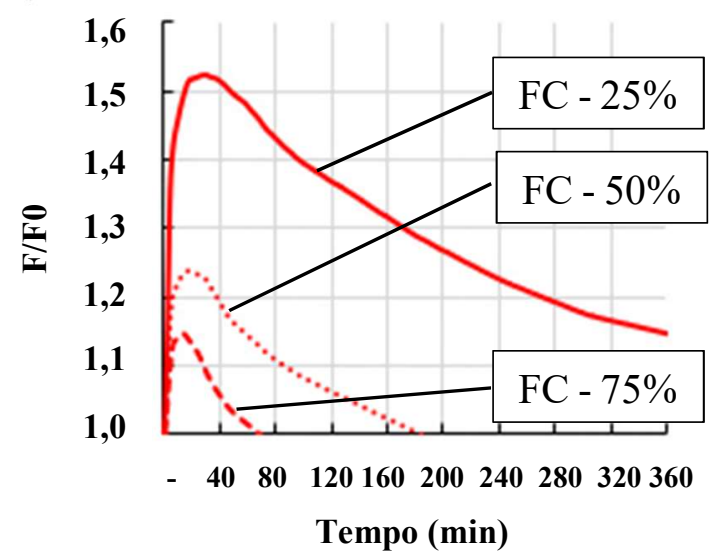

d)

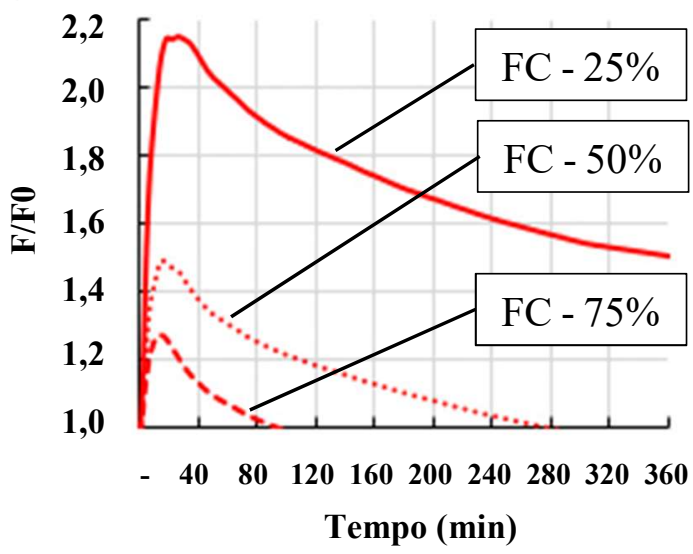

f)

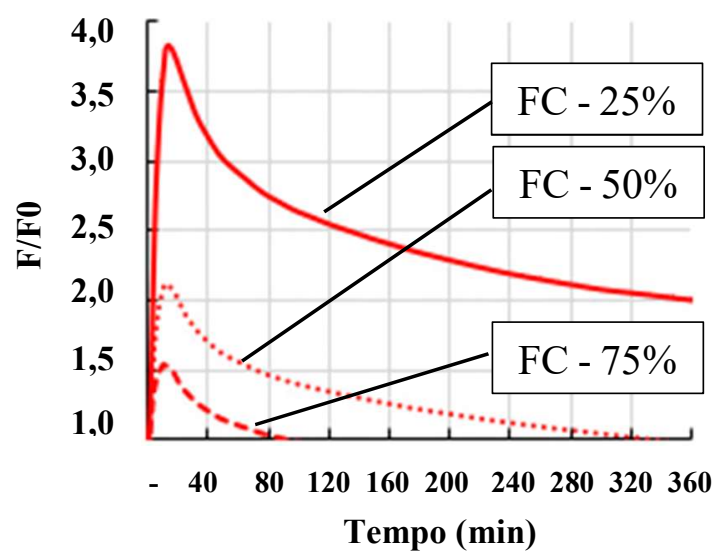

Figura 5.7 - Influência da variação do fator de carga no desenvolvimento das forças axiais relativas para os pilares de aço H220-ORT-T15 e H220-PAR-T15

Fonte: Autor da Pesquisa (2018).

Como já relatado no item 5.2.1.1, há uma diferença no formato (ou esboço) das curvas numéricas para pilares com gradientes térmicos ao longo da alma e ao longo da mesa o que também é evidenciado na Figura 5.7 para os elementos estruturais mais robustos. Observa-se, novamente, que no caso de pilares com a alma ortogonal à superfície da parede, a evolução das 
forças axiais apresenta dois picos de força máxima em resposta à ocorrência de um gradiente térmico fortemente evidenciado na seção transversal, enquanto que nos pilares com as paredes em contato com as mesas, o comportamento das forças de restrição se assemelha aquele desenvolvido nos pilares isolados por apresentar gradiente térmico menos evidenciado.

De forma análoga aos resultados obtidos para os pilares HEA100, para os pilares HEA 220 quanto maior o nível de carga aplicado antes do aquecimento, menor será o valor atingido da força axial relativa $\mathrm{F} / \mathrm{F}_{0}$, uma vez que quanto maior a força aplicada ao pilar no início do aquecimento, menor será a força axial adicional a ser incorporada àquela já aplicada e, consequentemente, haverá redução do tempo necessário para atingir a capacidade de carga dos elementos da seção transversal.

O aumento do fator de carga também resultou na diminuição do tempo crítico dos elementos estruturais. Como pode ser visto na Figura 5.7c, por exemplo, para o pilar H220ORT-T15, os tempos críticos encontrados resultaram iguais a ">240", 21,21 e 8,67 minutos para os fatores de carga iguais a 25\%,50\% e 75\%, respectivamente, em resposta à rigidez axial relativa igual a 0,3. Já para o pilar H220-PAR-T15, Figura 5.7d, para a mesma rigidez axial relativa, os tempos críticos obtidos foram iguais a ">360", 273,97 e 91,58 minutos para os fatores de carga iguais a $25 \%, 50 \%$ e $75 \%$, respectivamente.

Nesse aspecto, é importante ressaltar que, diferentemente dos resultados numéricos encontrados para os pilares constituídos pelo perfil HEA 100 inseridos em paredes, conforme apresentados na seção 5.2.1, para pilares formados pelo perfil HEA 220, mais robustos se comparados aos pilares HEA 100, quando sujeitos a gradientes térmicos com a alvenaria em contato com a alma, esses mesmos apresentam resistência ao fogo menor em comparação aos pilares HEA 220, cujas paredes se encontram em contato com as mesas.

Tal fato sinaliza que a ocorrência de gradientes térmicos mais intensos (mais evidenciados) nesse tipo de pilar, H220-ORT-T15, contribui para uma maior influência do fenômeno denominado Thermal Bowing, provocando momentos fletores de elevada intensidade nas extremidades dos pilares, que acabam apresentando falha por flexo-compressão em um tempo reduzido. Já o pilar H220-PAR-T15, a temperatura média do perfil foi o fator determinante para sua falha por instabilidade.

É possível identificar, por meio dos resultados obtidos, que se a esbeltez do pilar reduzir, a situação descrita tende a ser alterada. O gradiente térmico desenvolvido nos pilares de dimensões reduzidas resulta menor, de modo que o elemento estrutural apresente uma maior temperatura média e, aparentemente, devendo falhar com tempo diferente se comparado a pilares mais robustos. Nessa pesquisa, foi identificado que o pilar H100-PAR-T7 apresentou 
falha em um tempo menor quando comparado ao pilar H100-ORT-T7, uma vez que o fenômeno Thermal Bowing apresentou pouca influência nesses pilares formados por perfis mais esbeltos, tendo sido a temperatura média o fator determinante para o alcance da resistência ao fogo do pilar.

\subsubsection{Influência da restrição térmica}

\subsection{Rigidez Axial}

De forma semelhante ao que foi realizado no item anterior para os pilares formados pelo perfil de aço HEA 100, no presente item serão apresentadas nas Figuras 5.8a - 5.8f a evolução da força axial relativa fixando um nível de carregamento em resposta à variação da restrição axial. A apresentação dos resultados será feita de forma separada para os pilares H220-ORTT15 e H220-PAR-T15,

Inicialmente, analisa-se o desenvolvimento das forças axiais nos pilares. Pode-se observar claramente que a mudança da rigidez axial da estrutura circundante impacta sensivelmente na intensidade da força desenvolvida no pilar, sendo que quanto maior a intensidade da rigidez axial adotada, maior será o esforço gerado nos elementos.

No entanto, vale aqui ressaltar, como observado, que o comportamento descrito no último parágrafo ocorre de forma inversa para o pilar H220-ORT-T15, quando o fator de carregamento se situa em 75\%, conforme Figura 5.8e. Porém, ao comparar os picos de força máxima, a diferença entre as curvas com rigidez axial relativa de 0,05 e 1,0 resulta menor que $1 \%$, o que implica dizer que, em termos práticos, esses valores são os mesmos. Isso ocorreu, possivelmente, pelo fato de o pilar estar sujeito a um nível de força substancialmente alto de modo a não permitir elevar a força de restrição a valores elevados independente da restrição axial.

Em relação à resistência ao fogo dos pilares, nota-se que, para o elemento H220-ORTT15, a elevação do nível de rigidez axial diminuiu o tempo de resistência ao fogo, como pode ser constatado nas Figuras 5.8c e 5.8e. Na Figura 5.8a, porém, devido ao baixo fator de carga, as curvas não voltaram ao nível de carregamento aplicado antes da ação do fogo para o tempo de exposição igual a 360 min, não permitindo interpretações consistentes com relação ao tempo crítico. Vale ressaltar que a curva da Figura 5.8c, referente ao nível de rigidez axial relativa de 0,05 , apresentou comportamento atípico em seu final por problemas de convergência numérica, o que dificultou a análise da mesma. 


\section{H220-ORT-T15}

a)

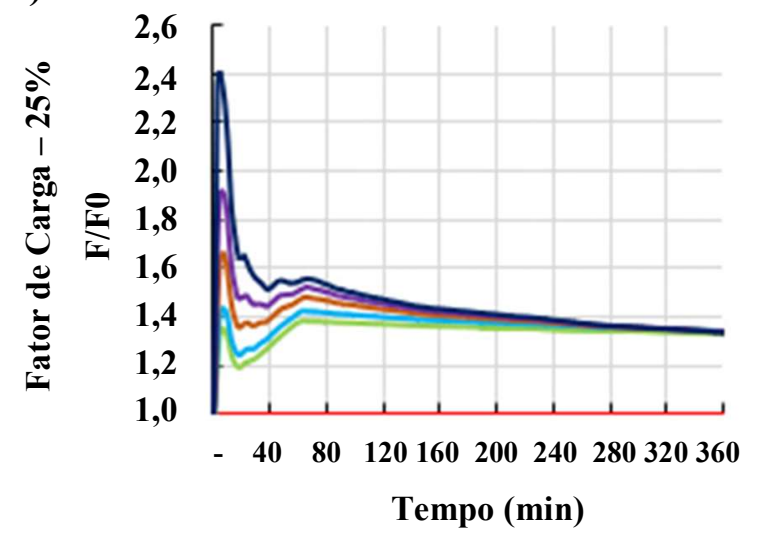

c)

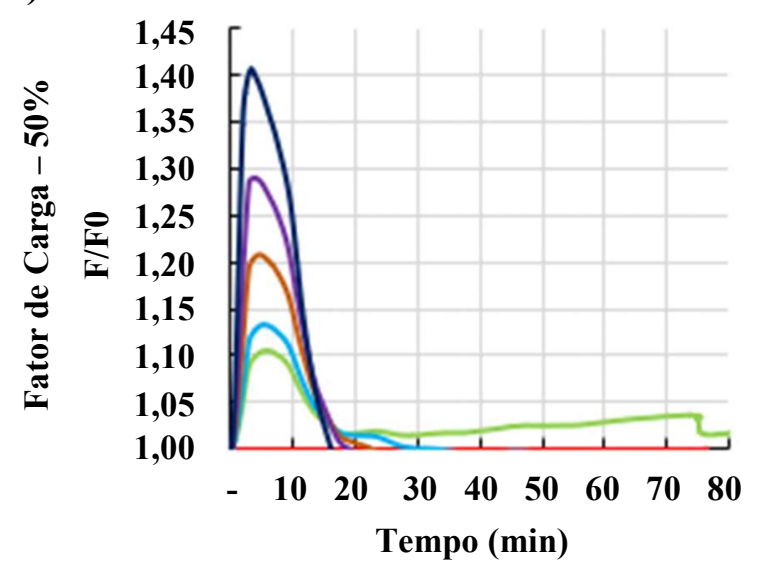

e)

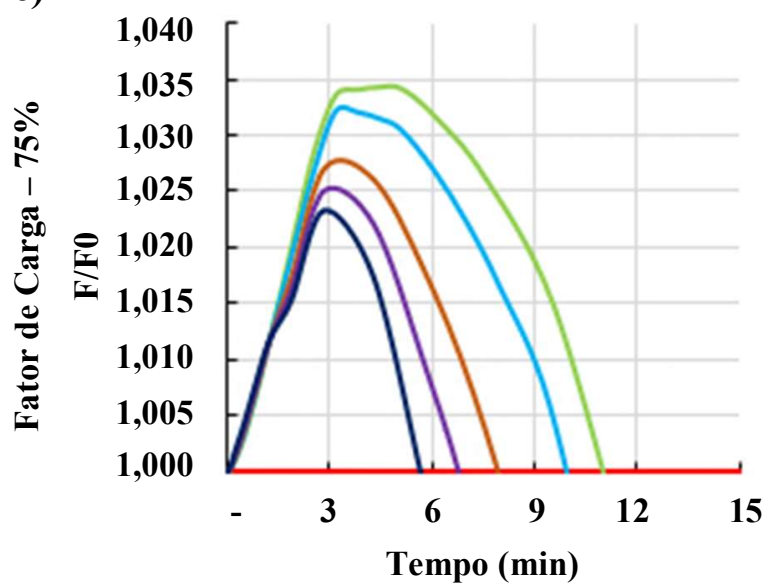

b)

H220-PAR-T15

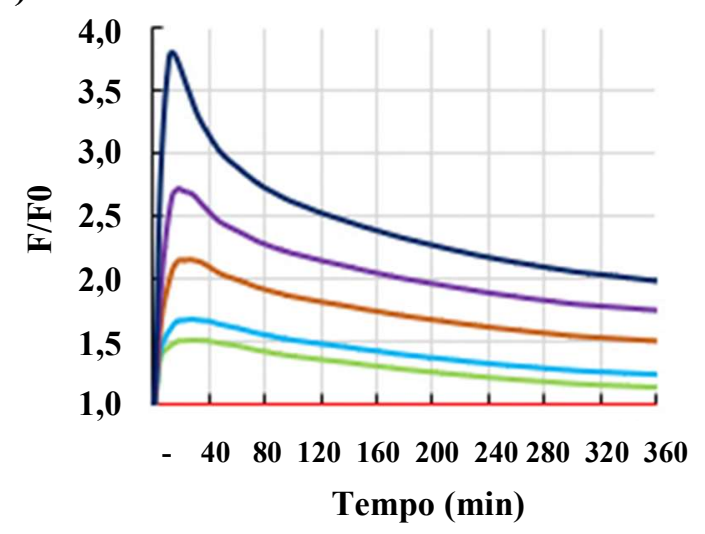

d)

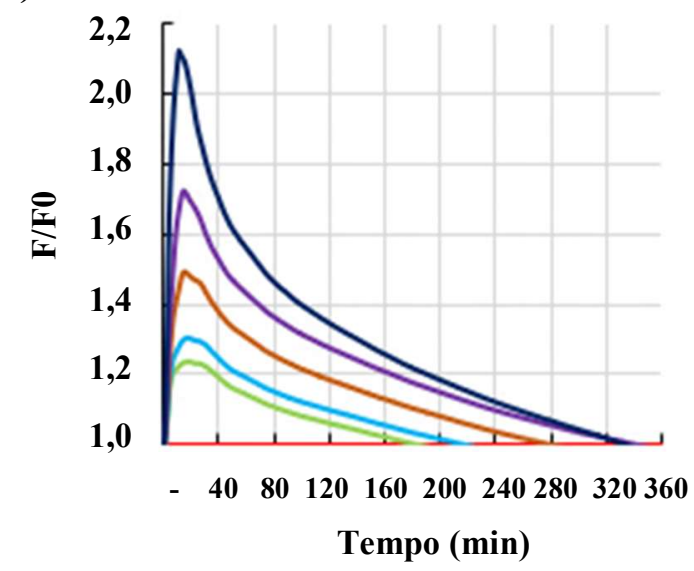

f)

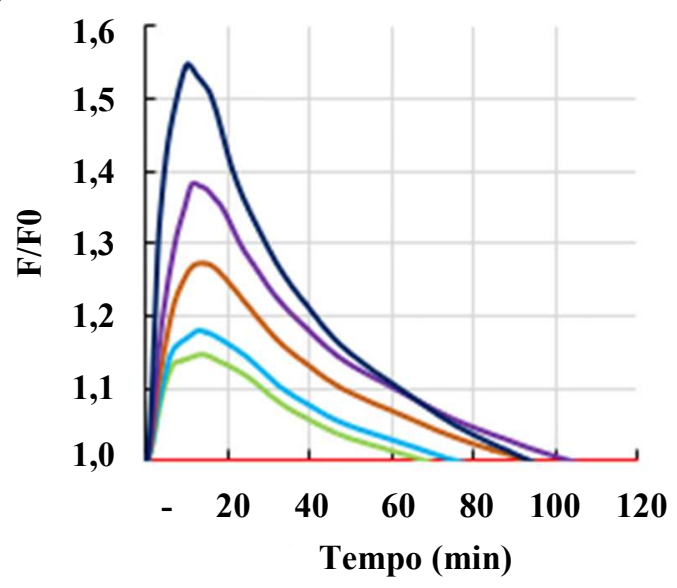

Rigidez Relativa

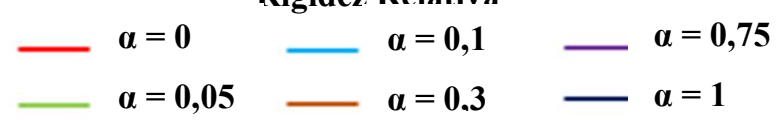

Figura 5.8 - Influência do nível de rigidez axial no desenvolvimento das forças axiais relativas para os pilares de aço H220-ORT-T15 e H200-PAR-T15

Fonte: Autor da Pesquisa (2018).

Já para os pilares H220-PAR-T15, a elevação da rigidez axial do sistema de restrição aumentou o tempo de resistência ao fogo. Tal comportamento difere dos resultados encontrados 
para outros pilares aqui estudados. Possivelmente, a presença da parede e do gradiente térmico gerado na seção transversal influencie de modo diferente o comportamento das forças axiais desenvolvidas no elemento estrutural.

Vale aqui ressaltar que, no meio científico, não foi encontrado qualquer estudo que tenha desenvolvido uma análise desse parâmetro em pilares inseridos em paredes, o que acaba por dificultar o entendimento acerca de alguns dos resultados aqui alcançados.

\subsection{Rigidez Rotacional}

No presente item serão apresentados estudos preliminares desenvolvidos com relação à influência da rigidez rotacional no comportamento de pilares com perfil HEA 220 em contato com paredes. Para tanto, foram adotados fator de carga equivalente a $75 \%$ e a rigidez axial relativa igual a 0,3 para os dois pilares de aço inseridos em alvenaria, ou seja, com alma ortogonal e alma paralela às paredes. Foram testados quatro valores para a rigidez rotacional, no caso, 500, 5000, 50000 e $500000 \mathrm{kN} . \mathrm{m} / \mathrm{rad}$. A Figura 5.9 traz os resultados numéricos para o pilar H220-ORT-T15 e H220-PAR-T15.

H220-ORT-T15

a)

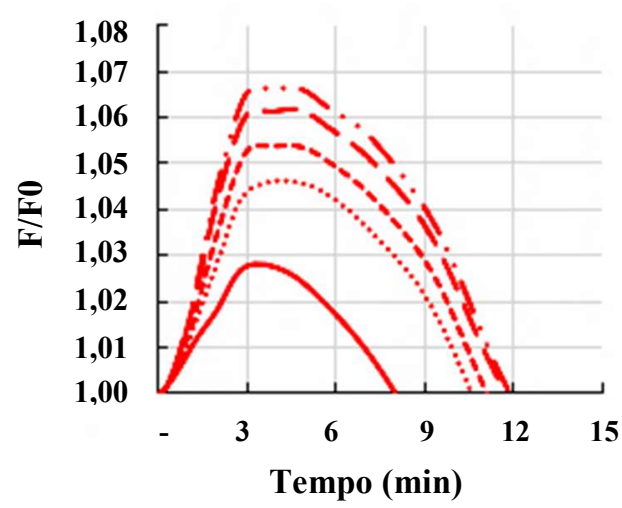

H220-PAR-T15

b)

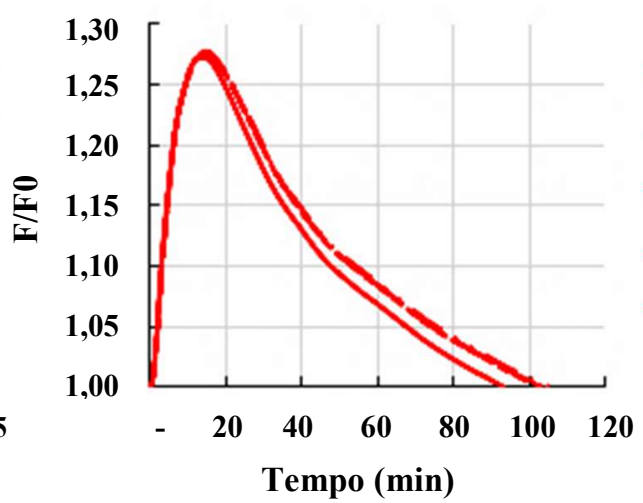

- Apenas Rig. Axial $500 \mathrm{kN} . \mathrm{m} / \mathrm{rad}$

$----5000 \mathrm{kN} . \mathrm{m} / \mathrm{rad}$

$-50000 \mathrm{kN} . \mathrm{m} / \mathrm{rad}$

- $500000 \mathrm{kN} . \mathrm{m} / \mathrm{rad}$

Figura 5.9 - Influência do nível de rigidez rotacional no desenvolvimento das forças axiais relativas para os pilares de aço H220-ORT-T15 e H220-PAR-T15

Fonte: Autor da Pesquisa (2018).

Iniciando a análise pela resistência ao fogo, pode-se observar que a presença da restrição rotacional aumentou o tempo crítico para ambos os pilares, comprovando a influência benéfica desse parâmetro no comportamento termoestrutural. Além disso, assim como nos outros pilares, 
a partir do momento que a rigidez rotacional apresentou valores elevados, o tempo crítico se estabilizou.

Em relação à evolução das forças de restrição, a rigidez rotacional não alterou a parte da curva numérica referente ao crescimento das forças axiais. A princípio, poder-se-ia imaginar que ela afetaria esse comportamento para os pilares H220-ORT-T15, porém, ao observar a escala vertical, a diferença entre a máxima força axial obtida no modelo numérico com maior rigidez rotacional e aquela correspondente ao modelo em que não se considerou essa rigidez foi de $3 \%$, o que permite dizer que, em fins práticos, as curvas são praticamente coincidentes. 


\section{CAPÍTULO 6}

\section{PROPOSTA DE MÉTODO SIMPLIFICADO PARA DETERMINAÇÃO DA EVOLUÇÃO DE TEMPERATURA EM PERFIS DE AÇO}

Os Capítulos 3 e 4 permitiram desenvolver modelos numéricos térmicos e termoestruturais consistentes para pilares de aço isolados e inseridos em paredes, o que resultou em um melhor entendimento desses elementos estruturais em situação de incêndio. A partir disso, um conjunto de análises paramétricas foram realizadas no Capítulo 5 com o intuito de avaliar a influência do fator de carga e do nível de restrição térmica na resistência ao fogo dos pilares modelados.

Tendo em vista o exposto, esse trabalho se volta ao estudo dos códigos normativos atuais que tratam sobre a temática aqui abordada com o objetivo de avaliar o método de cálculo de temperatura de perfis de aço proposto por tais códigos.

Como descrito no Capítulo 2, item 2.4, a norma brasileira ABNT NBR 14323:2013 define que, para uma distribuição uniforme de temperatura na seção transversal, aquecida pela curva de incêndio-padrão ISO 834:1999, a evolução de temperatura no perfil de aço sem revestimento será dada pela equação descrita em seu item 8.5.1.1.1 apresentada mais uma vez nesse trabalho pela Equação 6.1.

Portanto, a temperatura no elemento metálico é função do fator de correção para efeito de sombreamento $\left(\mathrm{k}_{\mathrm{sh}}\right)$, do fator de massividade $\left(\mathrm{u} / \mathrm{A}_{\mathrm{g}}\right)$, da massa específica $\left(\rho_{\mathrm{a}}\right)$ e do calor específico do aço $\left(c_{a}\right)$, do fluxo de calor por unidade de área $(\varphi)$ e do tempo de exposição ao fogo $(\Delta t)$.

$$
\Delta \theta_{a, t}=k_{s h} \frac{u / A_{g}}{c_{a} \rho_{a}} \varphi \Delta t
$$

Por outro lado, no que se refere aos pilares inseridos em paredes, os quais apresentam um gradiente térmico na seção transversal, a referida norma não fornece um método específico para essas situações, porém se admite utilizar o mesmo procedimento citado anteriormente. Para isso, no cálculo do fator de massividade, a área total bruta é calculada a partir da superfície delimitada pelo perímetro exposto ao fogo. 
Com base nisso, o presente capítulo busca verificar a eficiência da referida norma no cálculo das temperaturas da seção transversal para os pilares isolados e inseridos em paredes, a partir da comparação dos resultados determinados por meio do método normativo com aqueles alcançados por modelagens numéricas térmicas. Em seguida, novas análises serão realizadas, sendo concluídas com uma proposta de adaptação no emprego do método simplificado da ABNT NBR 14323:2013 para o caso de pilares inseridos em paredes.

\subsection{AVALIAÇÃO DO MÉTODO SIMPLIFICADO DA ABNT NBR 14323:2013}

\subsubsection{Emprego da metodologia de cálculo}

A aplicação do método simplificado da ABNT NBR 14323:2013 ocorre de maneira direta para os pilares que possuem aquecimento em suas quatro faces, a partir da determinação do fator de massividade e uso da Equação 6.1. No entanto, como mencionado anteriormente, para pilares inseridos em elementos de compartimentação, uma correção deve ser considerada no uso dessa equação, no que diz respeito a determinação da área bruta para o cálculo do fator de massividade, que passa a ser limitada pelo perímetro exposto ao fogo. A Figura 6.1 apresenta as seções transversais para os pilares considerados no presente trabalho, destacando o perímetro exposto ao fogo dos perfis que apresentaram interação com paredes.

a)

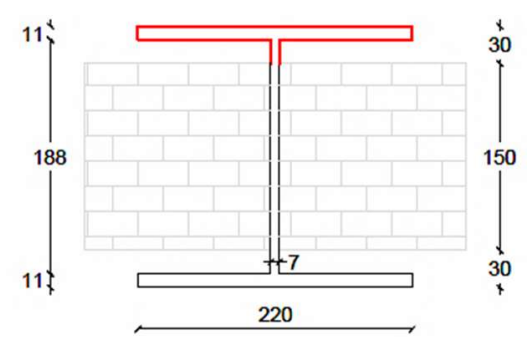

c)

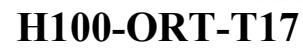

b)

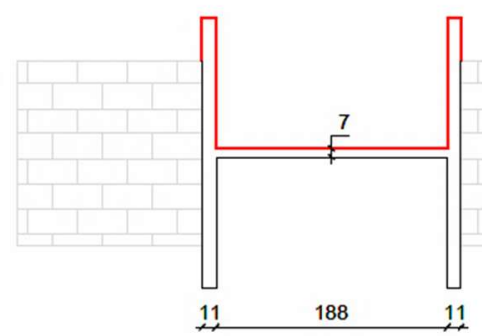

d)

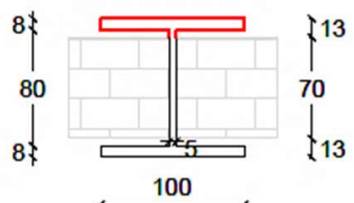

H100-PAR-T7

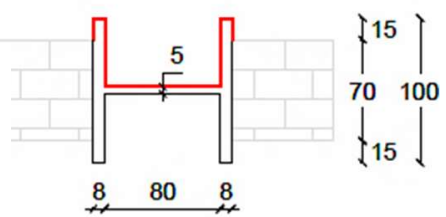

Figura 6.1 - Representação do perímetro exposto ao fogo para os pilares inseridos em paredes Fonte: Autor da Pesquisa (2018). 
Além da determinação do perímetro exposto ao fogo, é necessário medir a área bruta $\left(A_{g}\right)$ do perfil de aço para cálculo do fator de massividade e, consequentemente, da temperatura na seção transversal. No caso dos pilares isolados, essa grandeza coincide com a área total do perfil, porém, para os elementos inseridos em paredes, ela passa a ser delimitada pelo perímetro exposto ao fogo.

Com a análise da Figura 6.1 é possível determinar a área aquecida pelo fogo para os pilares com gradiente térmico ao longo da alma, no caso, H220-ORT-T15 e H100-ORT-T7, uma vez que as chamas envolvem completamente a mesa exposta e parte da alma do perfil de aço. Porém, para os pilares com aquecimento diferencial ao longo da mesa, no caso, H220PAR-T15 e H100-PAR-T7, não se consegue calcular essa área de maneira precisa, pois apenas um lado dos componentes do perfil de aço está aquecido, de modo que não pode ser tomada a área total dessa região. A norma brasileira não faz referência a esse cenário.

A Figura 6.2 traz a representação das seções transversais dos quatro pilares, indicando a área adotada. No caso dos elementos estruturais em que a alma se encontra paralela à superfície das paredes, a área exposta empregada foi aquela delimitada, por hipótese, pela metade da espessura dos elementos parcialmente aquecidos.

a)

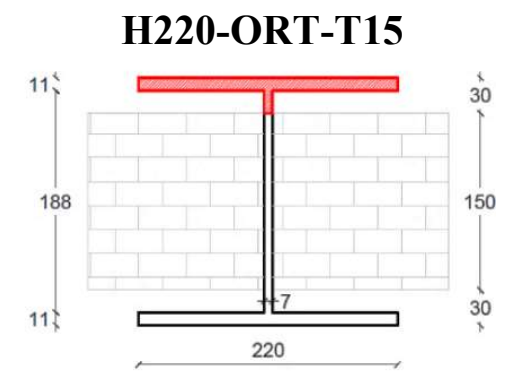

c)

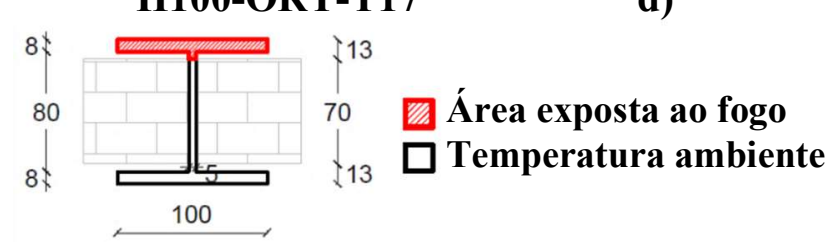

b)

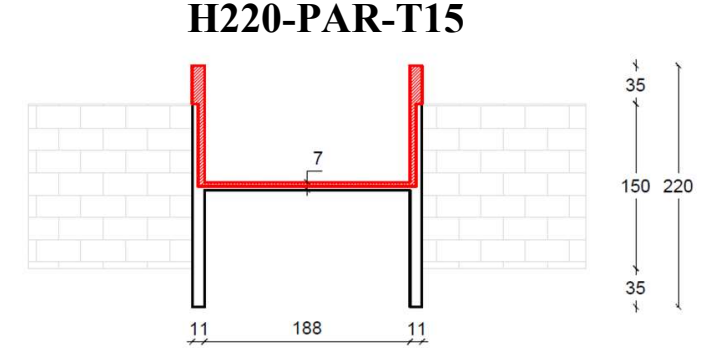

H100-PAR-T7

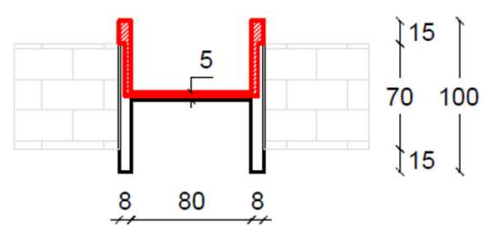

Figura 6.2 - Representação da área bruta $\left(A_{g}\right)$ adotada para os pilares inseridos em paredes Fonte: Autor da Pesquisa (2018).

Com base nas considerações apresentadas anteriormente, a Tabela 6.1 indica os valores do perímetro exposto $(u)$, área bruta $\left(A_{g}\right)$ e o correspondente fator de massividade $\left(u / A_{g}\right)$ que 
foram utilizados para determinar a evolução da temperatura média dos perfis de aço para os seis pilares.

Tabela 6.1 - Perímetro exposto, área bruta e fator de massividade para os perfis de aço

\begin{tabular}{cccc}
\hline & $u(\mathbf{m m})$ & $A_{g}\left(\mathbf{m m}^{\mathbf{2}}\right)$ & $u / A_{g}\left(\mathbf{m}^{-\mathbf{1}}\right)$ \\
\hline H220-ORT-T15 & 493 & 2553 & 193 \\
H220-PAR-T15 & 493 & 2253 & 219 \\
H220-ISO & 1286 & 6430 & 200 \\
H100-ORT-T7 & 221 & 825 & 268 \\
H100-PAR-T7 & 221 & 720 & 307 \\
H100-ISO & 582 & 2120 & 275 \\
\hline
\end{tabular}

Fonte: Autor da Pesquisa (2018).

\subsubsection{Considerações relativas à modelagem numérica}

Após breve descrição do modo como se apresenta o método simplificado proposto pela norma brasileira ABNT NBR 14323:2013, será realizada uma abordagem acerca dos aspectos utilizados na modelagem numérica térmica nessa etapa do trabalho.

A análise numérica foi realizada, inicialmente, para a determinação da curva de elevação de temperatura dos elementos estruturais e, posteriormente, para comparações com os valores obtidos pelo método de cálculo mencionado. Por esta razão, nessa etapa optou-se por utilizar os parâmetros normatizados referentes à emissividade e ao coeficiente de convecção, a fim de se estabelecer referencial entre resultados numéricos e normativos. Os valores correspondentes a esses parâmetros foram os mesmos descritos no Capítulo 5 para realização da análise paramétrica.

Na modelagem numérica, a curva de evolução da temperatura do perfil de aço foi obtida a partir da definição da temperatura representativa em cada passo de tempo para a seção transversal. Essa grandeza foi calculada a partir da média ponderada entre as temperaturas encontradas em cada nó formador da seção transversal analisada.

\subsubsection{Análise dos resultados do estudo comparativo}

A análise inicial consiste em avaliar a aplicabilidade do método simplificado para os pilares com aquecimento uniforme na seção transversal. A Figura 6.3 traz a comparação entre 
os resultados teóricos e aqueles obtidos pela modelagem numérica para os pilares aquecidos igualmente em todas as faces. Tal comparação permite constatar que a ABNT NBR 14.323:2013 consegue representar bem a evolução de temperatura para os pilares isolados tendo em vista a proximidade evidenciada nos gráficos apresentados.
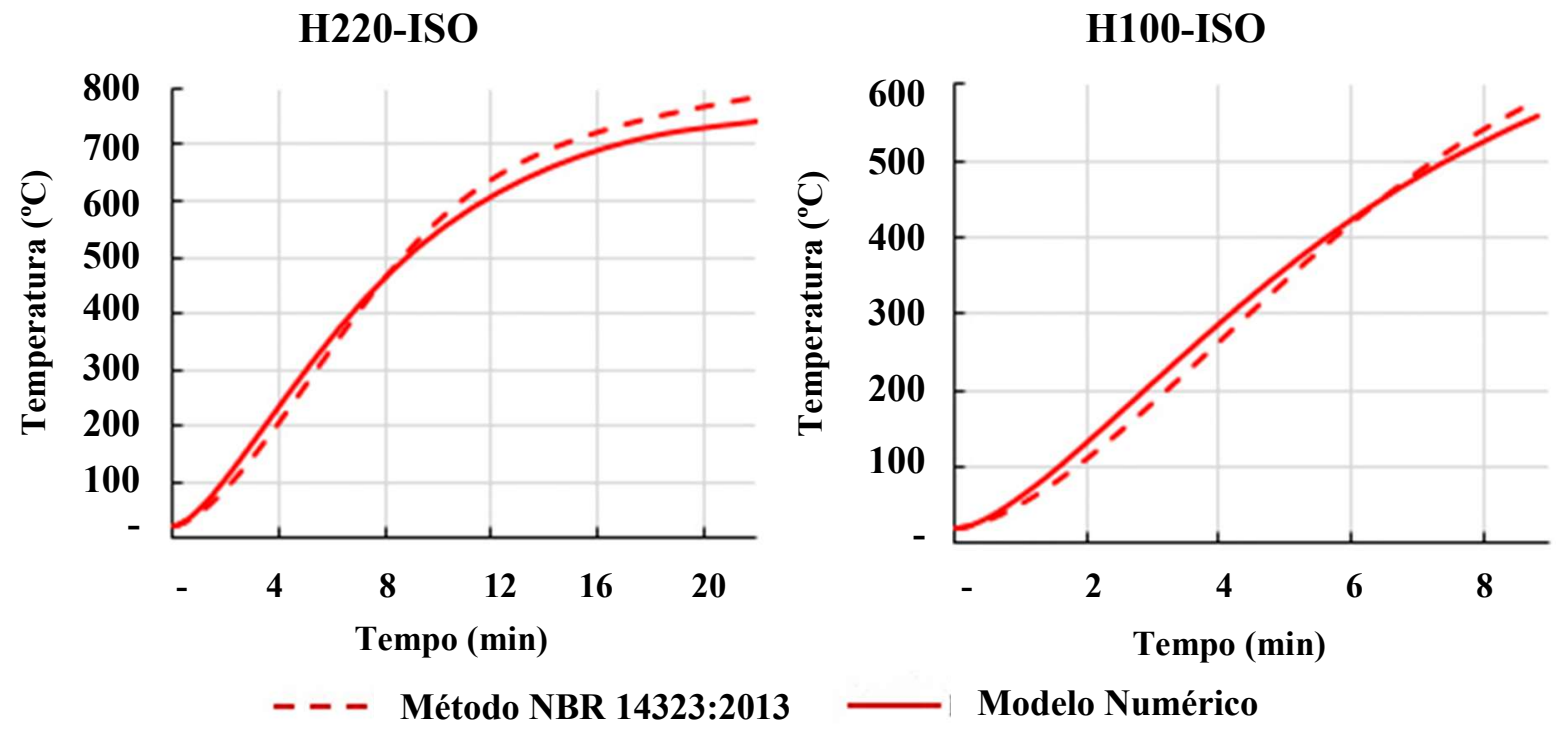

Figura 6.3 - Comparação dos resultados dos modelos numéricos com o Método Simplificado da ABNT NBR 14323:2013 para pilares isolados H220-ISO e H100-ISO

Fonte: Autor da Pesquisa (2018).

No referente aos elementos estruturais inseridos em paredes, a Figura 6.4 fornece os resultados numéricos e teóricos obtidos. Nelas estão representadas as curvas de evolução da temperatura média do modelo numérico, aquela obtida pelo método simplificado (utilizando os fatores de massividade da Tabela 6.1) e a curva obtida pelo método normatizado considerando aquecimento nas quatro faces do elemento estrutural (pilar isolado).

Análises com relação aos gráficos apresentados na Figura 6.4 permitem identificar que o método simplificado da ABNT NBR 14323:2013 fornece resultados conservadores para os pilares aquecidos em apenas uma das faces. Percebe-se ainda que, considerando o pilar com aquecimento nas quatro faces ou admitindo os requisitos da norma brasileira quando há contato do pilar com a alvenaria, o resultado do método simplificado é praticamente o mesmo, uma vez que o fator de massividade para ambos os casos foram similares como verificado na Tabela 6.1. 

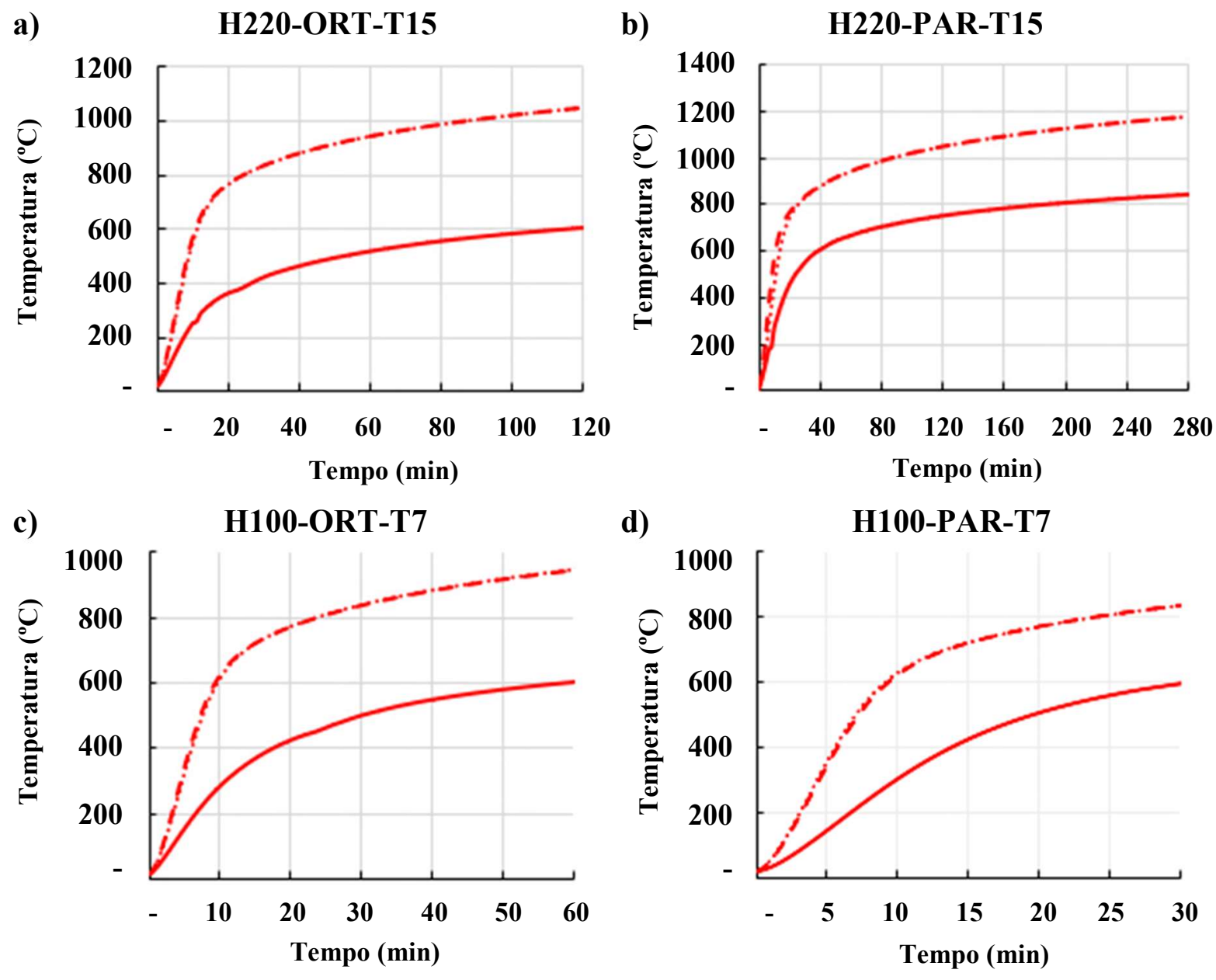

— Numérico ……. Método Simplificado - - - Pilar Isolado

Figura 6.4 - Comparação dos resultados do modelo numéricos com o Método Simplificado da ABNT NBR 14323:2013 para pilares inseridos em paredes

Fonte: Autor da Pesquisa (2018).

É importante destacar que o efeito sombra não foi considerado nos modelos numéricos. No caso dos pilares sem paredes, os resultados obtidos foram equivalentes ao do método simplificado. No caso dos pilares inseridos em paredes, apenas parte do perfil está exposto, diminuindo esse efeito de sombra.

Partindo do pressuposto que o fator de massividade é a grandeza que influencia diretamente o cálculo da temperatura média do aço, foi realizada uma variação desse parâmetro, em termos de porcentagem (Figura 6.5), em função do fator de massividade de um perfil totalmente exposto ao fogo (100\%), de modo a verificar se o método simplificado se tornava mais adequado para os pilares inseridos em paredes. Pode-se afirmar que, mesmo variando o fator de massividade, não se consegue definir uma curva, a partir do método simplificado, que represente satisfatoriamente a temperatura média da seção obtida pelos modelos numéricos térmicos de forma satisfatória. 
a)

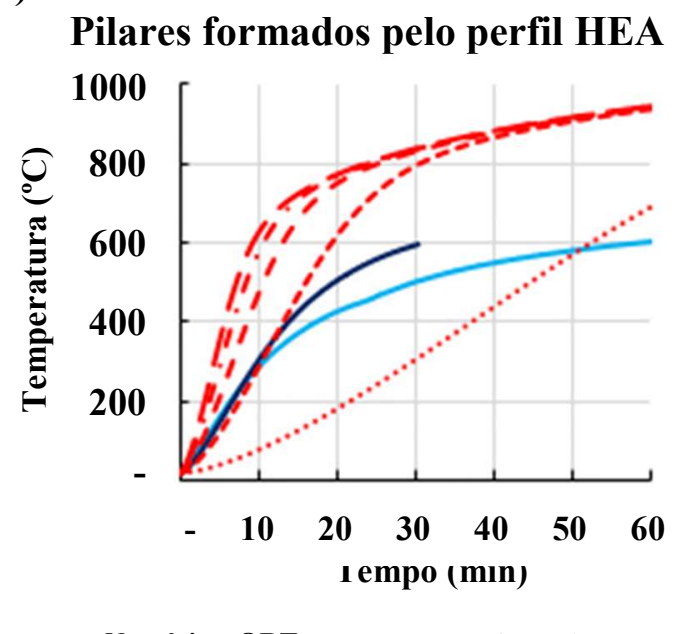

b)

Pilares formados pelo perfil HEA 220

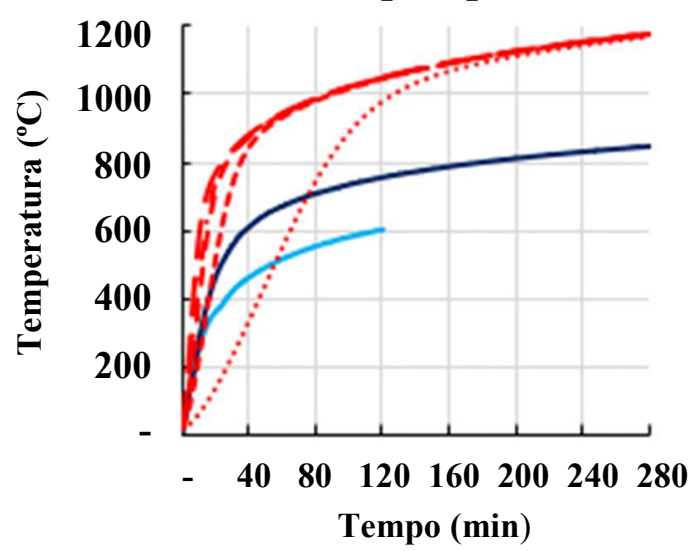

Figura 6.5 - Evolução da temperatura de pilares de aço em função da variação do fator de massividade por meio do método simplificado da ABNT NBR 14323:2013

Fonte: Autor da Pesquisa (2018).

Diante disso, a equação fornecida pela norma brasileira não permite determinar adequadamente a evolução de temperatura média da seção transversal de pilares de aço inseridos em paredes, uma vez que o gradiente de temperatura originado nessa configuração altera o comportamento térmico e, consequentemente, o comportamento termoestrutural dos pilares. Por essa razão, tem-se como ideia propor um procedimento alternativo de cálculo para a evolução da temperatura considerando união a pilar-parede, a qual será apresentada a seguir.

\subsection{PROPOSTA DE METODOLOGIA PARA DETERMINAÇÃO DA TEMPERATURA EM SEÇÕES TRANSVERSAIS DE PILARES INSERIDOS EM PAREDES}

A presente seção se dedica à proposição de um método, aqui também denominado simplificado, que seja capaz de determinar satisfatoriamente a evolução da temperatura média que ocorre em pilares de aço inseridos em paredes, tendo como base as informações descritas pela norma brasileira ABNT NBR 14323:2013.

\subsubsection{Hipóteses básicas de cálculo}

a) Admite-se que a seção transversal seja dividida em duas partes de áreas iguais: uma referente ao lado exposto ao fogo e outra ao lado não exposto ao fogo, de modo a representar o aquecimento diferencial do pilar, como mostrado na Figura 6.6. 
a)

H220-ORT-T15

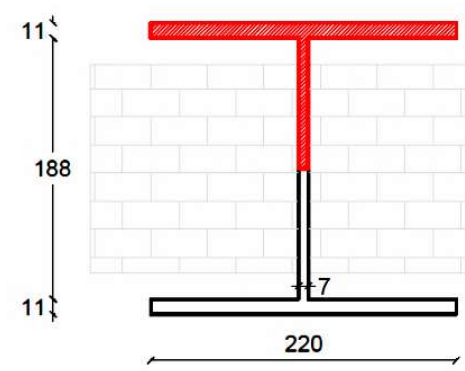

b)

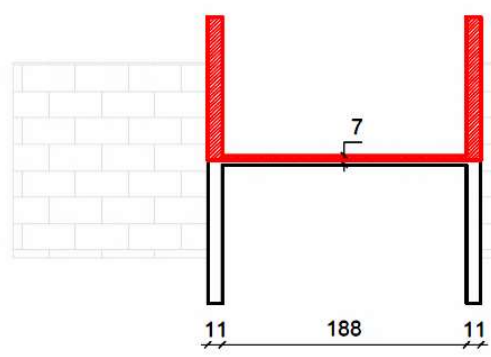

d)

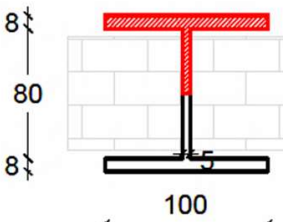

Área exposta ao fogo $\square$ Temperatura ambiente ação da seção transversal do pilar em duas áreas iguais Fonte: Autor da Pesquisa (2018).

b) Adota-se a Equação 6.1, ou seja, aquela correspondente ao item 8.5.1.1.1 da ABNT NBR 14323:2013, para o cálculo da elevação da temperatura no perfil de aço, porém com as seguintes alterações:

- para área exposta ao fogo, independente da configuração do perfil metálico em relação à superfície da parede, utiliza-se integralmente a equação citada;

- para a área não exposta ao fogo adota-se um fator de ajuste para a temperatura calculada pela equação do método normatizado. Para pilares com a alma ortogonal às paredes, esse valor corresponde a 0,25 , enquanto para pilares com a alma paralela à superfície das paredes, essa grandeza deve ser igual a 0,55 ;

c) $\mathrm{O}$ fator de massividade para os pilares inseridos em paredes utilizado no cálculo da Equação 6.1 será aquele correspondente ao perfil de aço com aquecimento nas quatro faces, pois, como apresentado na Tabela 6.1, mesmo admitindo diferentes formas para cálculo dessa grandeza, os resultados se apresentaram bastante semelhantes.

\subsubsection{Validação do método proposto}

De modo a garantir que o método proposto atenda a variadas situações envolvendo diversos tipos de perfil, além daquelas apresentadas na Figura 6.6, foram modelados os pilares 
apresentados em Correia, Rodrigues e Silva (2011), formados por perfis de aço com diferentes dimensões e espessuras de paredes.

A descrição das características dos pilares utilizados para validação do método proposto está indicada na Tabela 6.2. A nomenclatura apresentada para os mesmos foi baseada naquela que vem sendo utilizada nesse trabalho. Destaca-se que essa metodologia foi testada para um tempo de exposição ao fogo (nesse caso, TRRF) limitado a um período de quatro horas, valor este, superior ao máximo estipulado pelas normas brasileiras atualmente que é de três horas.

Tabela 6.2 - Identificação dos pilares empregados para validação do método simplificado proposto no presente trabalho

\begin{tabular}{ccccc}
\hline Nomenclatura & Perfil & $\begin{array}{c}\text { Orientação } \\
\text { do Perfil }\end{array}$ & $\begin{array}{c}\text { Espessura } \\
\text { da parede }\end{array}$ & Referência Bibliográfica \\
\hline H100-ORT-T7 & HEA 100 & Ortogonal & $7 \mathrm{~cm}$ & Rocha (2016) \\
H100-PAR-T7 & HEA 100 & Paralela & $7 \mathrm{~cm}$ & Rocha (2016) \\
H120-ORT-T9,8 & HEA 120 & Ortogonal & $9,8 \mathrm{~cm}$ & Correia, Rodrigues e Silva (2011) \\
H120-PAR-T10 & HEA 120 & Paralela & $10 \mathrm{~cm}$ & Correia, Rodrigues e Silva (2011) \\
H160-ORT-T13,4 & HEA 160 & Ortogonal & $13,4 \mathrm{~cm}$ & Correia, Rodrigues e Silva (2011) \\
H160- PAR -T14 & HEA 160 & Paralela & $14 \mathrm{~cm}$ & Correia, Rodrigues e Silva (2011) \\
H200-ORT-T17 & HEA 200 & Ortogonal & $17 \mathrm{~cm}$ & Correia, Rodrigues e Silva (2011) \\
H200- PAR -T18 & HEA 200 & Paralela & $18 \mathrm{~cm}$ & Correia, Rodrigues e Silva (2011) \\
H220-ORT-T15 & HEA 220 & Ortogonal & $15 \mathrm{~cm}$ & Rocha (2016) \\
H220- PAR -T15 & HEA 220 & Paralela & $15 \mathrm{~cm}$ & Rocha (2016) \\
H240-ORT-T20,6 & HEA 240 & Ortogonal & $20,6 \mathrm{~cm}$ & Correia, Rodrigues e Silva (2011) \\
H240- PAR -T18 & HEA 240 & Paralela & $18 \mathrm{~cm}$ & Correia, Rodrigues e Silva (2011) \\
H280-ORT-T18 & HEA 280 & Ortogonal & $18 \mathrm{~cm}$ & Correia, Rodrigues e Silva (2011) \\
H280- PAR -T18 & HEA 280 & Paralela & $18 \mathrm{~cm}$ & Correia, Rodrigues e Silva (2011) \\
\hline Font Autor da Pesquis & & &
\end{tabular}

Fonte: Autor da Pesquisa (2018).

O processo de validação do procedimento de cálculo para determinação da temperatura média em seções transversais aqui apresentado consiste basicamente em estabelecer comparações das curvas de temperatura média, das áreas exposta e não exposta ao fogo, obtidas numericamente, com as curvas de temperatura média determinadas por meio do método simplificado aqui proposto. As Figuras 6.7, 6.8 e 6.9 trazem os resultados para os pilares estudados. 
a)

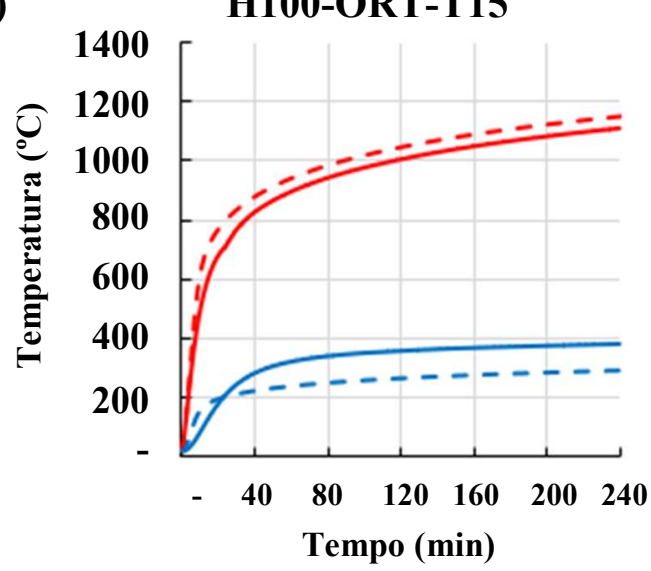

c)

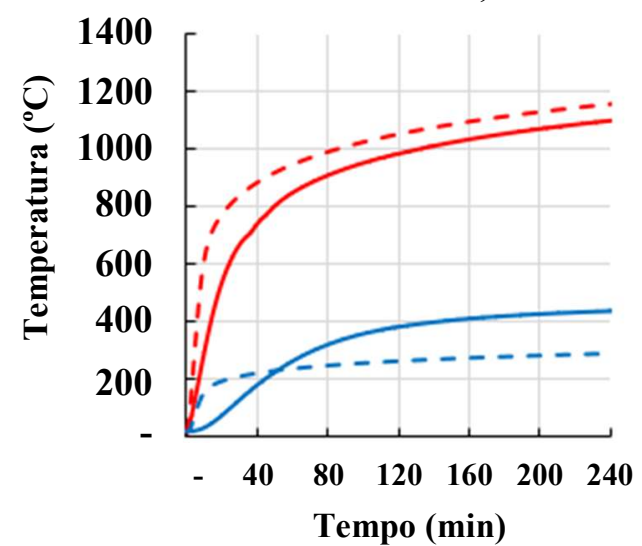

e)

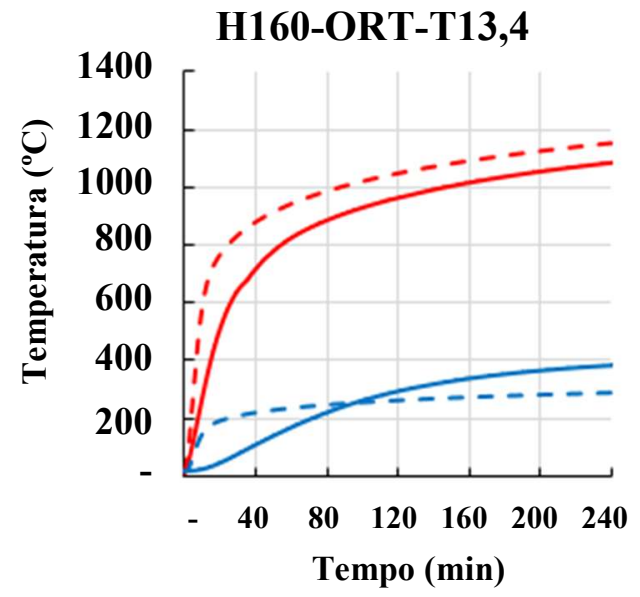

Numérico Área Aquecida b)

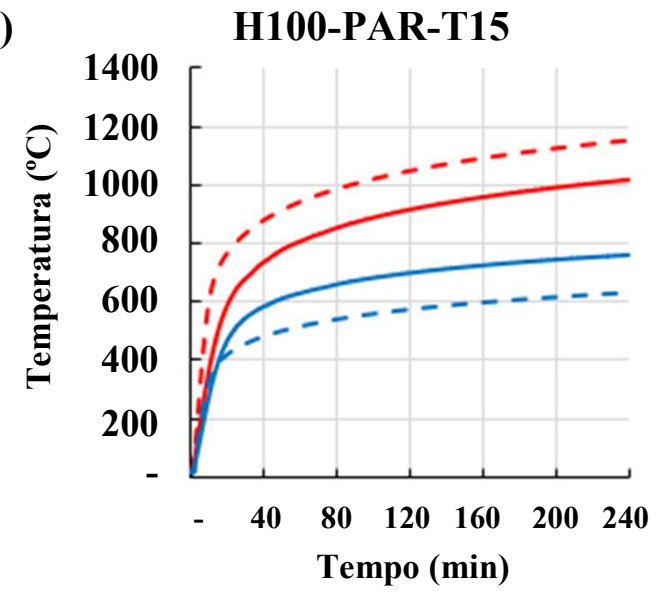

d)

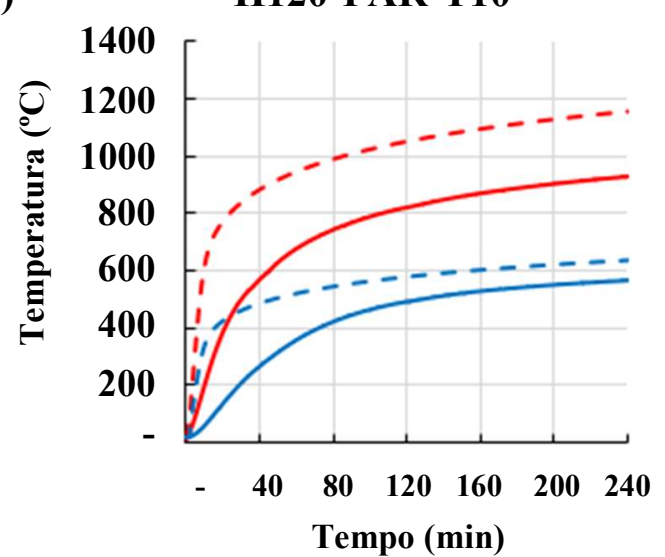

f) H160-PAR-T14

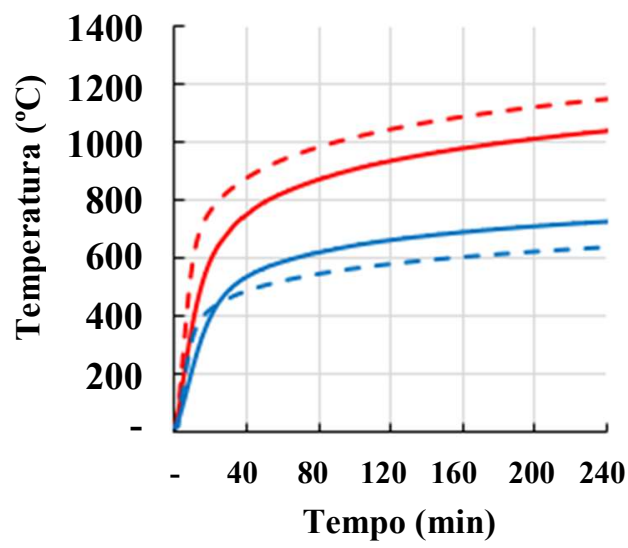

Numérico Método Proposto Área Não Aquecida "- Área Não Aquecida

Figura 6.7 - Comparação entre as temperaturas obtidas numericamente e pelo método simplificado proposto para os pilares inseridos em paredes (Parte 1)

Fonte: Autor da Pesquisa (2018). 
a)

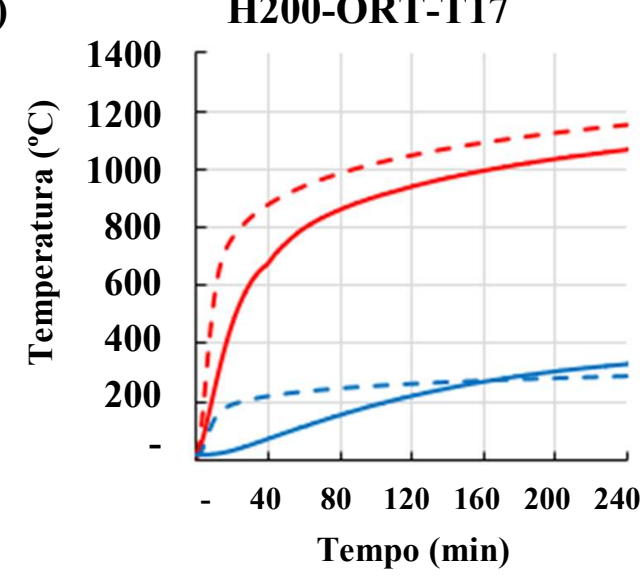

c)

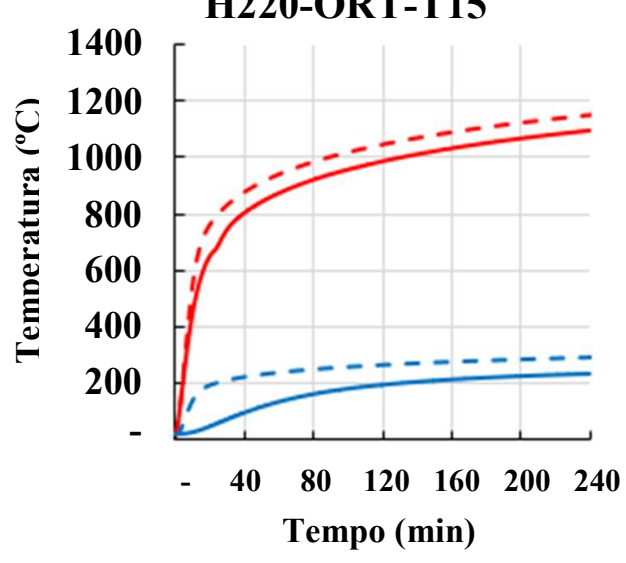

e)

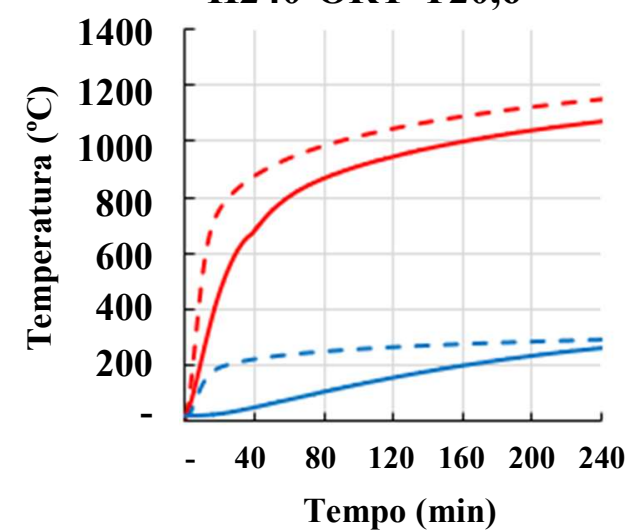

b)

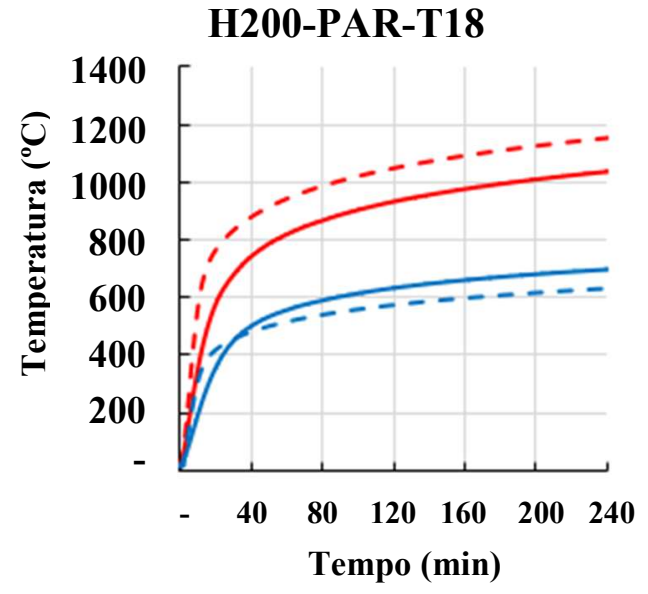

d)

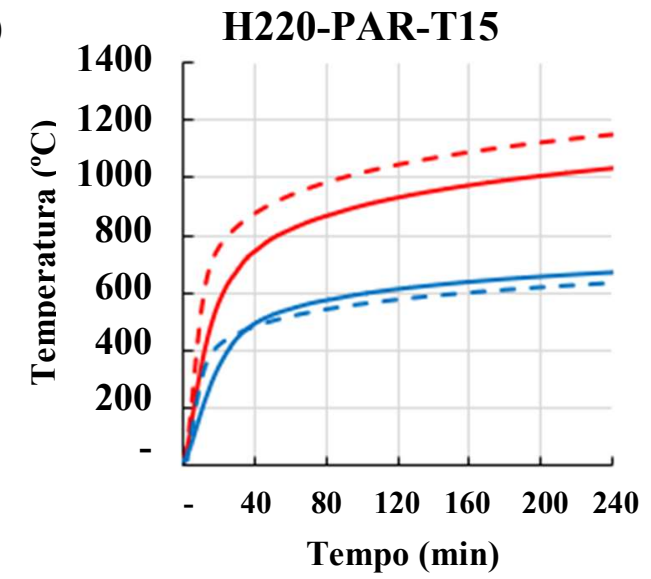

f)

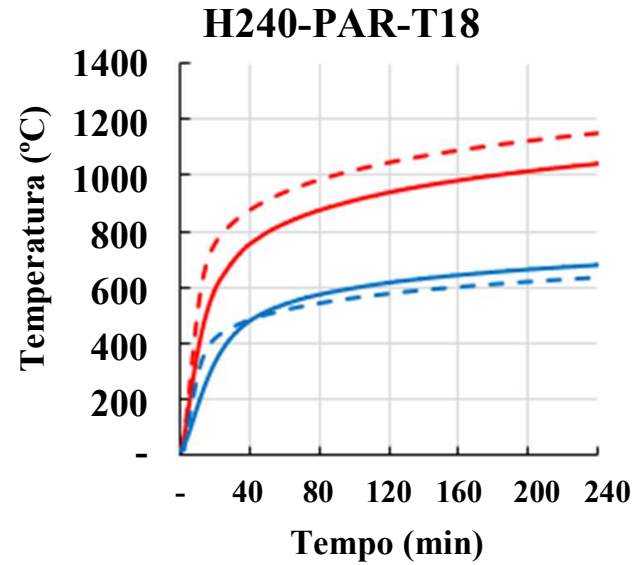

Numérico _ - - Método Proposto Área Não Aquecida Área Não Aquecida

Figura 6.8 - Comparação entre as temperaturas obtidas numericamente e pelo método simplificado proposto para os pilares inseridos em paredes (Parte 2)

Fonte: Autor da Pesquisa (2018). 
a)

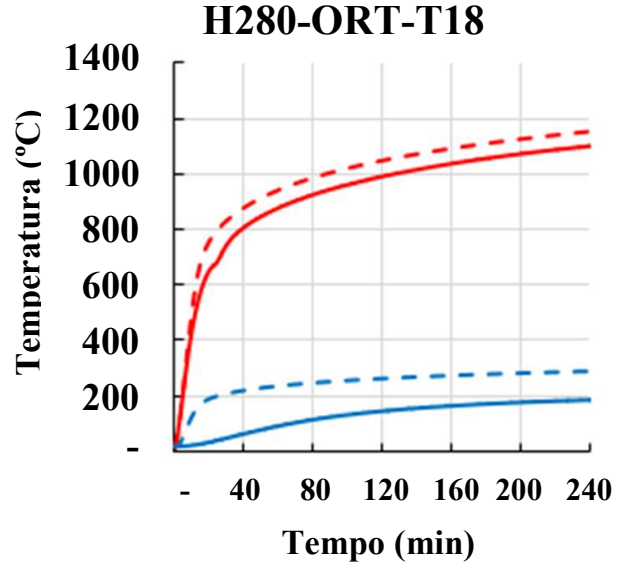

— Numérico Área Aquecida
Método Proposto

Área Aquecida b)

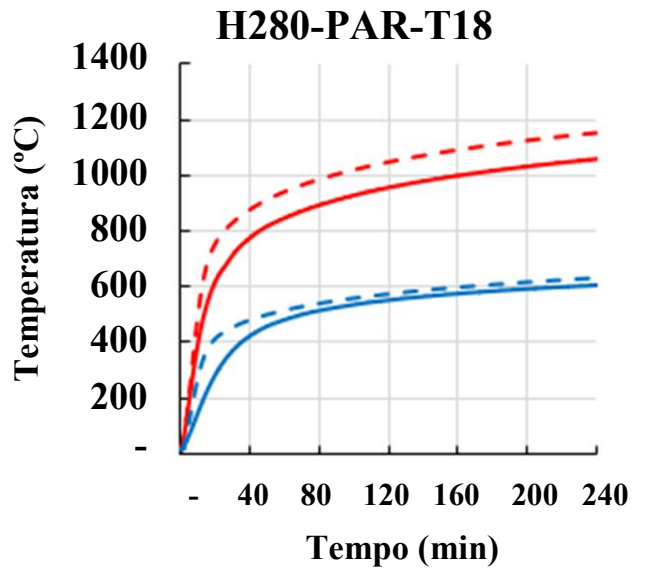

Numérico Área Não Aquecida
- - - Método Proposto

Área Não Aquecida

Figura 6.9 - Comparação entre as temperaturas obtidas numericamente e pelo método simplificado proposto para os pilares inseridos em paredes (Parte 3)

Fonte: Autor da Pesquisa (2018).

Análises, com relação aos resultados apresentados nas Figuras 6.7, 6.8 e 6.9 considerando a evolução de temperatura correspondente à área exposta ao fogo, permitem identificar que o método simplificado conseguiu representar adequadamente a temperatura independente da orientação do perfil associado ao pilar em análise. Ressalta-se que os resultados dos pilares com a alma ortogonal à superfície das paredes, em particular, voltados aos perfis HEA 100, HEA 220 e HEA 280, foram os que apresentaram os melhores resultados.

A maior diferença identificada quando da comparação entre temperaturas via modelagem numéricas e aquelas obtidas pelo método simplificado aqui proposto, para a região exposta ao fogo, foi observada para os casos cujos pilares apresentaram gradiente térmico com maior evidência ao longo da mesa, ou seja, com a alma paralela à superfície da parede. Nesses casos, pode-se verificar que há maior dissipação de calor pela alma do perfil, diferentemente do pilar com a alma ortogonal à parede, o que acarreta em uma temperatura numérica menor para a zona exposta ao fogo. Além disso, chama-se atenção para o fato de o método da ABNT NBR 14343:2013 não levar em consideração os mecanismos de transferência de calor para a face não exposta, o que eleva a temperatura média da área aquecida.

Em relação aos resultados associados ao lado não exposto ao fogo, também apresentados nas mesmas Figuras 6.7, 6.8 e 6.9, observa-se mais uma vez a eficiência do método proposto, principalmente para os pilares em que a alma é paralela ao plano da alvenaria. Em relação 
aqueles em que as paredes estão em contato com a alma, a maior diferença entre as curvas resulta nos primeiros 30 minutos de aquecimento.

\subsection{SINOPSE DOS RESULTADOS APRESENTADOS}

O presente capítulo foi responsável por avaliar a eficiência do método de cálculo proposto pela ABNT NBR 14323:2013 para determinação da temperatura em perfis de aço. Ao comparar os resultados numéricos e aqueles obtidos pelo método simplificado para os pilares com aquecimento em suas quatro faces, pode-se observar a proximidade das curvas analisadas. Apesar disso, quando a seção transversal apresentava aquecimento diferencial, o método de cálculo se mostrou conservador.

A partir disso, foi proposto uma nova metodologia para determinar a elevação da temperatura em pilares de aço associados a alvenaria. Esse método foi testado e validado para uma gama de perfis e espessuras de paredes, apresentando grande potencial para ser utilizado em uma futura atualização do código normativo atual.

Ainda sobre o método proposto, ressalta-se que na maioria dos casos em que o método não se adequou às temperaturas calculadas numericamente, os resultados obtidos se encontram a favor da segurança. Também, pode-se mencionar que, em comparação ao método simplificado da ABNT NBR 14323:2013, os resultados são mais próximos da realidade. 


\section{CAPÍTULO 7}

\section{BREVES CONSIDERAÇÕES E CONCLUSÕES}

Como considerações, no sentido de contextualização, vale lembrar que o presente estudo aqui desenvolvido contou, enquanto proposta, com um conjunto de análises numéricas, realizadas por meio do código computacional ABAQUS versão 6.14, voltadas a seis pilares de aço restringidos termicamente, sendo dois pilares isolados e quatro pilares inseridos em paredes, a fim de estudar o comportamento desses elementos em situação de incêndio. No caso de pilares com aquecimento uniforme nas quatro faces, houve variação somente do tipo de perfil de aço utilizado, porém, no caso dos elementos estruturais pertencentes a paredes foram analisados enquanto parâmetros, além daquele citado anteriormente, a espessura da parede e a orientação do perfil frente à ação térmica.

O tema da presente pesquisa apresenta considerável relevância para a área de engenharia estrutural em incêndio, principalmente por tratar da associação entre pilares de aço e alvenaria de compartimentação, bem como a influência (ou contribuição) dessa mesma alvenaria no comportamento estrutural desses pilares em elevadas temperaturas. Poucos são os trabalhos realizados que abordam essa interação, uma vez que a grande maioria dos estudos, por simplificação, trata apenas de pilares isolados. Adicionalmente, como justificativa para a presente proposta de trabalho, vale destacar que as pesquisas já desenvolvidas, ou em desenvolvimento, para pilares inseridos em paredes indicaram dificuldades em contexto de representação numérica, o que acaba, muitas vezes, dificultando a compreensão dos resultados.

As análises numéricas aqui desenvolvidas contaram com duas estratégias de modelagem numérica: uma primeira proposta considerando a alvenaria somente como elemento de compartimentação, bem como uma segunda proposta considerando a influência (ou interferência) dessa mesma alvenaria no desempenho termoestrutural dos pilares.

Assim, entendendo a forte necessidade de melhor compreender a influência das alvenarias na resposta dos pilares em incêndio, o presente estudo numérico de caráter inicial se desenvolveu com vistas a identificar de que forma essa interferência ocorre no conjunto pilarparedes, bem como quantificar tal interferência enquanto restrições impostas aos deslocamentos, no comportamento termoestrutural de pilares. Esses aspectos podem ser 
considerados como caráter inovador no meio científico, uma vez que na grande maioria dos casos estudados a alvenaria é considerada apenas como elemento de compartimentação.

Tendo em vista o exposto, no que segue, serão descritas as principais conclusões obtidas com base nos resultados e análises desenvolvidas na presente dissertação, as quais são divididas considerando cada uma das etapas realizadas. Ao final desse mesmo capítulo, são discutidas sugestões para trabalhos futuros, as quais são aqui consideradas fortemente relevantes para dar continuidade ao tema tratado nesse trabalho.

\subsection{COM RELAÇÃO ÀS ANÁLISES EM CONTEXTO TÉRMICO}

- Em uma comparação numérica no âmbito da modelagem térmica, os modelos que utilizaram elementos finitos do tipo casca para representação dos perfís de aço proporcionaram melhores resultados em relação àqueles que empregaram elementos finitos do tipo sólido, na maioria dos casos, permitindo consequentemente redução do tempo de processamento dos modelos numéricos;

- Os modelos térmicos propostos para os seis pilares de aço conseguiram representar de forma satisfatória os resultados experimentais utilizados como referência;

- Em relação às condições de contorno empregadas para o desenvolvimento da modelagem numérica, a utilização do valor de emissividade referente à superfície de aço recomendada pela ABNT NBR 14323:2013 não foi suficiente para calibração de todos os modelos numéricos. O modo de aquecimento de um forno elétrico, em um ensaio experimental, é diferente daquele de um incêndio real o que afetou o uso dos parâmetros normatizados.

\subsection{COM RELAÇÃO ÀS ANÁLISES EM CONTEXTO TERMOESTRUTURAL}

- A então denominada Estratégia Numérica I gerou resultados consistentes somente para os pilares isolados. No entanto, vale ressaltar que para os pilares inseridos em paredes para o perfil de aço HEA 100 houve boa concordância entre as curvas numéricas e experimentais até metade do tempo de exposição ao fogo. Vale lembrar que nessa metodologia, a parede foi considerada apenas como elemento de compartimentação; 
- Após várias análises realizadas, foi possível notar que as paredes, de algum modo, influenciam no comportamento termoestrutural dos pilares e não somente em temperatura ambiente, cuja interferência se fez confirmar ao se considerar vinculações nas três direções em sua face lateral (face de menor dimensão em planta), quando então o comportamento numérico se modificava;

- O travamento da alvenaria nas direções paralelas e ortogonais ao seu plano apresentou pouca influência para os pilares mais robustos, no caso, H220-ORT-T15 e H220-PAR-T15. Por outro lado, a resposta numérica para os pilares mais esbeltos, no caso, H100-ORT-T7 e H100-PAR-T7, apresentou melhora;

- Quanto ao travamento da alvenaria em sua direção axial, ou seja, perpendicular às suas dimensões em planta, quando totalmente travada elevava substancialmente a rigidez do sistema global, aumentando as forças axiais desenvolvidas nos pilares. No entanto, vale destacar que essa verificação resultou satisfatória apenas para o pilar representado pelo modelo H220-ORT-T15, indicando que tal configuração promove uma maior rigidez axial ao sistema que pode ser justificado pela temperatura média e gradiente térmico desenvolvidos nesse tipo de seção transversal.

- Observou-se que a contribuição da parede no comportamento dos pilares em situação do incêndio depende da espessura e das condições de vinculações adotadas para as paredes, bem como das dimensões da seção transversal e da orientação do pilar em análise frente à ação do fogo;

- Com relação à denominada Estratégia Numérica II, a calibração numérica das molas axiais da parede permitiu que todos os quatro modelos de pilares inseridos em elementos de compartimentação apresentassem resultados minimamente satisfatórios, de modo a possibilitar que o comportamento termoestrutural dos pilares estudados fosse melhor compreendido;

- Ao comparar os resultados numéricos e experimentais para o deslocamento axial, percebeu-se boa representatividade somente para os pilares H220-ISO e H220-PART15. Admite-se que o modo em que essa grandeza foi mensurada nos ensaios experimentais de referência contribuiu para tal situação, uma vez que sua precisão é discutível.

- Considerando as informações disponíveis no meio científico, voltadas às comparações entre resultados numéricos e experimentais, apresentadas por meio de diferentes trabalhos de pesquisa sobre modelagem numérica de pilares de aço 
inseridos em paredes, é possível contatar que os resultados numéricos obtidos na presente pesquisa resultaram suficientemente satisfatórios e com maior proximidade numérico-experimental, muito provavelmente, por considerar a influência da alvenaria no comportamento dos elementos estruturais.

\subsection{COM RELAÇÃO ÀS ANÁLISES PARAMÉTRICAS}

As análises paramétricas foram aqui desenvolvidas a partir dos modelos numéricos validados para os seis pilares dessa pesquisa, obviamente com vistas a ampliar o estudo para outros casos não abordados no programa experimental ou para quaisquer outras situações de interesse. Dentre os parâmetros considerados na análise, foram avaliadas variações no fator de carga e no nível de restrição térmica, ambos impostos ao elemento estrutural aqui em análise.

Em relação ao fator de carga, os resultados para todos os pilares, isolados e inseridos em paredes, foram os mesmos, de modo que quanto maior o nível de carga aplicado antes do aquecimento, menor o valor máximo atingido da força axial relativa. Além disso, o aumento desse fator também resultou na diminuição do tempo crítico.

Sobre a rigidez axial, em todos os modelos, a mudança desse parâmetro impactou na intensidade da força desenvolvida no pilar, sendo que quanto maior a intensidade dessa mesma rigidez, maior foi a força de restrição imposta aos elementos.

Foi possível constatar que a presença da restrição axial é muito mais impactante na resistência ao fogo do elemento estrutural do que sua intensidade para os pilares isolados e aqueles inseridos em paredes formados pelo perfil HEA 100. Já para o pilar H220-ORT-T15, a elevação do nível de rigidez axial diminuiu o tempo de resistência ao fogo, enquanto que para os pilares H220-PAR-T15, o aumento dessa mesma rigidez resultou no crescimento do tempo crítico. A compreensão desses resultados é limitada pela escassez de estudos sobre análise paramétrica em pilares inseridos em paredes.

No que concerne à rigidez rotacional, sua presença elevou o tempo crítico dos pilares, comprovando sua influência benéfica na resistência ao fogo. Apesar disso, a partir do momento que a rigidez rotacional apresentou valores elevados, o tempo crítico se estabilizou. Isso não foi obtido para o pilar H100-ORT-T7, que manteve seu tempo crítico invariável. Além do mais, esse tipo de rigidez não alterou a força axial máxima gerada nos elementos estruturais.

Observa-se que, para o melhor entendimento sobre o comportamento de pilares inseridos em paredes, sob o aspecto do fator de carga e da restrição térmica, faz-se necessário a realização de análises paramétricas, em contexto numérico e experimental, envolvendo outros 
perfis de aço que apresentem dimensões intermediárias àqueles usados nessa pesquisa, bem como também superiores ao maior perfil aqui estudado, HEA 220, para verificar se os resultados e os aspectos de comportamento obtidos nesse trabalho também se verificam em outros casos.

\subsection{PROPOSTA DE MÉTODO SIMPLIFICADO PARA CÁlCULO DA TEMPERATURA EM PILARES INSERIDOS EM PAREDES}

Por meio de uma revisão da literatura, constatou-se que não existe um método simplificado específico normatizado para determinar a evolução da temperatura de pilares de aço em contato com alvenaria.

A norma brasileira ABNT NBR 14323:2013 traz um método que considera somente o elemento estrutural com aquecimento uniforme em suas quatro faces, o que difere do caso citado anteriormente. No entanto, para pilares com aquecimento não uniforme, essa norma faz apenas uma breve menção da possibilidade de considerar as paredes associadas aos pilares, porém sem apresentar o método direcionado para essa situação. A presente pesquisa realizou uma avaliação de tal método para todos os pilares aqui estudados, permitindo assim estabelecer as seguintes conclusões:

- Para pilares com aquecimento uniforme na seção transversal, o método da norma brasileira ABNT NBR 14323:2013 gerou resultados bastante satisfatórios quando comparados com os modelos numéricos térmicos propostos;

- Para os pilares inseridos em paredes, o método da norma brasileira ABNT NBR 14323:2013 apresentou temperaturas substancialmente superiores àquelas que provavelmente seriam observadas em situações reais de pilares expostos ao fogo;

- A nova proposta de cálculo de temperatura para pilares em contato com paredes apresentou bons resultados para a maioria dos casos estudados. Vale destacar que para aquelas situações em que não foi possível representar satisfatoriamente a evolução de temperatura no perfil, ainda assim, os resultados se apresentam mais próximos do previsto quando comparados aos resultados obtidos pelo método normatizado;

- Considerando os resultados aqui obtidos, é possível considerar que o método simplificado proposto possui potencial para representar a evolução das temperaturas em perfis com aquecimento não uniforme e pode ser considerado para fins de 
atualização da atual norma brasileira ABNT NBR 14323:2013, na forma de proposta para versão futura.

\subsection{SUGESTÕES PARA TRABALHOS FUTUROS}

Tendo em vista a complexidade do tema aqui proposto, os autores do presente trabalho entendem que ainda existem algumas lacunas no conhecimento que necessitam ser sanadas para melhor entendimento da engenharia de estruturas em incêndio com ênfase aos elementos estruturais inseridos em paredes. A seguir estão descritas as sugestões propostas:

- Desenvolvimento de novos ensaios experimentais que considere pilares em contato com paredes, variando a seção transversal, orientação do perfil frente à ação do fogo, espessura do bloco de vedação, níveis de carga e restrição térmica;

- Dar continuidade ao estudo da influência da parede no desempenho termoestrutural dos pilares de aço, principalmente no comportamento elastoplástico das molas utilizadas na direção axial da alvenaria;

- Ampliar a análise paramétrica aqui apresentada, de modo a analisar a esbeltez dos pilares de aço, espessuras de paredes, diferentes perfis de aço, outros níveis de carga e de restrição térmica na resistência ao fogo dos pilares inseridos em alvenarias;

- Avaliar mais precisamente a influência da restrição axial e rotacional no comportamento termoestrutural de pilares de aço inseridos em paredes, em contexto experimental e numérico;

- Desenvolver modelos numéricos de pilares mistos inseridos em paredes, de modo a avaliar a influência desses elementos de compartimentação no comportamento termoestrutural de elementos mistos;

- Testar o método simplificado aqui apresentado para outros perfis de aço, diferentes espessuras de paredes e outras orientações do pilar de aço frente à ação térmica;

- Avaliar a aplicabilidade do método simplificado da ABNT NBR 14323:2013 sobre a capacidade resistente de pilares de aço para elementos estruturais inseridos em paredes. 


\section{REFERÊNCIAS BIBLIOGRÁFICAS}

AASEN, B. An experimental study on steel column behaviour at elevated temperatures. Division of Steel Structures, Norwegian Institute of Technology, University of Trondheim, Trondheim, Norway, 1985.

ABAQUS. ABAQUS Analysis User's Manual: Volume IV: Elements. Abaqus, 2013.

ABNT. ASSOCIAÇÃO BRASILEIRA DE NORMAS TÉCNICAS. NBR 14323:

Dimensionamento de estruturas de aço de edifícios em situação de incêndio - procedimento. Rio de Janeiro: ABNT, 1999.

. ASSOCIAÇÃO BRASILEIRA DE NORMAS TÉCNICAS. NBR 14323: Projeto de estruturas de aço e de estruturas mistas de aço e concreto de edifícios em situação de incêndio. Rio de Janeiro: ABNT, 2013.

ASSOCIAÇÃO BRASILEIRA DE NORMAS TÉCNICAS. NBR 14432: Exigências de resistência ao fogo de elementos construtivos de edificações - procedimento. Rio de Janeiro: ABNT, 2001.

ASSOCIAÇÃO BRASILEIRA DE NORMAS TÉCNICAS. NBR 15200: Projeto de estruturas de concreto em situação de incêndio - procedimento. Rio de Janeiro: ABNT, 2012.

ASSOCIAÇÃO BRASILEIRA DE NORMAS TÉCNICAS. NBR 8800: Projeto de estruturas de aço e de estruturas mistas de aço e concreto de edifícios. Rio de Janeiro: ABNT, 2008 .

AGARWAL, A.; CHOE, L.; VARMA, A.H. Fire design of steel columns: Effects of thermal gradients. Journal of Constructional Steel Research, v. 93, p. 107-118, 2014.

https://doi.org/10.1016/j.jcsr.2013.10.023 .

ALI, F.A. et al. The effect of axial restraint on the fire resistance of steel columns. Journal of Constructional Steel Research, v. 46, p. 305-306, 1998.

ALI, F.A.; O'CONNOR, D.J. Structural performance of rotationally restrained steel columns in fire. Fire Safety Journal, v. 36, n. 7, p. 679-691, 2001. https://doi.org/10.1016/S03797112(01)00017-0 .

ALI, F.A.; SIRNMS, I.W.; O'CONNOR, D.J. Behaviour of axially restrained steel columns during fire. Fire Safety Science, v. 5, p. 1105-1116, 1997.

https://doi.org/10.3801/IAFSS.FSS.5-1105 .

AZEVEDO, M.S. Determinação da temperatura em elementos estruturais de aço externos a edificações em situações de incêndio. 2005. 233p. Dissertação (Mestrado em Engenharia de Estruturas) - Centro Tecnológico, Universidade Federal do Espírito Santo, Vitória, 2005. 
AZEVEDO, M.S. Estruturas de aço sem revestimento contrafogo externas a edifício em incêndio. 2010. 303p. Tese (Doutorado em Engenharia de Estruturas) - Escola Politécnica, Universidade de São Paulo, São Paulo, 2010.

BUBACH, C.R. Pilares de aço com restrição axial e rotacional em situação de incêndio. 2016. 194p. Dissertação (Mestrado em Engenharia de Estruturas) - Universidade Federal do Espírito Santo, Vitória, 2016.

BUCHANAN, A. H. Structural Design for Fire Safety. University of Canterbury, New Zealand: John Wiley \& Sons, LTD, 2002. 421 p.

CADORIN, J.F. Compartment fire models for structural engineering. 2003. 201p. Thèse (Doctorat en Sciences Appliquées) - Faculté de Sciences Appliqués, Université de Liège, Belgium, 2003.

CORREIA, A.J.P.M. Fire resistance of steel and composite steel-concrete columns. 2011. 389p. Tese (Doutorado em Engenharia Civil) - Faculdade de Ciências e Tecnologia, Universidade de Coimbra, Coimbra, 2011.

CORREIA, A.J.P.M. et al. Section factor and steel columns embedded in walls. In: NORDIC STEEL CONSTRUCTION CONFERENCE, 11., 2009, Malmö, Sweden, Proceedings..., Malmö, 2009. p. 172-179.

CORREIA, A.J.P.M.; RODRIGUES, J.P.C. Fire resistance of partially encased steel columns with restrained thermal elongation. Journal of Constructional Steel Research, v. 67, n. 4, p. 593-601, 2011. https://doi.org/10.1016/j.jcsr.2010.12.002 .

CORREIA, A.J.P.M.; RODRIGUES, J.P.C. Fire resistance of steel columns with restrained thermal elongation. Fire Safety Journal, v. 50, p. 1-11, 2012.

https://doi.org/10.1016/j.firesaf.2011.12.010 .

CORREIA, A.J.P.M.; RODRIGUES, J.P.C.; GOMES, F.C.T. A simplified calculation method for fire design of steel columns with restrained thermal elongation. Computers and Structures, v. 116, p. 20-34, 2013. https://doi.org/10.1016/j.compstruc.2012.09.006.

CORREIA, A.J.P.M.; RODRIGUES, J.P.C.; REAL, P.V. Thermal bowing on steel columns embedded on walls under fire conditions. Fire Safety Journal, v. 67, p. 53-69, 2014. https://doi.org/10.1016/j.firesaf.2014.05.001 .

CORREIA, A.J.P.M.; RODRIGUES, J.P.C; SILVA, V.P. A simplified calculation method for temperature evaluation of steel columns embedded in walls. Fire and Materials, v. 35, n. 7, p. 431-441, 2011. doi/10.1002/fam.1063/full .

. Experimental research on the fire behaviour of steel columns embedded on walls.

In: INTERNATIONAL CONFERENCE APPLICATIONS OF STRUCTURAL FIRE

ENGINEERING, 2009, Prague, Czech Republic, Prooceedings..., Praga, 2009. p. 417-422. 
CORREIA, A.J.P.M.; RODRIGUES, J.P.C; SILVA, V.P. Numerical study on the behavior of steel columns embedded on brick walls subjected to fire. In: INTERNATIONAL SYMPOSIUM "SSCS 2010 - STEEL STRUCTURES: CULTURES \& SUSTAINABILITY 2010", 2010, Istambul, Trkey, Prooceedings..., Istambul, 2010.

DORR, J.B. Modelos numéricos de pilares de aço em situação de incêndio considerando a influência da restrição axial. 2010. 210p. Dissertação (Mestrado em Engenharia de Estruturas) - Escola de Engenharia de São Carlos, Universidade de São Paulo, São Carlos, 2010.

DRYSDALE, D. An Introduction to Fire Dynamics. 2. ed. University of Edinburgh, UK: John Wiley \& Sons, LTD, 1998. 451 p.

DWAIKAT, M.; KODUR, V. A simplified approach for evaluating plastic axial and moment capacity curves for beam-columns with non-uniform thermal gradients. Engineering Structures, v. 32, n. 5, p. 1423-1436, 2010. https://doi.org/10.1016/j.engstruct.2010.01.021

DWAIKAT, M.M.S. et al. Experimental behavior of steel beam-columns subjected to fireinduced thermal gradients. Journal of Constructional Steel Research, v. 67, n. 1, p. 30-38, 2011. https://doi.org/10.1016/j.jcsr.2010.07.007 .

EUROCODE. EUROPEAN COMMITTEE FOR STANDARDIZATION. EN 1991-1-1 Eurocode 1: Actions on structures - Part 1-2: General actions - Actions on structures exposed to fire. Brussels, 2002

EUROPEAN COMMITTEE FOR STANDARDIZATION. EN 1993-1-1 -

Eurocode 3: Design of Steel Structures - Part 1-1: General rules and rules for buildings. Brussels, 2005

EUROPEAN COMMITTEE FOR STANDARDIZATION. EN 1993-1-2. Eurocode 3: Design of Steel Structures - Part 1-2: General rules - Structural Fire Design. Brussels: CEN, 2005.

FRANSSEN, J.M. Failure temperature of a system comprising a restrained column submitted to fire. Fire Safety Journal, v. 34, n. 2, p. 191-207, 2000. https://doi.org/10.1016/S03797112(99)00047-8 .

GARLOCK, M.E.; QUIEL, S.E. Combined axial load and moment capacity of fire exposed beam-columns with thermal gradients. In: INTERNATIONAL WORKSHOP ON STRUCTURES IN FIRE, 4., 2006, Aveiro, Portugal, Proceedings..., Aveiro: University of Aveiro, 2006. p. 187-198.

Mechanics of wide-flanged steel sections that develop thermal gradients due to fire exposure. International Journal of Steel Structures, v. 7, n. 3, p. 153-162, 2007.

HUANG, Z.F.; TAN, K.H. Structural response of restrained steel columns at elevated temperatures. Part 2: FE simulation with focus on experimental secondary effects. Engineering structures, v. 29, n. 9, p. 2036-2047, 2007. https://doi.org/10.1016/j.engstruct.2006.09.012 . 
ISO. INTERNATIONAL STANDARD. ISO 834: Fire-resistance tests - Elements of building construct - Part 1: General requirements. ISO 834-1:1999. Genebra: ISO, 1999.

KIMURA, E.F.A. Análise termoestrutural de pilares de aço em situação de incêndio. 2009. 225p. Dissertação (Mestrado em Engenharia de Estruturas) - Escola de Engenharia de São Carlos, Universidade de São Paulo, São Carlos, 2009.

NEVES, I.C. The critical temperature of steel columns with restrained thermal elongation. Fire Safety Journal, v. 24, n. 3, p. 211-227, 1995. https://doi.org/10.1016/03797112(95)00026-P .

POH, K.W.; BENNETTS, I.D. Analysis of structural members under elevated temperature conditions. Journal of Structural Engineering ASCE, v. 121, n. 4, p. 664-675, 1995. https://doi.org/10.1061/(ASCE)0733-9445(1995)121:4(664) .

QUIEL, S.E. et al. Predicting the demand and plastic capacity of axially loaded steel beamcolumns with thermal gradients. Engineering Structures, v. 58, p. 49-62, 2014. https://doi.org/10.1016/j.engstruct.2013.10.005 .

REGOBELLO, R. Análise numérica de seções transversais e de elementos estruturais de aço e mistos de aço e concreto em situação de incêndio. 2007. 269p. Dissertação (Mestrado em Engenharia de Estruturas) -Escola de Engenharia de São Carlos, Universidade de São Paulo, 2007.

ROCHA, F.M. Pilares de aço e misto de aço e concreto inseridos em paredes em situação de incêndio. 2016. 256p. Tese (Doutorado em Engenharia de Estruturas) - Escola de Engenharia de São Carlos, Universidade de São Paulo, São Carlos, 2016.

RODRIGUES, J.P.C.; NEVES, I.C.; VALENTE, J.C. Experimental research on the critical temperature of compressed steel elements with restrained thermal elongation. Fire Safety Journal, v. 35, n. 2, p. 77-98, 2000. https://doi.org/10.1016/S0379-7112(00)00018-7 .

SHEPHERD, P.G.; BURGESS, I.W. On the bucking of axially restrained steel columns in fire. Engineering Structures, v. 33, p. 2832-2838, 2011.

https://doi.org/10.1016/j.engstruct.2011.06.007 .

SILVA, V. P.; CORREIA, A. M.; RODRIGUES, J. P. C. Simulação do comportamento ao fogo de pilares de aço em contato com alvenaria. In: Jornadas Sudamericana de Ingenieria Estructural, 33., Santiago, 2008. Anais..., 2008.

SIMÕES, T.C. Estudo da Resistência ao Fogo de Pilares de Aço Inseridos em Paredes. 2016. 148p. Dissertação (Mestrado em Engenharia Civil - Especialização em Construção Urbana) - Departamento de Engenharia Civil, Instituto Superior de Engenharia de Coimbra, Coimbra, 2016.

TAN, K.H. et al. Structural responses of restrained steel columns at elevated temperatures. Part 1: Experiments. Engineering Structures, v. 29, n. 8, p. 1641-1652, 2007. https://doi.org/10.1016/j.engstruct.2006.12.005 . 
VELARDE, J.S.S. Sobre o comportamento de pilares de aço em situação de incêndio. 2008. 144p. Dissertação (Mestrado em Engenharia) - Escola Politécnica, Universidade de São Paulo, São Paulo, 2008.

VALENTE, J.C.; NEVES, I.C. Fire resistance of steel columns with elastically restrained axial elongation and bending. Journal of Constructional Steel Research, v. 52, n. 3, p. 319331, 1999. https://doi.org/10.1016/S0143-974X(99)00033-4 .

WANG, Y.C. Steel and composite structures: behaviour and design for fire safety. London: Spon Press, 2002.

WEBBER, A. et al. The effective length of columns in multi-storey frames. Engineering Structures, v. 102, p. 132-143, 2015. https://doi.org/10.1016/j.engstruct.2015.07.039 .

ZHANG, C. et al. Behavior of unrestrained and restrained bare steel columns subjected to localized fire. Journal of Structural Engineering, v. 141, n. 10, p. 04014239, 2015. doi/abs/10.1061/(ASCE)ST.1943-541X.0001225 . 


\section{AP.A.1 CONSIDERAÇÕES A RESPEITO DA MODELAGEM NUMÉRICA}

\section{AP.A.1.1 TESTE DE MALHA}

De maneira geral, o primeiro passo de uma modelagem numérica consiste em realizar um teste de convergência de malha com o intuito de determinar o tamanho de seus elementos finitos. Inicialmente, esse teste foi realizado para os modelos numéricos térmicos, como pode ser visto na Figura AP.A.1.

a)

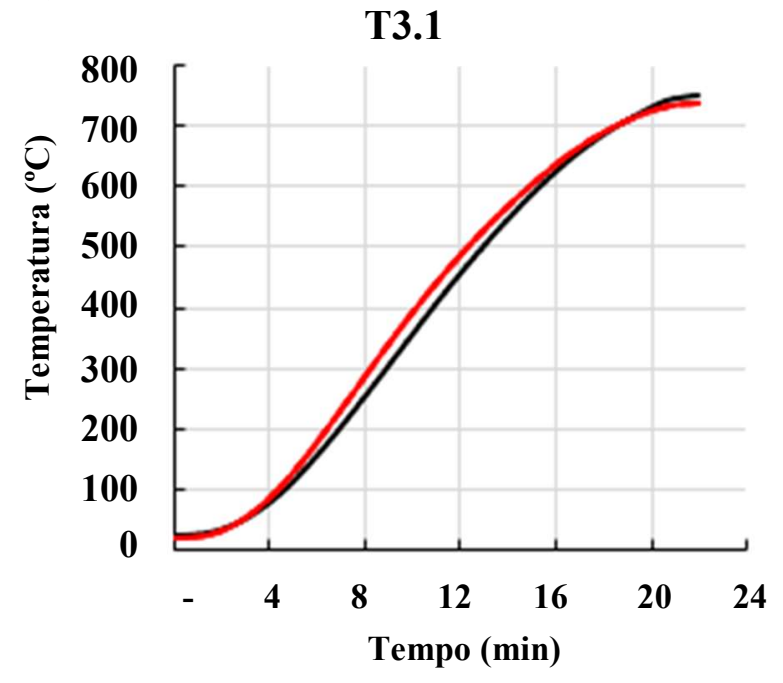

b)

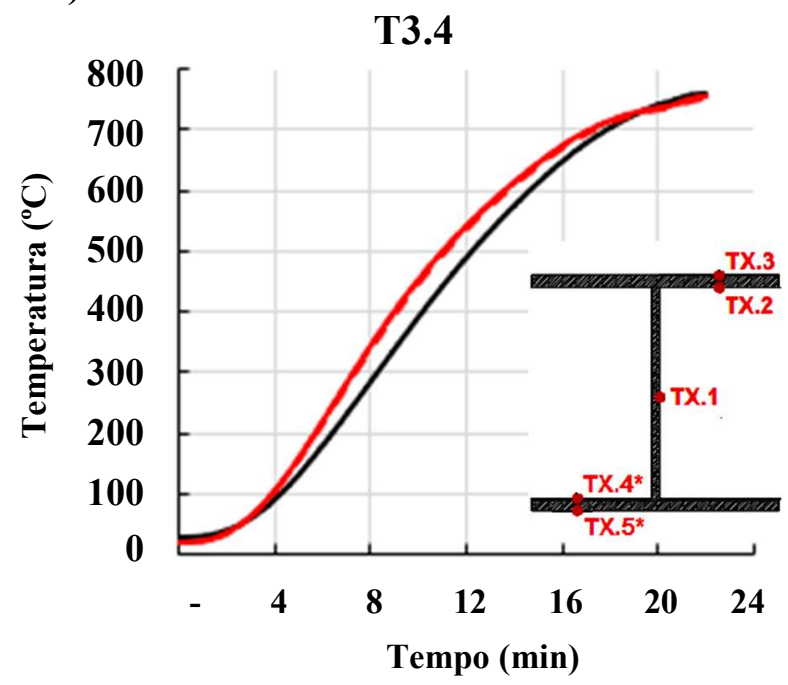

Malha 30 ---- Malha 50 - - -Malha 70

Figura AP.A.1 - Teste de malha para o modelo térmico H220-ISO

Fonte: Autor da Pesquisa (2018).

É possível observar que mesmo variando o tamanho da malha de 20 a 70 mm, não houve mudança significativa do campo de temperaturas devido à sobreposição das curvas numéricas. Apesar disso, como este trabalho consiste no desenvolvimento de modelagens térmicas e termoestruturais, o estudo foi ampliado para o segundo tipo de modelagem. Diante do exposto, foi desenvolvido o teste de malha representado no gráfico da Figura AP.A.2. Pode-se constatar que a partir do elemento finito com tamanho de $30 \mathrm{~mm}$, a redução da malha promoveu 
resultados praticamente iguais o que justifica a adoção desse valor para todas as estratégias de modelagem.

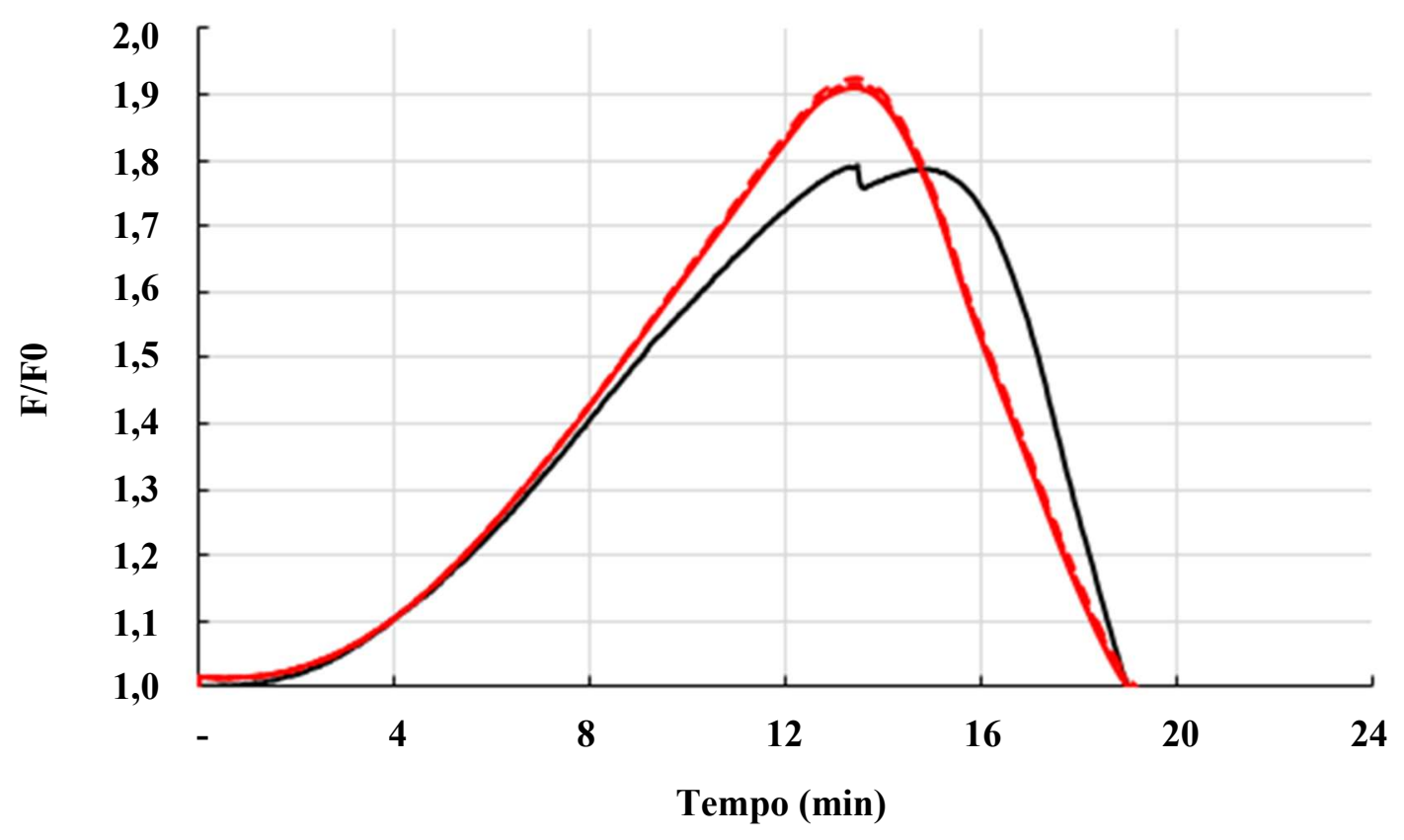

— Experimental - Malha $20 \quad \cdots \cdots . .$. Malha 30 ---- Malha 50 - - Malha 70

Figura AP.A.1 - Teste de malha para o modelo termoestrutural H220-ISO

Fonte: Autor da Pesquisa (2018).

\section{AP.A.1.2 SOBRE AS CURVAS EXPERIMENTAIS}

A Figura AP.A.3 traz a comparação entre as curvas de aquecimento dos ensaios experimentais e aquela recomendada pela ISO 834:1999 para os vinte primeiros minutos de aquecimento. É possível notar que, independentemente do tipo de pilar, a curva experimental se distanciou de forma significativa da curva normativa o que impossibilitou seu uso na calibração dos modelos numéricos térmicos. 

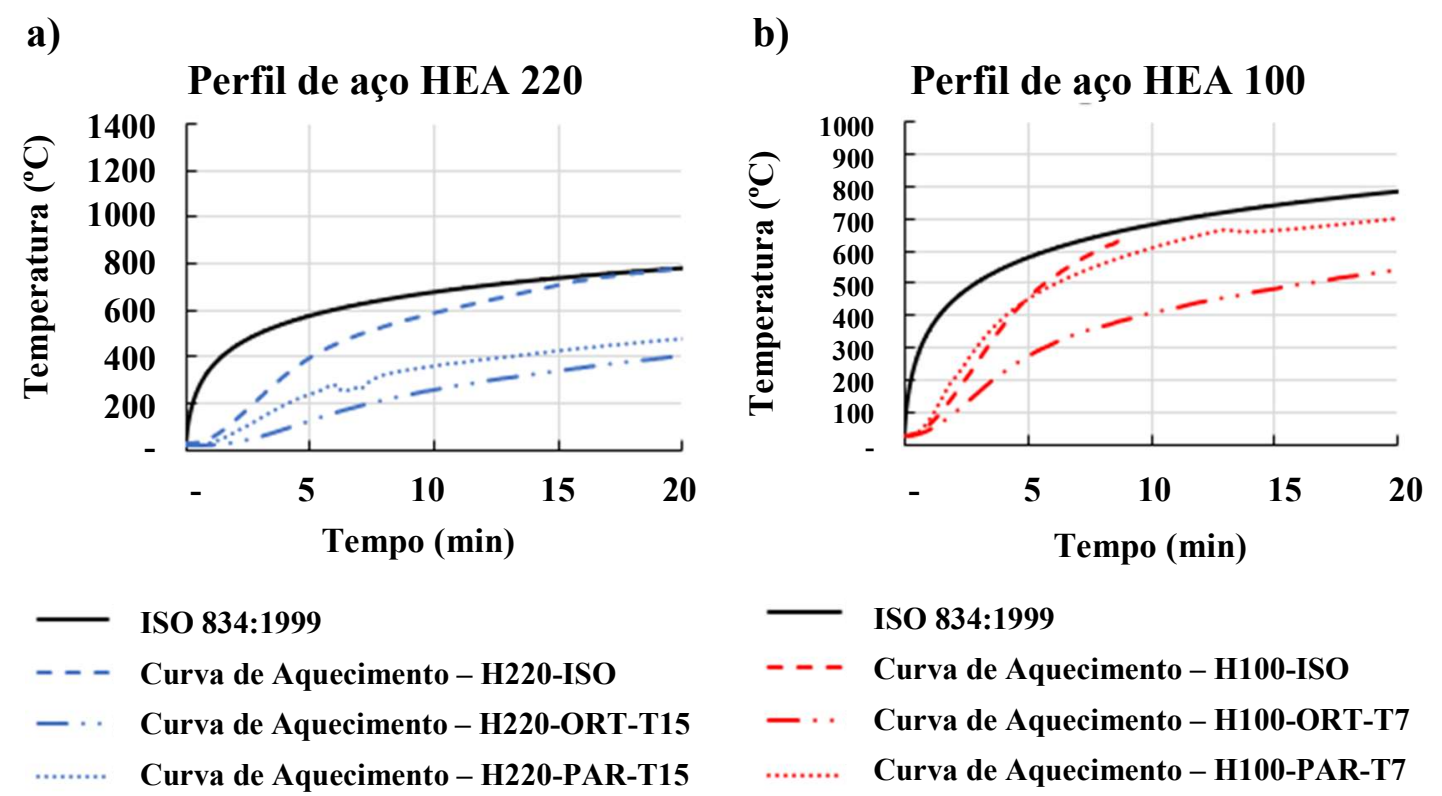

Figura AP.A.3 - Comparação entre as curvas experimentais e a curva de incêndio-padrão ISO 834:1999 para os 20 primeiros minutos de exposição ao fogo

Fonte: Autor da Pesquisa (2018).

\section{AP.A.1.3 TESTE SOBRE A CONSIDERAÇÃO DA ARGAMASSA NA PARTE NÃO EXPOSTA AO FOGO}

Tendo em vista que nos ensaios experimentais a região exposta ao fogo das paredes era revestida com uma camada de argamassa, a modelagem numérica dos pilares foi feita considerando duas situações para fins de comparação.

No primeiro caso, o pilar foi modelado com as paredes revestidas e no segundo caso, o elemento de vedação não foi revestido. Como as propriedades térmicas da argamassa não foram definidas em Rocha (2016), de modo a verificar a influência desse material no comportamento térmico dos pilares, foram adotados os valores propostos para o concreto indicados na ABNT NBR 15200:2012.

A Figura AP.A.4 traz as curvas de evolução da temperatura para os termopares T3.5 e T3.6 para o pilar H220-ORT-T15, pois esses medidores são os mais influenciados pela presença desse revestimento uma vez que eles se localizam na região não aquecida do pilar. É possível notar que não houve nenhum ganho significativo em termos de precisão dos resultados o que permitiu não o considerar nas modelagens seguintes. 
a)

T3.5

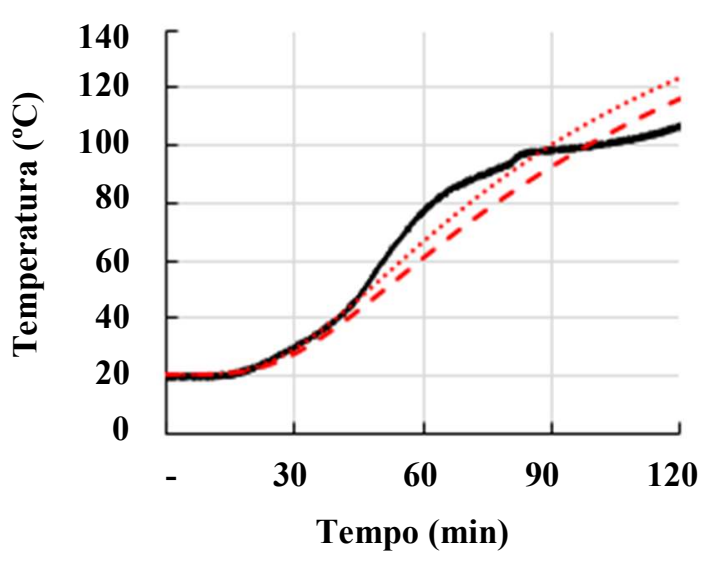

b)

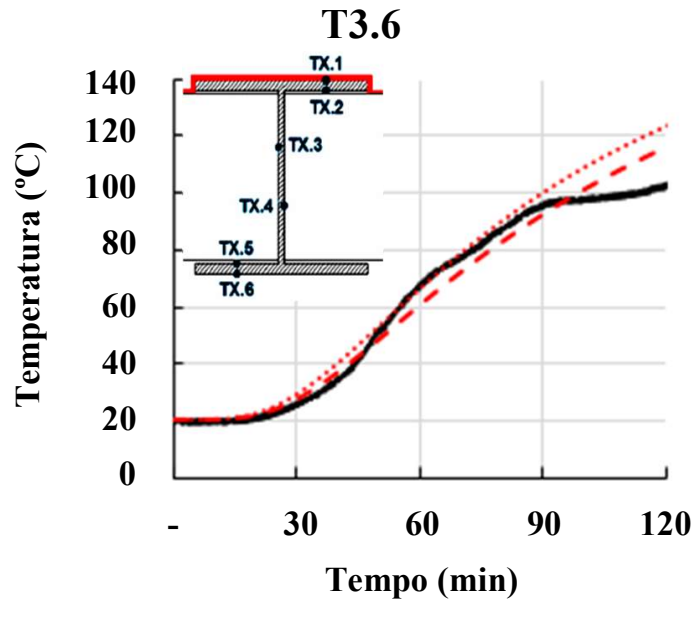

Experimental $\quad---$ Com Argamassa

Sem Argamassa

Figura AP.A.4 - Avaliação da influência da argamassa no comportamento térmico dos pilares inseridos em paredes

Fonte: Autor da Pesquisa (2018). 


\section{AP.B.1 CALIBRAÇÃO DOS MODELOS NUMÉRICOS}

\section{AP.B.1.1 MODELAGEM TERMOESTRUTURAL}

\section{AP.B.1.1.1 Rigidez axial e rotacional da mola de extremidade presente nos pilares}

A Figura AP.B.1 traz os resultados da calibração numérica realizada para os dois pilares isolados quanto ao nível de restrição térmica. Inicialmente, houve variação somente da rigidez axial para definir a sua intensidade. Além disso, para esse estudo, o elemento estrutural foi considerado sem imperfeição geométrica inicial, uma vez que essa abordagem possui caráter preliminar.

a)

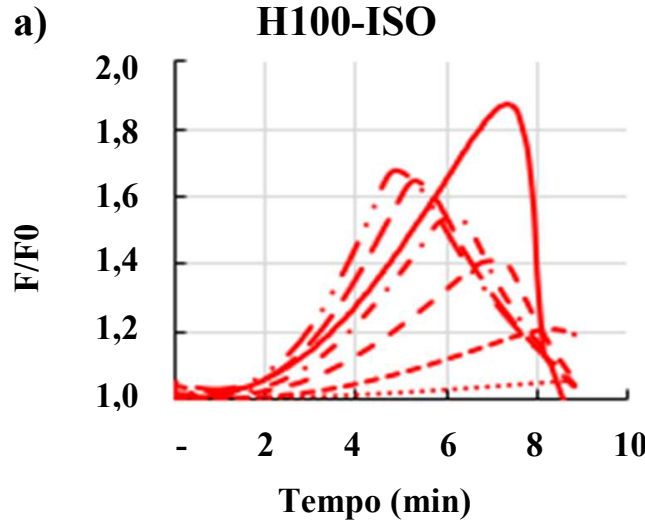

b)

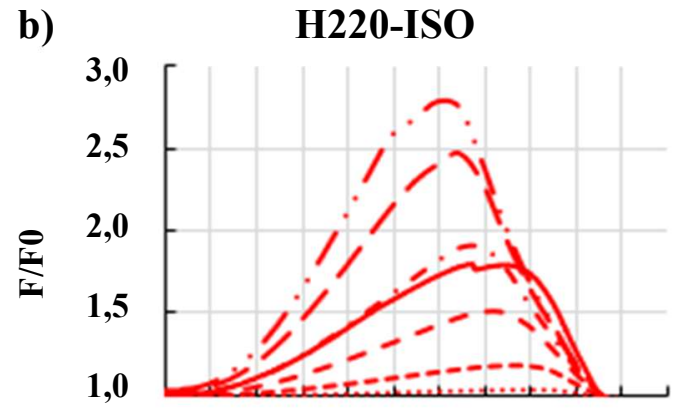

- 246810121416182022

Tempo (min)

- Experimental

$$
\begin{array}{lll}
\cdots \cdots \cdot \text { Rig. Axial }=1 \mathrm{kN} / \mathrm{mm} & -- \text { Rig. Axial }=15 \mathrm{kN} / \mathrm{mm} & -- \text { Rig. Axial }=60 \mathrm{kN} / \mathrm{mm} \\
-\cdots \cdot \text { Rig. Axial }=5 \mathrm{kN} / \mathrm{mm} & -\cdots-\text { Rig. Axial }=30 \mathrm{kN} / \mathrm{mm} \quad-\cdots \text { Rig. Axial }=90 \mathrm{kN} / \mathrm{mm}
\end{array}
$$

Figura AP.B.1 - Calibração numérica da rigidez axial do sistema de restrição Fonte: Autor da Pesquisa (2018).

A partir da análise gráfica da Figura AP.B.1 conclui-se que a intensidade da rigidez axial da mola é $30 \mathrm{kN} / \mathrm{mm}$, pois esse valor permitiu que a curva numérica tivesse uma maior aproximação da curva experimental "força axial relativa versus tempo". Partindo dessa abordagem, uma nova calibração numérica foi realizada para mensurar a rigidez rotacional da estrutura de restrição.

Para isso, a rigidez axial da mola foi mantida constante e variou-se somente a rigidez rotacional, como ilustrado na Figura AP.B.2. Pode-se observar que no pilar isolado H100-ISO 
(Figura AP.B.2a) a rigidez rotacional teve influência no seu comportamento termoestrutural, sendo o valor $5000 \mathrm{kN} . \mathrm{m} / \mathrm{rad}$ o mais adequado, uma vez que a curva referente a ele conseguiu acompanhar o crescimento da força relativa até o pico da curva experimental, o qual representa o momento em que o pilar de aço começa a plastificar. Entretanto, o comportamento do pilar H220-ISO (Figura AP.B.2b) não foi influenciado pela alteração da intensidade desse tipo de rigidez uma vez que houve superposição das curvas analisadas.

a)

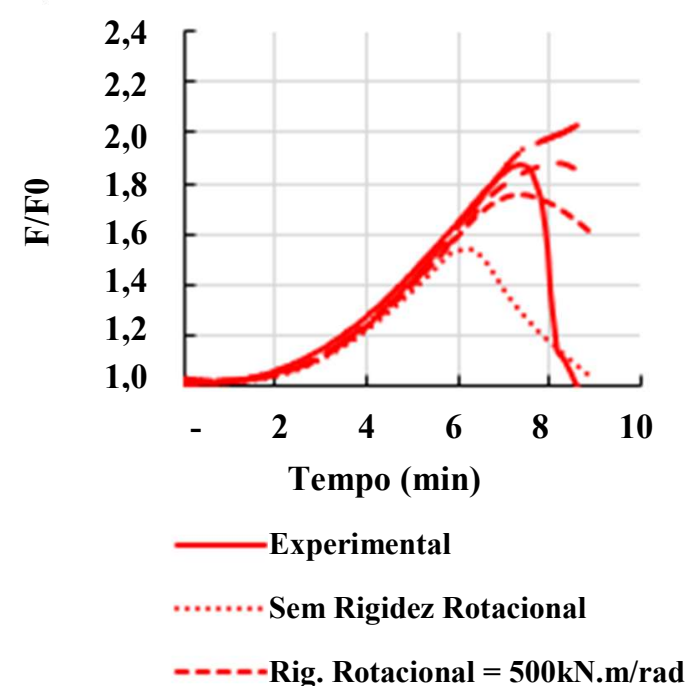

b)

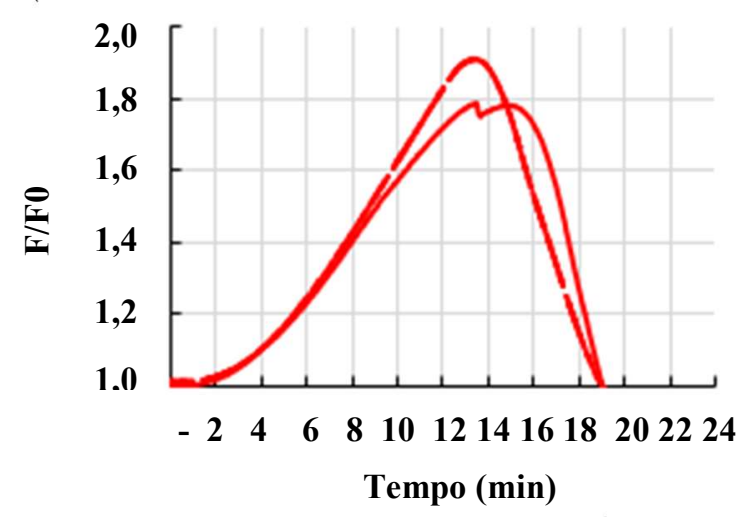

--- Rig. Rotacional $=1000 \mathrm{kN} \cdot \mathrm{m} / \mathrm{rad}$

- Rig. Rotacional $=5000 \mathrm{kN} . \mathrm{m} / \mathrm{rad}$

- Rig. Rotacional $=10000 \mathrm{kN} . \mathrm{m} / \mathbf{r a d}$

Figura AP.B.2 - Calibração numérica da rigidez rotacional do sistema de restrição Fonte: Autor da Pesquisa (2018).

Diante do exposto, definiu-se a intensidade da rigidez axial do sistema de restrição igual a $30 \mathrm{kN} / \mathrm{mm}$, e da rigidez rotacional equivalente a $5000 \mathrm{kN} \cdot \mathrm{m} / \mathrm{rad}$. Tais valores são considerados razoáveis, tendo em vista que o pórtico de restrição utilizado em Correia (2011), que é similar aquele em que foram ensaiados os protótipos de referência, apresentou valores de restrição similares ao aqui encontrados.

\section{AP.B.1.1.2 Influência da imperfeição geométrica inicial}

AP.B.1.1.2.1 Pilares isolados

Três valores de amplitude referentes à imperfeição geométrica inicial foram testados para identificar aquele que melhor representava o comportamento termoestrutural dos pilares isolados, a citar L/500, L/1000 e L/1500. No caso dos pilares com aquecimento nas quatro faces, 
a imperfeição foi testada nas direções dos eixos forte e fraco, ou seja, de maior e menor inércia, respectivamente. Além disso, foi criada uma nomenclatura para identificar a amplitude e sua direção no pilar de aço, descrita na Tabela AP.B.1.

Tabela AP.B.1 - Nomenclatura referente ao tipo imperfeição geométrica inicial adotada para os pilares isolados.

\begin{tabular}{ccc}
\hline Amplitude & Direção da imperfeição geométrica & Nomenclatura \\
\hline L/500 & Eixo fraco & IMP1A \\
L/500 & Eixo forte & IMP1B \\
L/1000 & Eixo fraco & IMP2A \\
L/1000 & Eixo forte & IMP2B \\
L/1500 & Eixo fraco & IMP3A \\
L/1500 & Eixo forte & IMP3B \\
\hline
\end{tabular}

Fonte: Autor da Pesquisa (2018).

A Figura AP.B.3 traz o resultado da calibração numérica realizada para imperfeição geométrica inicial dos dois pilares isolados dessa pesquisa. É perceptível que a amplitude exerce pouca ou nenhuma influência no comportamento termoestrutural dos pilares, uma vez que as curvas de cada teste se encontram sobrepostas.

a)
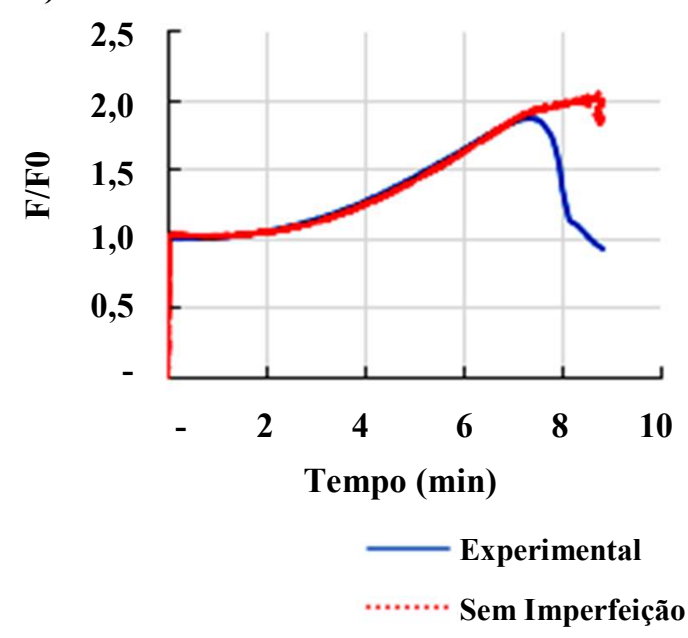

----- IMP1A

- - - IMP1B b) H220-ISO

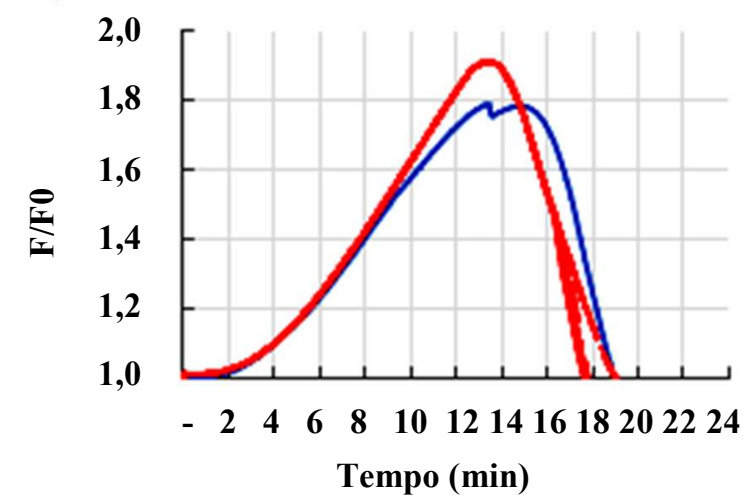

- - - IMP2A

- - IMP2B

$-\cdot-$ IMP3A

Figura AP.B.3 - Calibração numérica da imperfeição geométrica inicial para os pilares isolados

Fonte: Autor da Pesquisa (2018). 
AP.B.1.1.2.2 Pilares inseridos em paredes

No caso de pilares inseridos em paredes, a abordagem sobre a imperfeição geométrica inicial difere daquela realizada para pilares isolados. A amplitude da imperfeição passa a ser testada no lado exposto e não exposto ao fogo. Por essa razão, uma nova nomenclatura para esse estudo foi criada a qual está descrita na Tabela AP.B.2. Vale destacar que os resultados aqui mostrados foram alcançados utilizando a estratégia de modelagem de número I.

Tabela AP.B.2 - Nomenclatura referente ao tipo imperfeição geométrica inicial adotada para os pilares inseridos em paredes

\begin{tabular}{ccc}
\hline Amplitude & Direção da imperfeição geométrica & Nomenclatura \\
\hline L/500 & Lado exposto ao fogo & IMP1C \\
L/500 & Lado não exposto ao fogo & IMP1D \\
L/1000 & Lado exposto ao fogo & IMP2C \\
L/1000 & Lado não exposto ao fogo & IMP2D \\
L/1500 & Lado exposto ao fogo & IMP3C \\
L/1500 & Lado não exposto ao fogo & IMP3D \\
\hline
\end{tabular}

Fonte: Autor da Pesquisa (2018).

A Figura AP.B.4 traz o resultado da calibração numérica realizada para imperfeição geométrica inicial dos dois pilares inseridos em paredes formados pelo perfil de aço HEA 100. A análise gráfica permite concluir que, para o pilar H100-ORT-T7, a imperfeição geométrica, em contexto de amplitude e direção, quase não exerce influência no comportamento termoestrutural do mesmo. Porém, para o pilar H100-PAR-T7, essa grandeza influenciou o comportamento do elemento de tal forma, que o melhor resultado foi aquele em que a imperfeição geométrica inicial apresentou amplitude de L/500 na direção do fogo (IMP1C). Por essa razão, esse parâmetro foi adotado para a validação desses modelos. 

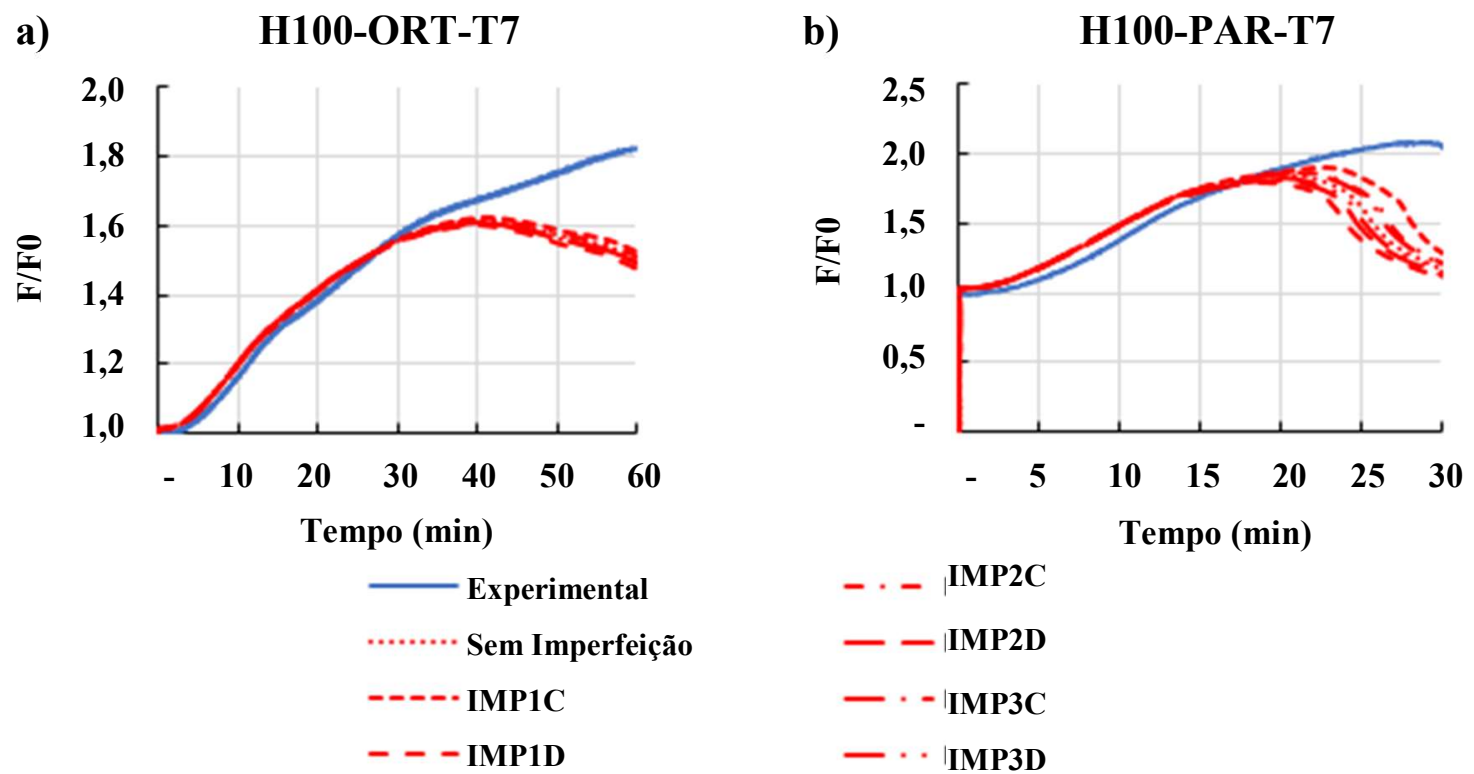

Figura AP.B.4 - Calibração numérica da imperfeição geométrica inicial para os pilares inseridos em paredes formados pelo perfil de aço HEA 100

Fonte: Autor da Pesquisa (2018).

Em relação aos pilares em contato com alvenaria cujo perfil de aço é o HEA 220, os resultados da calibração numérica da imperfeição geométrica inicial estão demonstrados na Figura AP.B.5. Conclui-se que essa grandeza não exerce qualquer influência no comportamento termoestrutural desses pilares. De modo a tornar a intensidade do parâmetro igual para todos os modelos, foi adotado L/500 para o lado exposto ao fogo.
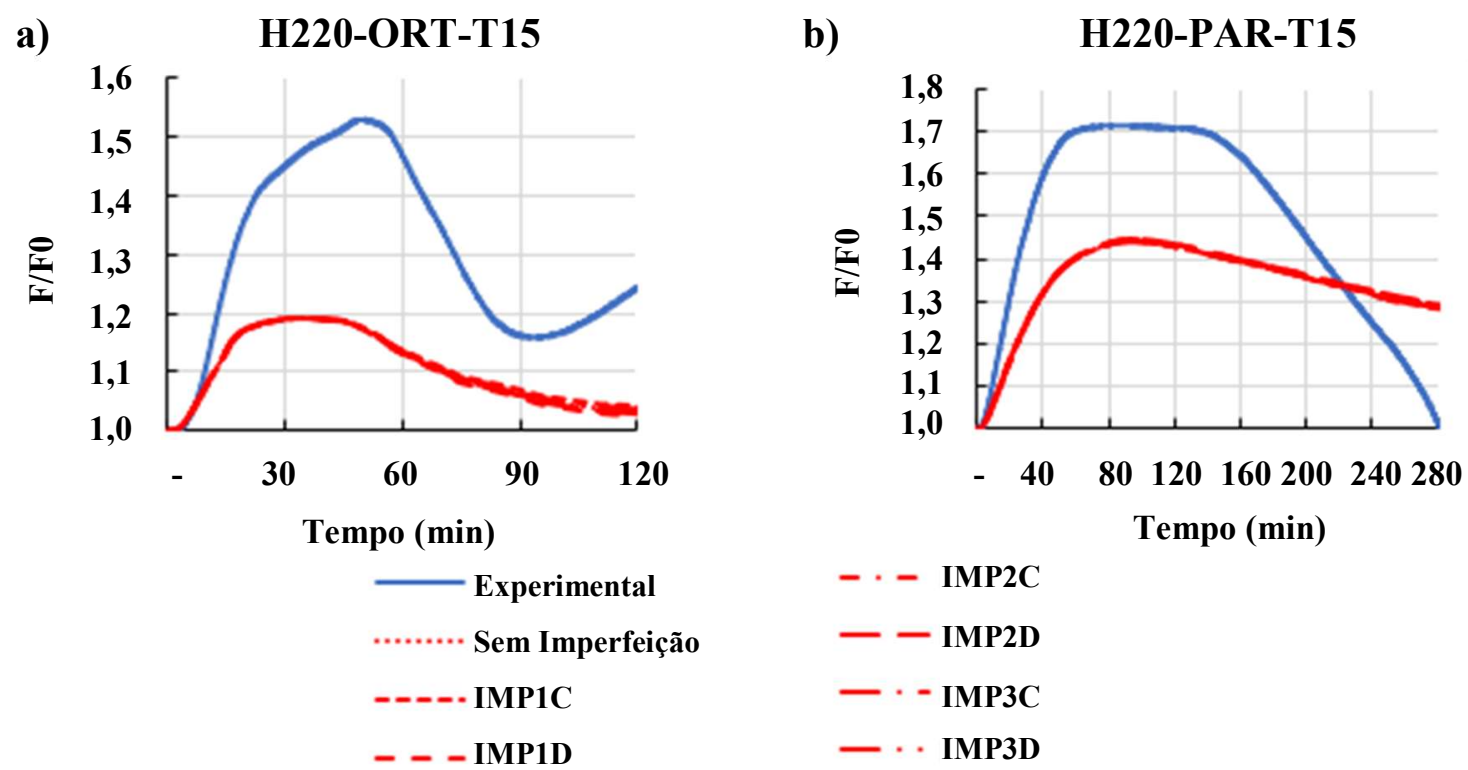

Figura AP.B.5 - Calibração numérica da imperfeição geométrica inicial para os pilares inseridos em paredes formados pelo perfil de aço HEA 220

Fonte: Autor da Pesquisa (2018). 


\section{AP.B.1.1.3 Rigidez axial das molas presentes na lateral das paredes}

Iniciando a calibração numérica para os pilares H100-ORT-T7 e H100-PAR-T7, a Tabela AP.B.3 traz os valores das forças máximas e deslocamentos axiais avaliados para a representação do comportamento elastoplástico da mola. A partir disso, definiu-se a rigidez desse elemento a partir da razão entre a força e seu respectivo deslocamento.

Tabela AP.B.3 - Parâmetros utilizados na calibração numérica das molas axiais das paredes para os pilares H100-ORT-T7 e H100-PAR-T7

\begin{tabular}{cccc}
\hline Teste & Força (kN) & Deslocamento axial (mm) & Rigidez axial (kN/mm) \\
\hline 1 & 10 & 2 & 5 \\
2 & 15 & 3 & 5 \\
3 & 40 & 2 & 20 \\
4 & 60 & 3 & 20 \\
5 & 60 & 2 & 30 \\
6 & 90 & 3 & 30 \\
\hline
\end{tabular}

Fonte: Autor da Pesquisa (2018).

A Figura AP.B.6 mostra os resultados dos seis testes realizados para os pilares H100ORT-T7 e H100-PAR-T7. Em relação aos resultados numéricos, observa-se que a curvas correspondentes a rigidez axial $5 \mathrm{kN} / \mathrm{mm}$ (testes 1 e 2 ) esteve mais próximo daquela correspondente ao ensaio experimental. Para essa pesquisa, será adotado os valores do teste 1 . Esse valor corresponde a uma rigidez baixa, indicando que para esses pilares a parede possui pouca influência no comportamento termoestrutural dos pilares. 

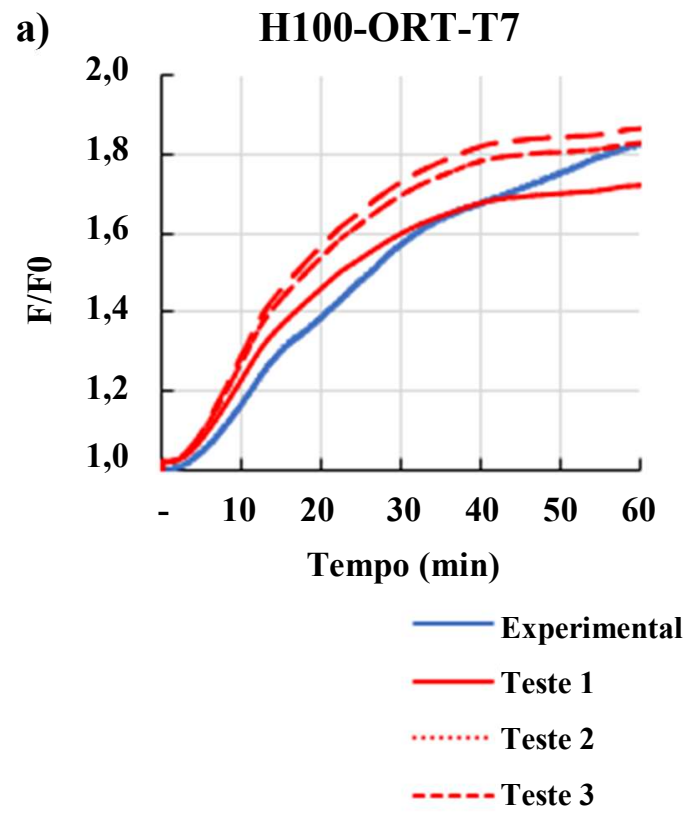

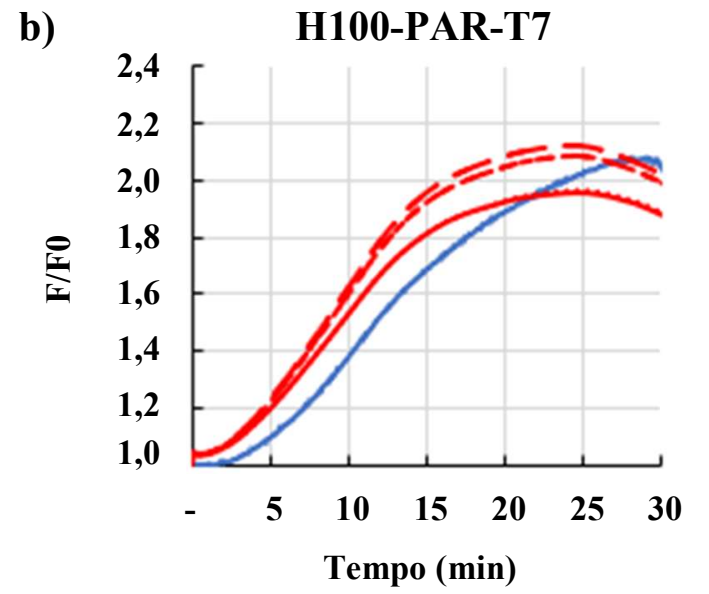

$$
\begin{aligned}
& --- \text { Teste } 4 \\
& -\cdot-\text { Teste } 5 \\
& - \text { - Teste } 6
\end{aligned}
$$

Figura AP.B.6 - Calibração numérica da mola presente nas paredes dos pilares formados pelos perfis HEA 100

Fonte: Autor da Pesquisa (2018).

Para a calibração numérica da mola presente nas paredes dos pilares H220-ORT-T15 e H220-PAR-T15, houve a necessidade de mudança dos valores mostrados na Tabela AP.B.3, uma vez que a influência da alvenaria nesses pilares é maior. A Tabela AP.B.4 traz os valores das forças máximas e deslocamentos axiais avaliados para a representação do comportamento elastoplástico dessa mola.

Tabela AP.B.4 - Parâmetros utilizados na calibração numérica das molas axiais das paredes dos pilares H220-ORT-T15 e H220-PAR-T15

\begin{tabular}{cccc}
\hline Teste & Força $(\mathbf{k N})$ & Deslocamento axial $(\mathbf{m m})$ & Rigidez axial $(\mathbf{k N} / \mathbf{m m})$ \\
\hline 1 & 60 & 2 & 30 \\
2 & 150 & 5 & 30 \\
3 & 90 & 1,5 & 60 \\
4 & 120 & 2 & 60 \\
5 & 90 & 0,5 & 180 \\
\hline
\end{tabular}

Fonte: Autor da Pesquisa (2018).

A Figura AP.B.7 traz os resultados dos testes de calibração realizados para os pilares H220-ORT-T15 e H220-PAR-T15. 

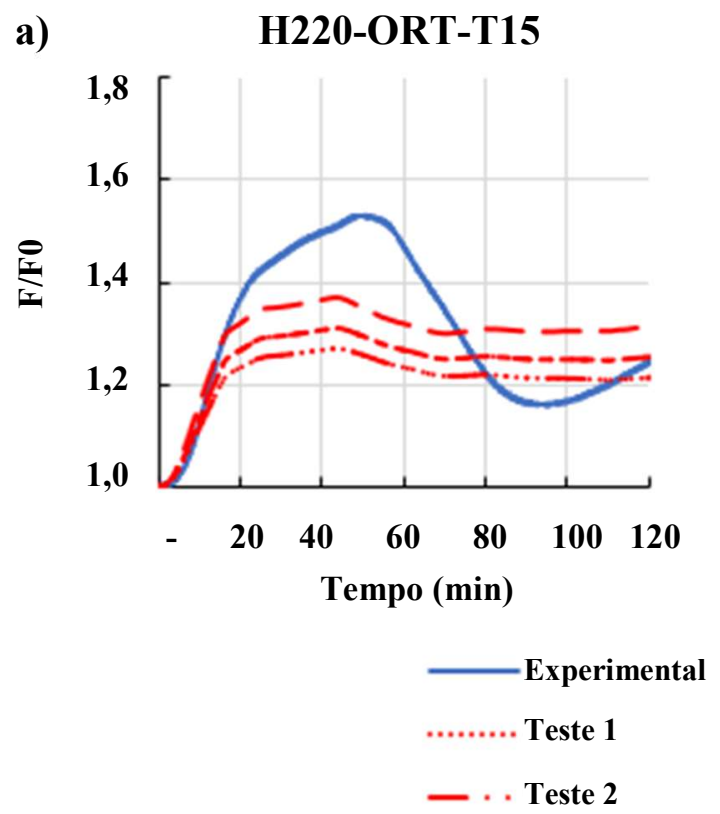

b)
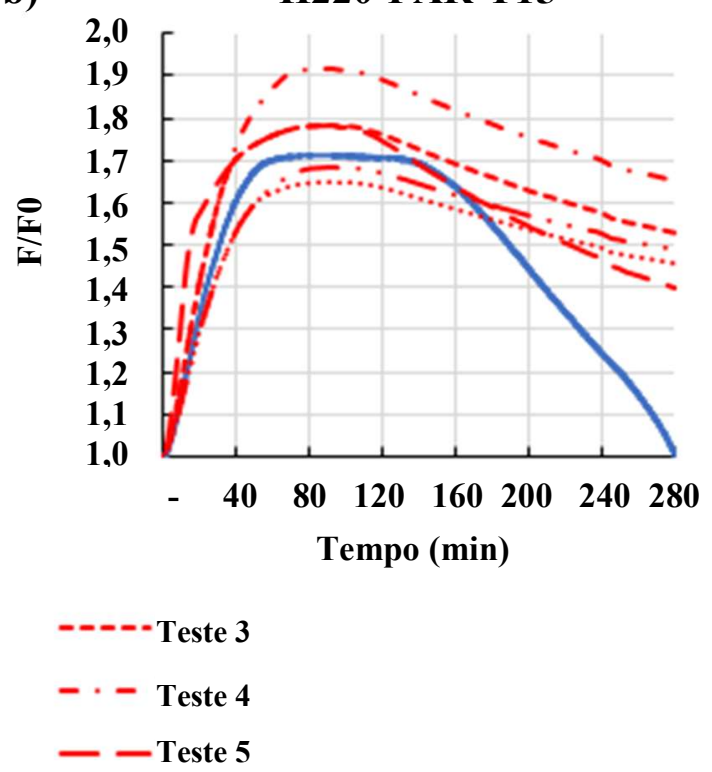

Figura AP.B.7 - Calibração numérica da mola presente nas paredes dos pilares formados pelos perfis HEA 220

Fonte: Autor da Pesquisa (2018).

A análise gráfica permite compreender que a variação dos parâmetros indicados na Tabela AP.B.4 afeta de forma diferente os dois tipos de pilares. Para o pilar com a alma ortogonal à superfície da parede, as curvas numéricas somente se alteraram com a mudança na rigidez axial da mola. Porém, para os pilares com a alma paralela à superfície da parede, a modificação de qualquer parâmetro, seja força ou deslocamento, mesmo mantendo a mesma rigidez, apresentou influência no comportamento numérico obtido.

A partir disso, observa-se por meio da Figura AP.B.7 que o teste 5 foi aquele que proporcionou os melhores resultados para ambos os modelos representados e, portanto, os parâmetros correspondentes a esse teste serão utilizados para a validação dos mesmos. 


\title{
AP.C.1 DETERMINAÇÃO DA CAPACIDADE DE CARGA E DA RIGIDEZ AXIAL DOS PILARES DE AÇO
}

\author{
AP.C.1.1 CAPACIDADE DE CARGA
}

\section{AP.C.1.1.1 Método de cálculo da força última de elementos comprimidos}

De acordo com ABNT NBR 8800:2008, a força axial de compressão resistente de um pilar, $\mathrm{N}_{\mathrm{c}, \mathrm{Rd}}$, é dada pela seguinte expressão:

$$
N_{C, R d}=\frac{\chi Q A_{g} f_{y}}{\gamma_{a 1}}
$$

Onde:

$\chi$ - fator de redução associado à resistência à compressão;

$Q$ - fator de redução total associado à flambagem local;

$A_{g}$ - área bruta da seção transversal do pilar

$f_{y}$ - tensão de escoamento do aço (355 MPa);

$\gamma_{a 1}$ - coeficiente de ponderação da resistência (1,1 para o aço estrutural em situações normais).

AP.C.1.1.1.1 Fator de redução $\chi$

O cálculo do fator de redução $\chi$ é função do índice de esbeltez reduzido definido pela letra grega $\lambda_{0}$. A seguir, são mostradas as equações necessárias para o cálculo desses parâmetros.

$$
\begin{aligned}
& \operatorname{para} \lambda_{0} \leq 1,5: \chi=0,658^{\lambda_{0}{ }^{2}} \\
& \operatorname{para} \lambda_{0}>1,5: \chi=\frac{0,877}{\lambda_{0}{ }^{2}}
\end{aligned}
$$


Sendo:

$\lambda_{0}=\sqrt{\frac{Q A_{g} f_{y}}{N_{e}}}$

Onde,

$N_{e}$ - é a força axial de flambagem elástica.

A força de flambagem elástica é definida pelo Anexo E dessa mesma norma, de modo que equação que define esse parâmetro está apresentada adiante.

$$
N_{e}=\frac{\pi^{2} E I}{(\mathrm{KL})^{2}}
$$

Em que,

$E$ - módulo de elasticidade do aço (210 GPa);

$I$ - momento de inércia em torno do eixo fraco;

$\mathrm{KL}$ - comprimento de flambagem por flexão (adota-se nessa pesquisa $\mathrm{K}=0,7$ ).

\section{AP.C.1.1.1.2 Determinação do parâmetro Q}

A norma brasileira define dois tipos de elementos que podem fazer parte da seção transversal dos perfis de aço, são eles: AA (duas bordas longitudinais rotuladas vinculadas) e AL (somente uma borda longitudinal vinculada). Para que esses elementos não estejam sujeitos à flambagem do tipo local $(\mathrm{Q}=1,0)$, a razão entre a largura e a espessura dos mesmos $(b / t)$ deve ser inferior àquela considerada limite $\left(\frac{b}{t} \mathrm{lim}\right)$ pelo código normativo.

O parâmetro Q, fator de redução total é calculado por:

$$
Q=Q_{s} Q_{a}
$$

Onde,

$Q_{S}$ - fator de redução para elementos $\mathrm{AL}$;

$Q_{a}$ - fator de redução para elementos AA.

Os perfis de aço empregados nessa pesquisa, HEA 100 e HEA 220, possuem elementos AA que fazem parte do Grupo 2 e elementos AL pertencentes ao Grupo 4, de acordo com as 
definições presentes no anexo F da ABNT NBR 8800:2008, de modo que as equações de $\left(\frac{b}{t}\right)_{\lim }$ são aquelas descritas abaixo.

Para elementos AA:

$$
\frac{b}{t} \lim =1,49 \sqrt{\frac{E}{f_{y}}}
$$

Para elementos AL:

$$
\frac{b}{t} \lim =0,56 \sqrt{\frac{E}{f_{y}}}
$$

\section{AP.C.1.1.2 Pilares formados pelo perfil HEA 100}

O primeiro passo para determinar a capacidade de carga de um pilar de aço é conhecer suas características geométricas. A Tabela AP.C.1 traz todos os parâmetros relacionados à seção transversal formada pelo perfil HEA 100.

Tabela AP.C.1 - Características geométricas do perfil HEA 100

\begin{tabular}{cc}
\hline Parâmetros & Valores \\
\hline $\mathrm{d}(\mathrm{mm})$ & 96 \\
$\mathrm{~b}_{\mathrm{f}}(\mathrm{mm})$ & 100 \\
$\mathrm{t}_{\mathrm{f}}(\mathrm{mm})$ & 8 \\
$\mathrm{t}_{\mathrm{w}}(\mathrm{mm})$ & 5 \\
$\mathrm{I}_{\mathrm{x}}\left(\mathrm{cm}^{4}\right)$ & 349 \\
$\mathrm{I}_{\mathrm{y}}\left(\mathrm{cm}^{4}\right)$ & 134 \\
Área $\left(\mathrm{cm}^{2}\right)$ & 21,2 \\
\hline
\end{tabular}

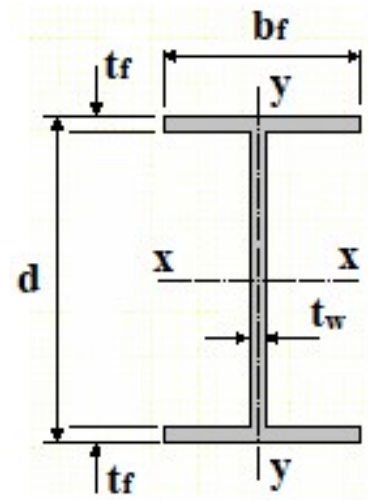

Fonte: Autor da Pesquisa (2018).

AP.C.1.1.2.1 Aplicação do método de cálculo

- Cálculo do parâmetro Q

Elementos AA $\left(Q_{a}\right)$ 
$\frac{b}{t}=\frac{80}{5}=16$

(AP.C.9)

$\frac{b}{t} \lim =1,49 \sqrt{\frac{210.10^{3}}{355}}=36,23$

(AP.C.10)

Como $\frac{b}{t}<\frac{b}{t} \lim , \boldsymbol{Q}_{\boldsymbol{a}}=\mathbf{1}, \mathbf{0}$.

Elementos AL $\left(Q_{s}\right)$

$\frac{b}{t}=\frac{50}{8}=6,25$

(AP.C.11)

$\frac{b}{t} \lim =0,56 \sqrt{\frac{210.10^{3}}{355}}=13,62$

Como $\frac{b}{t}<\frac{b}{t} \lim , \boldsymbol{Q}_{\boldsymbol{s}}=\mathbf{1}, \mathbf{0}$.

Diante dos cálculos realizados, conclui-se que a flambagem local não age no perfil HEA 100 e, portanto, $\mathrm{Q}=1,0$.

- Força axial de flambagem elástica $\left(N_{e}\right)$

$$
N_{e}=\frac{\pi^{2} E I}{(\mathrm{KL})^{2}}=\frac{\pi^{2} 210 \cdot 10^{3} \cdot 134 \cdot 10^{4}}{(0,7 \cdot 3600)^{2}}=437,3 \mathrm{kN}
$$

O comprimento do pilar (L) adotado corresponde àquele obtido no ensaio experimental que leva em consideração a altura do perfil somada a instrumentação localizada nas extremidades do elemento estrutural que equivale a $3600 \mathrm{~mm}$, como descrito em Rocha (2016).

- Índice de esbeltez reduzido $\left(\lambda_{0}\right)$

$$
\lambda_{0}=\sqrt{\frac{Q A_{g} f_{y}}{N_{e}}}=\sqrt{\frac{1.2120 .355}{437,3.10^{3}}}=1,31
$$


- Fator de redução $\chi$

$$
\chi=0,658^{\lambda_{0}^{2}}=0,658^{1,31^{2}}=0,49
$$

- Força axial de compressão resistente $\left(N_{c, R d}\right)$

$$
N_{C, R d}=\frac{\chi Q A_{g} f_{y}}{\gamma_{a 1}}=\frac{0,49 \times 1,0 \times 2120 \times 355}{1,1}=\mathbf{3 3 5} \boldsymbol{k N}
$$

\section{AP.C.1.1.3 Pilares formados pelo perfil HEA 220}

A Tabela AP.C.2 traz todos os parâmetros relacionados à seção transversal formada pelo perfil HEA 220.

Tabela C.2 - Características geométricas do perfil HEA 220

\begin{tabular}{cc}
\hline Parâmetros & Valores \\
\hline $\mathrm{d}(\mathrm{mm})$ & 210 \\
$\mathrm{~b}_{\mathrm{f}}(\mathrm{mm})$ & 220 \\
$\mathrm{t}_{\mathrm{f}}(\mathrm{mm})$ & 11 \\
$\mathrm{t}_{\mathrm{w}}(\mathrm{mm})$ & 7 \\
$\mathrm{I}_{\mathrm{x}}\left(\mathrm{cm}^{4}\right)$ & 5410 \\
$\mathrm{I}_{\mathrm{y}}\left(\mathrm{cm}^{4}\right)$ & 1950 \\
Área $\left(\mathrm{cm}^{2}\right)$ & 64,3
\end{tabular}

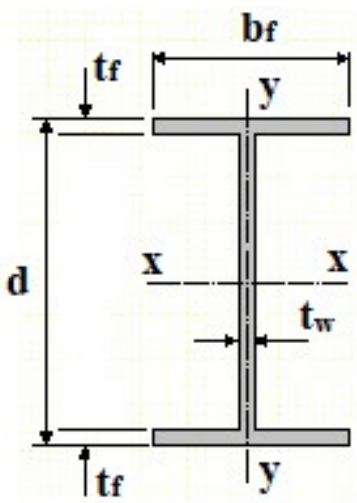

Fonte: Autor da Pesquisa (2018).

AP.C.1.1.3.1 Aplicação do método de cálculo

- Cálculo do parâmetro Q

Elementos AA $\left(Q_{a}\right)$

$$
\frac{b}{t}=\frac{188}{7}=26,86
$$

$$
\frac{b}{t} \lim =1,49 \sqrt{\frac{210.10^{3}}{355}}=36,23
$$


Como $\frac{b}{t}<\frac{b}{t} \lim , \boldsymbol{Q}_{\boldsymbol{a}}=\mathbf{1}, \mathbf{0}$

$\underline{\text { Elementos AL }\left(Q_{s}\right)}$

$\frac{b}{t}=\frac{110}{11}=10$

$\frac{b}{t} \lim =0,56 \sqrt{\frac{210.10^{3}}{355}}=13,62$

Como $\frac{b}{t}<\frac{b}{t} \lim , \boldsymbol{Q}_{\boldsymbol{s}}=\mathbf{1}, \mathbf{0}$.

Diante dos cálculos realizados, conclui-se que a flambagem local não age no perfil HEA 220 e, portanto, $\mathrm{Q}=1,0$.

- Força axial de flambagem elástica $\left(N_{e}\right)$

$$
N_{e}=\frac{\pi^{2} E I}{(\mathrm{KL})^{2}}=\frac{\pi^{2} 210 \cdot 10^{3} \cdot 1950 \cdot 10^{4}}{(0,7 \cdot 3600)^{2}}=6364,3 \mathrm{kN}
$$

O comprimento do pilar (L) adotado novamente corresponde àquele obtido no ensaio experimental que leva em consideração a altura do perfil somada a instrumentação localizada nas extremidades do elemento estrutural que equivale a $3600 \mathrm{~mm}$, como descrito em Rocha (2016).

- Índice de esbeltez reduzido $\left(\lambda_{0}\right)$

$$
\lambda_{0}=\sqrt{\frac{Q A_{g} f_{y}}{N_{e}}}=\sqrt{\frac{1.6430 .355}{6364,3 \cdot 10^{3}}}=0,60
$$

- Fator de redução $\chi$

$$
\chi=0,658^{\lambda_{0}{ }^{2}}=0,658^{0,6^{2}}=0,86
$$


- Força axial de compressão resistente $\left(N_{c, R d}\right)$

$$
N_{c, R d}=\frac{\chi Q A_{g} f_{y}}{\gamma_{a 1}}=\frac{0,86 \times 1,0 \times 6430 \times 355}{1,1}=\mathbf{1 7 8 5} \boldsymbol{k N}
$$




\title{
AP.D.1 RESULTADOS COMPLEMENTARES DAS ANÁLISES PARAMÉTRICAS
}

\author{
AP.D.1.1 PILARES ISOLADOS
}

\section{AP.D.1.1.1 Influência do fator de carga}

H100-ISO

a)

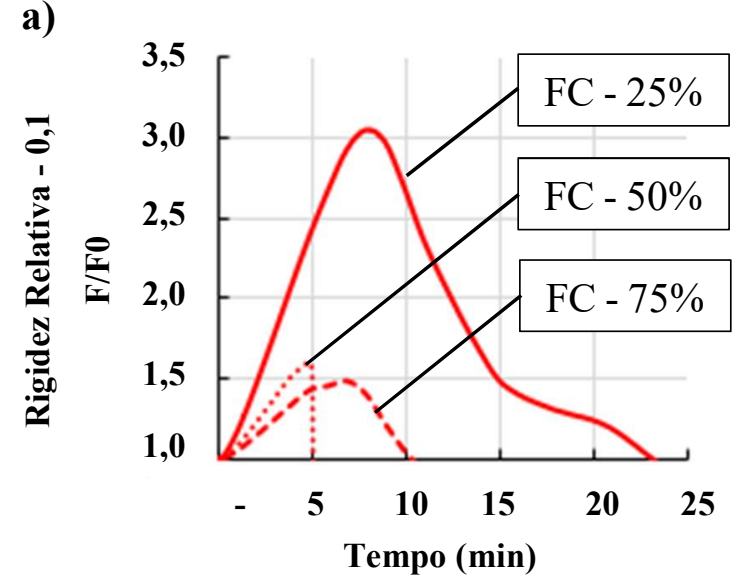

c)

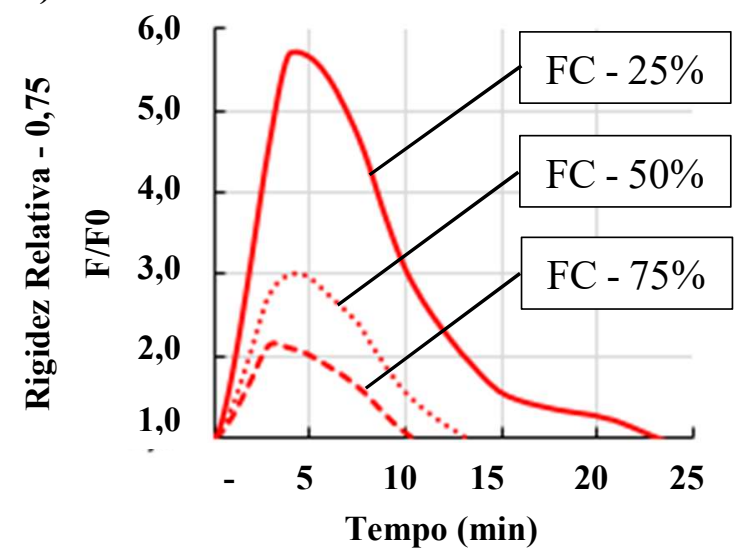

b)

H220-ISO

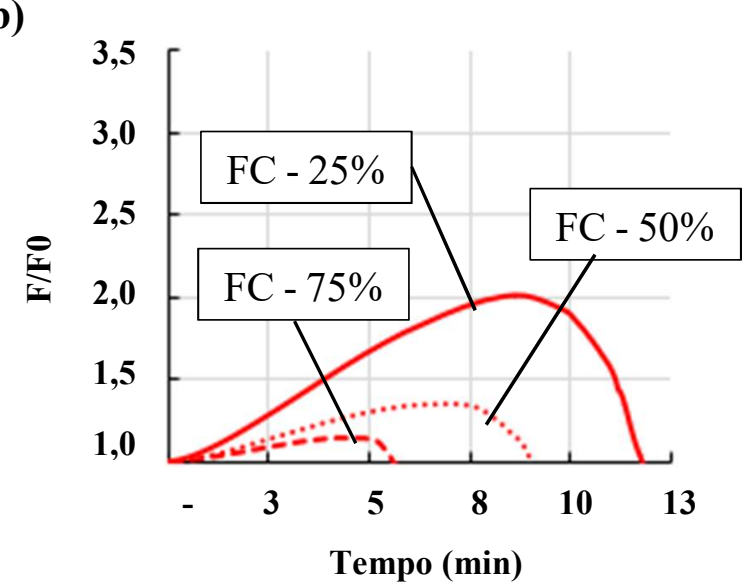

d)

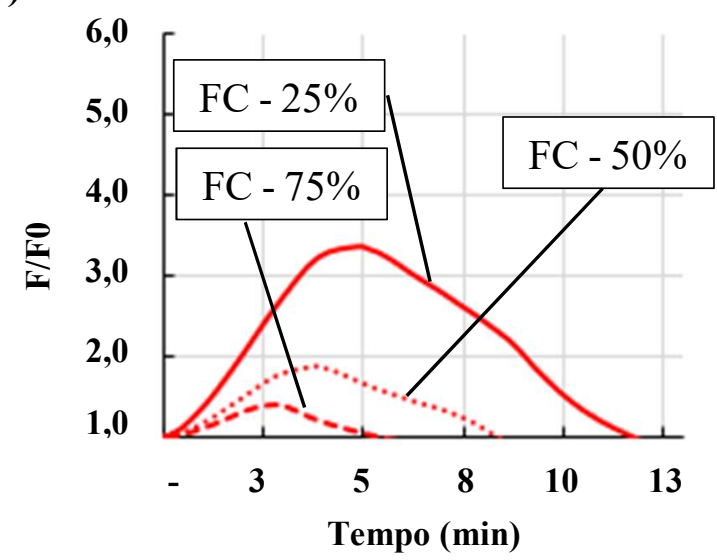

Figura AP.D.1 - Influência do fator de carga no desenvolvimento das forças axiais para os pilares de aço isolados

Fonte: Autor da Pesquisa (2018). 
AP.D.1.2 PILARES INSERIDOS EM PAREDES

\section{AP.D.1.2.1 Pilares formados pelo perfil HEA 100}

AP.D.1.2.1.1 Influência do fator de carga

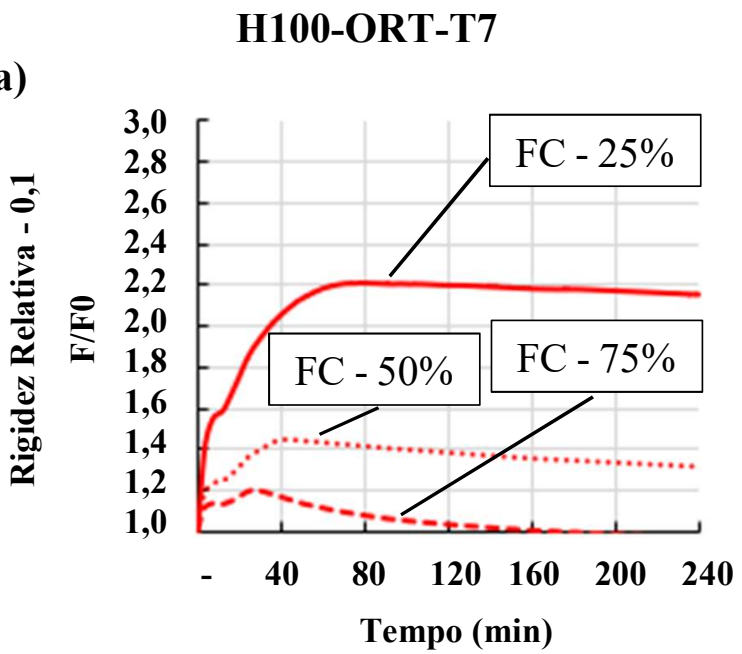

b)

H100-PAR-T7

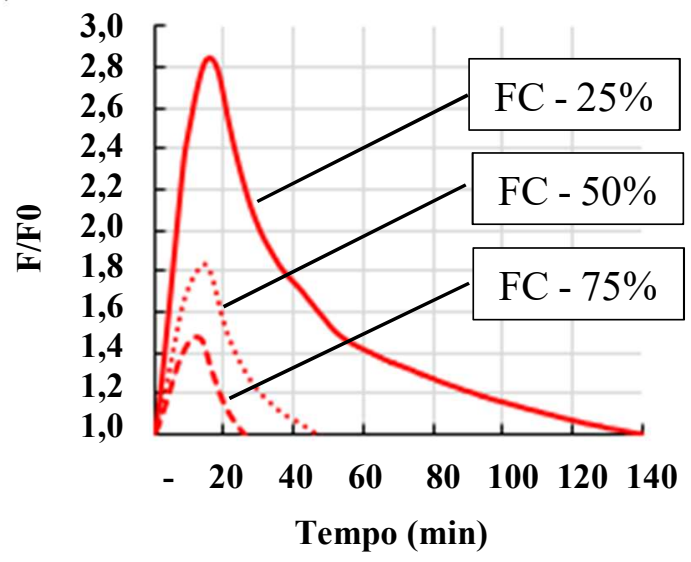

d)

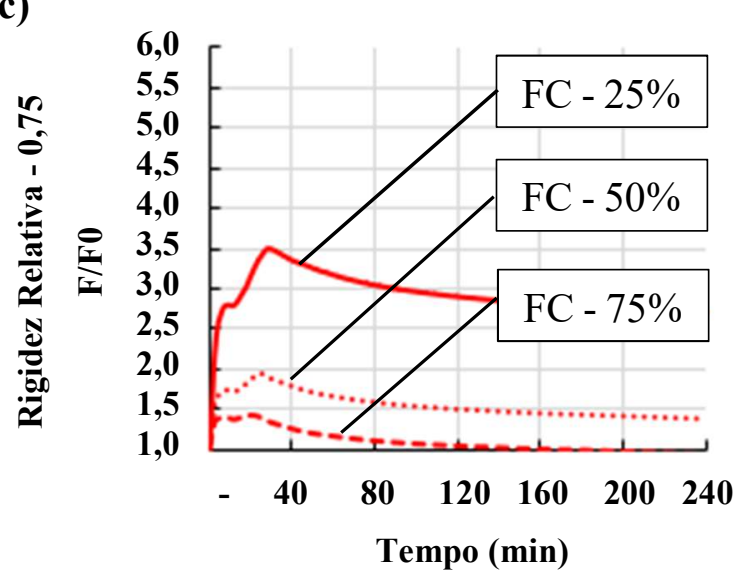

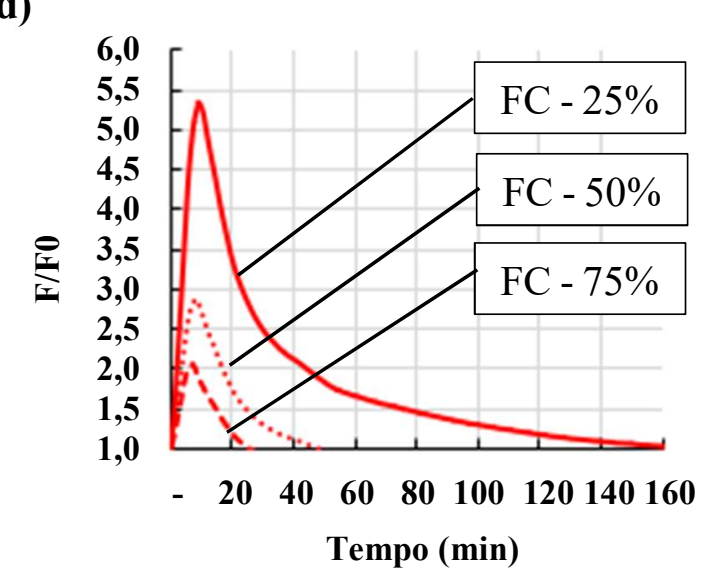

Figura AP.D.2 - Influência do fator de carga no desenvolvimento das forças axiais para os pilares de aço H100-ORT-T7 e H100-PAR-T7

Fonte: Autor da Pesquisa (2018). 


\section{AP.D.1.2.2 Pilares formados pelo perfil HEA 220}

AP.D.1.2.2.1 Influência do fator de carga

\section{H220-ORT-T15}

a)

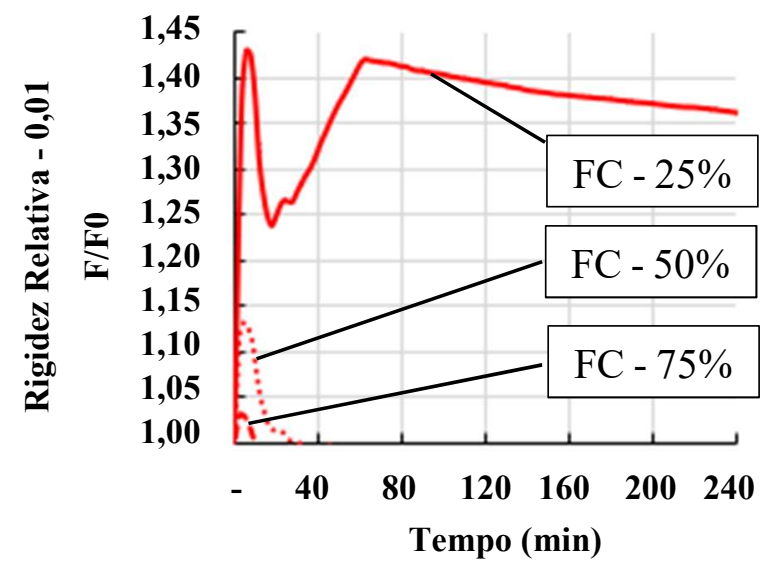

c)

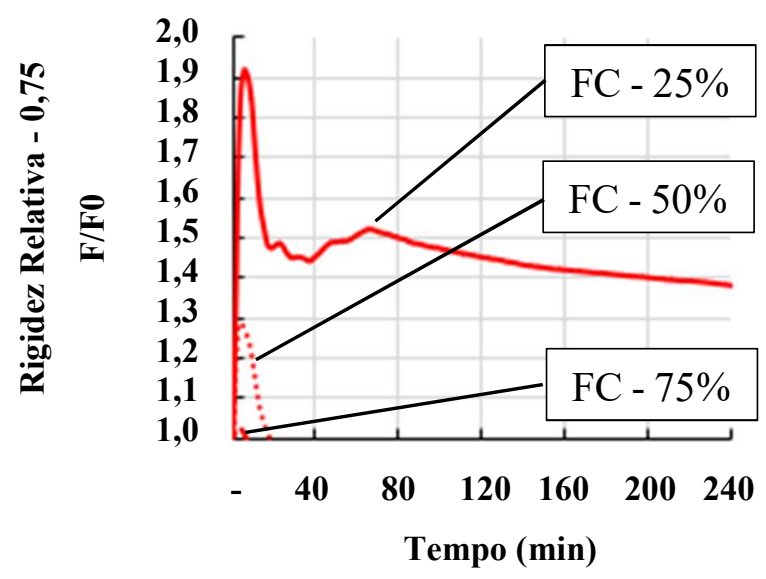

H220-PAR-T15

b)

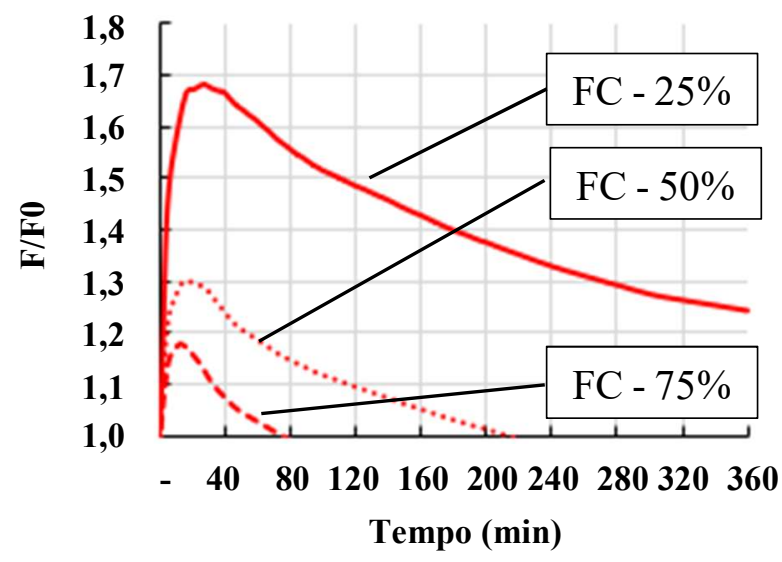

d)

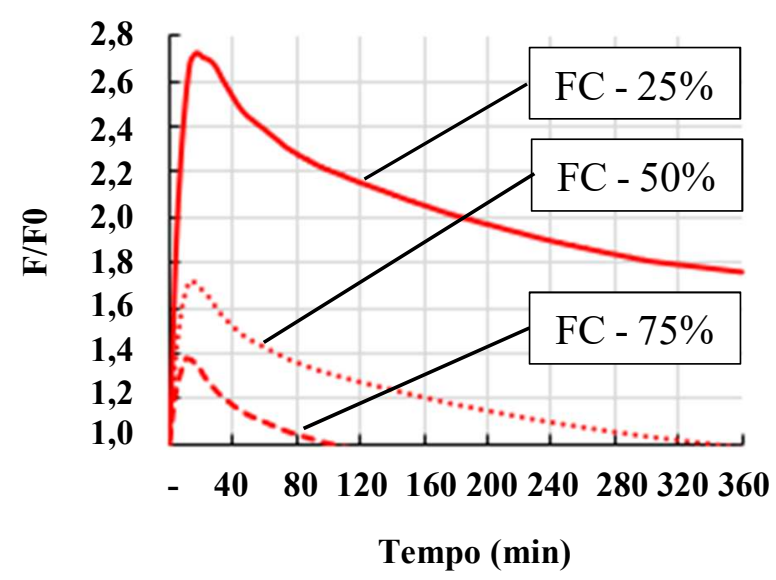

Figura AP.D.3 - Influência do fator de carga no desenvolvimento das forças axiais para os pilares de aço H220-ORT-T15 e H220-PAR-T15

Fonte: Autor da Pesquisa (2018). 


\section{AA.A.1 MECANISMOS DE TRANSFERÊNCIA DE CALOR}

O estudo sobre a transferência de calor é imprescindível quando se deseja realizar modelagem numérica de estruturas submetidas a elevadas temperaturas. Inicialmente, duas grandezas físicas são definidas e fornecem base teórica para entendimento do tema, são elas, temperatura e calor. A temperatura é a grandeza física que mede a quantidade de energia contida em uma matéria, indicando a direção em que ocorrerá a transferência de calor. Já o calor é definido como a energia transferida de um corpo para outro devido à diferença de temperatura entre eles.

Quando se analisam as curvas que caracterizam um incêndio, a temperatura fornecida pelos gráficos é aquela correspondente aos gases presentes no ambiente incendiado. Esses gases são responsáveis por elevar a temperatura dos elementos estruturais a partir de fenômenos de transferência de calor.

A solução de problemas envolvendo esses fenômenos em estruturas submetidas a elevadas temperaturas é considerada complexa, o que inviabiliza o uso de soluções analíticas para seu entendimento e, por essa razão, ensaios experimentais e modelagens numéricas são recomendados (WANG, 2002). Há três formas de ocorrência da transferência de calor, que podem ocorrer de forma simultânea ou separada, a citar: condução, convecção e radiação. A Figura AN.A.1 demonstra, de forma simplificada, a atuação dos três mecanismos de transferência de calor em um edifício em chamas. 


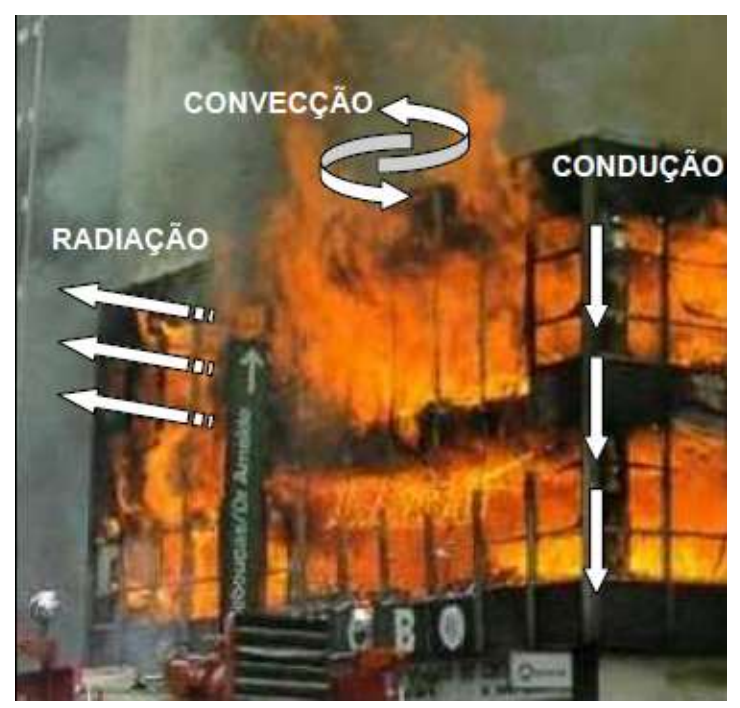

Figura AN.A.1 - Representação dos três mecanismos de transferência de calor Fonte: Azevedo (2005).

A seguir, são discutidos de forma sucinta os três mecanismos de transferência de calor. Detalhes a respeito da metodologia de cálculo desses fenômenos fogem do escopo desse trabalho. Maiores informações podem ser encontradas em Drysdale (1998), Buchanan (2002) e Wang (2002).

- Condução: principal ocorrência em materiais sólidos. O calor é transferido entre corpos com diferentes energias cinéticas, por meio de colisões moleculares que permitem que haja troca de elétrons entre os corpos envolvidos. De acordo com Azevedo (2010), o conhecimento da condução é importante fator no estudo da ignição de sólidos e da resistência ao fogo de elementos estruturais.

- Convecção: fenômeno de transferência de calor entre um material sólido e um fluido em movimento (gás ou líquido) próximo a este sólido, desde que eles possuam temperaturas distintas (REGOBELLO, 2007). Responsável pela propagação das chamas no ambiente incendiado devido à diferença de densidade entre gases com temperaturas desiguais, a convecção faz com que aqueles mais quentes se elevem e transfiram calor para a estrutura.

- Radiação: mecanismo que consiste na propagação de ondas eletromagnéticas de um corpo com maior temperatura para outro com temperatura inferior. É através desse processo que ocorre transferência de calor entre edifícios adjacentes e da fumaça quente para os elementos pertencentes à edificação (AZEVEDO, 2010). 


\section{AN.B.1 PROPRIEDADES MECÂNICAS E TÉRMICAS DO AÇO}

A seguir, são apresentadas as propriedades do aço utilizadas para o desenvolvimento dos modelos numéricos térmicos e termoestruturais desta pesquisa, conforme prescrito pelas normas brasileiras ABNT NBR 14323:2013 e ABNT NBR 15200:2012, que seguem basicamente a mesma formulação do Eurocode 3 Parte 1-2 (2005).

\section{AN.B.1.1 PROPRIEDADES MECÂNICAS}

\section{AN.B.1.1.1 Modelo constitutivo do aço}

Quando se trata de elementos estruturais em situação de incêndio, é indispensável, durante a análise termomecânica, conhecer a relação constitutiva do material a fimm de identificar seu comportamento com a elevação da temperatura. O modelo constitutivo do aço adotado pelas normas europeia e brasileira é mostrado na Figura AN.B.1:

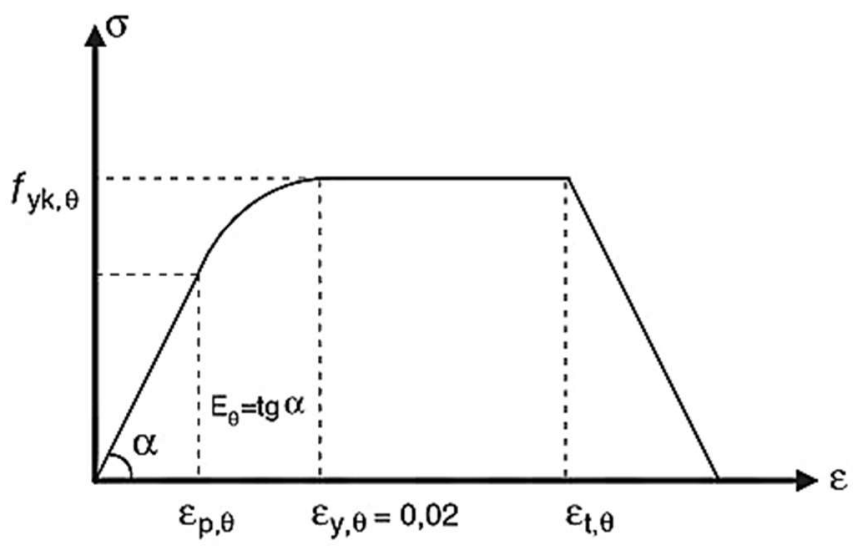

Figura AN.B.1 - Modelo constitutivo para as relações tensões-deformações do aço estrutural para elevadas temperaturas

Fonte: ABNT NBR 15200: 2012.

Para a determinação da curva apresentada acima, a norma brasileira traz as Equações AN.B.1 - AN.B.13 representadas adiante. 


$$
\begin{aligned}
& \sigma_{S, \theta}=\varepsilon_{S, \theta} \cdot E_{S, \theta} \quad \text { se } 0 \leq \varepsilon_{S, \theta} \leq \varepsilon_{p, \theta} \\
& \sigma_{S, \theta}=f_{p, \theta}-c+\frac{b}{a} \cdot \sqrt{a^{2}-\left(\varepsilon_{y, \theta}-\varepsilon_{S, \theta}\right)^{2}} \quad \text { se } \varepsilon_{p, \theta} \leq \varepsilon_{S, \theta} \leq \varepsilon_{y, \theta} \\
& \sigma_{S, \theta}=f_{y} \quad \text { se } \varepsilon_{y, \theta} \leq \varepsilon_{S, \theta} \leq \varepsilon_{t, \theta} \\
& \sigma_{S, \theta}=f_{y, \theta} \cdot\left[1-\frac{\varepsilon_{S, \theta}-\varepsilon_{t, \theta}}{\varepsilon_{u, \theta}-\varepsilon_{t, \theta}}\right] \quad \text { se } \varepsilon_{t, \theta} \leq \varepsilon_{S, \theta} \leq \varepsilon_{u, \theta} \\
& \sigma_{S, \theta}=0 \quad \text { se } \varepsilon_{S, \theta} \geq \varepsilon_{u, \theta} \\
& a^{2}=\left(\varepsilon_{y, \theta}-\varepsilon_{p, \theta}\right) \cdot\left(\varepsilon_{y, \theta}-\varepsilon_{p, \theta}+\frac{c}{E_{S, \theta}}\right) \\
& b^{2}=c .\left(\varepsilon_{y, \theta}-\varepsilon_{p, \theta}\right) \cdot E_{S, \theta}+c^{2} \\
& c=\frac{\left(f_{y, \theta}-f_{p, \theta}\right)^{2}}{\left(\varepsilon_{y, \theta}-\varepsilon_{p, \theta}\right) \cdot E_{S, \theta}-2 \cdot\left(f_{y, \theta}-f_{p, \theta}\right)} \\
& \varepsilon_{p, \theta}=\frac{f_{p, \theta}}{E_{S, \theta}} \\
& \varepsilon_{y, \theta}=0,02 \\
& f_{y k, \theta}=k_{s, \theta} \cdot f_{y k} \\
& f_{p k, \theta}=k_{p, \theta} \cdot f_{y k} \\
& E_{S, \theta}=k_{E, \theta} \cdot E_{S}
\end{aligned}
$$

As grandezas exibidas no gráfico e nas equações acima são definidas por:

$\varepsilon_{p, \theta}$ - deformação referente ao limite de proporcionalidade na temperatura $\theta$;

$\varepsilon y, \theta$ - deformação de escoamento na temperatura $\theta$;

$\varepsilon_{t, \theta}$ - deformação limite para o escoamento na temperatura $\theta$;

$\varepsilon_{u, \theta}$ - deformação última na temperatura $\theta$;

$E_{\theta}$ - inclinação da reta que representa o domínio elástico das tensões-deformações para o aço estrutural em altas temperaturas; 
$E_{s}$ - módulo de elasticidade a temperatura de $20^{\circ} \mathrm{C}$;

$f_{p, \theta}$ - resistência correspondente ao limite de proporcionalidade do aço a certa temperatura $\theta$ - obtida pela Tabela D.1 da norma ABNT NBR 15200:2012;

$f_{y, \theta}$ - tensão de escoamento em uma determinada temperatura $\theta$;

$f_{y, k}$ - tensão de escoamento do aço a $20^{\circ} \mathrm{C}$.

\section{AN.B.1.1.2 Tensão de escoamento e Módulo de elasticidade}

O aumento da temperatura provoca redução da tensão ao escoamento e do módulo de elasticidade do aço. Tendo em vista o exposto, a norma brasileira ABNT NBR 14323:2013 traz os coeficientes de ponderação para essas propriedades. Tais parâmetros podem ser encontrados na Tabela AN.B.1. As Equações AN.B.14 e AN.B.15 definem cálculo para a tensão de escoamento e para o módulo de elasticidade com a elevação da temperatura.

$f_{y, \theta}=k_{y, \theta} f_{y}$

Em que,

$f_{y, \theta}$ - tensão de escoamento na temperatura $\theta$;

$k_{y, \theta}$ - fator de redução na temperatura $\theta$ para a tensão de escoamento;

$f_{y}$ - tensão de escoamento em temperatura ambiente.

$E_{\theta}=k_{E, \theta} E_{S}$

(AN.B.15)

Em que,

$E_{\theta}$ - módulo de elasticidade do aço na temperatura $\theta$;

$k_{E, \theta}$ - fator de redução na temperatura $\theta$ para o módulo de elasticidade;

$E_{S}$ - módulo de elasticidade do aço em temperatura ambiente. 
Tabela AN.B.1 - Fatores de redução das propriedades mecânicas do aço

\begin{tabular}{cccc}
\hline $\begin{array}{c}\text { Temperatura do } \\
\text { aço } \\
\boldsymbol{\theta}_{\mathbf{a}\left({ }^{\circ} \mathbf{C}\right)}\end{array}$ & $\begin{array}{c}\text { Fator de redução } \\
\text { da tensão de } \\
\text { escoamento }\left(\boldsymbol{k}_{\boldsymbol{y}, \boldsymbol{\theta}}\right)^{\mathbf{a}}\end{array}$ & $\begin{array}{c}\text { Fator de redução } \\
\text { do módulo de } \\
\text { elasticidade }\left(\boldsymbol{k}_{\boldsymbol{E}, \boldsymbol{\theta}}\right)^{\mathbf{a}}\end{array}$ & $\begin{array}{c}\text { Fator de } \\
\text { redução } \\
\left(\boldsymbol{k}_{\boldsymbol{\sigma}, \boldsymbol{\theta}}\right)^{\mathbf{a}}\end{array}$ \\
\hline 20 & 1 & 1 & 1 \\
100 & 1 & 1 & 1 \\
200 & 1 & 0,9 & 0,89 \\
300 & 1 & 0,8 & 0,78 \\
400 & 0,78 & 0,7 & 0,65 \\
500 & 0,47 & 0,6 & 0,53 \\
600 & 023 & 0,31 & 0,3 \\
700 & 0,11 & 0,13 & 0,13 \\
800 & 0,06 & 0,09 & 0,07 \\
900 & 0,04 & 0,068 & 0,05 \\
1000 & 0,02 & 0,045 & 0,03 \\
1100 & 0 & 0,023 & 0,02 \\
1200 & 0 & 0 & 0 \\
\hline
\end{tabular}

${ }^{a}$ Para valores intermediários da temperatura do aço, permite-se interpolação linear. Fonte: ABNT NBR 14323:2013

Além dessas propriedades mecânicas, a norma brasileira apresenta outro coeficiente de redução para a tensão de escoamento, porém, aplicado somente para perfis sujeitos à flambagem local. A Equação AN.B.16 apresenta a degradação dessa propriedade com o aumento da temperatura.

$$
f_{y, \theta}=k_{\sigma, \theta} f_{y}
$$

O fator de redução $k_{\sigma, \theta}$ também pode ser encontrado na Tabela AN.B.1.

\section{AN.B.1.2 PROPRIEDADES TÉRMICAS}

\section{AN.B.1.2.1 Alongamento Térmico}

Os elementos estruturais apresentam grandes deformações com o aumento da temperatura, em virtude da dilatação térmica dos seus materiais constituintes. $\mathrm{O}$ alongamento 
térmico é a propriedade responsável por mensurar esse efeito. A seguir, são apresentadas as equações para o alongamento térmico em função da temperatura:

$$
\begin{aligned}
& \frac{\Delta l}{l}=1,2 \times 10^{-5} \theta_{a}+0,4 \times 10^{-8} \theta_{a}^{2}-2,416 \times 10^{-4}, 20^{\circ} \mathrm{C} \leq \theta_{a} \leq 750{ }^{\circ} \mathrm{C} \\
& \frac{\Delta l}{l}=1,1 \times 10^{-2}, 750^{\circ} \mathrm{C} \leq \theta_{a} \leq 860^{\circ} \mathrm{C} \\
& \frac{\Delta l}{l}=2 \times 10^{-5} \theta_{a}-6,2 \times 10^{-3}, 860^{\circ} \mathrm{C} \leq \theta_{a} \leq 1200^{\circ} \mathrm{C}
\end{aligned}
$$

De modo simplificado, a norma brasileira permite que essa propriedade possa ser calculada por uma única expressão definida pela Equação AN.B.20.

$$
\frac{\Delta \mathrm{l}_{a}}{l_{a}}=14 \times 10^{-6}\left(\theta_{a}-20\right)
$$

\section{AN.B.1.2.2 Calor específico}

Propriedade definida como a quantidade de calor necessária para que uma unidade de massa eleve sua temperatura a um grau Celsius. Ela pode ser calculada da seguinte maneira:

$$
\begin{aligned}
& c_{a}=425+7,73 \times 10^{-1} \theta_{a}-1,69 \times 10^{-3} \theta_{a}^{2}+2,22 \times 10^{-6} \theta_{a}^{3}, 20^{\circ} \mathrm{C} \leq \theta_{a} \leq 600{ }^{\circ} \mathrm{C} \\
& c_{a}=666+\frac{13002}{738-\theta_{a}}, 600^{\circ} \mathrm{C} \leq \theta_{a} \leq 735^{\circ} \mathrm{C} \\
& c_{a}=545+\frac{17820}{\theta_{a}-73}, 735^{\circ} \mathrm{C} \leq \theta_{a} \leq 900^{\circ} \mathrm{C} \\
& c_{a}=650,900^{\circ} \mathrm{C} \leq \theta_{a} \leq 1200^{\circ} \mathrm{C}
\end{aligned}
$$

A norma brasileira permite que o calor específico seja tratado de modo independente da temperatura, considerando seu valor igual a $600 \mathrm{~J} / \mathrm{kg}^{\circ} \mathrm{C}$. 


\section{AN.B.1.2.3 Condutividade térmica}

A condutividade térmica é definida como a capacidade do material em conduzir calor. Duas equações caracterizam essa propriedade com o aumento da temperatura e são definidas a seguir:

$$
\begin{aligned}
& \lambda_{a}=54-3,33 \times 10^{-2} \theta_{a}, 20^{\circ} \mathrm{C} \leq \theta_{a} \leq 800^{\circ} \mathrm{C} \\
& \lambda_{a}=27,3, \theta_{a} \geq 800^{\circ} \mathrm{C}
\end{aligned}
$$

Essa propriedade pode ser tratada de forma independente da temperatura. Dessa forma, o valor a ser empregado deve ser igual a $45 \mathrm{~W} / \mathrm{m}^{\circ} \mathrm{C}$.

\section{AN.B.1.2.4 Massa específica}

A norma brasileira admite considerar a massa específica independente da temperatura, com valor de $7850 \mathrm{~kg} / \mathrm{m}^{3}$. 